MÉTODO DE AQUISIÇÃO DE CONHECIMENTO PARA SISTEMAS ESPECIALISTAS DESTINADOS À DIAGNOSE DE FALHAS:

APLICAÇÃO DE TÉCNICAS DE ANÁLISE DE CONFIABILIDADE E DE RISCO.

Tese de doutorado apresentada à Escola Politécnica da Universidade de São Paulo para obtenção de Título de Doutor em Engenharia.

São Paulo 
ERICK MIGUEL PORTUGAL HIDALGO

\section{MÉTODO DE AQUISIÇÃO DE CONHECIMENTO PARA SISTEMAS ESPECIALISTAS DESTINADOS À DIAGNOSE DE FALHAS: APLICAÇÃO DE TÉCNICAS DE ANÁLISE DE CONFIABILIDADE E DE RISCO.}

Tese de doutorado apresentada à Escola Politécnica da Universidade de São Paulo para obtenção de Título de Doutor em Engenharia.

Área de Concentração:

Engenharia Mecânica de Projetos de Fabricação

Orientador:

Professor Dr.

Gilberto Francisco Martha de Souza

São Paulo 
Este exemplar foi revisado e corrigido em relação à versão original, sob responsabilidade única do autor e com a anuência de seu orientador.

São Paulo, 23 de janeiro de 2015.

Assinatura do autor Erick Miguel Portugal Hidalgo

Assinatura do orientador Gilberto Francisco Martha de Souza

Portugal Hidalgo, Erick Miguel

Método de aquisição de conhecimento para sistemas especialistas destinados à diagnose de falhas: aplicação de técnicas de análise de confiabilidade e de risco / E.M. Portugal Hidalgo. versão corr. -- São Paulo, 2015.

$266 \mathrm{p}$.

Tese (Doutorado) - Escola Politécnica da Universidade de São Paulo. Departamento de Engenharia Mecânica.

1.Aquisição de conhecimento (Métodos) 2.Falhas (Diagnóstico) 3.Análise de risco 4.Análise de confiabilidade I.Universidade de São Paulo. Escola Politécnica. Departamento de Engenharia Mecânica Il.t. 


\section{DEDICATÓRIA}

Dedico este trabalho a Deus, a minha família e especialmente aos meus sobrinhos Fabiana e Matías. 


\section{AGRADECIMENTOS}

Em primeiro lugar agradeço a Deus e à Virgem do Rosário pela saúde, proteção e força para me permitir avançar nessa etapa da minha vida;

Gostaria de agradecer a minha família, que sempre esteve comigo e espero retribuir o carinho com a realização deste trabalho;

Especialmente, gostaria de agradecer aos meus pais, Miguel e Matilde, às minhas Irmãs, Patricia e Greidy, e a meus sobrinhos, Matías e Fabiana que sempre acreditaram em mim, agradeço pelo apoio, pela força que sempre me dão quando mais preciso, pela paciência e perseverança.

Ao Prof. Dr. Gilberto Francisco Martha de Souza, que me orientou, pela confiança, amizade e atenção com que me ajudou a conduzir este trabalho de pesquisa;

Aos meus amigos Nayara, Erick, Maritza, Gerby, Claudia, Luz, Fanny e Jélis, obrigado pelo apoio, os momentos de alegria e pela grande amizade que perdura;

À Senhora Vera, pelo apoio e porque sempre confiou em mim.

Aos meus colegas e amigos do Laboratório de Confiabilidade da Escola Politécnica, Dennis, Érico, Camila, Fernando, Carmen, Marjorie e Fernando Domingues, Khalil, Claudio, Lucia que sempre se mostraram prestativos quando precisei, e pelos quais sinto apreço e gratidão;

Ao Programa de Pós-Graduação em Engenharia Mecânica pela oportunidade de integrar o grupo de Doutorado; à AES Tiete e CAPES, pela bolsa de estudos concedida durante parte do desenvolvimento deste trabalho.

Aos Eng. Juliano, Thiago e Tiago pelo apoio nas informações técnicas prestado ao trabalho. 


\section{RESUMO}

O processo de aquisição do conhecimento é uma das principais etapas de desenvolvimento de um sistema especialista e é considerado como um dos estágios mais difíceis. Essa dificuldade se dá em virtude da inexistência de uma metodologia eficiente, confiável e padrão para extração e organização do conhecimento das várias fontes.

O método apresentado neste trabalho é uma alternativa que pode ser empregada para adquirir o conhecimento para desenvolver sistemas especialistas para diagnóstico de falhas em diferentes áreas da indústria. Este trabalho apresenta um método que integra as técnicas de confiabilidade e risco, tais como, Análise de Modos e Efeitos de Falha (FMEA), Análise de Árvore de falhas (FTA) e Estudo de Perigo e Operabilidade (HAZOP) para aquisição do conhecimento para o diagnóstico de falhas. O método também permite estimar a periocidade da manutenção preventiva aplicando os conceitos de manutenção imperfeita e teoria de decisão multicritério.

O método utilizada técnicas empregadas em análise de confiabilidade e risco para determinar a relação entre efeito da falha em um sistema e as suas causas raiz com o objetivo de estabelecer um procedimento estruturado para aquisição do conhecimento associado à relação causa-efeito em um sistema.

O método foi validado com a comparação do histórico de falhas de um sistema hidráulico de uma usina hidrelétrica e, considerando-se que os eventos definidos como causa raiz registrados no histórico de falhas foram encontrados como resultados da análise pelo sistema especialista, tem-se a validação. O método para determinar a periocidade da manutenção preventiva foi validado com os resultados de artigos e com os planos de manutenção da usina.

Palavras-chave: Confiabilidade, Risco, HAZOP, FMEA, FTA e Sistema especialista. 


\begin{abstract}
The process of knowledge acquisition is a major step in developing an expert system and is considered as one of the most difficult stages. This difficulty is due to the lack of an efficient, reliable and standard methodology for extraction and organization of knowledge from various sources.

The method presented in this thesis is an alternative that can be used to acquire the knowledge to develop expert systems for fault diagnosis in different areas of industry. This thesis presents a method that integrates risk and reliability analysis techniques such as Failure Modes and Effects Analysis (FMEA), Fault Tree Analysis (FTA) and Hazard and Operability Study (HAZOP) for the acquisition of knowledge to fault diagnosis. The method also allows estimating the optimal intervention times of preventive maintenance by applying the imperfect maintenance and multicriteria concepts.

The method uses techniques that are employed in reliability and risk analysis to determine the relationship between fault effect in the system and its root causes in order to establish a structured acquisition of knowledge associated with the causeeffect relationship in a system procedure.

The method was validated by comparing the failure database related to a hydropower plant hydraulic system and, considering that the events defined as root causes recorded in the failure database were found by expert system, the method was validated. The method for determining the optimal intervention time for preventive maintenance has been validated with the results of articles and maintenance plans of the plant.
\end{abstract}

Keywords: Reliability, Risk, HAZOP, FMEA, FTA and Expert Systems. 


\section{LISTA DE ILUSTRAÇÕES}

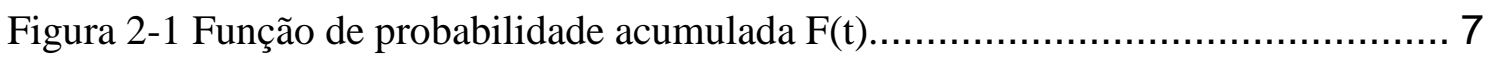

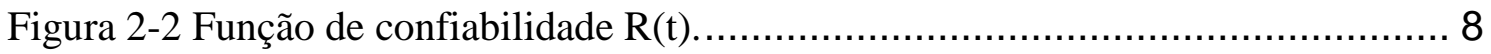

Figura 2-3 Representação da curva da banheira. ............................................ 10

Figura 2-4 Exemplo de FTA...................................................................... 12

Figura 2-5 Símbolos dos eventos do FTA. ............................................ 13

Figura 2-6 Conectores lógicos do FTA. ................................................. 14

Figura 2-7 Efeito da manutenção preventiva na confiabilidade.......................... 21

Figura 2-8 Curva de tendência para o valor de um parâmetro de interesse. ................ 23

Figura 3-1 Estrutura do Sistema Especialista.................................................. 32

Figura 3-2 Estrutura das Redes Semânticas.................................................... 40

Figura 3-3 Estrutura dos Quadros. ......................................................... 41

Figura 4-1 Procedimento para estudo e descrição funcional do sistema ................... 53

Figura 4-2 Arranjo geral da árvore funcional.......................................... 54

Figura 4-3 Aplicação das técnicas de confiabilidade e risco na aquisição do conhecimento para o diagnóstico de falhas ............................................. 56

Figura 4-4 Diagrama de decisão da Manutenção Centrada em Confiabilidade para seleção de políticas de manutenção ............................................................6 60

Figura 4-5 Modelo recursivo para evolução da taxa de falha............................... 62

Figura 4-6 Fluxograma do modelo aplicado para a determinação dos intervalos de manutenção preventiva .............................................................. 65

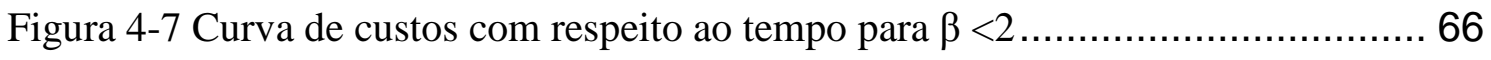

Figura 4-8 Curva de custos com respeito ao tempo para $\beta \geq 2 \ldots \ldots \ldots \ldots \ldots \ldots \ldots \ldots \ldots . \ldots \ldots$

Figura 5-1 Diagrama do regulador de velocidade da turbina Kaplan ....................... 74

Figura 5-2 Mecanismo de regulação das pás da turbina Kaplan............................ 78

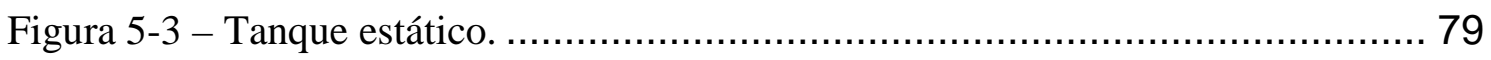

Figura 5-4 Árvore funcional do regulador de velocidade da turbina Kaplan..............81 81

Figura 5-5 Diagrama do regulador de velocidade da turbina Kaplan com os nós a

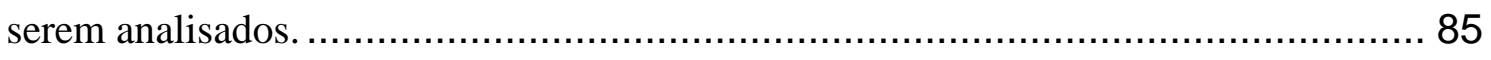

Figura 5-6 Aplicação das técnicas HAZOP e FTA para o nó 3 ................................ 87

Figura 5-7 Base de dados da Norma NPDR-95 ............................................... 93

Figura 5-8 Resultados do motor para a manutenção preventiva com degradação, para o valor de $\mathrm{K}=5$. 
Figura 5-9 Resultados do motor para a manutenção preventiva com degradação, para o valor de $K=10$.

Figura 5-10 Resultados do Motor para a manutenção preventiva com degradação, para o valor de $\mathrm{K}=15$.

Figura 5-11 Árvore de decisão para temperatura elevada do óleo. 104

Figura 5-12 O sistema especialista identifica a causa do desvio. 106

Figura 5-13 O sistema especialista realiza perguntas para identificar a causa do desvio. 


\section{LISTA DE TABELAS}

Tabela 2.1 Evolução das filosofias de manutenção (CARAZAS, 2011; SOUZA e MOLINARI, 2008)

Tabela 2.2 Problemática em função do tipo de problema (HELMAN e MARÇAL, 2007) 29

Tabela 4.1 Palavras-Guias para a análise (KUMAMOTO e HENLEY, 2000) …....... 57

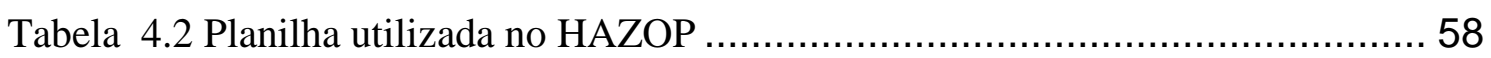

Tabela 4.3 Formulário empregado na análise de tipo FMEA …………………....... 59

Tabela 4. 4 Tabulação de Resultados na Análise de decisão pelo Método RCM (MOUBRAY, 2000).

Tabela 4.5 Comparação entre diversas aplicações de sistemas especialistas em diagnóstico de falhas ....

Tabela 5.1 Nós de Referência, Parâmetros, Palavras Guia, Desvios e Consequências - Análise HAZOP

Tabela 5.2 Aplicação da Análise de Modo e Efeito de Falha para o Motor elétrico AC.

Tabela 5.3 Políticas de manutenção para o Motor elétrico A.C. 90

Tabela 5.4 Porcentagem de falha para distribuição de Weibull

Tabela 5.5 Componentes com suas respectivas taxas de falha ............................... 95

Tabela 5.6- Dados de entrada 95

Tabela 5.7 Alternativas dos intervalos de intervenção (Ti) para fazer a manutenção preventiva do motor

Tabela 5.8 Alternativas dos intervalos de intervenção (Ti) para fazer a manutenção preventiva do atuador

Tabela 5.9 Alternativas dos intervalos de intervenção (Ti) para fazer a manutenção preventiva do bomba

Tabela 5.10 Alternativas dos intervalos de intervenção (Ti) para fazer a manutenção preventiva do trocador de calor

Tabela 5.11 Alternativas dos intervalos de intervenção (Ti) para fazer a manutenção preventiva do acumulador

Tabela 5.12 Função de preferência e características dos critérios.

Tabela 5.13 Resultados das periocidades da manutenção preventiva da bomba. ...... 100

Tabela 5.14 Resultados das periocidades da manutenção preventiva do atuador...... 100 
Tabela 5.15 Resultados das periocidades da manutenção preventiva do acumulador. 101

Tabela 5.16 Resultados das periocidades da manutenção preventiva do trocador de calor.

Tabela 5.17 Resultados dos das periocidades da manutenção preventiva do motor elétrico

Tabela 6.1 Registro de falhas do regulador de velocidade no período 01/01/2001 até 27/07/2012. 109

Tabela 6.2 Dados de entrada................................................................... 114

Tabela 6.3 Função de preferência e características dos critérios............................ 114 


\section{LISTA DE SÍMBOLOS}

$\beta \quad$ Constante de forma na distribuição de Weibull.

$\eta \quad$ Constante de escala na distribuição de Weibull.

$\lambda \quad$ Taxa de falha constante no tempo.

$\lambda(t) \quad$ Taxa de falha no tempo $t$.

$a_{i} \quad$ Fator de redução de idade.

$b_{i} \quad$ Fator de crescimento da taxa de falha.

$C_{f} \quad$ Custo de manutenção corretiva do sistema.

$\mathrm{C}_{\mathrm{p}} \quad$ Custo de manutenção preventiva do sistema.

$f(t) \quad$ Função densidade de probabilidade de falha no tempo t.

$F(t) \quad$ Função de probabilidade acumulada de falha no tempo $t$.

i I Índice do número do ciclo de manutenção preventiva.

MTBF Tempo médio entre falhas.

MTTR Tempo médio para reparo.

$R(t) \quad$ Confiabilidade no tempo t.

Ri(t) Confiabilidade do componente i no tempo t.

$R s(t) \quad$ Confiabilidade do sistema no tempo $t$.

$T \quad$ Tempo até ocorrer a falha.

$T_{i} \quad$ Intervalo de intervenção preventiva do sistema máquina do período anterior.

$t_{p} \quad$ Intervalo de tempo para efetuar a manutenção preventiva no ciclo $(i+1)$ de operação. 


\section{SUMÁRIO}

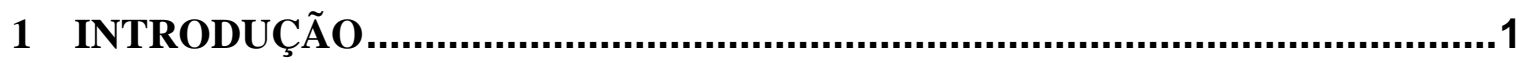

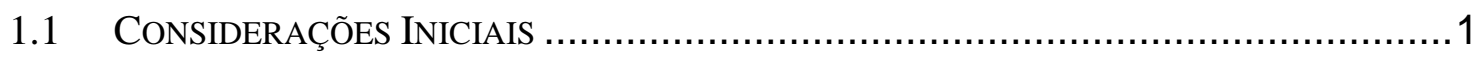

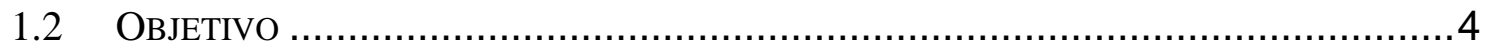

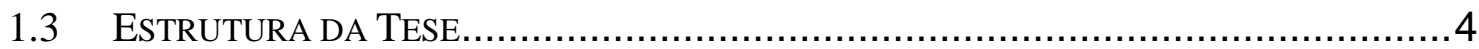

2 FUNDAMENTOS TEÓRICOS: CONFIABILIDADE, ANÁLISE DE RISCO

E MANUTENÇÃ̃

2.1 DefiniçÃo de Defeito, Falha e Probabilidade de FALHA. .......................... 6

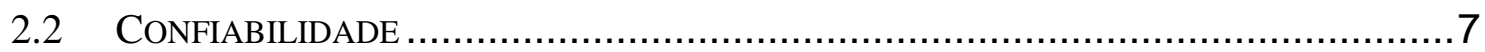

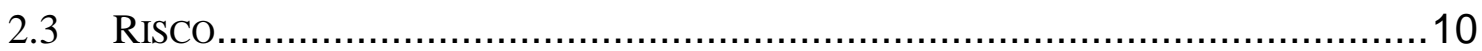

2.4 TÉCNICAS PARA ANÁLISE DE CONFIABILIDADE E RISCO ............................. 11

2.4.1 Análise de Árvore de Falhas - FTA ............................................ 11

2.4.2 Método da Análise de Modos e Efeitos de Falhas - FMEA ......................14

2.4.3 Estudo de Perigo de Operação - HAZOP ...........................................15

2.5 MANUTENÇÃO................................................................................ 16

2.5.1 Manutenção Corretiva ........................................................... 18

2.5.2 Manutenção Preventiva ............................................................ 19

2.5.3 Manutenção Preditiva ........................................................22

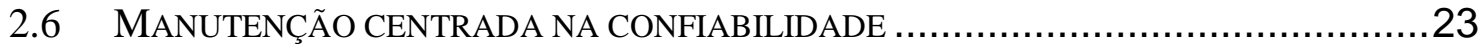

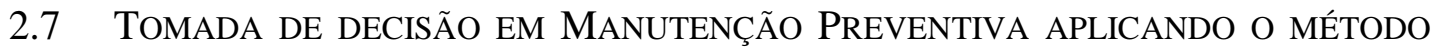

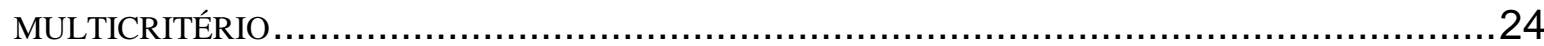

2.7.1 Métodos multicritério de apoio a decisão.......................................27

3 SISTEMAS ESPECIALISTAS …................................................................30

3.1 CONCEITO DO SISTEMA ESPECIALISTA ................................................. 30

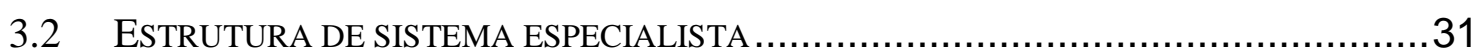

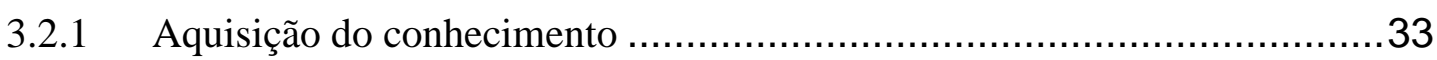

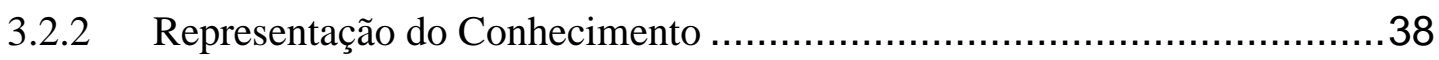

3.3 ENGENHARIA DO CONHECIMENTO .................................................... 42

3.4 APLICAÇÕES DOS SiSTEMAS ESPECIALISTAS .........................................43 
3.5 ESTADO DA ARTE DOS SISTEMAS ESPECIALISTAS APLICADOS NO DIAGNÓSTICO DE FALHAS.

\section{PROPOSTA DO MÉTOdO PARA AQUISIÇÃo DE CONHECIMENTO PARA A ELABORAÇÃO DE UM SISTEMA ESPECIALISTA PARA O DIAGNÓSTICO DE FALHAS}

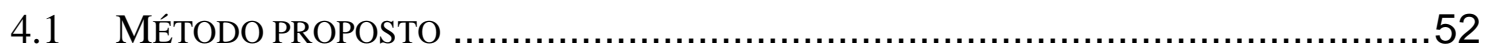

4.1.1 Estudo e descrição operacional do sistema.......................................53

4.1.2 Aquisição do conhecimento para o diagnóstico de falhas........................55

4.1.3 Aquisição do conhecimento para propor políticas de manutenção.............59

4.1.4 Cálculo da periocidade da manutenção preventiva ..............................61

4.2 ANÁLISE COMPARATIVA ENTRE OS DIVERSOS ARTIGOS APRESENTADOS NAS REFERÊNCIAS BIBLIOGRÁFICAS E O PROPOSTO NESTE TRABALHO..............................67

4.3 PRINCIPAIS INOVAÇÕES E CONTRIBUIÇÕES DO MÉTODO PROPOSTO ..................70

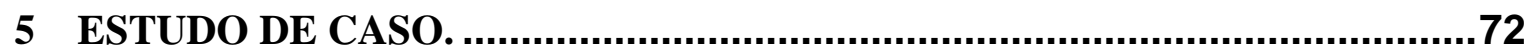

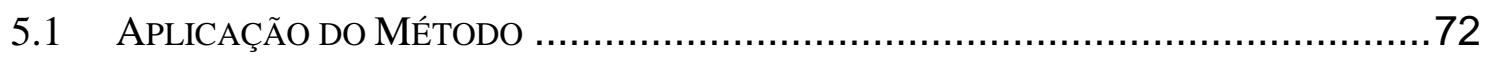

5.1.1 Estudo e descrição operacional do sistema..................................... 72

5.1.2 Aquisição do conhecimento para o diagnóstico de falhas........................82

5.1.3 Aquisição do conhecimento para seleção das políticas de manutenção......89

5.1.4 Periocidade da manutenção preventiva ..........................................92

5.2 DESENVOLVIMENTO DO SISTEMA ESPECIALISTA PARA O DIAGNÓSTICO DE FALHAS NO REGULADOR DE VELOCIDADE DA TURBINA KAPLAN............................... 102

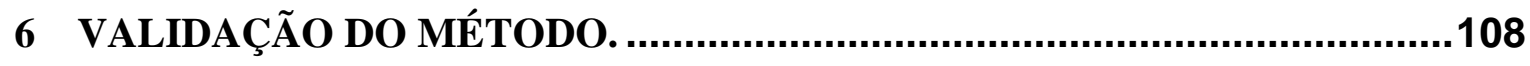

7 CONCLUSÕES ............................................................................ 116

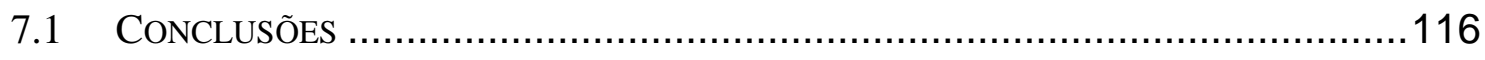

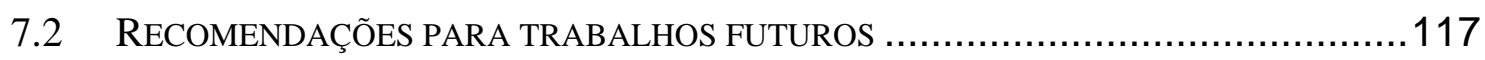

8 REFERÊNCIAS BIBLIOGRÁFICAS.................................................. 119

ANEXO A: MÉTODO PROMETHEE II ................................................ 137

ANEXO B: REGULADOR DE VELOCIDADE .......................................... 141 
B.1 CENTRAIS HIDRELÉTRICAS .............................................................. 141

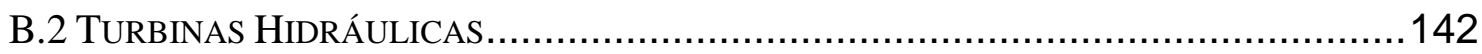

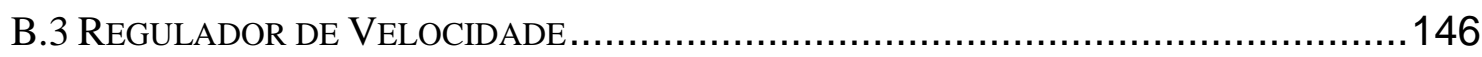

B.3.1 Sistema de controle do Regulador de Velocidade. .............................. 148

B.3.2 Sistema eletro-hidráulico para controle de posição ................................151

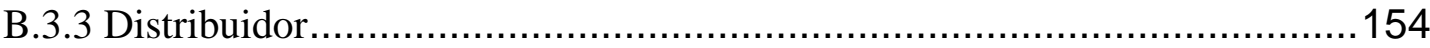

B.4 REGULAÇÃO DOS TIPOS DE TURBINAS COM OS REGULADORES DE VELOCIDADE .... 155

B.4.1 Regulação da turbina Pelton...................................................... 155

B.4.2 Regulação das turbinas Francis................................................. 156

B.4.3 Regulação da Turbina Kaplan ........................................................ 158

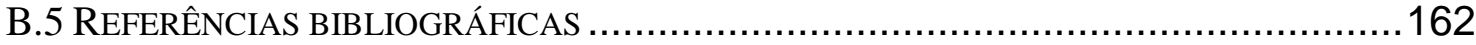

APÊNDICE A: DESCRIÇÃO FUNCIONAL ................................................. 164

APÊNDICE B: APLICAÇÃO DO HAZOP E FTA ........................................... 170

APÊNDICE C: ANÁLISE DE MODOS E EFEITOS DE FALHA......................... 195

APÊNDICE D: POLITICAS DE MANUTENÇÃO.......................................206

APÊNDICE D: ÁRVORES DE DECISÃO ..................................................218

APÊNDICE F: CÓDIGO DE PROGRAMAÇÃO EM CLIPS ............................224 


\section{INTRODUÇÃO}

\subsection{Considerações Iniciais}

Do final dos anos 60 ao início dos anos 70 do século $X X$, os sistemas especialistas começaram a surgir como um ramo da Inteligência Artificial. Esta surgiu em 1956, de uma reunião feita nos Estados Unidos que contou com cientistas de várias áreas do conhecimento, todos com o mesmo objetivo, estudar como criar máquinas inteligentes e saber como estas afetariam os processos existentes (FILHO, 2003; BASSETTO, 2006; SUNJURA, 1996). A inteligência artificial é uma área de estudo da ciência da Computação relativa ao projeto e programação de máquinas que visam realizar tarefas em que as pessoas precisam utilizar sua inteligência para realizá-las; além disso, também se dedica ao entendimento de como o ser humano pensa, por meio do estudo do comportamento e de desenvolvimento de programas que modelam as hipóteses correntes e as conjecturas de alguns dos aspectos do processo cognitivo humano (LIAO, 2005; O'KEEFE e PREECE, 1996).

Os sistemas especialistas permitem solucionar problemas de forma inteligente $\mathrm{e}$ reproduzir decisões de um especialista humano, numa determinada área de interesse. É importante o desenvolvimento e aplicação de sistemas deste gênero nas mais variadas áreas do conhecimento humano, a fim de ampliar e difundir as teorias e conhecimentos adquiridos pelo especialista humano na prática de seu dia a dia. A ideia central é que o sistema obtenha uma solução para um problema de uma forma eficiente a partir de várias alternativas. Esta solução depende do conhecimento adquirido sobre o problema a solucionar e será satisfatória na medida em que encontrar a resposta suficientemente boa para os recursos existentes (BARR e FEIGENBAUM, 1981; ASHARAFI et al, 1995).

Uma das principais etapas para o desenvolvimento de um sistema especialista é o processo de aquisição do conhecimento, que é considerado como um dos estágios mais difíceis, conforme Barr e Feigenbaum (1981) e Maher et al (1984). Essa dificuldade se dá em virtude da inexistência de uma metodologia eficiente, confiável 
e padrão para extração e organização do conhecimento das várias fontes de informações disponíveis.

Li e Liu (2010) realizaram uma revisão de artigos de sistemas especialistas para o diagnóstico de falha e apontaram que existem alguns pontos a serem melhorados na elaboração de sistema especialista como a dificuldade em adquirir e gerenciar a extração do conhecimento, baixa eficiência no processo de inferência, entre outros.

Uma das grandes dificuldades no desenvolvimento e construção de um sistema especialista é atribuída à extração do conhecimento do especialista. Um problema inicial é a comunicação entre o especialista e o engenheiro de conhecimento. $O$ engenheiro pode realizar uma série de entrevistas sem ter boa noção do assunto em questão. Assim, o especialista para ser compreendido deverá usar termos triviais, mas esses não são termos que expressam sua maneira natural de trabalho, logo há uma considerável perda de informação na transmissão do conhecimento (FILHO, 2003; NIKOPOULOS, 1997). O ideal é que ambos, o engenheiro de conhecimento e o especialista, aprendam um pouco sobre o trabalho do outro para que a conversa flua mais naturalmente. No entanto, até que isso ocorra, já se terá perdido muito tempo. Por esse motivo, a qualidade, precisão e a integridade do conhecimento adquirido têm um grande efeito na qualidade e acurácia do sistema do especialista (SUNJURA, 1996; FILHO, 2003; O'KEEFE e PREECE, 1996).

As fontes potenciais de conhecimento usadas no processo de aquisição do conhecimento podem ser documentadas ou não. As fontes documentadas são: livros, filmes, gráficos, diagramas, manuais, entre outras. Já as fontes não documentadas residem na mente das pessoas que atuam no domínio de aplicação do sistema (especialistas que detêm o conhecimento que se quer armazenar no sistema especialista) (NIKOPOULOS, 1997).

Com o intuito de tornar mais efetivo o processo de aquisição de conhecimento, varias técnicas têm sido desenvolvidas. Elas podem ser classificadas como manuais, semi-automáticas e automáticas. As técnicas manuais o Engenheiro de Conhecimento é responsável por adquirir o conhecimento do Especialista e outras fontes e codificá-lo na base do conhecimento. As semi-automaticas objetivam dar aos especialistas ferramentas que possibilitam a criação dos sistemas minimizando 
a necessidade de um engenheiro de conhecimento. As técnicas automáticas ou técnicas de aprendizado de máquina constroem sistemas capazes de aprender com a experiência. Isto é, um sistema que realiza determinada tarefa deve poder obter informações que permitam que realizações futuras desta tarefa tenham melhor desempenho.

O método apresentado neste trabalho é uma alternativa que pode ser empregada para adquirir o conhecimento para desenvolver sistemas especialistas para diagnóstico de falhas em diferentes áreas da indústria.

O método utilizada técnicas empregadas em análise de confiabilidade e risco para determinar a relação entre efeito da falha em um sistema e as suas causas raiz com o objetivo de estabelecer um procedimento estruturado para aquisição do conhecimento associado à relação causa-efeito em um sistema.

O sistema selecionado para aplicar o método proposto é o regulador de velocidade de turbina hidráulica. O regulador de velocidade tem a função de controlar a energia hídrica que se converte em energia mecânica, compatibilizando a capacidade de geração de energia elétrica com a sua demanda e evitando perda de sincronismo. Em função da demanda por energia elétrica, o sistema regulador da turbina atua sobre a posição das pás do distribuidor controlando a abertura e consequentemente a vazão que chega ao rotor, gerando apenas a energia necessária para atender a demanda requerida (ANDIA, 2005).

Os reguladores de velocidade desenvolvem mecanismos de falha associados a processo de dano acumulado. Por isso, é importante e necessário monitorar e diagnosticar falhas em componentes críticos (aqueles cuja falha causa perda de desempenho ou mesmo paralisação do regulador de velocidade e, por conseguinte do hidrogerador). Diagnosticar falhas em um regulador de velocidade é um processo complexo que requer um alto nível de conhecimento da interação entre os componentes e a sua relação com o desempenho da turbina, incluindo o efeito da ocorrência de falhas de seus componentes. (COSTA, 2010; SONG et al., 2008).

A justificativa de selecionar o regulador de velocidade como caso de aplicação do método proposto é que no âmbito da produção de energia elétrica, as 
consequências associadas com uma paralisação de um hidrogerador que pode ser causada pela indisponibilidade do regulador de velocidade, envolvem a redução da capacidade de geração de energia elétrica em relação a um valor contratado. Esta redução pode resultar em penalidades ou multas impostas pela legislação vigente. Na resolução $n^{\circ} .161$ da ANEEL de 2001, o valor mínimo da multa é de cem mil reais mais o pagamento da energia que não foi produzida (ANEEL, 2001).

Na resolução n 318 da ANEEL de 1998, lê-se que "a inexecução parcial ou total de obrigações legais e contratuais, caracterizadas entre outras, por violação dos padrões de qualidade dos serviços, atraso da entrada em operação das instalações está sujeita a suspensão temporária de participação de licitações para obtenção de novas concessões, permissões ou autorizações, bem como impedimento de contratos com a ANEEL e de recebimento de autorização para serviços e instalação de energia elétrica" (ANEEL, 1998).

\subsection{Objetivo}

Este trabalho tem como objetivo desenvolver um método que integre as técnicas de confiabilidade e risco para adquirir o conhecimento para desenvolver um sistema especialista para o diagnóstico de falhas.

O método integra as técnicas de confiabilidade e risco, tais como, Análise de Modos e Efeitos de Falha (FMEA), Análise de Árvore de falhas (FTA) e Estudo De Perigo e Operabilidade (HAZOP) para aquisição do conhecimento para o diagnóstico de falhas. O método também permite estimar a periocidade da manutenção preventiva aplicando os conceitos de manutenção imperfeita e multicritério.

\subsection{Estrutura da Tese}

O presente capítulo traz uma introdução que expõe a justificativa para o desenvolvimento de um método estruturado da aquisição de conhecimento de um sistema especialista e a sua aplicação em sistemas de geração de energia elétrica com o emprego de usinas hidrelétricas. Apresenta o objetivo do trabalho e sua estrutura. 
No Capítulo 2, são tratados os conceitos de manutenção, confiabilidade e risco. Finalmente, é feita uma apresentação das principais técnicas de análise de relação causa-efeito das falhas utilizadas na área de risco e confiabilidade que são empregadas na aquisição do conhecimento para o sistema especialista.

No Capítulo 3, é apresentada a fundamentação teórica relativa a Sistemas Especialistas, incluindo o seu funcionamento, a estrutura e aplicação na área industrial.

No Capítulo 4, apresenta-se o método proposto para aquisição do conhecimento para desenvolver um sistema especialista para o diagnóstico as falhas, utilizando os conceitos revisados nos capítulos anteriores, visando cumprir o objetivo definido no Capítulo1.

O Capítulo 5 apresenta a aplicação do método proposto no capítulo 4 em um regulador de velocidade de turbinas hidráulicas. Além disso, apresenta as árvores de decisão que foram elaboradas partindo do conhecimento adquirido para desenvolver o sistema especialista.

O Capítulo 6 apresenta a validação do método proposto com a aplicação descrita no capítulo 5.

O Capítulo 7 apresenta as conclusões a respeito do referido trabalho além de fazer uma sequência de recomendações para trabalhos futuros. 


\section{FUNDAMENTOS TEÓRICOS: CONFIABILIDADE, ANÁLISE DE RISCO E MANUTENÇÃO.}

Este capítulo tem por objetivo apresentar os fundamentos teóricos de Manutenção, Confiabilidade e análise de Risco. São apresentadas as principais técnicas utilizadas na análise de Confiabilidade e Risco.

\subsection{Definição de Defeito, Falha e Probabilidade de Falha.}

A norma NBR 5462 (ABNT, 1994) conceitua o termo defeito como "qualquer desvio de uma característica de um item em relação aos seus requisitos". Um defeito pode, ou não, alterar a capacidade de um item desempenhar uma função requerida dentro de um contexto operacional específico.

A norma NBR 5462 (ABNT, 1994) define que a falha não pode estar relacionada somente com a paralisação do componente e sim com a incapacidade deste operar com um determinado desempenho mínimo especificado, incluindo a possibilidade de paralisação completa, comumente denominada de quebra. Nesse caso, a falha pode ser associada a uma probabilidade de ocorrência de um desempenho insatisfatório dentro de um intervalo de tempo t. Definindo-se o tempo $t$ até ocorrer a falha como uma variável aleatória, pode-se definir sua correspondente função densidade de probabilidade $f(t)$ como sendo:

$$
f(t) . \Delta t=P\{t<T \leq t+\Delta t\}
$$

Sendo $F(t)$ a função probabilidade acumulada, tem-se que:

$$
F(t)=P(T \leq t)
$$

ou seja, $F(t)$ expressa a probabilidade de a falha ocorrer até um tempo t, enquanto $f(t)$ representa a função densidade de probabilidade da falha.

$F(t)$ é crescente no tempo, atingindo o valor unitário quando $t$ tende a infinito, como mostra a Figura 2.1 (LEITCH, 1995). 
Figura 3-1 Função de probabilidade acumulada $F(t)$.

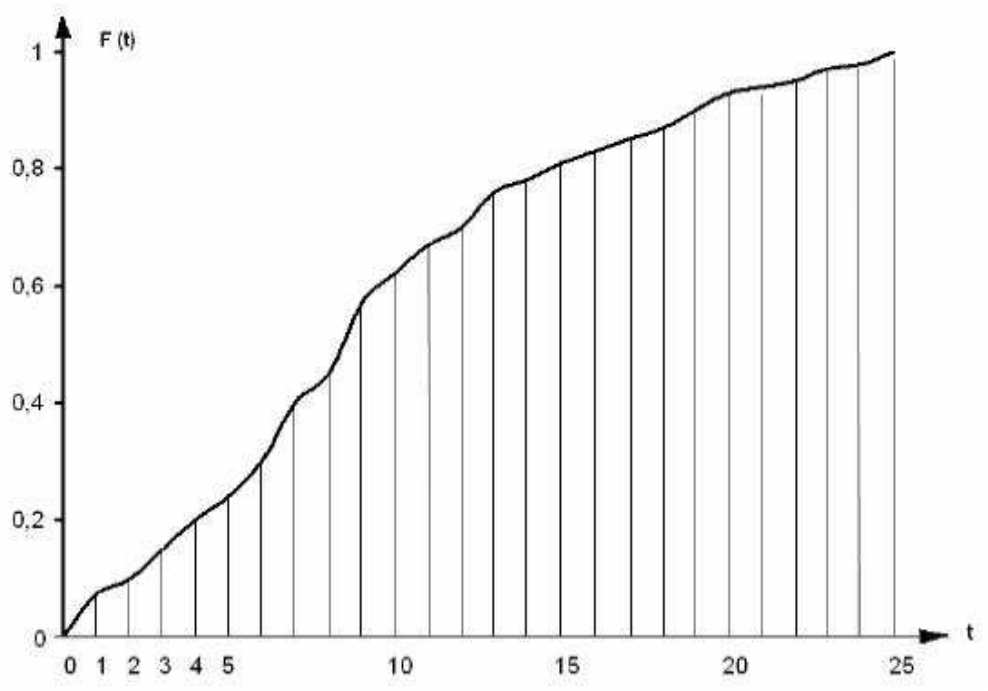

Fonte: Leitch (1995).

Sob o ponto de vista da lógica de sua operação, um componente ou equipamento ou está operando adequadamente, conforme previsto no projeto, ou está no estado de falha, mostrando assim que são eventos mutuamente excludentes.

\subsection{Confiabilidade}

Ao longo da Segunda Guerra Mundial, iniciou-se o estudo da Engenharia da Confiabilidade. Devido ao desenvolvimento de armamentos de maior complexidade, a indústria bélica passou a necessitar de meios que permitissem estimar a vida ou mesmo a probabilidade de um equipamento operar com sucesso (SOUZA e MOLINARI, 2008). Após o término da Segunda Guerra Mundial, com o desenvolvimento de centrais termoelétricas abastecidas com combustível nuclear, foi possível sua utilização para a geração de energia elétrica. A confiabilidade começou a ser aplicada na redução da probabilidade de falha do sistema cuja consequência seria a ocorrência de vazamentos de material radioativo. A indústria nuclear segue utilizando os conceitos de confiabilidade em todas as etapas de desenvolvimento do projeto e da forma de operação de seus sistemas. 
A confiabilidade é definida como "a probabilidade de um item irá executar sua função sob determinadas condições operacionais e de manutenção por um determinado período de tempo" (ABNT, 1994).

Para a análise de engenharia é necessário definir a confiabilidade como uma probabilidade. Assim, uma definição possível é de que a confiabilidade é a probabilidade de um produto, sistema, máquina ou equipamento operar sem falha por um período de tempo determinado sob condições de operação especificas (SOUZA, 2008).

A confiabilidade pode ser expressa pela relação (LEITCH, 1995):

$$
\begin{aligned}
& R(t)=P(T>t) \\
& F(t)=1-R(t)
\end{aligned}
$$

A função confiabilidade está mostrada na Figura 2.2.

Figura 3-2 Função de confiabilidade $R(t)$.

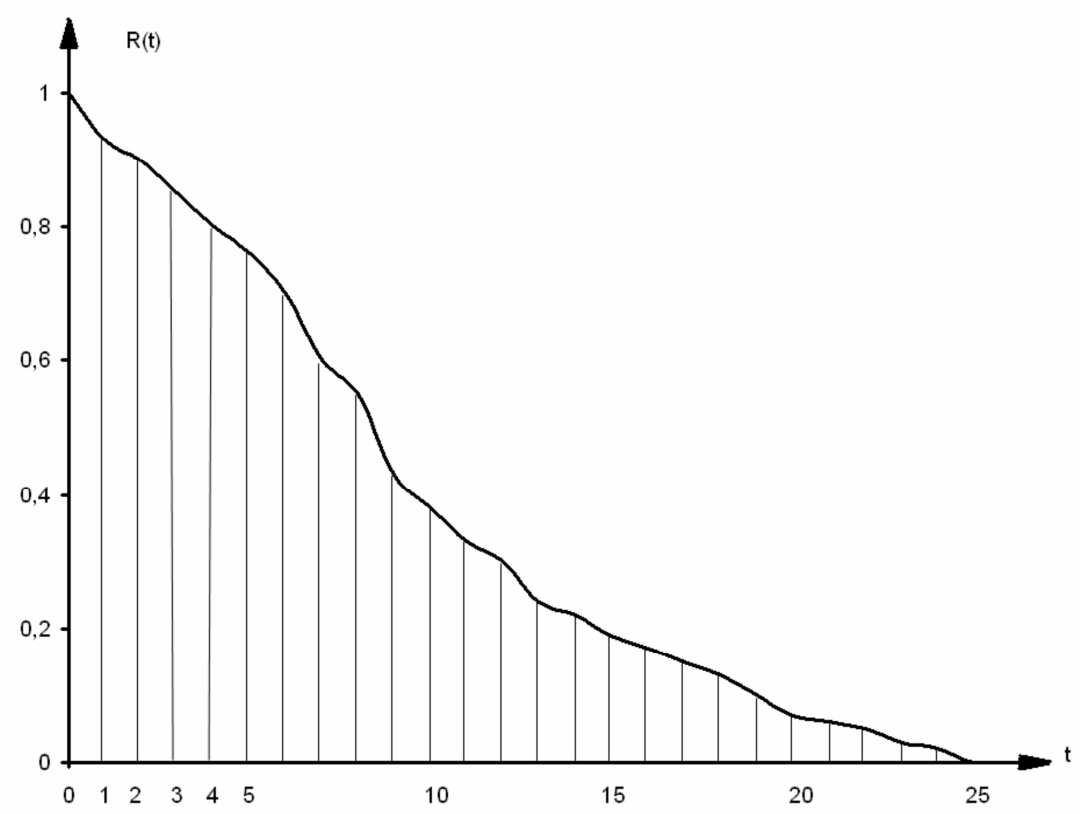

Fonte: Leitch (1995). 
Como decorrência desta definição, tem-se que:

$$
\begin{aligned}
& R(0)=1 \\
& R(\infty)=0
\end{aligned}
$$

A partir do gráfico apresentado na Figura 2.2, pode-se observar que a confiabilidade de um sistema decai com o tempo. Quanto maior é o tempo de operação, maior será a probabilidade de este apresentar falha. Portanto, apenas no instante em que o equipamento é colocado em operação sua confiabilidade é de $100 \%$.

O comportamento de determinado produto com relação à falha é melhor compreendido pelo estudo do comportamento de sua taxa de falha $\lambda(t)$. Esta taxa de falha, $\lambda(t)$, pode ser definida como sendo a probabilidade de que, tendo 0 equipamento trabalhado sem falha até o ciclo $t-1$, ele apresente falha no ciclo de operação $t$. Também pode ser definida como se segue.

"Sendo $\lambda(t) \Delta t$ a probabilidade de que o sistema falhará em um tempo $T<t+\Delta t$, dado que ainda não falhou até o tempo $T=t$, tem-se que $\lambda(t) \Delta t$ é a probabilidade condicional":

$$
\lambda(t) \Delta t=P(T<t+\Delta t \mid T>t)
$$

Assim, com base na definição de probabilidade condicional, tem-se:

$$
P(T<t+\Delta t \mid T>t)=\frac{P\{(T>t) \cap(T<t+\Delta t)\}}{P(T>t)}
$$

Como o numerador da equação 2.8 é a própria $f(t)$, e o denominador é a $R(t)$, a taxa de falhas instantânea é expressa por:

$$
\lambda(t)=\frac{f(t)}{R(t)}
$$


O comportamento da taxa de falha $\lambda(t)$ ao longo do tempo $t$ é indicador das causas da falha. A "curva da banheira", mostrada na Figura 2.3, representa graficamente esta relação, de forma genérica, para um sistema sem redundância.

Figura 3-3 Representação da curva da banheira.

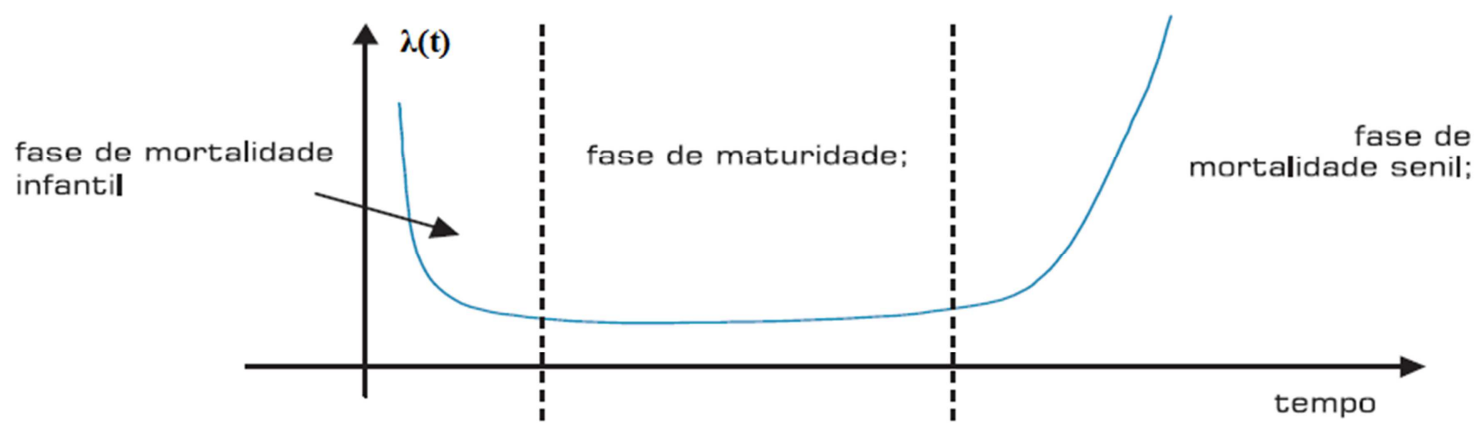

Fonte: Smith (2001).

Nessa curva, no primeiro intervalo a taxa de falha é alta e decresce a partir de $t=0$. Esta região é conhecida como fase de mortalidade infantil; nesta etapa, pode-se representar problemas de manufatura, montagem ou mesmo com material empregado na fabricação do componente. No segundo intervalo, encontra-se o período de falha aleatória, quando a taxa de falha é constante, sendo os componentes eletrônicos um típico exemplo deste comportamento. No último intervalo, conhecido como fase de mortalidade senil ou envelhecimento, a taxa de falha cresce por causa do envelhecimento, quando os fenômenos de dano acumulado como o desgaste e a fadiga, entre outros, começam a ser relevantes no desempenho do equipamento (LEWIS, 1987; SOUZA, 2008).

\subsection{Risco}

Segundo a norma técnica da PETROBRÁS N-2782 (2004), o risco é definido como a medida de perdas econômicas, danos ambientais ou lesões à vida humana em termos da probabilidade de ocorrência de um acidente (frequência) e magnitude das perdas, dano ao meio ambiente e/ou de lesões (consequências). Por outro lado, 
Haimes (1998) define o risco como a medida da probabilidade de ocorrência de um efeito indesejado e severidade dos seus efeitos sobre um sistema.

De forma mais geral, o risco pode ser definido simplesmente como a combinação da probabilidade $\left(P_{i}\right)$ e da severidade da consequência $\left(c_{i}\right)$, como se observa na equação 2.10 .

$$
\text { Risco }=P_{i} * c_{i}
$$

A consequência se manifesta com os efeitos físicos que causam impactos aos recursos humanos, ambientais e/ou materiais, ocasionados por incêndios, explosões ou vazamentos de produtos tóxicos ou perigosos entre outros, e é expressa sob forma de danos à saúde, perdas econômicas e impactos ao meio ambiente (HAIMES, 1998).

\subsection{Técnicas para análise de Confiabilidade e Risco}

Existe uma variedade de técnicas de análise de confiabilidade e risco. Neste trabalho serão explicadas detalhadamente três técnicas, que são utilizadas na elaboração do método proposto no capítulo 4, as quais são:

- Análise de Árvore de Falhas (FTA)

- Análise de Modos e Efeitos de Falhas (FMEA);

- Estudos De Perigo De Operação (HAZOP);

\subsubsection{Análise de Árvore de Falhas - FTA}

Em 1962 foi introduzida a análise da Árvore de Falhas (FTA - Fault Tree Analysis) pela empresa Bell Telephone Laboratories, a qual foi utilizada para a avaliação de confiabilidade do sistema de controle de lançamento do míssil Minuteman. Desde aquela época a análise do tipo FTA se tornou uma das principais técnicas para avaliação da confiabilidade de sistemas, sendo aplicada em diversos setores industriais em que a confiabilidade dos sistemas envolvidos é de 
fundamental importância para sua operação segura e eficiente, (RAUSAND e ARNLJOT, 2004).

Uma árvore de falhas é uma representação gráfica organizada das condições que contribuem para ocorrência de um evento previamente definido, chamado de evento topo. Uma típica árvore de falhas é formada por um evento topo, eventos básicos e portas lógicas. A Figura 2.4 ilustra a estrutura de uma árvore de falhas com componentes típicos. O evento topo representa uma condição indesejável do sistema, os eventos básicos representam os estados dos componentes do sistema, e as portas lógicas descrevem a combinação entre os eventos básicos para gerar o evento superior a eles. Quando se tem uma porta lógica "E", para que ocorra um evento, todos os eventos básicos têm que acontecer simultaneamente. Quando se indica a porta lógica "OU", para que ocorra um evento, só é necessária a ocorrência de um evento básico, (RAUSAND e ARNLJOT, 2004).

Figura 3-4 Exemplo de FTA.

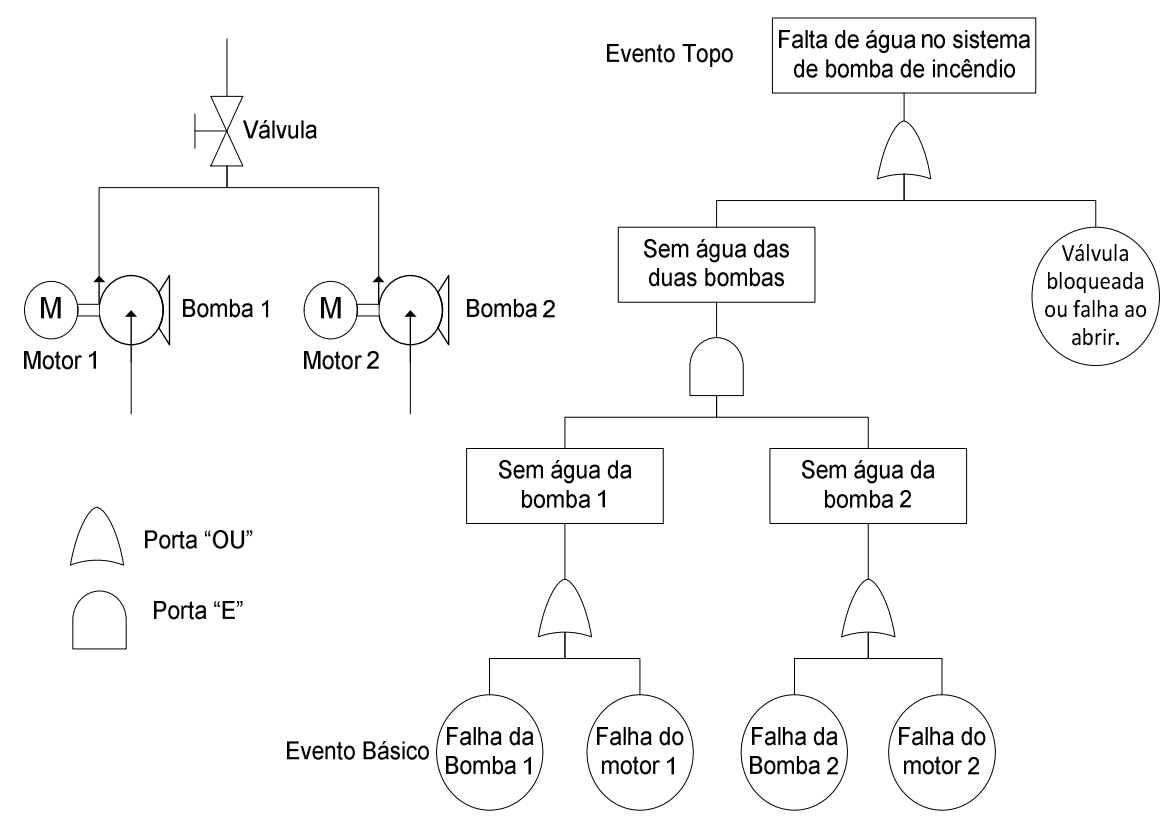

Fonte: Rausand e Arnljot (2004).

A análise da Figura 2.4 possibilita verificar quão rápida e precisa pode ser a identificação da causa da falha no sistema com o emprego da Árvore de Falhas. Como se observa na árvore de falhas, o evento topo é: falta de água no sistema de bomba de incêndio. Os eventos básicos são: válvula bloqueada ou falha ao abrir, falha na bomba 1, falha na bomba 2, falha do motor $1 \mathrm{e}$, por último, falha no motor 2 . 
Observando a árvore de falhas, o componente mais crítico é a válvula, porque se esta está bloqueada ou falha ao abrir, o sistema ficaria sem água. No caso das bombas e motores deve acontecer uma falha simultânea dos sistemas de bombeamento para que o sistema fique sem água.

A análise do tipo FTA é basicamente um método dedutivo que visa identificar as causas ou combinação de causas que possam levar a ocorrência do evento topo definido. A análise pode ser qualitativa e/ou quantitativa, (LEWIS, 1987).

Determinar a origem do problema corresponde à parte qualitativa da análise; além disso, permite uma compressão das possíveis combinações de como o sistema pode falhar e, portanto, determinar quais serão as medidas que podem ser tomadas para minimizar os efeitos e as consequências do evento indesejável. A avaliação quantitativa nos permite calcular a probabilidade de ocorrência do evento topo, a partir dos vários eventos iniciais (eventos básicos), desde que seja conhecida a probabilidade de falha de cada um dos componentes candidatos a causar o evento topo (HIDALGO, 2011; LEWIS, 1987).

Para a construção de uma FTA são usados símbolos padronizados para descrever eventos, conexões lógicas e símbolos de transferência. Estes são mostrados nas Figuras 2.5 e 2.6 (O'CONNOR, 1985; BROOKE e PAIGE, 2003).

Figura 3-5 Símbolos dos eventos do FTA.

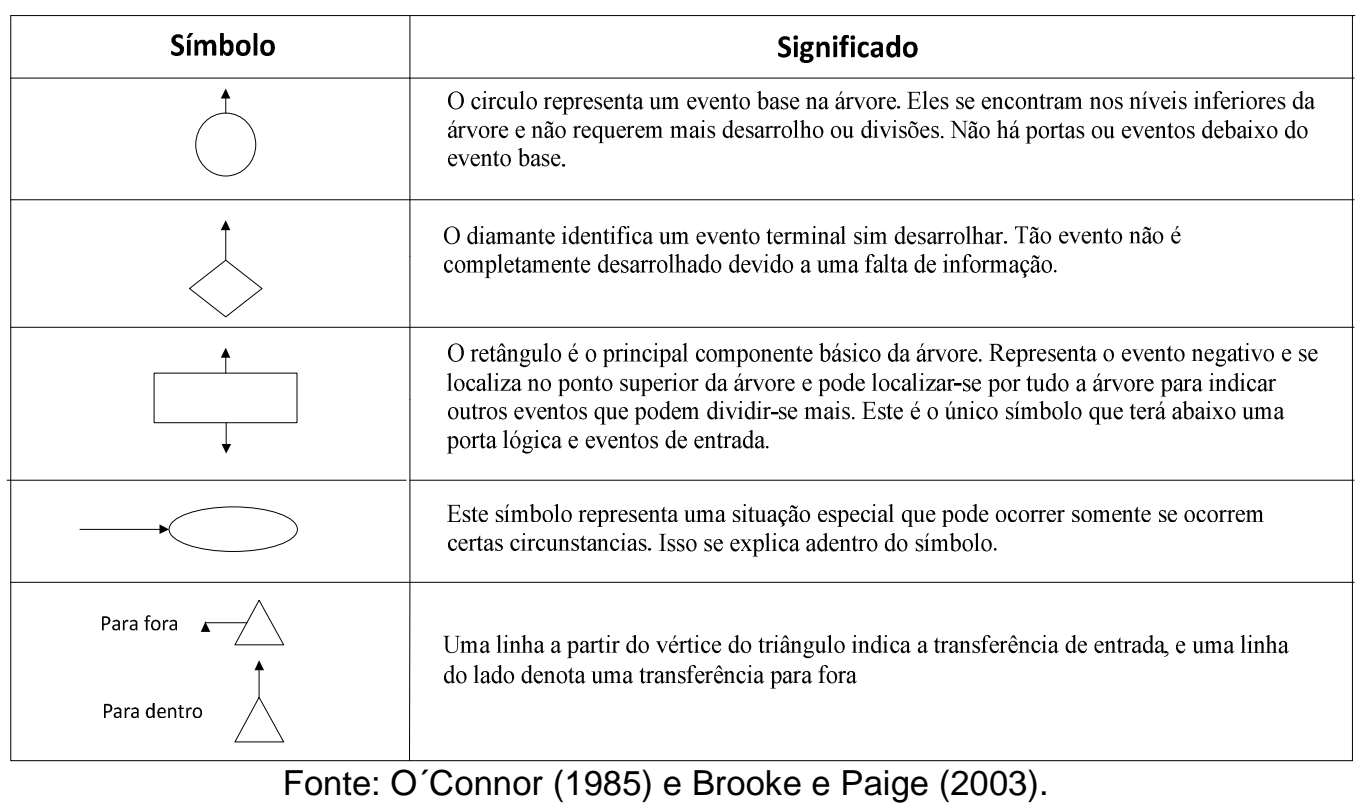


Figura 3-6 Conectores lógicos do FTA.

\begin{tabular}{|c|c|c|}
\hline Símbolo & Nome & \multicolumn{1}{c|}{ Significado } \\
\hline Ou & $\begin{array}{l}\text { Evento de saída só ocorre se todos os ventos de entrada } \\
\text { ocorrem simultaneamente. }\end{array}$ \\
\hline combinação dos eventos de entrada ocorre
\end{tabular}

Fonte: O'Connor (1985) e Brooke e Paige (2003).

\subsubsection{Método da Análise de Modos e Efeitos de Falhas - FMEA}

Ao final da década de 1940 foi desenvolvido o método de Análise de Modos e Efeitos de Falhas (do inglês FMEA - Failure Mode and Effects Analysis) pelas Forças Armadas dos Estados Unidos. Em 1949 foi apresentado o primeiro guia para a análise do tipo FMEA conhecida como a norma MIL-STD 1629 "Procedures for performing a failure mode, effects and criticality analysis", pioneira na divulgação dos conceitos de análise de modos e efeitos de falhas (US MIL-STD-1629A, 1977).

De acordo com Cassanelli (2006), a análise FMEA é conhecida por ser um procedimento sistemático de análise de um sistema para identificar os possíveis modos de falha, suas causas e efeitos sobre o desempenho do sistema. Vale ressaltar que a análise do tipo FMEA é um dos métodos de análise de confiabilidade mais utilizados, devido a sua capacidade de identificar os possíveis modos pelos quais os componentes falham, e conjuntamente, identificar as causas e os efeitos destas falhas (SOUZA, 2008; O'CONNOR, 1985). 
A aplicação da análise do tipo FMEA é necessária para refletir e responder as cinco perguntas mostradas na sequência deste texto. Estas perguntas precisam ser respondidas para todos os componentes do sistema (SUNDARARAJAN, 1991):

1) Como pode falhar o componente (quais são seus modos de falha)?

2) Quais são os efeitos destas falhas sobre o sistema?

3) Quão críticos são estes efeitos?

4) Como detectar a falha?

5) Quais as medidas contra estas falhas (evitar, prevenir a ocorrência das mesmas ou minimizar seus efeitos)?

Responder à primeira questão nos auxilia a identificar todos os modos de falha de todos os componentes do sistema. Os modos de falha, de acordo com Vinadé (2001), podem ser definidos como a maneira pela qual o defeito se apresenta ou a maneira como $o$ item falha ou deixa de apresentar o resultado desejado ou esperado de sua operação. A segunda questão estabelece como a falha nas operações e falhas dos equipamentos afetam o desempenho do sistema, visando evitar que as falhas causem a perda de funcionalidade do sistema. Os efeitos são as consequências e podem ser facilmente confundidos com os modos de falha. A expressão "o que" representa o efeito, enquanto a pergunta "como surge o efeito?" é o modo de falha. No entanto, esta estratégia deve ter um ponto limite, onde as descrições de "como surge o efeito" possam ser controladas. Na terceira pergunta classifica-se a severidade associada a uma falha (que representa o grau de deterioração do sistema quando da sua ocorrência). Na sequência, a quarta questão avalia os diferentes métodos e mecanismos que existem para detectar a falha. $\mathrm{E}$ finalmente, a última questão tem como objetivo sugerir atividades que evitem a ocorrência de falhas e minimizem os efeitos associados a esta ocorrência (MOUBRAY, 2000).

\subsubsection{Estudo de Perigo de Operação - HAZOP}

O termo HAZOP provém do inglês Hazard and Operability Studies. Em 1963, a companhia ICI (Imperial Chemical Industries) deu origem ao HAZOP e em 1977 foi 
apresentada a primeira guia para a análise de HAZOP conhecida como "A Guide to Hazard and Operability Studies" elaborada pela $\mathrm{ICl} e$ Chemical Industries Associations. Como se pode observar, o HAZOP teve seu início na análise de processos de sistemas no setor químico, mas com o passar dos anos sua aplicação se consolidou em todos os setores indústrias, incluindo os setores mecânicos e eletrônicos, entre outros (ERICSON, 2005; KUMAMOTO e HENLEY, 2000).

O HAZOP se caracteriza por ser uma análise qualitativa e é usado principalmente na identificação de problemas de operabilidade e ineficiências de um processo para assim identificar os desvios do mesmo que possam se transformar em eventos de perigo. O perigo é definido como todo evento acidental com potencial para causar danos às pessoas, às instalações ou ao meio ambiente. Este método visa eliminar, mitigar ou controlar estes desvios, (ERICSON, 2005).

Para realizar uma análise, a aplicação da técnica HAZOP é dividida em locais diferentes conhecidas como nós de estudo (ALENCAR, 2005). Um grupo de especialistas realiza atividades de reflexão dentro de cada nó de estudo. Esses especialistas são ajudados por palavras-guias, que lhes permitam cobrir todas as possíveis avarias e desvios operacionais de uma planta de uma forma sistemática. As palavras de guia frequentemente utilizado são: não, menos, mais, entre outras. Quando estas palavras de guia são aplicadas para as variáveis do processo (pressão, temperatura, entre outras) em qualquer unidade de uma planta, obtêm-se os desvios dos processos correspondentes as variáveis do mesmo, tais como mais pressão, mais temperatura, nenhum fluxo, entre outros. Uma vez identificados os desvios, suas causas e consequências, são propostas medidas visando eliminar, mitigar ou controlar o perigo ou que resolvam o problema de operabilidade do sistema (ERICSON, 2005).

\subsection{Manutenção}

O aparecimento do termo manutenção na indústria ocorreu por volta da década de 50, no século XX, nos Estados Unidos da América. A manutenção teve sua 
origem na área militar, cujo sentido era manter, nas unidades de combate, o efetivo e o material num nível constante de desempenho. Souza (2008) definiu manutenção como o termo usado para abordar a forma pela qual as organizações tentam evitar as falhas ao cuidar de suas instalações físicas. Por outro lado, a manutenção pode ser definida como um conjunto de conhecimentos, técnicas e habilidades cuja aplicação tem por objetivo único garantir a funcionalidade dos sistemas ao longo da vida útil planejada (KRISHNASAMY et al, 2005; MOUBRAY, 2000).

No contexto histórico da manutenção, o período entre os anos 40 e 50 do século passado é conhecido por ser o da primeira geração da manutenção. Naquela época, a manutenção era efetuada após a falha do componente caracterizando uma política centrada na correção. Após o término da Segunda Guerra Mundial até a década de 70, o período foi denominado de segunda geração da manutenção. As atividades de manutenção passaram a ser atividades planejadas envolvendo: planejamento de manutenção preventiva (manutenção baseada em períodos de operação ou tempos e sistemas de planejamento e controle das atividades).

A terceira geração da manutenção foi no período entre os anos 70 e 90 . Nesse período expuseram-se os conceitos de confiabilidade aplicadas na manutenção e da filosofia da Manutenção Centrada em Confiabilidade com ênfase na manutenção preditiva. Segundo Moubray (2000), os fatores que motivaram o surgimento da terceira geração são: a) nova expectativa quanto aos itens físicos como a confiabilidade, disponibilidade, integridade ambiental, segurança humana e ao aumento dos custos totais de manutenção; b) novas pesquisas que evidenciaram a existência de seis padrões de falhas de equipamentos; e c) surgimento de novas ferramentas e técnicas, tais como o monitoramento de condições dos equipamentos, projeto de equipamento com ênfase na manutenção e ênfase no trabalho em equipe.

Atualmente os conceitos de risco estão sendo aplicados na área da manutenção, ou seja, esta geração moderna da manutenção está caracterizada pelas técnicas de conservação baseada em risco, tais como inspeção baseada em risco (RBI) e a manutenção baseada em risco (RBM). A Tabela 2.1 apresenta a evolução da manutenção dividida em quatro gerações 
Tabela 3.1 Evolução das filosofias de manutenção (CARAZAS, 2011; SOUZA e MOLINARI, 2008)

\begin{tabular}{|c|c|c|c|}
\hline Geração & Período & Características & $\begin{array}{l}\text { Filosofia e Técnicas } \\
\text { de Manutenção }\end{array}$ \\
\hline Primeira & $\begin{array}{l}\text { Antes da Segunda } \\
\text { Guerra Mundial }\end{array}$ & $\begin{array}{l}\text { Equipamentos e projetos simples, fáceis } \\
\text { de reparar, poucos mecanizados. }\end{array}$ & Manutenção corretiva \\
\hline Segunda & $\begin{array}{l}\text { Durante e após a } \\
\text { Segunda Guerra } \\
\text { Mundial. }\end{array}$ & $\begin{array}{l}\text { Sistemas mais complexos, demanda por } \\
\text { bens de produção capazes de alimentar } \\
\text { a máquina de guerra, aumento da } \\
\text { mecanização da produção, necessidade } \\
\text { de redução dos tempos de reparo e } \\
\text { programação dos tempos de reparo. }\end{array}$ & $\begin{array}{l}\text { Planejamento de } \\
\text { manutenção preventiva }\end{array}$ \\
\hline \multirow[t]{3}{*}{ Terceira } & \multirow[t]{3}{*}{$\begin{array}{l}\text { A partir dos anos } \\
1980 .\end{array}$} & $\begin{array}{l}\text { Aumento da complexidade de produção, } \\
\text { introdução da automatização, } \\
\text { construção de grandes aeronaves. }\end{array}$ & \multirow[t]{3}{*}{$\begin{array}{l}\text { Manutenção Centrada } \\
\text { em Confiabilidade } \\
\text { RCM com ênfase ne } \\
\text { manutenção preditiva. }\end{array}$} \\
\hline & & $\begin{array}{l}\text { Introdução de normas de qualidade para } \\
\text { produtos e serviços, inclusão de normas } \\
\text { de segurança. Uso de confiabilidade } \\
\text { para o planejamento de manutenção } \\
\text { preventiva. }\end{array}$ & \\
\hline & & $\begin{array}{l}\text { Predição de falhas, evolução dos } \\
\text { sistemas computacionais. }\end{array}$ & \\
\hline \multirow{3}{*}{ Atual } & \multirow{3}{*}{$\begin{array}{l}\text { Final dos 90s até } \\
\text { hoje }\end{array}$} & $\begin{array}{l}\text { Aperfeiçoamento do RCM, inclusão dos } \\
\text { conceitos de Risco. }\end{array}$ & \multirow{2}{*}{$\begin{array}{l}\text { Manutenção / Inspeção } \\
\text { baseada em Risco. }\end{array}$} \\
\hline & & Inclusão de normas de controle & \\
\hline & & $\begin{array}{l}\text { ambiental e de segurança, sistemas } \\
\text { totalmente automatizados } \\
\text { computadorizados. }\end{array}$ & $\begin{array}{l}\text { Manutenção baseada } \\
\text { em diagnose }\end{array}$ \\
\hline
\end{tabular}

A seguir são apresentadas as características das três práticas básicas de manutenção: manutenção corretiva, manutenção preventiva e manutenção preditiva.

\subsubsection{Manutenção Corretiva}

A manutenção corretiva é a mais simples e direta de ser entendida: quando uma máquina quebrar, conserte-a. Entende-se por quebra a falha, ou seja, incapacidade de atingir um desempenho operacional. Antes da primeira Guerra Mundial os equipamentos de produção eram mantidos somente por conta de ações corretiva. A norma NBR 5462 (ABNT, 1994) define esta modalidade de manutenção como "manutenção efetuada após a ocorrência de uma pane destinada a recolocar um item em condições de executar uma função requerida". 
$\mathrm{Na}$ grande maioria das vezes, as ações de manutenção corretiva são as que mais sobrecarregam as atividades de manutenção, pois provocam perda de produção e/ou qualidade do produto, necessidade de aquisição de peças de reposição em caráter de urgência, horas extras, e muitas vezes um tempo maior de execução do que uma atividade de manutenção preventiva, pois a diagnose tende a ser mais demorada. Uma das contribuições da manutenção corretiva foi fornecer dados históricos para o acompanhamento dos sistemas e futuras tomadas de decisão sobre melhoria e modificações dos planos de manutenção.

No caso da manutenção corretiva, a máquina é desmontada e inspecionada para determinar os reparos necessários para retornar a máquina em serviço. Se as peças necessárias para o reparo não estiverem no estoque, elas devem ser encomendadas. Mesmo quando as peças já estão no estoque da planta industrial, os responsáveis pela área de manutenção devem desmontar a máquina para localizar a fonte do problema ou problemas que ocasionaram a falha. Admitindo que eles identifiquem corretamente o problema, o tempo e o custo requerido para desmontar, reparar, e remontar a máquina seria, pelo menos, maior do que teria sido requerido por um reparo planejado (DUARTE, 2007).

\subsubsection{Manutenção Preventiva}

A manutenção preventiva, a partir da década $\mathrm{dE} 50$, foi a prática utilizada pelos departamentos de manutenção nas organizações. Após diversos refinamentos, o seu uso perdura até os dias atuais. Como estratégia da manutenção, a manutenção preventiva é baseada em revisões, inspeções, trocas e ajustes, realizados com certas frequências, em diferentes equipamentos de um processo produtivo, com o fim de assegurar sua condição operativa adequada, minimizando o risco de ocorrências de ações corretivas de emergência (MONTILLA et al., 2007). A manutenção preventiva apresenta desvantagens devido ao desperdício da vida útil do equipamento, devido à substituição de componentes em bom estado operacional, a fim de evitar a ocorrência da falha operacional (ZHOU et al, 2007). 
A manutenção preventiva, segundo a norma NBR 5462 (ABNT, 1994), é a manutenção efetuada em intervalos predeterminados, ou de acordo com critérios prescritos, destinada a reduzir a probabilidade de falha ou a degradação do funcionamento de um item.

Essa modalidade de manutenção não pode ser aplicada a todos os tipos de máquinas. Deve ser aplicada a equipamentos que têm taxa de falha crescente com o uso. A Distribuição Normal truncada, Gama e Weibull podem ser utilizadas para modelar taxa de falha crescente. Adota-se a distribuição Weibull, que é útil em uma variedade de aplicações, particularmente, como modelo da vida de dispositivos. A distribuição de Weibull assume uma variedade muito grande de formas e por isso é bastante flexível, podendo ser empregada para modelar diversos padrões de distribuição temporal de ocorrência de falhas (Lewis, 1987). Ela pode ser representada por dois parâmetros:

- $\beta$ : parâmetro de forma

- $\quad \eta$ : parâmetro de escala

A função confiabilidade é dada por:

$$
R(t)=e^{-\left(\frac{t}{\eta}\right)^{\beta}}
$$

Variando-se o parâmetro $\beta$ da distribuição de Weibull, pode-se representar a confiabilidade de componentes com taxa de falha crescente, constante, ou decrescente. Segundo Lewis (1987), $\beta$ tem o seguinte significado:

- $\beta<1$ : A taxa de falha é decrescente;

- $\beta>1$ : A taxa de falha é crescente;

- $\beta=1:$ A taxa de falha constante. 
A partir do conhecimento do comportamento da taxa de falha do equipamento pode-se verificar a utilidade da aplicação da prática preventiva para reduzir a probabilidade da falha ao longo de uma campanha operacional. Para tanto considere-se a ação preventiva realizada em intervalos de tempo [0,T], ao longo da campanha operacional, sendo analisado o efeito sobre a confiabilidade, como indicado na Figura 2.7. Nesta análise considera-se que o equipamento volta ao estado "tão bom quanto novo" após a ação da manutenção.

Figura 3-7 Efeito da manutenção preventiva na confiabilidade.

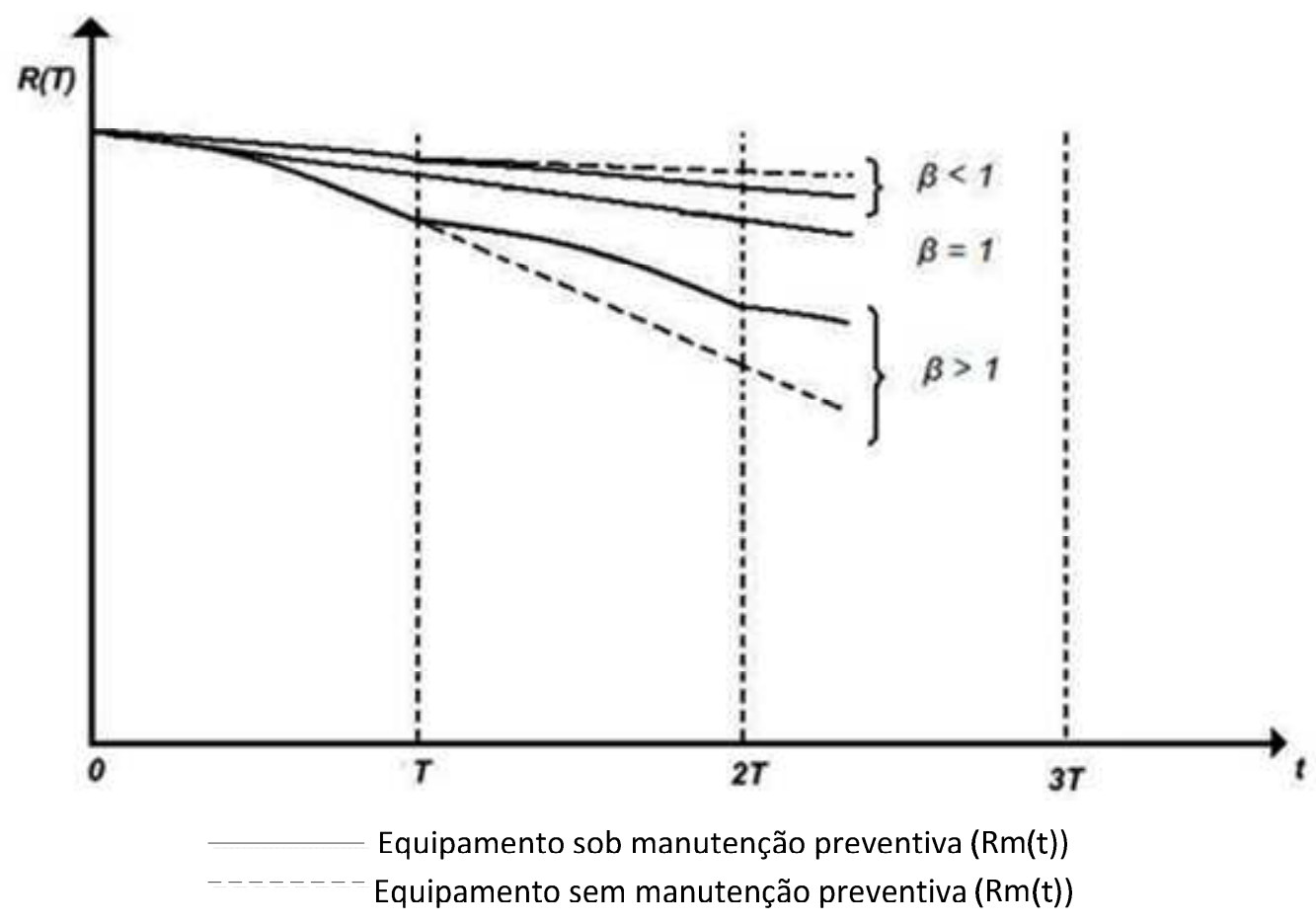

Fonte: Lewis (1987)

Na Figura 2.7 observa-se que quando $\beta<1$ a manutenção preventiva prejudica o componente, fazendo com que o equipamento volte a operar na taxa de falha inicial (fase de mortalidade infantil) que é elevada e decrescente. Quando $\beta>1$, a manutenção preventiva é adequada para reduzir a degradação da confiabilidade do componente ou equipamento. Quando $\beta=1$, as ações preventivas de manutenção são inúteis, por exemplo, componentes eletronicos. Dessa forma, a execução da manutenção preventiva só tem efeito para equipamentos que falham devido à ocorrência de processos de degradação que ocorre ao longo do tempo de operação como fadiga, desgaste e corrosão. 


\subsubsection{Manutenção Preditiva}

A norma NBR 5462 (ABNT, 1994) conceitua a manutenção preditiva como a manutenção que permite garantir uma qualidade de serviço desejada, com base na aplicação sistemática de técnicas de análise e monitoração, utilizando-se de meios de supervisão centralizados ou de amostragem, para reduzir ao mínimo a manutenção preventiva e diminuir a manutenção corretiva.

A manutenção preditiva tem como objetivo diminuir o número de falhas de todos os equipamentos mecânicos da planta industrial e assegurar que o equipamento reparado esteja em condições mecânicas aceitáveis para atingir o desempenho operacional desejado (TAI e CHAN, 2010). Ela pode identificar problemas da máquina antes que estes se caracterizam como falha, pois a maioria dos problemas mecânicos podem ser minimizados se forem detectados e reparados com antecedência, antes da falha (SARANGA e KNEZEVIC, 2001).

A manutenção preditiva é erroneamente confundida ou tratada como o sinônimo de monitoramento. Define-se manutenção preditiva como sendo a execução de ações de manutenção em função do estado técnico real do equipamento, a partir de medições e monitoração de algum parâmetro e a execução da intervenção para manutenção segundo a fixação de níveis desejados, permissíveis ou de alarme para este parâmetro. A partir deste momento, a manutenção preditiva é a medição de variáveis que identifiquem um parâmetro operacional, o que é conhecido como monitoramento de estado. Este monitoramento de estado se executa planejando inspeções, que são executadas segundo uma frequência, prevista em função das características das variáveis e do parâmetro cuja variação temporal deve ser identificada (DUARTE, 2007; SMITH e HINCHCLIFFE, 2004).

Para executar a manutenção preditiva é de vital importância executar uma análise de tendência do parâmetro. $\mathrm{O}$ estado atual do parâmetro no momento da medição é de pouca utilidade na decisão de parar ou não o equipamento. É importante ter o histórico dos parâmetros e recorrer-se a algum método numérico, como regressões polinomiais e exponenciais, obtendo uma curva semelhante à mostrada na Figura 2.8, que permite definir o comportamento temporal do parâmetro (XENOS, 2006). 
Figura 2-8 Curva de tendência para o valor de um parâmetro de interesse.

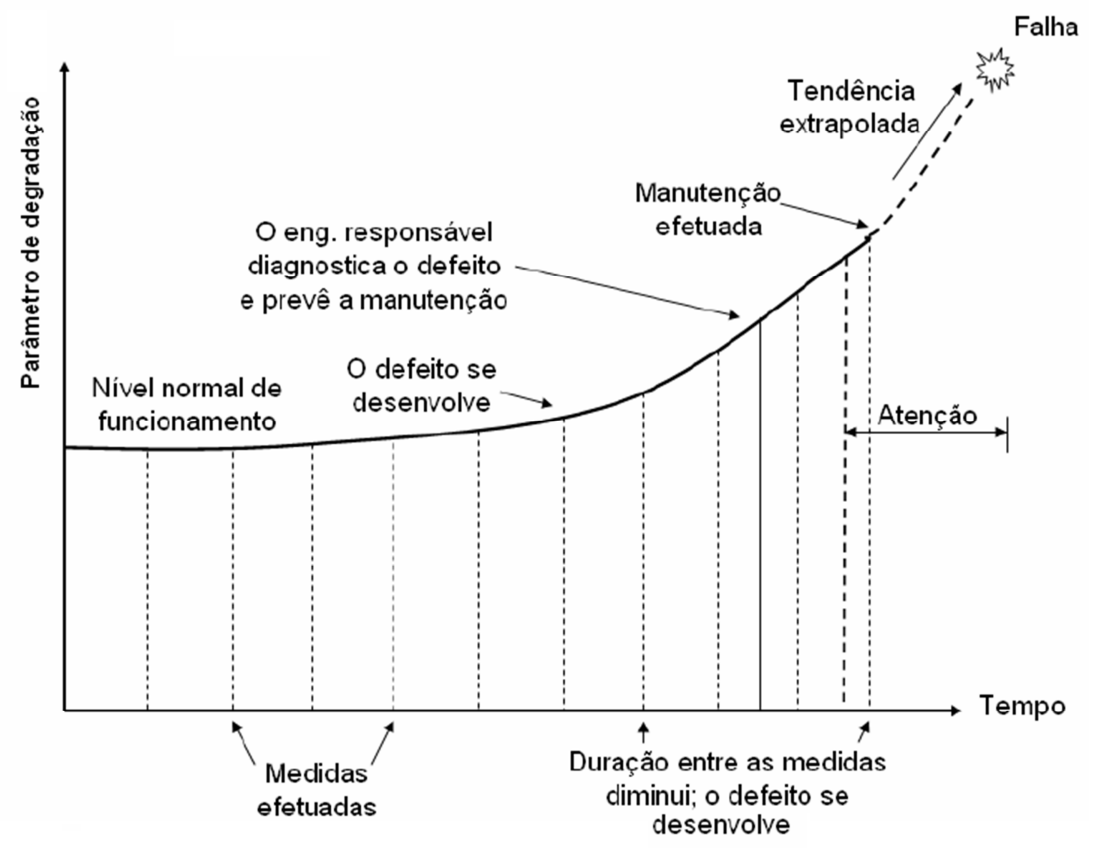

Fonte: Xenos (2006)

A Figura 2.8 mostra que, enquanto não se conhece o valor limite admissível para o parâmetro (onde se dá a falha), precisa-se reduzir o intervalo de tempo entre as inspeções quando se nota uma aceleração na deterioração do equipamento. Depois de diagnosticado o desenvolvimento de um modo de falha, necessita-se programar a parada. Portanto, entre o instante da detecção e a imobilização do equipamento, este deve operar satisfatoriamente, caso contrário, a manutenção preditiva perderia todo o seu significado. Com o passar do tempo, a estimativa desta curva passa a ser bastante fidedigna ao mecanismo de degradação característico do equipamento (XENOS, 2006).

\subsection{Manutenção centrada na confiabilidade}

A manutenção centrada na confiabilidade ( $R C M)$ foi um processo desenvolvido durante os anos 60 e 70, com a finalidade de ajudar as equipes de manutenção a determinar as melhores políticas de intervenção para manter as funções dos ativos e para controlar as consequências de suas falhas.

Conforme Moubray (2000), uma definição mais ampla da filosofia RCM poderia ser "um processo que se usa para determinar o que deve ser feito para assegurar 
que um elemento físico continue desempenhando as funções desejadas em seu contexto operacional".

O objetivo principal da filosofia RCM é reduzir custo de manutenção, focando-se nas funções mais importantes do sistema e evitando ações de manutenção que não são estritamente necessárias. Se um programa de manutenção já existe, o resultado de uma análise de RCM será frequentemente eliminar as tarefas de manutenção preventiva ineficazes.

A manutenção centrada em confiabilidade dá prioridade à manutenção de componentes cujas falhas causam perda de desempenho, às quais estão associadas a perdas financeiras. Daí a importância à priorização das práticas preventivas ou preditivas, as quais diminuem a possibilidade de ocorrências destas perdas. O maior custo da manutenção preventiva está associado com o período de indisponibilidade do sistema, e também associado a esse custo estão a mão de obra e as peças sobressalentes. No caso da manutenção preditiva estão associados os custos de aquisição, implantação e operação dos instrumentos de monitoramento dos parâmetros indicativos do desempenho do sistema, bem como os custos de análise dos dados coletados, além dos custos de mão de obra e de sobressalentes. Existem falhas que não causam prejuízo ao desempenho do sistema, para as quais se recomenda a pratica da manutenção corretiva, pois o custo associado com estas tarefas será inferior aos custos de ações de manutenção preditiva e preventiva (MOUBRAY, 2000).

\subsection{Tomada de decisão em manutenção preventiva aplicando o método multicritério}

Segundo Fouladirad et al (2008), a maioria das abordagens atuais de programação da manutenção preventiva são baseadas no pressuposto clássico de que a falha do sistema pode ser explicada por um processo de deterioração com natureza estocástica, o que é a realidade para mecanismos de falha, tais como corrosão, desgaste, e fadiga. Estas abordagens geralmente supõem uma execução de manutenção preventiva com intervalo de intervenções constante. O objetivo da manutenção preventiva periódica é fazer o melhor uso de paradas programadas de produção. No entanto, considerando-se o risco de alteração da taxa de falha em 
sistema sujeitos a degradação, um modelo melhorado para a programação da manutenção preventiva deve ser desenvolvido para determinar dinamicamente 0 programa de manutenção ideal. Portanto, para o planejamento de forma otimizada dos intervalos de execução de manutenção preventiva, duas questões cruciais devem ser respondidas: (1) como descrever com precisão a taxa de falha do sistema, (2) como modelar o programa de manutenção considerando diversos requisitos (tais como custo, confiabilidade e opinião do gestor), se a alteração da taxa de falha do sistema é conhecida.

O modelo de manutenção preventiva com melhoria sequencial, ou seja, baseado na otimização do intervalo de intervenção com o objetivo de manter a confiabilidade do sistema em um determinado nível aceitável, pode ser usado para organizar as ações de manutenção visando reduzir a frequência de falhas do sistema. Para tanto é fundamental um conhecimento do comportamento da taxa de falha do sistema ao longo do tempo. Este conhecimento pode ser obtido através de um vasto histórico de falhas. Além disso, em modelos de manutenção preventiva periódica, existe a suposição comum de restauração perfeita, que traz um sistema para o estado de "tão bom quanto novo" (NAKAGAWA, 1988 e MALIK, 1979). A hipótese de que a manutenção preventiva recupera o sistema para o estado inicial de operação pode ser válida em situações em que um grande número de componentes é substituído e quando a ação de manutenção não deteriora o sistema. No entanto, esta situação extrema não é suficientemente geral para explicar como as atividades de manutenção e o regime de operação afetam o estado do sistema. Assim, este estudo considera os efeitos de imperfeições de atividades de manutenção na seleção do intervalo entre as ações preditivas. Pham e Wang (1996) e, mais recentemente, Doyen e Gaudoin (2004), Zhou et al (2007) e Xia et al (2012) discutiram os modelos de tomada de decisão e, manutenção com manutenção imperfeita. Um dos métodos mais importantes é o método de fator de melhoria, que é mais prático para aplicações em engenharia. Este método ajuda a descrever com precisão a taxa de falha do sistema em ciclos diferentes de manutenção preventiva.

Além da descrição do estado do sistema considerando a sua deterioração, outro problema é como modelar e aperfeiçoar a programação sequencial da manutenção preventiva. Existem duas categorias populares de planejamento para agendar os 
intervalos de manutenção preventiva. A primeira é o método baseado em confiabilidade (Zhou et al, 2007), onde a manutenção é efetuada sempre que a confiabilidade do sistema atinge um limite pré-determinado. O segundo é o método de aperfeiçoamento (Bartholomew-Biggs et al, 2009), que normalmente procura por períodos de manutenção com base em qualquer minimização de custos ou maximização do lucro. No entanto, existem muitas situações em que a confiabilidade do sistema pode ser considerada mais importante do que o custo de manutenção. Portanto, um modelo de planejamento de manutenção adequado incorpora vários critérios para a tomada de decisão sobre os critérios de decisão sobre o intervalo de execução de restaurações. A teoria de sistemas de decisão multicritérios fornece uma ferramenta para trabalhar com este tipo de problema. Além disso, um modelo de manutenção precisa dinamicamente programar o intervalo de manutenção preventiva ótimo para cada ciclo de operação, em vez de elaborar um plano de longa duração e estático. Para este fim, no modelo de multicritérios é necessário estabelecer um compromisso entre a confiabilidade do equipamento e os custos de manutenção, tendo em conta a atual evolução da taxa de falha do sistema.

Segundo Cavalcante e Almeida (2005), apesar da adequação da metodologia multicritério no tratamento simultâneo de critérios conflitantes envolvidos no problema de substituição de equipamentos, na literatura, há poucas aplicações dessa metodologia na área de manutenção programada, mais raro, ainda, é o uso de uma abordagem multicritério de uma forma que permita o tratamento de incertezas relacionadas aos dados de manutenção. Por outro lado, há uma diversidade muito grande de textos que tratam do problema de seleção do intervalo de substituição de equipamentos, pelos mais diferentes enfoques e considerando aspectos bastante diferenciados. Entretanto tais textos têm como característica, quase que geral, o uso do paradigma de otimização, onde um único critério ou função objetivo é considerado.

No contexto da manutenção programada, realizaram se diversos trabalhos que fazem uso da abordagem da teoria multicritério para calcular o tempo de manutenção preventiva. Gopalaswamy et al (1993), apresentam um modelo de decisão multicritério para a manutenção de frotas de veículos. Considerando três critérios: minimizar os custos de substituição, maximizar a disponibilidade e a 
confiabilidade. Kralj e Petrovic (1995) apresentam uma abordagem para a programação de manutenção preventiva das unidades geradoras térmicas em sistemas elétricos de potência. $O$ artigo utiliza uma abordagem de otimização combinatória, com o objetivo de minimizar os custos de combustível, maximizar a confiabilidade e minimizar as penalidades ou multas. Lofti (1995) apresenta um modelo baseado em programação linear inteira mista multiobjectivo para estabelecer o próximo intervalo de manutenção preventiva. Chareonsuk et al (1997), estabeleceram o intervalo entre ações de manutenção preventiva levando em consideração dois critérios: o custo médio esperado de manutenção preventiva por unidade de tempo e a confiabilidade, fazendo uso da metodologia multicritério PROMETHEE. Azaiez (2002) determina o tempo de intervenção de manutenção preventiva considerando quatros critérios: custo, qualidade, produtividade e fluxo de caixa. Almeida (2005) apresenta um modelo de decisão que apoia decisores na escolha da melhor combinação dos fatoresde custo e confiabilidade. O modelo de decisão é baseado na teoria da utilidade multiatributo (MAUT). Cavalcante e Almeida (2005) apresentam um modelo de decisão que, fazendo uso do método multicritério PROMETHEE II e de análise Bayesiana, permite que se estabeleça a periodicidade da manutenção preventiva, observando-se o parâmetro custo e confiabilidade. Cavalcante e Almeida (2007) apresentam um modelo para auxiliar a tomada de decisão no planejamento de manutenção preventiva, através da aplicação da técnica PROMETHEE III. Almeida (2012) apresenta um modelo de tomada de decisão multicritério para apoiar a decisão na escolha do melhor intervalo de manutenção com base na combinação de critérios de confiabilidade e custo, aplicando o modelo da teoria da utilidade multiatributo (MAUT). Wijava e Kumar (2012) apresentaram um modelo para determinar o tempo de intervenção de manutenção preventiva tendo como objetivo minimizar os custos de manutenção e maximizar a confiabilidade e disponibilidade do equipamento.

\subsubsection{Métodos multicritério de apoio a decisão}

Os problemas de tomada de decisão são comuns em diversas áreas. Na área da manutenção, o planejado de manutenção tenta resolvê-los, apoiando-se em abstrações, heurísticas e raciocínios dedutivos, com o objetivo de orientar e validar as suas escolhas. Na manutenção industrial, a todo momento os gestores deparam- 
se com situações que exigem decisões complexas. Os profissionais buscam uma série de ferramentas que os auxiliem no processo de tomada de decisão.

Os métodos multicritério têm sido muito utilizados na solução de problemas de tomada de decisão, uma vez que procuram expor ao decisor as possibilidades de escolha. Apóiam o processo decisório, embasado nas informações existentes, incorporando valores dos agentes, na busca da melhor solução.

O principal objetivo dos modelos de apoio a decisão multicritério é auxiliar o decisor na formulação da melhor relação de compromisso entre os critérios envolvidos.

$\mathrm{Na}$ área de manutenção, dependendo do tipo de equipamento e da filosofia de gestão de ativos da empresa pode-se adotar diferentes critérios para fazer as análises que subsidiam a tomadas de decisão. Nesse sentido podem ser levados em consideração critérios relacionados com os custos, a confiabilidade, o tempo de parada da máquina, e a perda da produção, mas de uma maneira conjunta.

Existem vários métodos desenvolvidos para a abordagem e tratamento de problemas com múltiplos critérios. Destacam-se duas abordagens para os métodos multicritérios de apoio a decisão (HELMAN e MARÇAL, 2007).

- Critério único de síntese

- Abordagem de sobreclassificação

A primeira abordagem busca maximização através de agregação de diferentes critérios em uma única função de síntese, e é conhecida como Escola Americana. A teoria de utilidade multiatributo, ou Multiple Attribute Utility Theory MAUT do inglês, é um dos métodos desta abordagem. O MAUT é classificado como um método de critério único de síntese, por agregar os critérios em um único critério de síntese.

A segunda abordagem avalia os critérios par a par e define uma relação de superação, prevalência ou subordinação. Este tipo de abordagem também é conhecida como Escola Europeia. Destacam-se dentre os métodos de sobreclassificação o ELECTRE e o PROMETHEE. 
A escolha do método vai depende de vários fatores destacando-se as características: do problema analisado, do contexto considerado, da estrutura de preferencias do decisor e da problemática em si.

As soluções dos problemas de decisão variam em função do resultado pretendido. Determinado um problema uma das seguintes problemáticas é abordada, conforme exposto na Tabela 2.2.

Tabela 2.2 Problemática em função do tipo de problema (HELMAN e MARÇAL, 2007).

\section{Tipo de problema}

\section{Problemática abordada}

Tipo $\alpha \quad$ Selecionar a melhor alternativa ou as melhores alternativas

Tipo $\beta \quad$ Aceitar alternativas que parecem "boas" e descartar as que parecem "ruins", ou seja, realizar uma classificação das alternativas.

Tipo $\gamma \quad$ Gerar uma ordenação das alternativas

Tipo $\sigma \quad$ Realizar uma descrição das alternativas 


\section{SISTEMAS ESPECIALISTAS}

O presente capítulo se inicia com a definição de sistema especialista, bem como a descrição dos benefícios de sua aplicação na área industrial. A seguir, são mostradas a evolução desses sistemas, e a descrição de algumas técnicas de aquisição e representação do conhecimento básico considerado para a estruturação de um sistema especialista.

\subsection{Conceito do Sistema Especialista}

A Inteligência Artificial tem como objetivo desenvolver sistemas computacionais que exibam características que são associados com inteligência no comportamento humano, por exemplo, linguagem, raciocínio, capacidade de resolver problemas, entre outros (FILHO, 2003; MEZCUA, 2011).

Feigenbaum et al (1971), um dos pesquisadores reconhecidos em trabalhos de sistemas especialistas, definiu o sistema especialista como um programa inteligente de computador que utiliza conhecimentos e procedimentos de inferência para solucionar problemas que, sendo complexos o suficiente, requerem um especialista humano para a sua solução. Os conhecimentos necessários para desempenhar em tal nível os procedimentos de inferência utilizados podem ser pensados como um modelo do melhor especialista da área. O conhecimento de um sistema especialista constitui-se de fatos e heurísticas. Os fatos formam o corpo da informação que é largamente difundida, publicamente disponível e geralmente acordada entre os especialistas da área. A heurística é, em sua maior parte, um conhecimento restrito, de poucas e eficientes regras de bom julgamento que caracterizam o nível do conhecimento do especialista e as decisões de um especialista em uma dada área.

Segundo Yamaki (1990) e Matijevics e Józsa (1995) os sistemas especialistas são programas que se comportam como especialistas humanos em domínio específico do conhecimento. A maioria dos problemas em um domínio de especialidade não tem uma solução baseada em algoritmos devido à complexidade do contexto e, das serem informações incompletas e inexatas. Portanto, os sistemas especialistas trabalham em áreas restritas do conhecimento, e são capazes de 
resolver problemas para os quais não existem algoritmos que levem forçosamente à solução. Porém, isto não significa que os sistemas especialistas não sejam baseados em algoritmos, e sim que seus algoritmos podem não encontrar a solução do problema proposto.

Em síntese, o sistema especialista pode ser definido como um sistema informatizado (hardware e software) que é capaz de resolver problemas e de realizar tomadas de decisão, que normalmente são resolvidos por especialistas humanos que possuem grande conhecimento numa área de especialização.

O objetivo dos sistemas especialistas é solucionar problemas de forma inteligente e reproduzir decisões de um especialista humano numa determinada área de interesse. A ideia central é que o sistema obtenha uma solução de uma forma eficiente a partir de várias alternativas. Esta solução depende do conhecimento sobre o problema a solucionar e conseguirá ser satisfatória na medida em que encontrar a resposta suficientemente boa para os recursos existentes (BARR e FEIGENBAUM, 1981; ASHARAFI et al, 1995).

Com o surgimento dos sistemas especialistas, foi introduzida uma nova filosofia de programação. A filosofia de programação dos códigos existentes até então, ditos convencionais, consistia no processamento de rotinas, sendo por isso denominado de programas procedimentais. Por outro lado, os sistemas especialistas, por meio de seus mecanismos de inferência, realizam o processamento simbólico do conhecimento contido em sua base de regras, durante o processo de inferência, podendo usar o encadeamento para frente ou para trás, dependendo das características do problema que é tratado.

\subsection{Estrutura de sistema especialista}

Existem citadas na literatura várias maneiras de representar os componentes de um sistema especialista, dependendo do tipo de problema que se pretende resolver (CHAU e YANG, 1992) Uma maneira genérica de representá-los é mostrada na Figura 3.1. De acordo com a Figura 3.1 um sistema especialista apresenta uma arquitetura com os seguintes componentes: 
Figura 3-1 Estrutura do Sistema Especialista.

Especialista

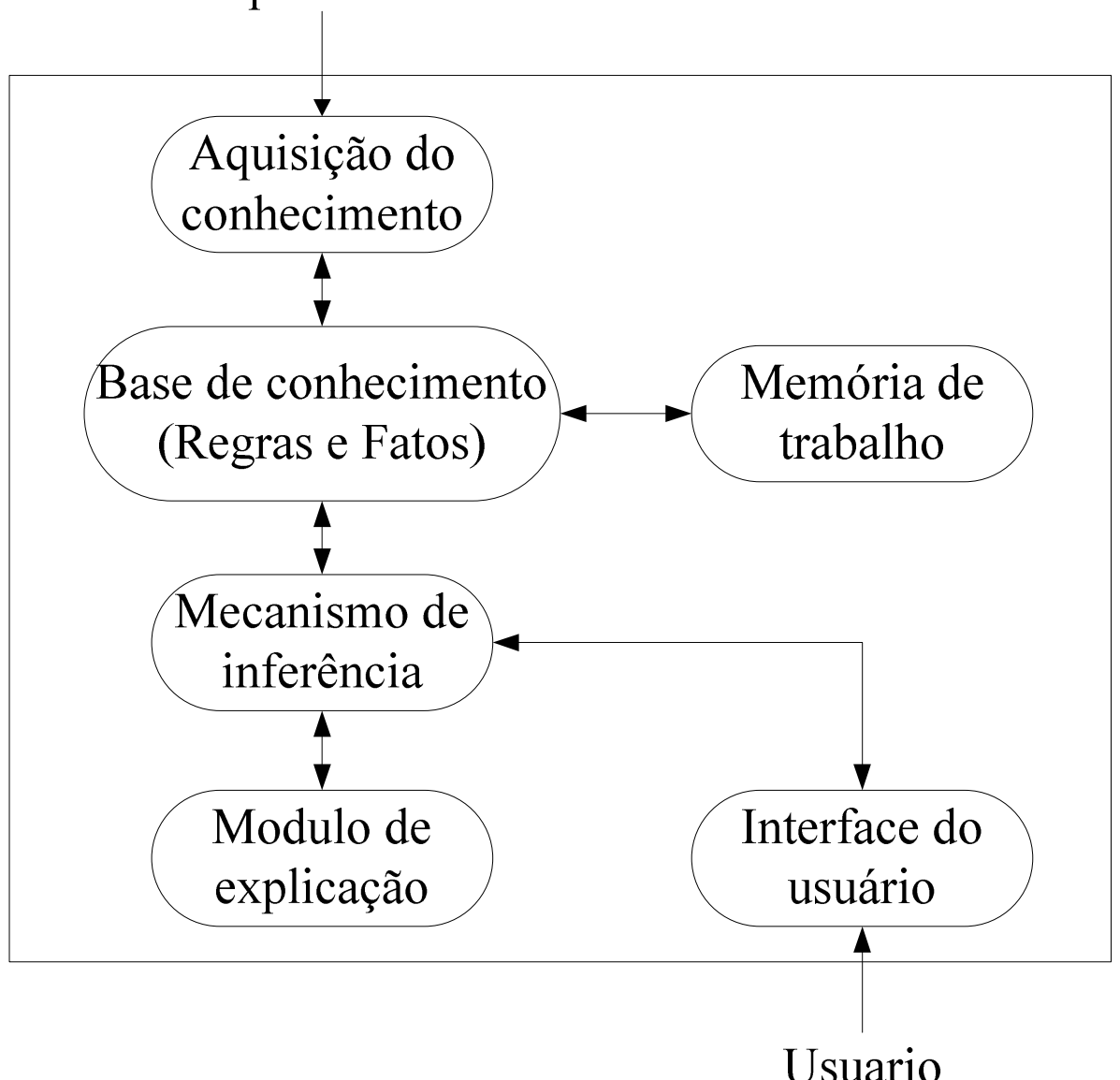

Fonte: Nikolopoulos (1997).

- Módulo de aquisição do conhecimento: por meio das técnicas de aquisição do conhecimento, que podem ser manual ou automatizada, adquire-se o conhecimento de um ou mais especialistas e procede-se com a implementação da base de conhecimento utilizando as estruturas de dados definidas pelas técnicas de representação do mesmo (GRAHAMJONES e MELLOR, 1995).

- Base de conhecimento: contém o conhecimento específico do domínio em questão. Esta parte inclui um conjunto de regras, fatos e modelos de comportamento, dentro do domínio do problema (equivalente à memória de longo prazo) (GUERREIRO, 1995).

- Memória de trabalho: onde são armazenadas as conclusões intermediárias de um processo de raciocínio e as respostas fornecidas pelo usuário durante a interação (GRAHAM-JONES e MELLOR, 1995). 
- Mecanismo de inferência: contém o conhecimento geral para a solução de problemas. O mecanismo de inferência usa a base do conhecimento e o contexto para solucionar o problema (equivalente à habilidade humana de solucionar problemas) (RAO, MILLER e LIN, 2005). O mecanismo de inferência é um programa apto para associar o subsistema de aquisição de conhecimento com a base de conhecimento, com o objetivo de produzir uma solução aceitável (PINHEIRO, 1995).

- Módulo de explicação: permite ao usuário entender o processo de raciocínio usado pelo sistema especialista para chegar a uma solução. A habilidade de se explicar uma resposta ou linha de raciocínio é uma importante característica de um programa inteligente (JUNIOR, 1988).

- Interface com o usuário: esta interface permite a comunicação com o usuário para apresentação da solução, elaboração de perguntas, e obtenção de respostas, entre outras ações. (BERRAIS 1996; PINHEIRO, 1995).

\subsubsection{Aquisição do conhecimento}

Aquisição do conhecimento pode ser definida como o processo de compreender e organizar o conhecimento especializado por intermédio da extração, estruturação, organização e representação do mesmo. Ela deverá ser codificada e armazenado em uma base de conhecimento para posterior resgate de um sistema especialista (O'KEEFE e PREECE, 1996; NUNES, 1990).

$\mathrm{Na}$ área da aquisição do conhecimento muitos esforços têm sido destinados para sistematizar ou automatizar esse processo. As técnicas existentes mais utilizadas para a extração do conhecimento podem ser classificadas em técnicas manuais, semi-automáticas e aprendizado de máquina (SUNIURA, 1990).

\subsubsection{Técnicas Manuais}

As técnicas manuais são a forma tradicional e convencional nas quais o engenheiro de conhecimento centraliza a incorporação do mesmo e constrói o programa, baseado na interação direta com o especialista do domínio. Nessa técnica 
são realizadas entrevistas com os especialistas, sendo utilizados dois tipos de entrevistas: as não estruturadas e as estruturadas.

As entrevistas não estruturadas são mais livres e propiciam um bom relacionamento entre o engenheiro de conhecimento e o especialista. Entrevista não estruturada apresenta poucas restrições, isso significa que não existe uma rota ou sequência pré-definida de perguntas ou de rumo da conversa. As entrevistas não estruturadas não são recomendadas para além das fases iniciais, de identificação do conhecimento e ambientação do engenheiro de conhecimento com o domínio (ROSÁRIO, 2012).

As entrevistas estruturadas são mais formais e as perguntas são elaboradas com cuidado e tendem a levar a conversa à aquisição de conhecimentos específicos sobre o domínio. Um problema encontrado nesse tipo de entrevista estruturada é que ela pode produzir resultados influenciados pelo entrevistador, por isso deve ser planejada e revisada antes de ser aplicada (NIKOPOULOS, 1997).

\subsubsection{Técnicas semi-automáticas}

As técnicas semi-automáticas consistem na utilização de ferramentas computacionais que fornecem uma interface estruturada que auxiliam aos especialistas e os engenheiros de conhecimentos a codificar a base do conhecimento dentro de uma arquitetura pré-determinada. Uma das vantagens é que o processo de construção da base de conhecimento permite que o engenheiro e os especialistas tenham respostas mais rápidas, pois à medida que a base de conhecimento vai sendo construída ela pode ser testada, além disso, reduz o número de agentes humanos envolvidos, e por consequência, diminui os problemas de comunicação e torna mais rápidos 0 processo de construção (NIKOPOULOS,2007; RESENDE, 2003).

Entre as ferramentas semi-automáticas para aquisição de conhecimento, destacam-se a EMYCIN que oferece uma série de facilidades para a aquisição de conhecimentos, tais como uma linguagem abstrata para descrição de regras e um mecanismo de geração automática da interface com o usuário. As ferramentas ART e ProKappa contêm mecanismos de busca e diversas formas de representar 0 
conhecimento pronto para serem configuradas. A ferramenta MOLE é uma ferramenta de aquisição de conhecimento e um sistema de desempenho que interpreta a Base de Conhecimento, adquirida (RESENDE, 2003).

\subsubsection{Tecnologia de aprendizado de Máquina.}

Aprendizado de Máquina é uma área da inteligência artificial cujo objetivo é o desenvolvimento de técnicas computacionais sobre o aprendizado bem como a construção de sistemas capazes de adquirir conhecimento de forma automática.

As tecnologias de aprendizado de Máquina podem ser classificadas por paradigmas: simbólico (algoritmos baseados em lógica), estatístico, baseado em exemplos, conexionista, evolutivo e raciocínio baseado em casos (FLACH, 2000; MAGLOGIANNIS, 2007).

\subsection{Simbólico.}

Simbólicos buscam aprender construindo representações simbólicas de um conceito através da análise de exemplos e contra exemplos desse conceito. As representações simbólicas estão tipicamente na forma de alguma expressão lógica: árvore de decisão e regras (RESENDE, 2003).

As regras são comumente usadas para representar conhecimento em sistemas especialistas, e podem ser facilmente interpretas por especialistas humanos por causa da sua grande modularidade, ou seja, uma simples regra pode ser interpreta sem a necessidade de outras regras. Existem algoritmos como o AQ1, de Michalski, que realizam a indução de regra diretamente a partir de conjunto de treinamento.

As árvores de decisão podem ser representadas como um conjunto de regras. Cada regra começa na raiz da árvore e caminha para baixo ("top down"), em direção as folhas. Cada nó de decisão acrescenta um teste às premissas (condições) da regra. O nó da folha representa a conclusão da regra (NIKOPOULOS, 1997). 


\subsection{Estatísticos}

No paradigma estatístico é utilizado um modelo estatístico que encontre uma hipótese que representa uma boa aproximação do conceito a ser induzido. O aprendizado consiste em encontrar os melhores parâmetros para o modelo. Estes modelos podem ser paramétricos (quando se faz alguma suposição sobre a distribuição dos dados), ou podem ser não paramétricos (quando não fazem suposição sobre a distribuição dos dados).

Entre os métodos estatísticos, destacam-se os de aprendizado Bayesiano, que utilizam um modelo probabilístico baseado no conhecimento prévio do problema, o qual é combinado com os exemplos de treinamento para determinar a probabilidade final de uma hipótese (MAGLOGIANNIS, 2007).

As Máquinas de Vetores de Suporte é uma técnica de aprendizado que vem recebendo crescente atenção da comunidade de aprendizado de máquina. Os resultados da aplicação dessa técnica são comparáveis e muitas vezes superiores aos obtidos por outros algoritmos de aprendizado, como as Redes Neurais Artificiais (LORENA e CARVALHO, 2007).

\subsection{Baseado em exemplos.}

Uma maneira de classificar um exemplo é lembrar-se de outro similar cuja classe é conhecida e assumir que o novo exemplo terá a mesma classe. Isso caracteriza os sistemas baseados em exemplos, ou em inglês "instance based learning", que classificam exemplos nunca vistos por meio de exemplos similares conhecidos.

Este tipo de sistema de aprendizado é chamado de "lazy". Sistemas "lazy" necessitam manter os exemplos na memória para classificar novos exemplos, em oposição aos sistemas "eager", que utilizam os exemplos para induzir o modelo, descartando-se logo após. Assim, saber quais exemplos de treinamento deve ser memorizado por um indutor "lazy" é muito importante. Os Algoritmos de aprendizagem "lazy" exigem menos tempo de computação durante a fase de treinamento do que os algoritmos de aprendizagem "eager" (como árvores de 
decisão, redes neurais e redes de Bayes), mas mais tempo de computação durante o processo de classificação (RESENDE, 2003; FLACH, 2000).

\subsection{Conexionistas}

O nome conexionista vem da área de pesquisa de redes neurais artificiais. Uma rede neural artificial é um modelo computacional inspirado no funcionamento do cérebro humano. As redes neurais artificiais consistem em um método de solucionar problemas de inteligência artificial. As redes neurias artificiais possuem três componentes principais: unidade de processamento "os neurônios", conexões "sinapses" e uma topologia. As redes neurais possuem como principal característica aprender através de exemplos e poder de generalização (RESENDE, 2003).

As redes neurais são modelos matemáticos que se assemelham às estruturas neurais biológicas e que tem a capacidade computacional adquirida por meio de aprendizado e generalização. O aprendizado em redes neurais consiste na modificação dos pesos das conexões entre os neurônios de forma iterativa. $O$ aprendizado pode ser classificado basicamente em três paradigmas distintos: aprendizado supervisionado, aprendizado não supervisionado e aprendizado por reforço (FLACH, 2000).

\subsection{Evolutivo}

Aprendizado evolutivo é derivado do modelo biológico de aprendizado. Um classificador evolutivo consiste de uma população de elementos de classificação que competem para fazer a predição. Elementos que possuem um desempenho fraco são descartados, enquanto os elementos mais fortes proliferam, produzindo variações de si mesmos.

Trata-se de sistemas para a resolução de problemas que utilizam modelos computacionais baseados na teoria da evolução natural ou genética natural. A computação evolutiva pode ser dividida em três categorias: algoritmos genéticos, estratégias de evolução e programação genética. Cada ramo é visto como tentativas de explorar aspectos diferentes dos algoritmos evolutivos (FLACH, 2000; MAGLOGIANNIS, 2007). 


\subsection{Raciocínio baseado em casos}

Raciocínio baseado em casos é um método que resolve problemas por meio da recuperação e adaptação de soluções anteriores. Ele não se baseia em um único conhecimento generalizado acerca de um domínio de problemas e nem realiza associações logicas ao longo de relacionamentos abstratos entre descritores de problemas e conclusões. O raciocínio baseado em casos utiliza conhecimento especifico para soluções de problemas concretos, experimentadas anteriormente, denominadas de casos.

A medida que uma experiência é utilizada para solucionar um problema, a mesma é armazenada na memória para que possa ser reutilizada em problemas futuros, ou seja sua proposta é a solução de problemas através de analogias com outros previamente resolvidos (MAGLOGIANNIS, 2007)..

\subsubsection{Representação do Conhecimento}

Uma das áreas mais importantes da inteligência artificial é a representação do conhecimento. A representação do conhecimento é uma combinação de estruturas de dados e procedimentos de interpretação que são usados dentro de sistemas para melhorar o seu comportamento inteligente. A representação do conhecimento é um processo interativo (MEZCUA et al, 2011; GUERREIRO, 1995).

A escolha da representação do conhecimento é um fator muito importante para o sucesso do sistema especialista, dado que pode afetar o número de estados do problema domínio e assim aumentar ou diminuir a complexidade do mesmo (FILHO, 2003).

Vários modelos de representação do conhecimento têm sido desenvolvidos pelo esforço de muitos pesquisadores da área de inteligência artificial para diversas aplicações. Cada um tem suas vantagens e desvantagens dependendo onde serão aplicados (JUNIOR, 1988; NUNES 1990; VINADE, 2003):

- Regras;

- Quadros ou Frames;

- Redes semânticas; 
- Orientada a objetos

\subsubsection{Regras}

As regras são o método de representação mais conhecido e utilizado na área de sistemas especialistas. As regras fornecem uma maneira formal de representação de recomendações ou estratégias. A técnica de regras deverá ser usada quando o conhecimento for o resultado de uma longa experiência resolvendo problemas na área, com o consequente estabelecimento de correlações empíricas (FREDERICK, 1985).

As regras fornecem um modo formal e simples de representar recomendações, diretivas, estratégias, além de serem bastante apropriadas quando a área de conhecimento requer muita heurística, como é o caso do processo de diagnóstico da condição operacional de uma dada máquina (HIGA e LEE, 1998).

Uma regra é uma afirmação lógica que relaciona dois ou mais objetos e inclui duas partes, a condição e a ação. Cada uma destas partes consiste em uma expressão lógica com uma ou mais afirmações objeto - valor conectado mediante os operadores lógicos (RAMASWAMY et al, 1997; KUMAMOTO et al, 1984).

Uma regra se escreve normalmente como "se tal condição é satisfeita, então esta ação é apropriada". Durante a execução do sistema, se a parte esquerda de uma regra for satisfeita ela pode disparar, isto é, a ação indicada pelo lado direito é executada (MULVANEY. 1997), por exemplo:

Regra 1: Se nota $>9$, então conceito $=$ A.

Regra 2: Se falha a válvula direcional, então = os atuadores param.

\subsubsection{Redes Semânticas}

As redes semânticas surgiram em 1968 com os estudos realizados por Quillian a respeito da memória humana. Segundo Vinade (2003), as redes semânticas são representações gráficas do conhecimento. Como uma árvore de decisão, elas consistem em nós que são representados por círculos, e arcos que são 
representados por linhas com setas. As redes semânticas podem ser consideradas uma forma de programação orientada a objetos e tem a vantagem de facilitar a visualização por parte das pessoas.

Os nós geralmente representam eventos, conceitos ou objetos. Os objetos podem ser físicos, que podem ser vistos e tocados, como também entidades como atos, eventos ou categorias abstratas (SUNIURA, 1996).

Os arcos podem ser definidos em uma variedade de forma, dependendo do tipo de conhecimento a ser representado. Os arcos normalmente são rotulados por termos como "é-um" ou "tem-parte" e estabelecem uma propriedade de herança e hierarquia na rede, isto é, os nós em níveis mais baixos podem herdar propriedades dos nós em níveis mais altos de uma rede. Os "é-um" são utilizados para representar a relação entre classes e instâncias e os "tem-parte" identificam os nós que são propriedades de outros nós, mostrando uma relação de parte e subparte ou conjunto e subconjunto (SUNIURA, 1996, NUNEZ 1990). Na Figura 3.2 se mostra exemplos de redes semânticas tipo "é-um" e "tem-parte"

Figura 3-2 Estrutura das Redes Semânticas.

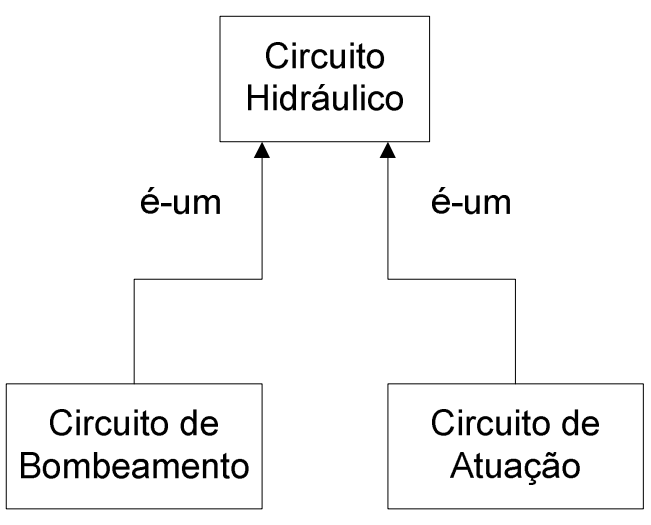

(a)

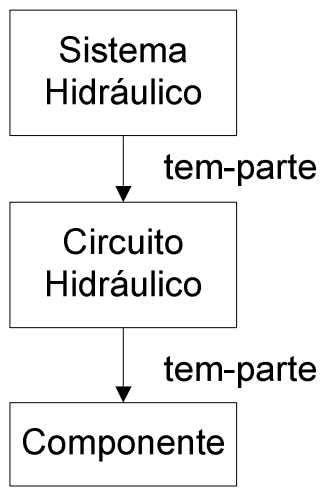

(b)

Fonte: Vinade (2003).

\subsubsection{Quadro}

O quadro (da palavra em inglês frames) foi introduzido inicialmente em 1975 por Marvin Minsky, pela comparação das propriedades observadas nos objetos e os padrões estereotipados, previamente definidos na memória. Em geral, um quadro é 
uma coleção de atributos, chamados de slots (os slots podem conter dados ou outros quadros). Os quadros integram conhecimento declarativo sobre objetos e eventos e conhecimento procedimental sobre como recuperar informações ou calcular valores.

A estrutura dos quadros é muito semelhante à das redes semânticas. Os quadros são compostos por uma rede de nós e relações organizadas segundo uma hierarquia. Os nós do topo da hierarquia representam os conceitos gerais e à medida que se desce na hierarquia representam os conceitos mais genéricos. À medida que se desce na hierarquia os conceitos vão ficando mais específicos. Basicamente um frame é uma estrutura de dados que inclui informações procedurais e declarativas em relações pré-definidas (NIKOLOPOULOS, 1997). A Figura 3.3 mostra um exemplo de estrutura dos quadros.

Figura 3-3 Estrutura dos Quadros.

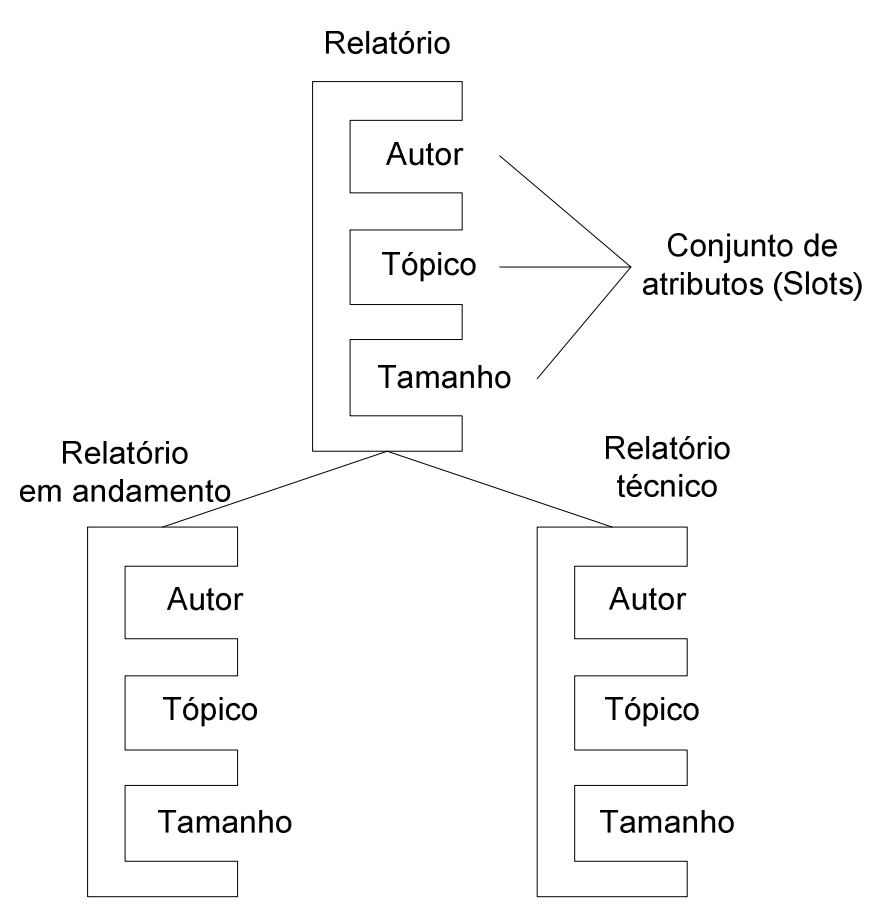

Fonte: Nunes (1990).

\subsubsection{Orientada a objetos}

A representação baseada em objetos modela o domínio através das suas entidades físicas e conceituais. Essas entidades chamam-se objetos que são 
definidos em classes hierarquicamente estruturadas, de modo que níveis inferiores na estrutura acessam atributos e relacionamentos de níveis superiores.

Um conceito importante em orientação a objetos é o de encapsulamento, que pode ser entendido como 0 ato de agrupar dados e métodos relacionados a um objeto. O conhecimento encapsulado por ser ocultados de outros objetos, sendo isso denominado de ocultamento de informação (REZENDE, 2005).

\subsection{Engenharia do Conhecimento}

Segundo Vinade (2003), a engenharia do conhecimento é "a arte de desenhar e construir um sistema especialista". Um engenheiro do conhecimento é um professional da área da computação que sabe projetar e põe programas em execução que incorporam técnicas de inteligência artificial. $O$ engenheiro do conhecimento entrevista e observa o especialista ou um grupo de especialistas e aprende o que eles sabem e como raciocinam com seu conhecimento. Os engenheiros traduzem o conhecimento em uma linguagem de programação. Além disso, determinam como integrar o uso do conhecimento incerto no processo de raciocínio e que tipo de explicação será útil para o usuário final.

Para iniciar o desenvolvimento de um sistema especialista é necessário saber qual é o tipo de conhecimento a ser representado na base de conhecimento. De acordo com Rezende (2005), os sistemas de base de conhecimento variam quanto ao grau de sucesso na representação do conhecimento. Para tanto, ele têm sido classificados em: conhecimento declarativo (conhecimento descritivo e genérico sobre fatos e eventos - "o que é"); conhecimento procedural (conhecimento prescritivo difícil de expressar e explicar - "como funciona"); conhecimento de senso comum (composto de conhecimento declarativo e procedural - "o julgamento do certo e do errado") e conhecimento heurístico (não pode ser obtido em nenhuma fonte, envolve avaliação sistemática e o uso de regras heurísticas). 


\subsection{Aplicações dos Sistemas Especialistas}

Segundo Blanning (1984), Nunes (1990), Afgan e Carvalho (1995), Matsatsinis; Doumpos e Zopounidis (1996), Suniura (1996), Puñal; Roca e Lema (2002) e Rezende (2005), as aplicações dos sistemas especialistas encontram seu perfil na maioria das áreas de trabalho do conhecimento. As aplicações mais importantes são:

- Tomada de decisões financeiras: Os sistemas especialistas foram criados para auxiliar os administradores na determinação de se fazer empréstimos a clientes. As companhias de seguro utilizam os sistemas especialistas para avaliar o risco apresentado pelo cliente e determinar o preço para a aplicação típica do seguro.

- Planejamento: Sistemas que planejam ações, com várias aplicações comerciais, por exemplo, programação de vôos de companhias áreas.

- Diagnose e Monitoração: o diagnóstico médico foi uma das primeiras áreas em que foram aplicados os sistemas especialistas. $\mathrm{Na}$ área de monitoração, são sistemas que observam e analisam o comportamento de outro sistema. Os aspectos cruciais ou vulnerabilidades correspondem as potenciais falhas do sistema observado. Incluem-se sistemas de monitoramento computadorizado da operação de usinas nucleares, para controle de tráfego aéreo, identificação de epidemias, entre outros.

- Previsão: Sistemas que inferem consequências sobre uma dada situação. Nessa categoria incluem-se: previsão meteorológica, previsão de crescimento demográfico, previsão de tráfego, estimativa de colheita, entre outros.

- Projeto: Sistemas que auxiliam no projeto de dispositivos e de processos físicos. Esses programas incluem layout de circuitos eletrônicos, projetos de construção e orçamentos.

- Vigilância e controle: Sistemas que adaptativamente controlam todo o ambiente de outro sistema. Para isso o sistema de controle deve repetidamente interpretar a situação corrente, prever, diagnosticar antecipadamente causas de problemas, formular planos de solução e monitorar a execução dos mesmos. Problemas endereçados a sistemas 
de controle incluem: controle de trafego aéreo, gerenciamento de negócios, gerenciamento de batalhas e controle de missões militares.

\subsection{Estado da arte dos sistemas especialistas aplicados no diagnóstico de falhas.}

Um levantamento bibliográfico de artigos relacionados aos sistemas especialistas para o diagnóstico de falhas foi realizado. Estes foram classificados através de sua área de aplicação: geração de energia elétrica, gestão de manutenção, petroquímica, entre outros. Além disso, outro levantamento bibliográfico relacionado a artigos que aplicaram as técnicas de confiabilidade e risco para aquisição de conhecimento em sistemas especialista foi conjuntamente elaborado. No capítulo 4 esses artigos são utilizados para apresentar as diferenças existentes entre o método proposto e os artigos referenciados.

Dentro os artigos aplicados ao diagnóstico de falhas no setor de geração elétrica tem-se o de Tanaka et al. (1992), na década de 1990, descrevendo as perspectivas futuras para o desenvolvimento e utilização de sistemas especialistas no setor de energia elétrica no Japão. Chung et al (1992) apresentaram um protótipo de um sistema especialista, chamado NSSS-DS, tem sido desenvolvido para o diagnóstico de falha de dois sistemas principais (as bombas de refrigeração do reator e o pressurizador) no sistema principal da central nuclear Kori-2 na Coreia. $O$ sistema de diagnóstico de falha oferece orientações aos operadores. Os sintomas de diagnóstico incluem alarmes, lâmpadas de indicação e mostra parâmetros de operação que são enviados ao sistema de controle principal que processa a informação dos alarmes disparada e diagnostica os possíveis efeitos transitórios e os sistemas que podem ter falhado.

Upadhyaya (2003) analisa o monitoramento de falhas em usinas termoelétricas com combustível nuclear discutindo fatores econômicos e de confiabilidade das mesmas. Albert (2003) destaca várias tecnologias empregadas no sistema de aquisição de dados em sistemas elétricos de potência. Kunze (2003) apresenta um sistema de monitoramento e diagnóstico de falhas a distância utilizando a internet aplicado em uma usina nuclear. 
Algan et al. (2006), desenvolveram um sistema especialista para a monitoração e diagnóstico de falhas em uma câmara de combustão de turbina a gás. O sistema recebe informações do sistema de monitoração e compara com valores simulados por métodos numéricos em diferentes situações de operação. O sistema permite identificar um mau funcionamento da câmara de combustão e deterioração de seu desempenho em função da comparação entre estes valores. O diagnóstico de falha é de grande importância para os usuários de turbinas a gás, facilitando a execução da sua manutenção e maximizando sua disponibilidade.

Song et al (2008) descrevem um projeto de pesquisa com o objetivo de desenvolver um sistema de diagnóstico de falhas para a turbina hidráulica, apresentando o processo de diagnóstico de falhas e as dificuldades envolvidas no desenvolvimento do sistema. O diagnóstico de falhas da turbina hidráulica é um processo complexo e que requer um alto nível de especialização $O$ sistema é baseado em uma arquitetura com os seguintes componentes: base de conhecimento, motor de inferência, interface de gestão do conhecimento, interface de usuário, a unidade de gestão do conhecimento e base de dados integrada. $O$ sistema especialista emprega regras heurísticas para diagnosticar a falha da turbina hidráulica

Unidades hidrogeradoras de energia elétrica são, em geral, bem construídas e robustas, contudo, há sempre a possibilidade de desenvolvimento de mecanismos de falha associados a processo de dano acumulado. Assim torna-se necessário monitorar e diagnosticar falhas em componentes críticos (aqueles cuja falha causa perda de desempenho ou mesmo paralisação do hidrogerador). Diagnosticar falhas em uma turbina hidráulica é um processo complexo que requer um alto nível de conhecimento da interação entre os componentes e a sua relação com o desempenho da turbina, incluindo o efeito da ocorrência da sua falha. (COSTA, 2010; SONG et al., 2008).

Os sistemas especialistas podem ser adaptados para interpretação de dados de monitoramento da condição da máquina, pois esses possuem a capacidade de simular processos de raciocino sistemáticos (EBERSBACH e PENG, 2008). Na área de geração de energia elétrica, os sistemas de monitoração por condição têm sido 
desenvolvidos para detectar e diagnosticar anomalias de vários subsistemas de turbinas eólicas e turbinas hidráulicas, tendo o objetivo de reduzir custos de operação e manutenção. Esse tipo de abordagem é apresentada nos trabalhos de Hameed et al. (2009), Simani e Patton (2008), Salahshoor et al. (2010), Dochain et al. (2006) e Tonaco (2008). Subsequente a esses trabalhos, Kusiak e Li (2010) apresentam uma metodologia para predizer falhas em turbinas eólicas. A mesma utiliza informações proporcionadas pelo sistema SCADA (Supervisory Control and Data Acquisition), em que foram registrados 60 parâmetros e podem ser agrupados em quatro categorias: Parâmetro do vento (parâmetros associados à condição do vento, por exemplo, velocidade do vento, direção do vento, entre outros), parâmetro da conversão da energia (parâmetros nesta categoria são relacionados com o processo de conversão de energia), parâmetros de vibração (indicam as condições de operação da turbina) e parâmetros de temperatura (inclui medidas de temperatura dos componentes da turbina).

Artigos aplicados ao diagnóstico de falhas na área de manutenção tem-se o de Streichfuss e Burgwinkel (1995) que apresentaram um sistema especialista para o diagnóstico, que opera em conjunto com o planejamento da manutenção, aplicado a veículos de transporte empregados em mineração de carvão. Segundo Majstorovic e MILACIC (1990), o diagnóstico de falhas e manutenção de sistemas mecânicos complexos representa uma tarefa de engenharia com característica multidisciplinar. Nesse trabalho se analisa a aplicação de sistemas especialistas em aspectos diferentes, como: (i) o conhecimento da engenharia de manutenção em sistemas especialistas; (ii) as hipóteses básicas para o desenvolvimento de sistemas especialistas para a manutenção; (iii) o nível de desenvolvimento e aplicação de sistemas especialistas no domínio da manutenção e (iv) a análise de sistemas especialistas desenvolvidos para a manutenção. Miller et al. (1990) desenvolveram um sistema especialista capaz de diagnosticar problemas de falhas em sistemas elétricos e hidráulicos. Batanov et al. (1993) apresenta uma abordagem para a concepção e desenvolvimento de sistemas baseados em conhecimento aplicados no campo da gestão de manutenção. Foi desenvolvido um software chamando EXPERT-MM que suporta três funções principais: sugestões de políticas de manutenção, diagnóstico de máquinas e programação de manutenção. A utilização adequada e eficaz da tecnologia de diagnóstico de falhas pode aumentar a vida 
operacional de todos os tipos de sistemas complexos, além de reduzir as despesas de manutenção.

No setor petroquímico, alguns artigos para diagnóstico de falhas são os de Batanov e Cheng (1995), que apresentaram um sistema especialista para o diagnóstico de falhas no processo de destilação de etileno. Chan (2005) mostrou o processo de desenvolvimento de um sistema de suporte especializado de decisão para o controle, monitoramento e diagnóstico de falha de uma planta de processamento de petróleo. O sistema pode monitorar as operações na instalação com base nos parâmetros de operação de entrada (temperatura, vazão, pressão, entre outros), detectar anomalias nos parâmetros e sugere medidas de diagnóstico para o operador. O sistema LUBRES ajuda os operadores de plantas no monitoramento e diagnóstico de situações anormais no processo de refino de óleo lubrificante (QIAN et al., 2008). Tang e Wnag (2008) desenvolveram um sistema especialista com o objetivo de diagnosticar falhas no processo de descarregamento de petróleo do navio para o porto.

Azadah, Ebrahimipour e Bavar (2010) desenvolveram um sistema especialista para o diagnóstico de falhas em bombas utilizadas na indústria petroquímica. $O$ objetivo deste estudo é fornecer um mecanismo de diagnóstico de falhas na bomba através de um mecanismo de inferência difusa baseado em regras. Como resultados da análise, foi possível conseguir uma redução do erro humano, redução do tempo de reparo, redução de custos de manutenção e conhecimento de especialistas que podem ser utilizados para treinamento de mantenedores.

Artigos aplicados para diagnóstico de falhas em outros setores na indústria tem-se o de White (1991) que apresentou o impacto da aplicação dos sistemas especialistas em diagnóstico de falhas de máquinas. $O$ autor introduz o conceito básico de um ambiente operacional de máquinas e em seguida discute as principais características do sistema especialista. Ali e Khamis (2003) desenvolveram um sistema especialista chamado TIREDDX, que tem como objetivo principal diagnosticar falhas no processo de fabricação de pneus. Este sistema foi desenvolvido porque a fabricação de pneus é um processo complexo, devido ao número de variáveis de processamento envolvidas. 
O trabalho de pesquisa de Zhou et al. (2009) teve como objetivo projetar e construir um sistema baseado em conhecimento para monitorar, controlar e diagnosticar falhas no processo de captura de dióxido de carbono, o qual é uma tarefa complexa porque envolve a manipulação de dezesseis componentes e seus respectivos parâmetros de operação.

Tran et al (2009) utilizam as técnicas de árvores de decisão e neuro fuzzy para aquisição de conhecimento para o diagnóstico de falhas em motores de indução. O sistema processa os dados de vibração para identificar a falha.

Sun; Chen e Li (2007) desenvolveram um sistema hibrido para o diagnóstico de falhas em máquinas rotativas aplicando as técnicas de aprendizado de máquinas, como mineração de dados, árvore de decisão e redes neurais. Saimurugan et al (2011) desenvolveram um sistema de diagnóstico de falhas em máquinas rotativas. O eixo e rolamentos são os componentes mais críticos em máquinas rotativas. A maioria dos problemas surge a partir de rolamentos defeituosos que por sua vez, afetam o eixo. Os sinais de vibração são amplamente utilizados para determinar o estado de elementos de máquina. Os sinais de vibração são utilizados para extrair os recursos para identificar o estado de uma máquina. Este artigo apresenta o uso de modelos C-SVC e nu-SVC de máquina de vetor de suporte (SVM), com quatro funções de Kernel para a classificação de falhas utilizando recursos estatísticos extraídos de sinais de vibração.

Castellanos et al (2011) desenvolveram um sistema de diagnóstico de falhas em gasoduto que tem como propósito identificar o possível mecanismo de falha mecânica de um gasoduto, com a identificação de testes específicos para validar a falha potencial. $O$ treinamento do sistema especialista foi realizado através da inclusão do banco de dados de falha de um gasoduto, constatando que o sistema FAES apresentou uma boa correlação da diagnose com as explicações constantes na documentação dos casos de falha.

Wang et al (2012) utilizam as tecnologias baseadas em rede neurais e árvore de falhas. Este artigo faz uso das vantagens de ambas às tecnologias para elaborar o sistema especialista para o diagnóstico da falha em um sistema de controle digital. 
Realizou-se um levantamento de artigos que utilizaram as técnicas de confiabilidade e risco para aquisição do conhecimento. Classificaram-se os artigos pelas aplicações das técnicas.

Dentro os artigos que aplicaram a técnica do HAZOP tem-se o de Leone (1996) que apresentou os principais aspectos da SERO, uma estrutura de representação do conhecimento, que foi desenvolvido para codificar os diferentes tipos de conhecimento utilizados em um estudo HAZOP.

Khan e Abbasi (2000) desenvolveram um sistema especialista chamado EXPERTOP. Uma das principais características desta ferramenta é a base de conhecimento. A base de conhecimentos é dividida em quatro características principais: causas, consequências do processo geral, as causas específicas do processo e consequências específicas do processo.

Venkatasubramanian et al (2000) apresentaram um sistema inteligente que permite medidas de mitigação de risco identificando e fazendo sugestões em uma instalação de processo químico baseado na análise de riscos por meio das técnicas APP (Análise preliminar de perigo) e HAZOP.

Chan (2005) apresentou o processo de desenvolvimento de um sistema especialista de apoio na decisão de controle, monitoramento e diagnóstico de falhas na produção de petróleo baseando-se na aplicação da técnica HAZOP. O sistema pode monitorar as operações na planta com base nos parâmetros de entrada, detectar anomalias nos parâmetros e sugerir ações de diagnóstico ao operador.

Rahman et al (2009) desenvolveram o sistema ExpHAZOP +, baseando-se na técnica de análise de risco HAZOP. O sistema especialista apresenta as etapas da metodologia do Exp HAZOP+, a qual foi dividida em interface gráfica, o mecanismo de inferência e a base do conhecimento. Para o mecanismo de inferência foi criado um algoritmo de propagação de falhas. A base de conhecimento dinâmica de ExpHAZOP + permite que o usuário possa atualizar os conhecimentos durante a realização da análise HAZOP. 
Dentro os artigos que aplicaram a técnica do FTA tem-se o de Papadopoulos (2003) que desenvolveu um sistema para o diagnóstico de falhas on-line no sistema de combustível do avião.

Zhou et al. (2009) apresentaram um sistema especialista de diagnóstico de falhas para planta criogênica baseado na análise da árvore de falhas. A planta criogênica consiste em um refrigerador de hélio de $2 \mathrm{~kW} / 4 \mathrm{~K}$ e também como um sistema de distribuição desse gás.

Zhi-Ling et al (2012) desenvolveram um sistema especialista para o diagnóstico de falhas na caixa de engrenagens de uma turbina eólica tomando como base da aquisição de conhecimento a aplicação da técnica de árvore de falhas.

Wang et al (2012) desenvolveram um sistema especialista de diagnóstico de falhas baseado em redes neurais e árvore de falhas para estudar as falhas em um sistema de controle digital.

Duan e Zhou (2012) apresentaram um método para diagnosticar falhas através da análise da árvore de falhas e redes Bayesianas. Essa metodologia tem como propósito otimizar o diagnóstico de falhas no sistema de pressão do óleo do sistema de monitoração.

De acordo com a revisão bibliográfica realizada para a aplicação de sistemas especialistas para o diagnóstico de falhas, se observou que foram desenvolvidos para solucionar problemas em diversas áreas da indústria. Dependendo do diagnóstico a ser realizado se escolhe a técnica ou conjunto de técnicas para realizar a aquisição de conhecimento para a elaboração do sistema especialista.

Dentro das técnicas de análise de confiabilidade e risco observa-se que a aplicação da técnica de HAZOP é uma das mais exploradas na elaboração de sistemas especialistas para diagnóstico de falhas, geralmente aplicados na indústria química. O conhecimento adquirido pela aplicação do HAZOP foi representado em forma de regras se/então. 
A técnica do FTA está sendo utilizada em conjunto com redes bayesianas, redes neurais e lógica fuzzy, o que indica que esta técnica está sendo associada a técnicas de aprendizado de máquina para a elaboração de sistemas especialistas.

A técnica do FMEA ainda não foi aplicada para aquisição de conhecimento para a elaboração de sistemas especialistas para o diagnóstico de falhas. A técnica de FMEA foi aplicada por Vinade (2003) para o desenvolvimento de um sistema especialista para sistematização do conhecimento relativo ao projeto de sistemas hidráulicos que facilite o processo de projeto para a confiabilidade e mantenabilidade destes sistemas. 


\section{PROPOSTA DO MÉTODO PARA AQUISIÇÃO DE CONHECIMENTO PARA A ELABORAÇÃO DE UM SISTEMA ESPECIALISTA PARA O DIAGNÓSTICO DE FALHAS}

Neste capítulo é apresentado o método para aquisição de conhecimento para a elaboração de um sistema especialista para o diagnóstico de falhas, utilizando os conceitos apresentados nos capítulos anteriores, visando cumprir os objetivos definidos no Capítulo 1.

\subsection{Método proposto}

Propõe-se um método para aquisição de conhecimento para a elaboração de um sistema especialista para o diagnóstico de falhas baseado na integração e aplicação de técnicas de análise de confiabilidade e risco, tais como Estudos de Perigo de Operação (HAZOP), Análise de Árvore de Falhas (FTA), e Análise de Modos e Efeitos de Falha (FMEA) explicados no Capítulo 2.

O processo de aquisição do conhecimento é considerado o desafio mais difícil para se desenvolver um sistema especialista. A qualidade dos resultados da análise obtida do sistema especialista depende da qualidade do conhecimento adquirido.

O processo de aquisição do conhecimento proposto nesta pesquisa se divide em três etapas. A primeira etapa é a obtenção do conhecimento do funcionamento do sistema por meio do estudo e descrição operacional dos equipamentos que o compõem. A segunda etapa é o processo de aquisição do conhecimento para o diagnóstico de falhas. A terceira etapa é propor políticas de manutenção baseada na filosofia de Manutenção Centrada em Confiabilidade, e determinar a periocidade da manutenção preventiva. A seguir são explicadas de maneira detalhada cada uma das etapas apresentadas na metodologia. 


\subsubsection{Estudo e descrição operacional do sistema.}

Esta primeira etapa é caracterizada por uma sequência de atividades que visa realizar uma descrição operacional do equipamento a ser analisado. Para cumpri-la é importante seguir os passos especificados na Figura 4.1.

Figura 4-1 Procedimento para estudo e descrição funcional do sistema

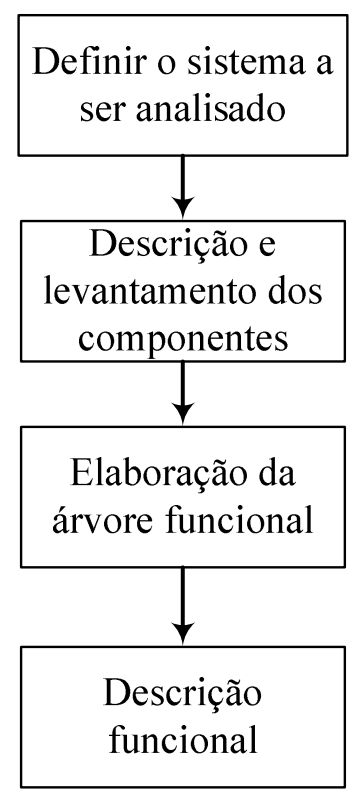

Fonte: Própria

Conforme a Figura 4.1 pode-se observar que o estudo e a descrição operacional do sistema começam por definir o sistema a ser analisado, definindo as fronteiras da análise. Após essa etapa, é necessário realizar a descrição e o levantamento dos principais subsistemas e componentes. Para realizar uma ampla descrição operacional é necessário realizar um levantamento das características técnicas dos componentes através do estudo dos planos operacionais, catálogos, manuais do fabricante, entre outros. Nesta etapa podem surgir algumas dificuldades já que na indústria estas informações podem não estar disponíveis. O êxito da análise depende de sua correta realização; além disso, permitirá a identificação dos componentes e suas funções desempenhadas no sistema dentro de um contexto operacional especifico.

A árvore funcional tem como objetivo traduzir a estrutura física do sistema em uma estrutura hierárquica que permita relacionar de forma lógica a interligação 
funcional entre os componentes que compõem o sistema. Para desenvolver o método é necessário definir claramente as funções do sistema, ou seja, estabelecer as atividades que o sistema desempenha do ponto de vista operacional (SOUZA, 2008).

A árvore funcional pode ser aplicada para analisar vários tipos de sistemas. $\mathrm{O}$ nível de detalhe da análise depende da quantidade de componentes e nível de funções a serem analisadas. A análise funcional é representada por um gráfico, denominado árvore funcional, que possui uma estrutura hierárquica, não uniforme, formada por ramos, conforme indicado na Figura 4.2. Esta ferramenta sugere dividir o sistema em vários níveis. Este sistema seria composto por subsistemas, os quais podem ser divididos até chegar ao nível de componente, permitindo analisar cada uma das funções, de cada um dos componentes de uma maneira independente (HAWKINS e WOLLONS, 1998; KRISHNASAMY et al., 2005).

Para desenvolver a árvore funcional deve-se responder às seguintes perguntas: como é executada uma determinada função? (permite definir quais componentes devem ser utilizados para executar esta função); e por que uma determinada função deve ser executada? (serve para verificar se a árvore, baseada na primeira pergunta, está correta).

Figura 4-2 Arranjo geral da árvore funcional

Como?

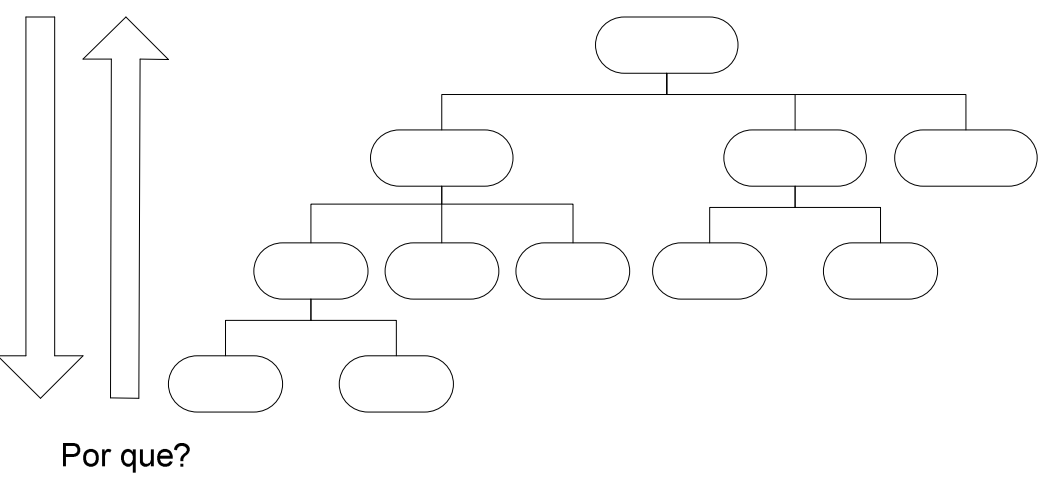

Fonte: Souza (2008). 
Segundo a Figura 4.2, no topo da árvore encontra-se a função principal do sistema. No nível seguinte, as funções que apoiam diretamente a função topo e as demais funções aparecerão na sequência. Por sua vez, cada função pode ter novas funções de apoio, seguindo o processo até chegar aos componentes básicos de cada sistema.

Finalmente, a descrição funcional consiste em estabelecer a interligação entre os componentes que compõem o sistema. Para se elaborar a descrição funcional, é necessário identificar as funções que cada um dos componentes identificados na árvore funcional possam vir a desempenhar. Isso pode ser realizado por meio de revisão bibliográfica ou estudo do manual de operação, por exemplo, a função principal do filtro é "manter o fluido livre de partículas estranhas". Dessa forma serão conhecidas as funções mais importantes de cada um dos subsistemas e dos seus respectivos componentes. O desenvolvimento desta ferramenta torna-se importante já que ela permitirá entender a complexidade das relações funcionais entre os componentes do sistema, que permitirá a delimitação da análise (RAUSAND, 2004; SOUZA, 2010).

\subsubsection{Aquisição do conhecimento para o diagnóstico de falhas.}

O método de detecção e isolação de falhas se baseia em dados históricos explorando os dados armazenados e identificando assim os padrões que indicam ocorrência de falhas (DETROJA et al., 2006). Estes padrões ou sinais podem ser classificados em diferentes grupos que podem representar uma operação normal ou anormal. Deste modo, a tarefa de monitoração é frequentemente relacionada à capacidade de classificar os sinais disponíveis da planta (variáveis medidas e manipuladas) em modos de operação normal ou com falhas, a qual subsidiaria a elaboração do HAZOP.

A aquisição de conhecimento para o diagnóstico de falhas será realizada por meio de entrevistas com o especialista na operação do sistema, revisão bibliográfica de livros, artigos, entre outros materiais. Neste trabalho é proposta a utilização das técnicas de análise de confiabilidade e risco para auxiliar o engenheiro do conhecimento, a organizá-lo de forma clara para subsidiar o desenvolvimento da etapa seguinte, a aplicação das técnicas de representação do conhecimento. 
As técnicas de análise de confiabilidade e risco utilizados são: Estudos de Perigo de Operação (HAZOP), Análise da Árvore de Falhas (FTA) e Análise de Modos e Efeitos da Falha (FMEA). Na Figura 4.3 é apresentada a forma sequencial de como são aplicadas as técnicas de análise de confiabilidade e risco na aquisição do conhecimento para o diagnóstico de falhas.

Figura 4-3 Aplicação das técnicas de confiabilidade e risco na aquisição do conhecimento para o diagnóstico de falhas

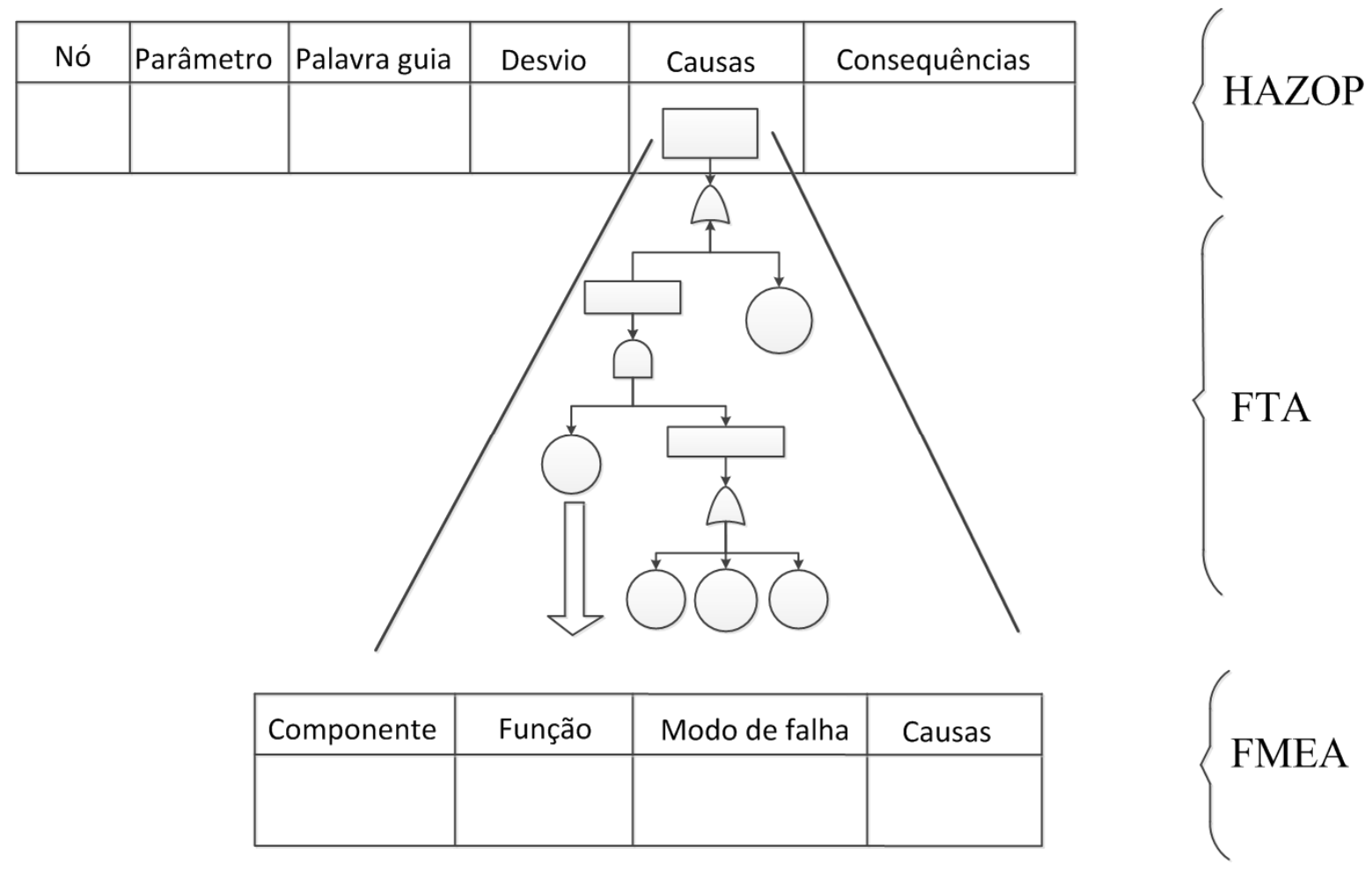

Fonte: Própria

Conforme sugerido pela Figura 4.3, o primeiro passo é a aplicação da técnica HAZOP. O procedimento para execução desta técnica para o diagnóstico de falhas pode ser sintetizado nos seguintes passos:

- Escolha do nó (são os pontos de processo) a ser analisado;

- Identificar os parâmetros de operação que podem ser medidos em cada nó que for analisado: temperatura, vazão, vibração, pressão, entre outros;

- Aplicação das "palavras-guias", verificando quais os desvios que são possíveis de ocorrer naquele nó. Para cada desvio, investigar as causas 
possíveis de provocá-lo. Para procurar as possíveis causas, recomenda-se a aplicação da técnica de análise de Árvore de Falhas.

A Tabela 4.1 apresenta uma lista de parâmetros e de palavras-guias juntamente com os tipos de desvios comumente usados na análise HAZOP.

Tabela 4.1 Palavras-Guias para a análise (KUMAMOTO e HENLEY, 2000)

\begin{tabular}{ccl}
\hline Parâmetro & Palavra-Guia & \multicolumn{1}{c}{ Desvio } \\
\hline \multirow{2}{*}{ Vazão } & Nenhum & Nenhum fluxo \\
& Menos & Menos fluxo \\
& Mais & Mais fluxo \\
& Reverso & Fluxo reverso \\
\hline \multirow{2}{*}{ Pressão } & Menos & Pressão baixa \\
& Mais & Pressão alta \\
\hline \multirow{2}{*}{ Temperatura } & Menos & $\begin{array}{l}\text { Temperatura } \\
\text { baixa }\end{array}$ \\
& Mais & Temperatura alta \\
\hline \multirow{2}{*}{ Nível } & Menos & Nível baixo \\
& Mais & Nível alto \\
\hline \multirow{2}{*}{ Viscosidade } & Menos & Viscosidade \\
& baixa \\
& Mais & Viscosidade alta \\
\hline \multirow{2}{*}{ Vibração } & Menos & Vibração baixa \\
& Mais & Vibração alta \\
\hline
\end{tabular}

Para a realização da análise HAZOP, é utilizada uma tabela composta por seis colunas como é indicada na Tabela 4.2 a qual contêm as seguintes informações: localização do nó (são os pontos do processo, localizados através dos fluxogramas da planta, onde serão analisados os desvios); parâmetro (são os fatores ou componentes da intenção de operação, ou seja, são as variáveis físicas do processo); palavra guia (são aplicadas aos parâmetros de processo que permanecem dentro dos padrões estabelecidos pela intenção de operação); desvio (são afastamentos das intenções de operação, que são evidenciados pela aplicação sistemática das palavras-guias nos nós de estudo); causas (são os motivos pelos quais os desvios ocorrem; nesta etapa é aplicada a Árvore de Falhas) e consequências (são os resultados decorrentes de um desvio da intenção de operação em um determinado nó em estudo). 
Tabela 4.2 Planilha utilizada no HAZOP

\begin{tabular}{|l|l|l|l|l|l|}
\hline Sistema & \multicolumn{5}{|l|}{} \\
\hline Componente & \multicolumn{5}{|l|}{$\mid$} \\
\hline $\begin{array}{c}\text { Localização } \\
\text { do nó }\end{array}$ & Parâmetro & Palavra-guia & Desvio & Causas & Consequências \\
\hline & & & & & \\
\hline
\end{tabular}

Uma vez identificado um desvio, deve-se realizar a identificação de suas possíveis causas, por meio da aplicação da técnica da Árvore de Falhas, sendo esse desvio considerado como evento topo. O principal motivo de se aplicar a Árvore de Falhas é a possibilidade de ocorrer falhas simultâneas, o que geralmente ocorre em sistemas mecânicos. Com a elaboração da Árvore de Falhas é possível identificar os eventos básicos que levaram a ocorrência do desvio ou do evento topo.

Uma vez identificados os eventos básicos que levam à ocorrência do desvio na condição operacional, é desenvolvida a Análise de Modos e Efeitos de Falha, pois os eventos básicos listados no FTA são os modos de falhas dos componentes do sistema. A análise auxiliará a identificação das causas das falhas e proporcionará subsídios para a elaboração das recomendações de manutenção para reparar a máquina.

A tabela tradicional da análise FMEA foi transformada em uma tabela mais simples, conforme as características apresentadas na Tabela 4.3, a qual é composta por quatro colunas: componente (identificação de cada componente que pertence ao sistema); função (descrição resumida e precisa da tarefa que deve ser executada pelo componente); modo de falha potencial (descrição da forma como a perda da função é observada pela equipe de operação) e causa da falha (descrição simples e concisa das causas que geram a ocorrência do modo de falha).

A aplicação do FMEA auxilia na criação de um critério que permite realizar a seleção e recomendação das políticas de manutenção, que visem reduzir a ocorrência dos modos de falha. 
Tabela 4.3 Formulário empregado na análise de tipo FMEA

\begin{tabular}{|l|c|c|c|}
\hline \multicolumn{4}{|c|}{ Análise de Modo e Efeito de Falhas - FMEA } \\
\hline Componente & Função & $\begin{array}{c}\text { Modo de falha } \\
\text { Potencial }\end{array}$ & Causa(s) da(s) falha(s) \\
\hline & & & \\
\hline
\end{tabular}

\subsubsection{Aquisição do conhecimento para propor políticas de manutenção.}

Para selecionar a política de manutenção mais apropriada para um equipamento do sistema, é necessário definir um processo de decisão que permita determinar as práticas de manutenção mais apropriadas para os componentes em análise. A escolha deve ser executada em função das características dos modos de falha e suas causas.

Deve-se realizar a seleção das tarefas de manutenção recomendadas para cada um dos componentes do sistema. A elaboração das políticas de manutenção tem como base os diagramas de decisão empregados pela Manutenção Centrada em confiabilidade, apresentados na Figura 4.4.

Para ajudar a tabulação das questões no diagrama de decisão do RCM, pode-se utilizar uma tabela, tal como a Tabela 4.4, onde se indica Sim ou Não para cada uma das questões listadas. Esse mecanismo possibilitará a seleção da melhor prática de manutenção para o componente (MOUBRAY, 2000). 
Figura 4-4 Diagrama de decisão da Manutenção Centrada em Confiabilidade para seleção de políticas de manutenção

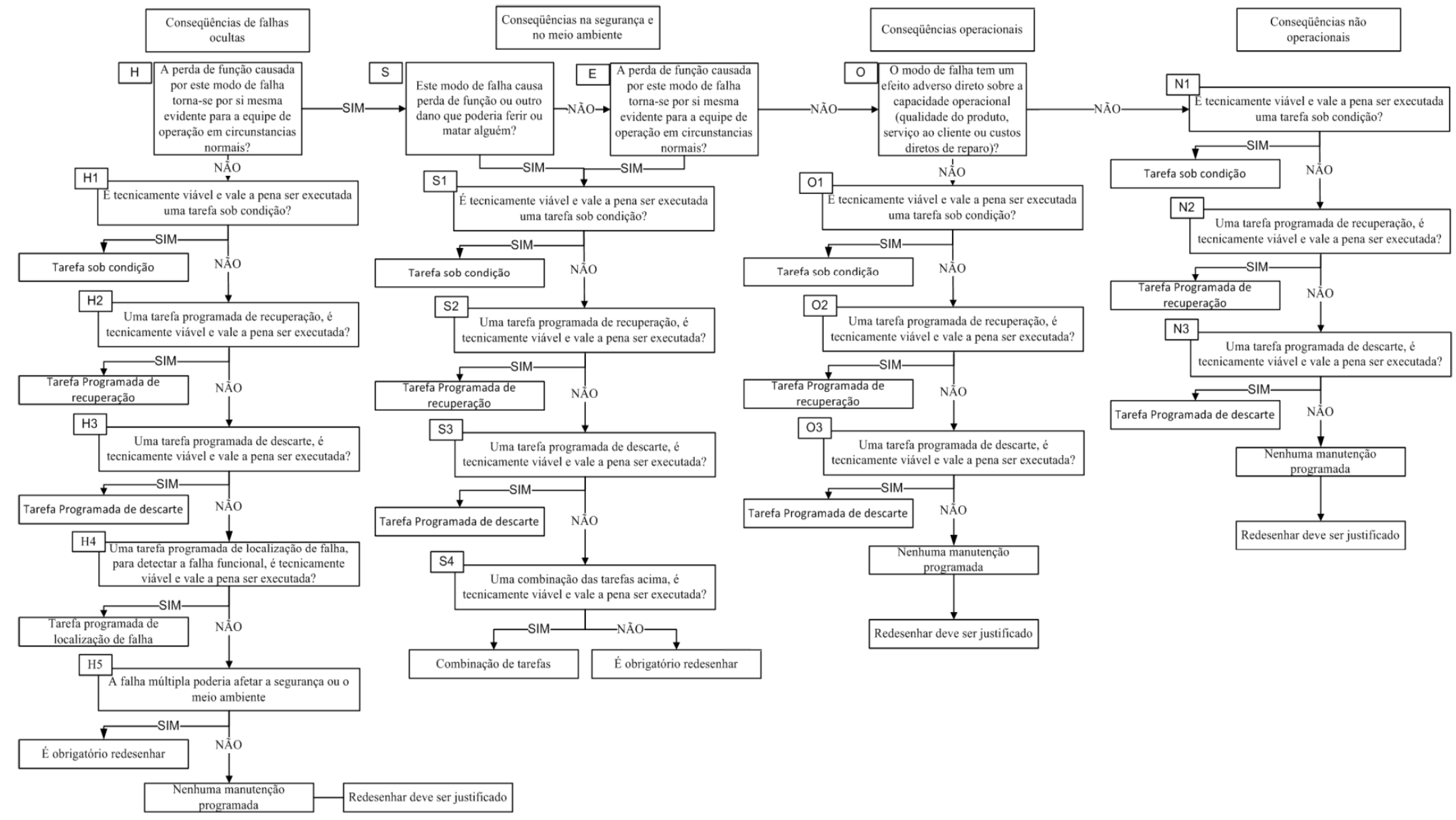


Tabela 4. 4 Tabulação de Resultados na Análise de decisão pelo Método RCM (MOUBRAY, 2000)

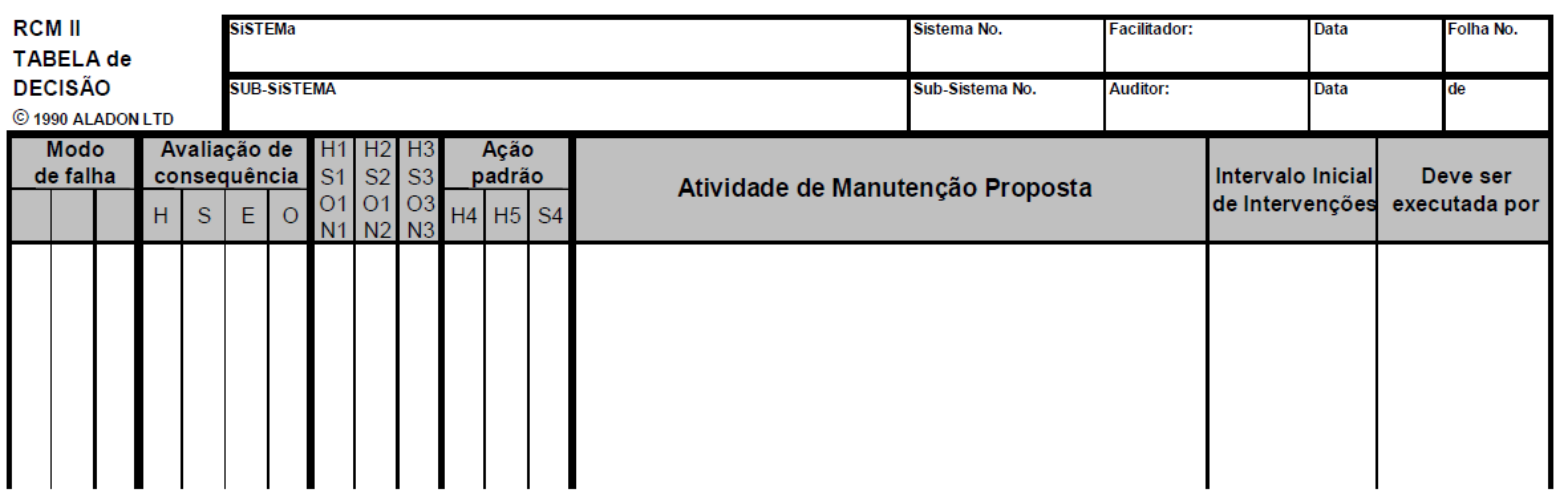

\subsubsection{Cálculo da periocidade da manutenção preventiva}

Uma vez identificadas às políticas de manutenção para os componentes, será calculado o intervalo de manutenção preventiva considerando a ação de manutenção imperfeita. Na prática, depois que um sistema é submetido à ação de manutenção preventiva, o estado do sistema não retorna à situação de "tão bom quanto novo", ou seja, o valor da taxa de falha varia e ocorre um aumento de sua magnitude em comparação com a taxa de falha de um sistema "novo". Simultaneamente, o sistema tende a necessitar de ação de manutenção mais frequente já que a taxa de falha aumenta rapidamente do que o observado no intervalo de operação anterior. A variação da taxa de falha que leva em consideração a degradação do componente pela ação da manutenção pode ser definida pela equação 4.1, (NAKAGAWA, 1988; MALIK 1979).

$$
\lambda_{\mathrm{i}+1}=\mathrm{b}_{\mathrm{i}} \lambda_{\mathrm{i}}\left(\mathrm{t}+\mathrm{a}_{\mathrm{i}} \mathrm{T}_{\mathrm{i}}\right)
$$

Onde: $t \in\left(0, T_{i+1}\right), T_{i}$ é o intervalo entre as manutenções preventivas do i-ésimo ciclo. A Figura 4.5 ilustra a variação da taxa de falha obtida de forma recursiva em relação à taxa de falha no intervalo anterior em função de diferentes modelos de degradação. Esta degradação é expressa por fatores, $a_{i}$ e $b_{i}$. 
Figura 4-5 Modelo recursivo para evolução da taxa de falha

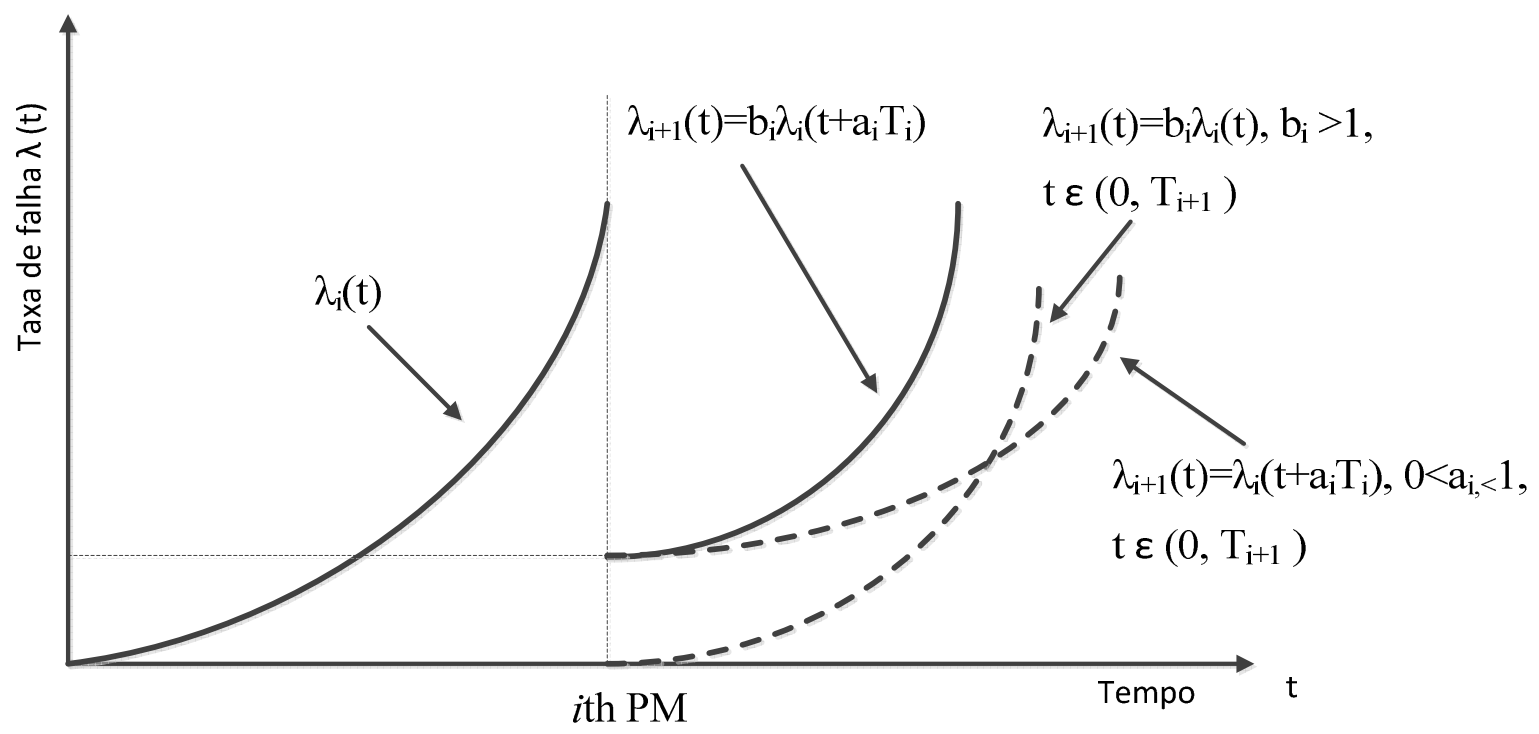

Fonte: Zhou et al (2007)

De acordo com Zhou et al (2007), estes fatores podem ser encontrados em função do número de intervenções das manutenções preventivas realizadas, i, através das Equações 4.2 e 4.3 .

$$
\begin{aligned}
& a_{i}=\frac{i}{3 i+7} \\
& b_{i}=\frac{12 i+1}{11 i+1}
\end{aligned}
$$

Onde:

$a_{i}$ : fator de redução de idade $\left(0<a_{i}<1\right)$ que mostra que cada ação de manutenção imperfeita faz a taxa de falha inicial da unidade tornar-se $\lambda_{i}\left(a_{i} T_{i}\right)$ para 0 próximo ciclo de manutenção, ou seja, a taxa de falha considera que o equipamento não é "tão bom quanto novo", comportando-se como se já tivesse uma vida inicial.

$b_{i}$ : fator de crescimento da taxa de falha $\left(b_{i}>1\right)$ : indica que a atividade de manutenção imperfeita aumenta a taxa de falha para o valor $b_{i} \cdot \lambda_{i}\left(t_{i}\right)$ acelerando 0 processo de deterioração (Nakagawa, 1988).

i: índice do número do ciclo de manutenção preventiva. $(i=1,2, \ldots, M)$ 
Para calcular a periocidade da manutenção preventiva foi aplicada a teoria de Multicritério, que consiste de um conjunto estruturado de abordagens para a análise de problemas com vários critérios e alternativas, a fim de ajudar o departamento de manutenção na tomada decisão da periocidade para execução da manutenção preventiva.

O processo de tomada de decisão para definir o intervalo de manutenção preventiva pode ser afetado por muitas variáveis, tais como os: custos totais por unidade de tempo, confiabilidade, inatividade, perda de qualidade, perda de produção, peças de reposição os custos de estoque e de risco. Neste trabalho são utilizados dois critérios: confiabilidade e custos. As alternativas correspondem aos intervalos de manutenção preventiva.

O processo de decisão multicritério pode ser executado com a aplicação de várias técnicas como se observou no Capítulo 2. Para este estudo será utilizada a abordagem de sobreclassificação buscando a minimização dos custos e maximização da confiabilidade. A técnica utilizada no presente trabalho é o método PROMETHEE II que é apresentado no Anexo A.

Para aplicação do método necessita-se expressar a variação da confiabilidade e o custo da manutenção como indicado na sequência do texto.

Critério 1: Confiabilidade pode ser determinada de acordo com a Equação 4.4 que está relacionada com a taxa de falha do sistema.

$$
R(t)=e^{-\int \lambda(t) d t}
$$

Especificamente, considerando o emprego da distribuição de Weibull para a modelagem da confiabilidade, a taxa de falha é dada pela Equação 4.5.

$$
\lambda(t)=\left(\frac{\beta}{\eta}\right)\left(\frac{t}{\eta}\right)^{\beta-1}
$$

Levando-se em consideração a Equação 4.1 pode-se determinar a taxa de falha para o próximo período operacional, após a execução de um procedimento de manutenção preventiva através da Equação 4.6. 


$$
\lambda_{i+1}(t)=b_{i}\left(\frac{\beta}{\eta}\right)\left(\frac{t+a_{i} T_{i}}{\eta}\right)^{\beta-1}
$$

Desta forma, a equação de confiabilidade para o $i+1$ do ciclo de manutenção, levando-se em consideração a degradação do sistema, pode ser determinada pela Equação 4.7.

$$
R(t)=e^{-b_{i}\left(\frac{t+a_{i} T_{i}}{n}\right)^{\beta}} e^{b_{i}\left(\frac{a_{i_{i}} T_{j}}{n}\right)^{\beta}}
$$

Critério 2: O modelo proposto para calcular o custo de manutenção é baseado na referência de Chareonsuk et al (1997), sendo expresso em termos dos custos médios esperados por unidade de tempo "E[C(tp)]", conforme a Equação 4.8. Este modelo é modificado de forma a incorporar os valores de confiabilidade, probabilidade de falha acumulada e função densidade de probabilidade, expressos nas equações anteriormente apresentadas. Assim, a Equação 4.10 expressa o valor esperado para o custo total de manutenção incluindo o efeito da degradação.

$$
\begin{array}{r}
E\left[C\left(t_{p}\right)\right]=\frac{C_{p} R\left(t_{p}\right)+C_{f} F\left(t_{p}\right)}{t_{p} R\left(t_{p}\right)+\int_{0}^{t} t f(t) d t} \\
\frac{E\left[C\left(t_{p}\right)\right]}{C_{p}}=\frac{R\left(t_{p}\right)+k \cdot F\left(t_{p}\right)}{t_{p} R\left(t_{p}\right)+\int_{0}^{t} t f(t) d t}
\end{array}
$$

Onde $k=C_{f} / C_{p}$

$$
E\left[C\left(t_{p}\right)\right]=\frac{C_{p} e^{-b_{i}\left(\frac{t_{p}+a_{i} T_{i}}{n}\right)^{\beta}}+C_{f}\left(1-e^{-b_{i}\left(\frac{t_{p}+a_{i} T_{i}}{n}\right)^{\beta}}\right)}{t_{p} \cdot e^{-b_{i}\left(\frac{t p+a_{i} T_{i}}{n}\right)^{\beta}}+b_{i}\left(\frac{\beta}{n}\right) e^{b_{i}\left(\frac{a_{i} T_{i}}{n}\right)^{\beta}} \int_{0}^{t_{p}} t\left(\frac{t+a_{i} T_{i}}{n}\right)^{\beta-1} \cdot e^{-b_{i}\left(\frac{t+a_{i} T_{i}}{n}\right)^{\beta}} d t}
$$

Onde:

$\mathrm{C}_{f}=$ custo de manutenção corretiva do sistema;

$\mathrm{C}_{p}=$ custo de manutenção preventiva do sistema;

$T_{i}=$ intervalo de intervenção preventiva do sistema máquina do período anterior;

$f(t)$ = função densidade de probabilidade; 
$F(t)$ = função distribuição acumulada;

$R(t)=$ função confiabilidade do sistema;

$t_{p}=$ intervalo de tempo para efetuar a manutenção preventiva no ciclo $(i+1)$ de operação;

$\beta$ : fator de forma da distribuição de Weibull;

$\eta$ : fator de escala da distribuição de Weibull.

Na Figura 4.6, é apresentado o fluxograma com as etapas da aplicação do modelo multicritério para a determinação dos intervalos de intervenção da manutenção preventiva considerando a degradação.

Figura 4-6 Fluxograma do modelo aplicado para a determinação dos intervalos de manutenção preventiva

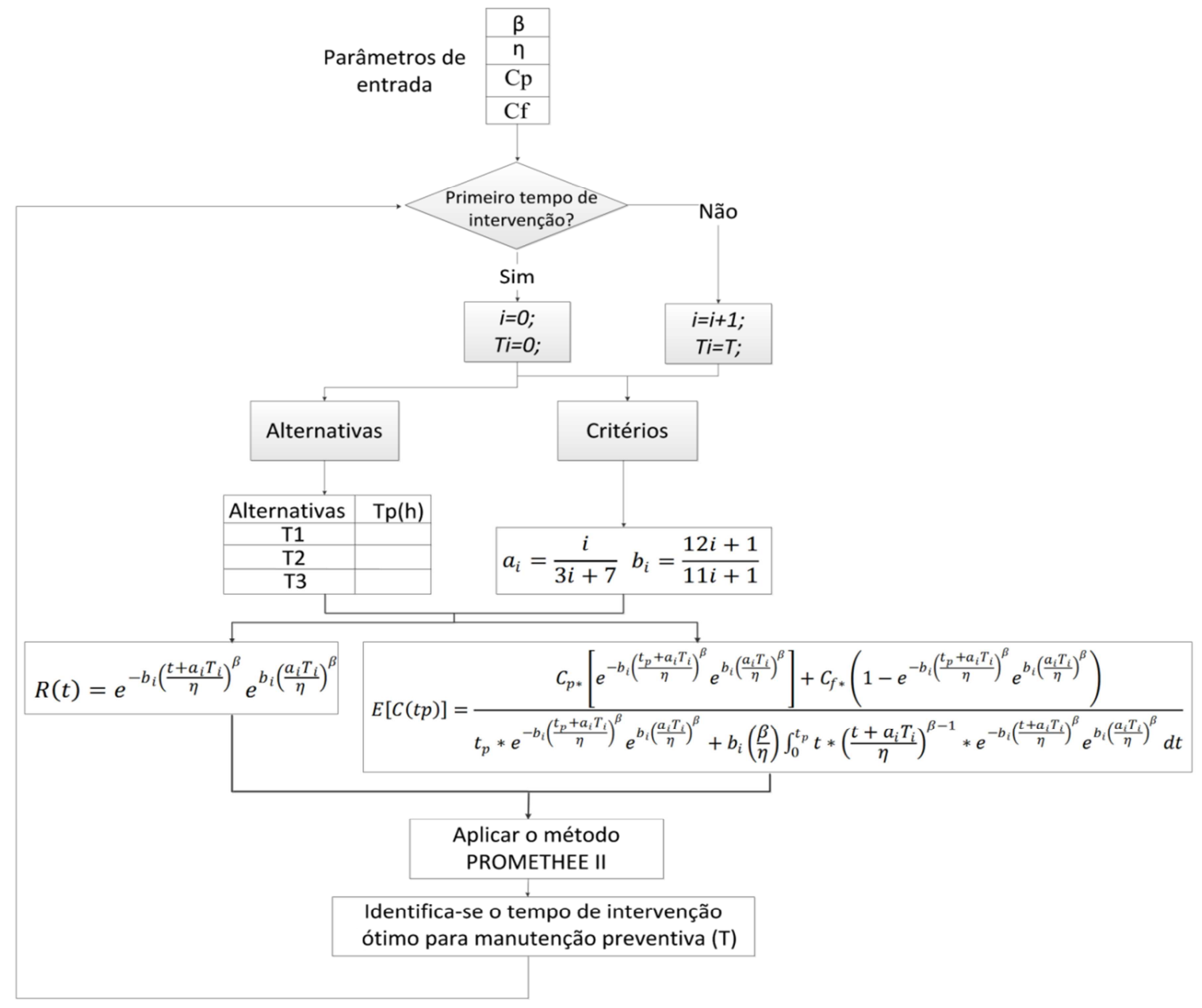

Fonte: Própria 
O modelo proposto para calcular o intervalo de intervenção para manutenção preventiva tem suas limitações, descritas na sequencia deste texto.

Para calcular os tempos de intervenções de manutenção preventiva deve-se considerar que o modelo só estima os intervalos de manutenção para valores de $\beta \geq$ 2. Quando $\beta$ for menor que 2, os tempos de intervenção são maiores a cada novo intervalo de operação, fato este que não pode ocorrer, pois o equipamento esta degradando-se e os tempos de intervenção deveriam ser menores. O cálculo que é feito pelo modelo quando $\beta<2$ é graficamente apresentado na Figura 4.7. Embora os custos totais de manutenção aumentem para os futuros intervalos de manutenção em relação ao primeiro período de intervenção, o seu ponto de mínimo se desloca para a direita, gerando um aumento no tempo de intervenção associado ao custo mínimo. Este fato é incoerente com a necessidade de garantir confiabilidade para um equipamento em processo de degradação.

Figura 4-7 Curva de custos com respeito ao tempo para $\beta<2$

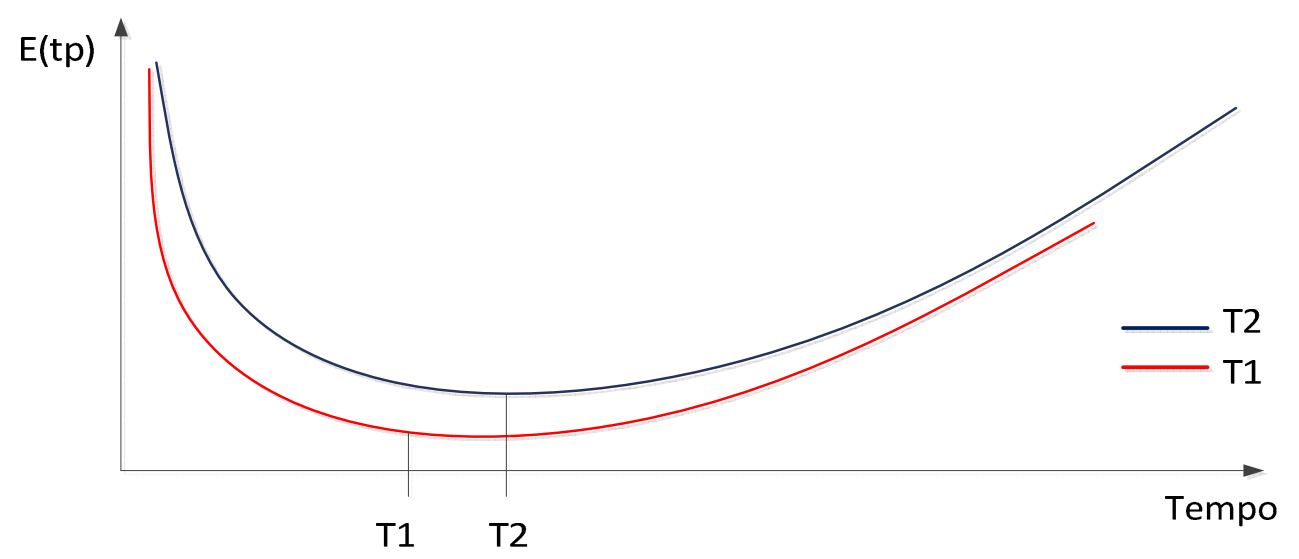

Fonte: Própria

Para valores de $\beta \geq 2$ os tempos de intervenção são menores, já que os componentes estão se degradando e farão com que os custos de manutenção aumentem, como pode ser observado na Figura 4.8. Por esse motivo é importante levar em consideração esta advertência quando for necessário calcular os intervalos de manutenção preventiva. 
Figura 4-8 Curva de custos com respeito ao tempo para $\beta \geq 2$.

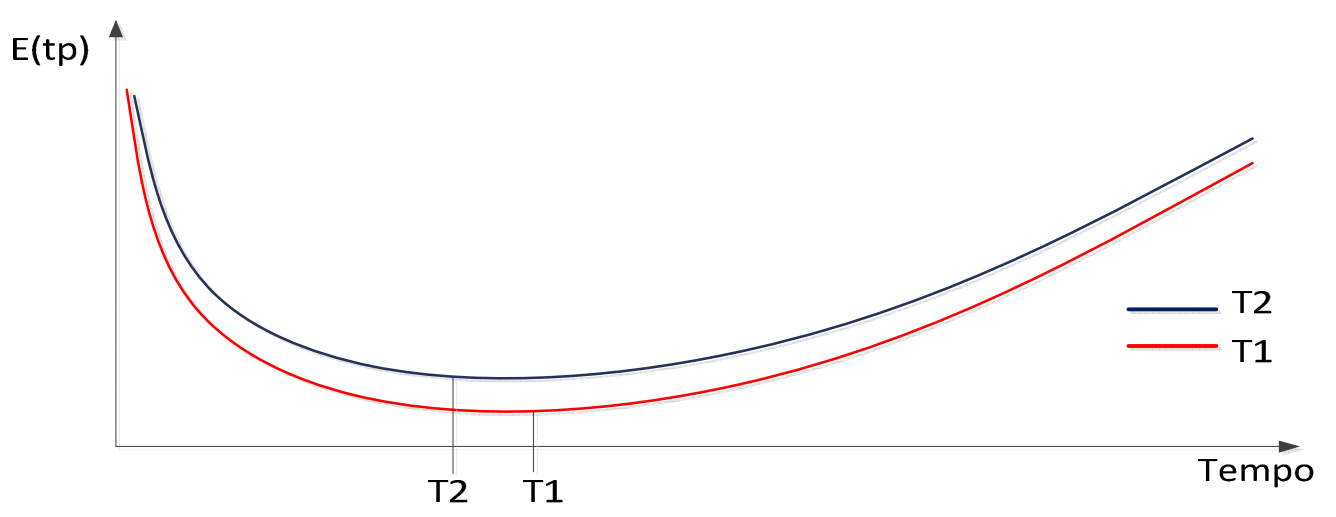

Fonte: Própria

\subsection{Análise comparativa entre os diversos artigos apresentados nas referências bibliográficas e o proposto neste trabalho.}

O método proposto foi dividido em três etapas: estudo e descrição operacional do sistema; aquisição do conhecimento para o diagnóstico de falhas; e aquisição do conhecimento para propor políticas de manutenção.

As duas primeiras etapas do método proposto se diferenciam dos outros trabalhos que foram elaborados visando 0 desenvolvimento de sistemas especialistas para o diagnóstico de falhas em diversas áreas da indústria. A revisão bibliográfica dos artigos que utilizaram as técnicas de confiabilidade e risco para a aquisição do conhecimento foi apresentada no item 3.5 do Capítulo 3. A revisão bibliográfica dos artigos que aplicaram teoria multicritério e manutenção imperfeita foi apresentada no item 2.6 do Capítulo 2.

$\mathrm{Na}$ terceira etapa do método proposto, realizou-se a comparação entre os artigos que aplicaram a teoria de manutenção imperfeita e a tomada de decisão com multicritério para estimar a periocidade da manutenção preventiva.

A Tabela 4.5 tem como objetivo identificar as diferenças entre os métodos apresentados pelos diversos autores citados nas referencias bibliográficas e o método proposto neste trabalho. 
Tabela 4.5 Comparação entre diversas aplicações de sistemas especialistas em diagnóstico de falhas

\begin{tabular}{|c|c|c|c|c|c|c|c|c|}
\hline \multirow[b]{2}{*}{ Autores } & \multicolumn{8}{|c|}{ Aquisição de conhecimento } \\
\hline & $\begin{array}{l}\text { Árvore } \\
\text { funcional }\end{array}$ & $\begin{array}{l}\text { Descrição } \\
\text { funcional }\end{array}$ & $\mathbf{A P P}$ & HAZOP & FTA & FMEA & $\begin{array}{l}\text { Manutenção } \\
\text { imperfeita }\end{array}$ & $\begin{array}{c}\text { Manutenção } \\
\text { e Multicritério }\end{array}$ \\
\hline Chan e Shaw (1993) & & & & & & & $\mathrm{x}$ & \\
\hline Kralj e Petrovic (1995) & & & & & & & & $\mathrm{x}$ \\
\hline Chareonsuk et al (1997) & & & & & & & & $\mathrm{x}$ \\
\hline Leone (1996) & & & $\mathrm{x}$ & $\mathrm{x}$ & & & & \\
\hline Khan e Abbasi (2000) & & & & $\mathrm{x}$ & & & & \\
\hline Venkatasubramanian et al (2000) & & & $\mathrm{x}$ & $\mathrm{x}$ & & & & \\
\hline Papadopoulos (2003) & & & & & $\mathrm{x}$ & & & \\
\hline Doyen e Gaudoin (2004) & & & & & & & $\mathrm{x}$ & \\
\hline Khan (2005) & & & & $\mathrm{x}$ & & & & \\
\hline Almeida (2005) & & & & & & & & $\mathrm{x}$ \\
\hline Calvacante e Almeida (2005) & & & & & & & & $\mathrm{x}$ \\
\hline Zhou et al (2007) & & & & & & & $\mathrm{x}$ & \\
\hline Calvacante e Almeida (2007) & & & & & & & & $\mathrm{x}$ \\
\hline Zhou et al (2009) & & & & & $\mathrm{x}$ & & & \\
\hline Rahman et al (2009) & & & & $\mathrm{x}$ & & & & \\
\hline Zhi-ling et al (2012) & & & & & $\mathrm{x}$ & & & \\
\hline Wang et al (2012) & & & & & $\mathrm{x}$ & & & \\
\hline Dun e Zhou (2012) & & & & & $\mathrm{x}$ & & & \\
\hline Almeida (2012) & & & & & & & & $\mathrm{x}$ \\
\hline Xia et al (2012) & & & & & & & $\mathrm{x}$ & \\
\hline Hidalgo (2014) & $\mathbf{x}$ & $\mathbf{x}$ & & $\mathbf{x}$ & $\mathbf{x}$ & $\mathbf{x}$ & $\mathbf{x}$ & $\mathbf{x}$ \\
\hline
\end{tabular}


$\mathrm{Na}$ Tabela 4.5, são analisados vinte e um artigos que utilizaram as técnicas de confiabilidade e risco para aquisição do conhecimento. Com a elaboração desta análise, pode-se concluir que:

- O ponto de partida do método proposto tem como base as técnicas da árvore funcional e da descrição funcional e, conforme a Tabela 4.5, os artigos analisados nesta tese não aplicam estas técnicas.

- A técnica HAZOP foi utilizada pelos autores Leone (1996), Khan e Abbasi (2000), Venkatasubramanian et al. (2000), Chan (2005), e Rahman et al. (2009). Os sistemas especialistas foram elaborados para monitorar as operações da planta com base nos parâmetros de entrada, detectar anomalias nos parâmetros e sugerir ações de diagnóstico ao operador. $O$ HAZOP permitiu identificar e avaliar os perigos relacionados com a segurança e a operabilidade.

- A técnica de Árvore de Falhas foi utilizada por Papadopoulos (2003), Zhou et al (2009), Zhi-ling et al (2012), Wang et al (2012) e Dun e Zhou (2012). Quando se realizou o levantamento bibliográfico dos artigos, observou-se que a técnica de FTA foi aplicada em conjunto com redes Bayesianas, redes neurais e lógica fuzzy, indicando que essa técnica está sendo utilizada atualmente em conjunto com técnicas de aprendizado de máquina.

- A técnica de Análise de Modos e Efeitos de Falhas, conforme a Tabela 4.5, não foi utilizada para aquisição de conhecimento em sistemas especialistas.

- Pode-se concluir que a integração das técnicas de confiabilidade e risco (HAZOP, FTA e FMEA) não foi aplicada por outros autores para aquisição do conhecimento.

- Os artigos que utilizam os conceitos de manutenção imperfeita são os de Chan e Shaw (1993), Zhou et al (2007) e Xia et al (2012). Os artigos que aplicam os conceitos da teoria de multicritério para determinar o tempo de 
intervenção em manutenção preventiva são os de Kralj e Petrovic (1995), Chareonsuk et al. (1997), Almeida (2005), Calvacante e Almeida (2005), Calvacante e Almeida (2007) e Almeida (2012). Como se pode observar, o método proposto para calcular a periocidade da manutenção preventiva é calculado de forma diferente porque integra os conceitos de manutenção imperfeita com a teoria de multicritério.

\subsection{Principais inovações e contribuições do método proposto}

As principais inovações do método proposto neste trabalho de Doutorado são:

- O método apresentado é diferente dos existentes na literatura pelo fato de integrar e aplicar as técnicas de análise de confiabilidade e risco para a aquisição do conhecimento na elaboração do sistema especialista. A integração das técnicas HAZOP, FTA e FMEA, conforme indicado na Figura 4.5, não foi aplicada em outros trabalhos.

- Com a aplicação da técnica de HAZOP, é possível selecionar os nós a serem analisados e identificar os possíveis desvios de parâmetros operacionais e consequências sobre a operação do sistema em cada um deles.

- A aplicação da técnica FTA permite modelar a ocorrência de eventos simultâneos para identificar as causas dos desvios analisados no HAZOP. O HAZOP tem a desvantagem de não conseguir visualizar eventos simultâneos. Se for aplicada a técnica de FTA em conjunto com a de HAZOP, é possível solucionar essa desvantagem.

- Com a aplicação da técnica FMEA, são fornecidos subsídios para a elaboração dos procedimentos de planejamento das ações de manutenções preventivas e preditiva aplicando os diagramas de decisão baseados em conceitos da Manutenção Centrada em Confiabilidade.

- O método para determinar a periocidade da manutenção preventiva considera a degradação do componente e também a aplicação da teoria 
de decisão com multicritério. Leva em consideração os critérios de confiabilidade e custo, tendo como objetivo maximizar a confiabilidade e reduzir os custos.

- O método proposto mostrou-se apropriado para o desenvolvimento de um sistema especialista voltado para o diagnóstico de desvios operacionais do processo, visando à detecção dos componentes cujas falhas podem causar estes desvios.

- O método proposto permite melhorar a comunicação entre o engenheiro de conhecimento e o especialista, proporcionando uma transferência eficiente do conhecimento para a base de conhecimento do sistema especialista. 


\section{ESTUDO DE CASO.}

Neste capítulo, será aplicado o método proposto no Capítulo 4 para a aquisição do conhecimento para a elaboração de um sistema especialista. O método será aplicado no regulador de velocidade da turbina Kaplan instalada em uma usina hidrelétrica com capacidade de geração de 120 MW localizada no estado de São Paulo.

\subsection{Aplicação do Método}

A aplicação segue as etapas do método proposto para aquisição do conhecimento, visando à elaboração de um sistema especialista para o diagnóstico de falhas em um regulador de velocidade. Conforme apresentado no Capítulo 4, a aquisição do conhecimento foi dividida em três etapas. A primeira etapa está relacionada com a obtenção do conhecimento relacionado ao funcionamento do regulador de velocidade por meio do estudo e descrição operacional do sistema. A segunda etapa apresenta o processo de aquisição do conhecimento para o diagnóstico de falhas. Finalmente, a terceira etapa propõe as recomendações de manutenção para os componentes do regulador de velocidade.

\subsubsection{Estudo e descrição operacional do sistema}

O regulador de velocidade da turbina Kaplan possui um sistema de regulação complexo, com dois sistemas de controle:

a) O primeiro controla o ângulo das pás do distribuidor através de um anel de pás ajustáveis que envolvem o rotor da turbina, e que permite alterar a velocidade de rotação da turbina com a modificação do ângulo das pás do distribuidor.

b) O segundo sistema de controle é um servomotor interno que está localizado no eixo da turbina e é responsável pela variação do ângulo das pás do rotor em sincronismo com a variação do ângulo das pás do distribuidor.

$\mathrm{Na}$ Figura 5.1, mostra-se o diagrama do regulador de velocidade da turbina Kaplan. O sistema é composto por seis sistemas principais: Sistema de 
pressurização de óleo, sistema de controle hidráulico, sistema de resfriamento, unidade de trabalho do distribuidor, unidade motora e unidade de trabalho para o rotor. A fim de entender o funcionamento do regulador de velocidade, foi realizada um estudo do manual de operação da máquina e a realização de entrevistas não estruturadas com os responsáveis pela manutenção e operação da máquina. No Anexo A apresenta-se a revisão bibliográfica utilizada para conhecer as funções executadas pelo regulador de velocidade dentro de uma usina hidrelétrica. 


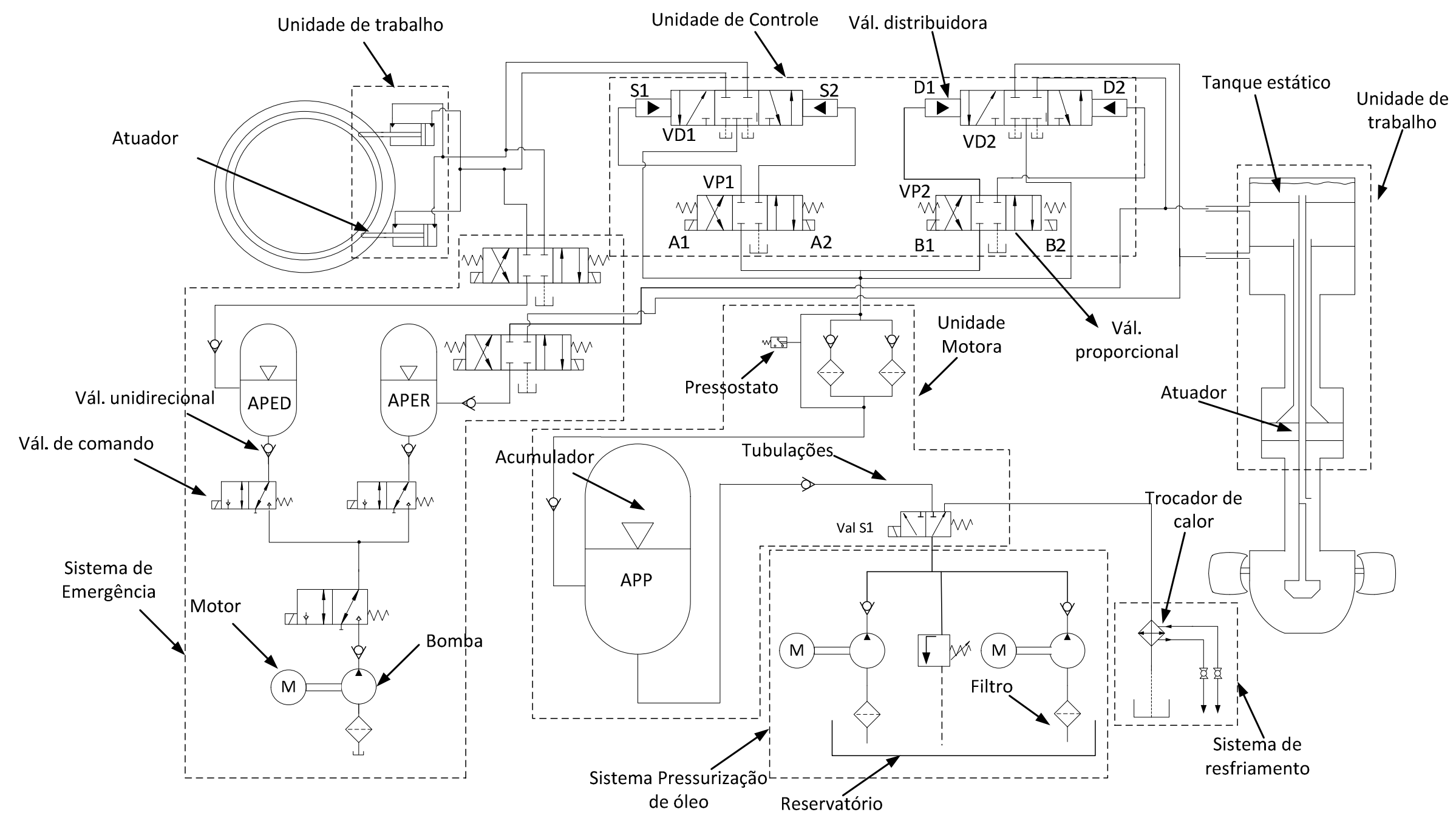

Figura 5-1 Diagrama do regulador de velocidade da turbina Kaplan 
O sistema de pressurização de óleo é composto por três sistemas: o sistema de pressurização de óleo principal, de reserva e de emergência. O sistema principal e o de reserva estão em paralelo, gerando assim uma maior confiabilidade do sistema. Para que o sistema falhe é necessário que ocorram falhas simultâneas nos dois sistemas de pressurização de óleo, principal e de reserva. O sistema de pressurização de emergência entra em funcionamento quando acontece falha simultânea nos dois sistemas de pressurização de óleo. O sistema de emergência só permite realizar a manobra de fechamento das pás do distribuidor e do rotor, ou seja, o desligamento seguro da máquina.

O sistema de pressurização de óleo principal, assim como o de reserva, é composto por duas bombas hidráulica, dois motores elétricos A.C., tubulações para o transporte do fluido, dois filtros, duas válvulas de alívio, duas válvulas unidirecionais e dois pressostatos.

Em regime normal de funcionamento, a bomba principal é a que abastece o sistema, porém, quando há uma queda brusca de pressão, a bomba de reserva é ligada, a fim de elevar a pressão de operação no sistema. Quando a pressão do sistema se normaliza, a bomba de reserva é desligada, mantendo em funcionamento somente a bomba principal.

A válvula de alívio é calibrada para trabalhar a uma pressão de 25 bar, ou seja, a pressão máxima de operação do circuito hidráulico. Esta válvula tem a função de não permitir sobre-pressão na linha do sistema. Esta só irá se abrir quando a pressão for superior a 25 bar, enviando assim o fluido em direção ao reservatório hidráulico.

A válvula unidirecional, também conhecida como antiretorno, fica localizada na linha da bomba e é utilizada para proteção das bombas contra o golpe de aríete.

O sistema de resfriamento é o responsável por manter a temperatura do óleo de acordo com as especificações do manual de operação. O sistema de resfriamento é composto por tubulações, trocador de calor, fluxímetro e sensor de temperatura. 
O regulador de velocidade é composto por três acumuladores: o acumulador de pressão principal (APP), o acumulador de pressão de emergência do distribuidor (APED) e o acumulador de pressão de emergência do rotor (APER).

O óleo sob pressão é fornecido pelo sistema de pressurização de óleo principal e pelo de reserva, sendo armazenado no acumulador de pressão principal (APP). Quando é necessário movimentar o ângulo das pás do distribuidor e do rotor, o acumulador de pressão principal fornecerá o óleo sob pressão para executar a tarefa.

Os acumuladores de pressão de emergência do distribuidor e rotor são abastecidos com óleo sob pressão pela bomba de emergência. Quando acontece uma falha nos sistema de pressurização de óleo principal e reserva e no acumulador de pressão principal (APP), o sistema de emergência será ligado e os acumuladores fornecerão óleo sob pressão para poder realizar o fechamento das pás do distribuidor e rotor.

A unidade de trabalho para o distribuidor e para o rotor é constituída pela válvula distribuidora (VD1), válvula distribuidora (VD2), válvula proporcional (VP1) e válvula proporcional (VP2). A razão de se utilizar uma válvula proporcional em conjunto com uma válvula distribuidora é a limitação da força que o solenóide é capaz de suportar quando este tipo de válvula está totalmente aberto. Para movimentar os atuadores dos reguladores de velocidade nas hidrelétricas, são necessárias grandes vazões. Um solenóide não é capaz de vencer as forças de escoamento do carretel que são causadas pelo escoamento nas câmaras das válvulas, razão pela qual é usada uma válvula proporcional pilotada por solenóide acoplada a uma válvula distribuidora.

No procedimento de abertura do distribuidor, a válvula proporcional (VP1) recebe um sinal elétrico de tensão ou corrente do sistema regulador de velocidade eletrônico no solenoide A1. Este transformará o sinal elétrico em deslocamento do carretel, e o fluido é enviado para o piloto hidráulico $S 1$ da válvula distribuidora (VD1). O carretel desta válvula se deslocará e permitirá a passagem de óleo, possibilitando a abertura do distribuidor. 
No procedimento de fechamento do distribuidor, a válvula proporcional (VP1) recebe um sinal elétrico de tensão ou corrente do sistema regulador de velocidade eletrônico no solenoide A2. Este transformará a sinal elétrico em deslocamento do carretel, e o fluido é enviado para o piloto hidráulico S2 da válvula distribuidora (VD1). O carretel desta válvula se deslocará e permitirá a passagem de óleo, possibilitando o fechamento do distribuidor.

No procedimento de abertura do rotor, a válvula proporcional (VP2) recebe um sinal elétrico (tensão ou corrente) do sistema regulador de velocidade eletrônico no solenoide B1. Este transformará o sinal elétrico em deslocamento do carretel, e o fluido é enviado para o piloto hidráulico D1 da válvula distribuidora (VD2). O carretel desta válvula se deslocará e permitirá a passagem de óleo, possibilitando a abertura do rotor.

No procedimento de fechamento do rotor, a válvula proporcional (VP2) recebe um sinal elétrico (tensão ou corrente) do sistema regulador de velocidade eletrônico no solenoide B2. Este transformará o sinal elétrico em deslocamento do carretel, e o fluido é enviado para o piloto hidráulico D2 da válvula distribuidora (VD2). O carretel desta válvula se deslocará e permitirá a passagem de óleo, possibilitando o fechamento do rotor.

A unidade de trabalho do distribuidor é constituída por dois atuadores. A válvula distribuidora (VD1) atua sobre os dois atuadores hidráulicos que estão interligados ao anel de regulação do distribuidor. Os atuadores são instalados um em cada lado do anel e as suas câmaras de acionamento estão interligadas de forma invertida, ou seja, enquanto um atuador avança, o outro atuador retorna.

A unidade de trabalho do rotor é apresentada na Figura 5.2, mostra-se um diagrama do mecanismo de regulação das pás móveis do rotor. Cada pá estendese através de um eixo, que penetra dentro do cubo, perpendicularmente ao eixo de rotação da turbina. Cada eixo da pá articula em dois pontos de apoio P1 e P2, sendo que a alavanca $L$ regula a orientação das pás que, por sua vez, é fixada ao eixo da roda.

As bielas $X$ localizadas na extremidade da alavanca $L$ estão ligadas ao 
eixo através de um suporte $E$, e todos são acionados por uma haste que passa pelo interior do eixo $A$, de modo que qualquer deslocamento axial desta haste provoca uma rotação simultânea de todas as pás.

Figura 5-2 Mecanismo de regulação das pás da turbina Kaplan.
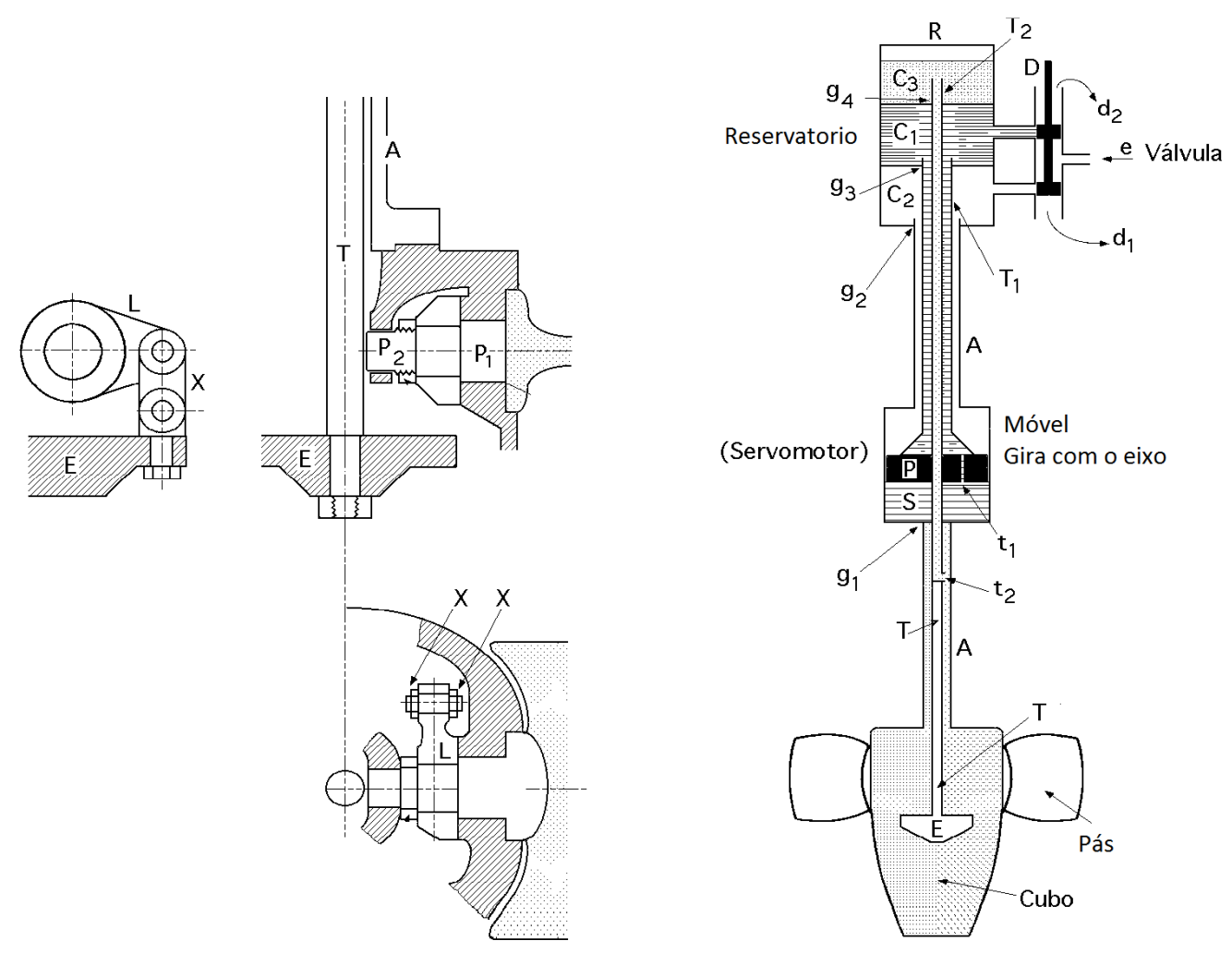

Fonte: Diez (1996).

A haste $T$ é acionada por um servomotor $S$ que gira em conjunto com o eixo $T$, acima deste está localizado um tanque estático $R$ (que pode ser observado na Figura 5.3 mais detalhadamente, que é geralmente instalado no topo do gerador), as câmaras $C 1$ e $C 2$ estão ligadas a uma válvula hidráulica $D$ de uma entrada e duas saídas. No interior do eixo $A$ se encontram dois tubos concêntricos $T 1$ e T2, por onde passa o óleo pressurizado. O tubo entre o eixo e $T 1$ permite a comunicação entre a câmara $C 1$ e a parte inferior do servomotor através do furo $t 1$ feito no pistão $P$, que age diretamente sobre a haste $T$ de regulação.

Por se tratar de peças rotativas, uma atenção especial deve ser dada para as vedações $g 2$, g3 e g4, a fim de prevenir o vazamento do óleo entre as várias câmaras que estão em pressões diferentes. Do mesmo modo, o conjunto formado pelo pistão $\mathrm{P}$, a haste $T$ e os tubos $T 1$ e $T 2$ se localizam dentro do eixo da turbina, 
sendo lubrificados pelo óleo. A vedação g1 evita a comunicação entre a parte interior do cubo da turbina e a parte inferior do pistão $P$ do servomotor.

Figura 5-3 - Tanque estático.

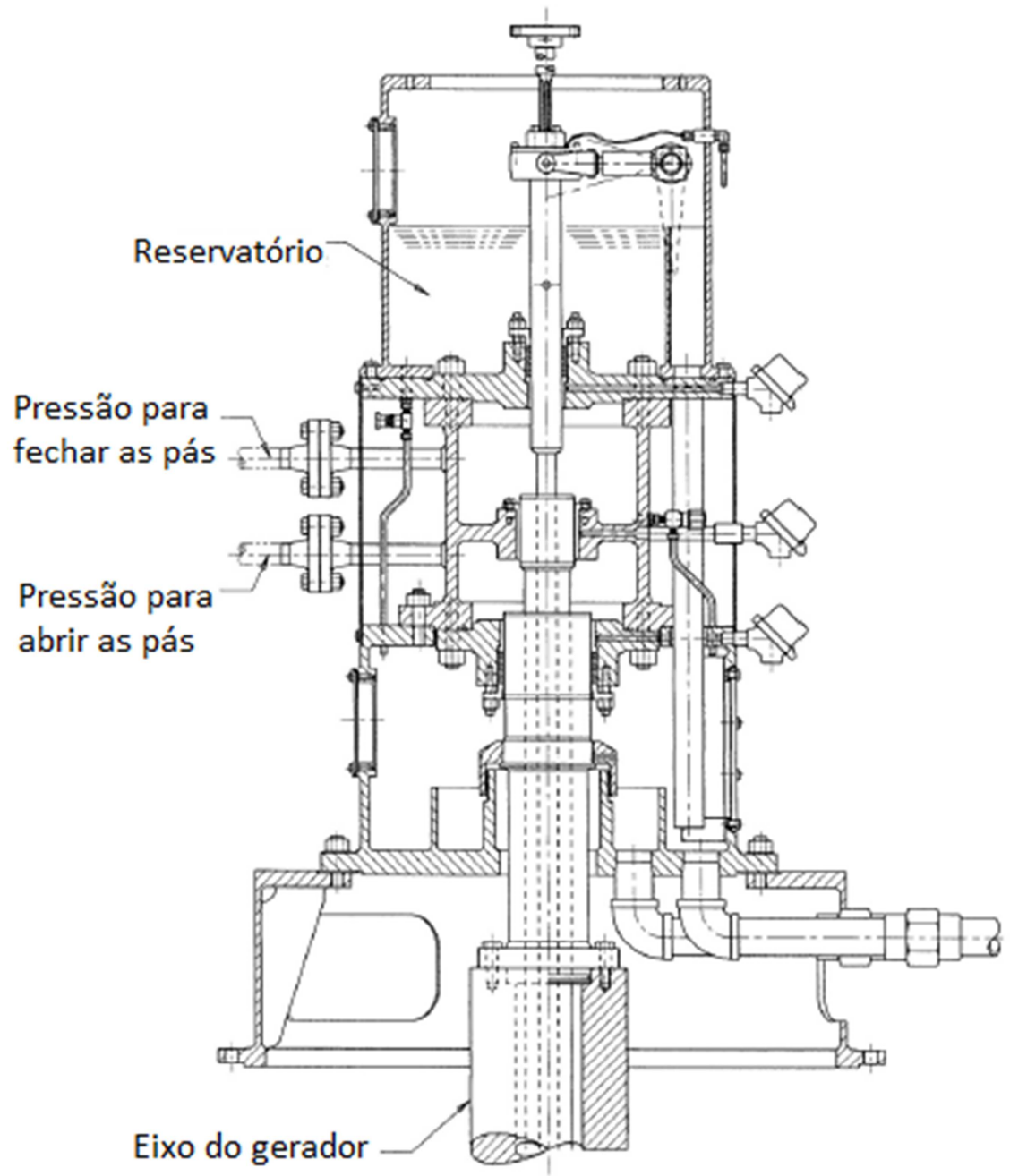

Fonte: Andia (2005).

Dependendo da posição do distribuidor de óleo $D$, é possível colocar uma das faces do pistão $P$ em comunicação com a alimentação do óleo com a pressão do tubo de entrada, enquanto o outro lado do pistão $P$ está com a pressão de descarga. O tubo T2 liga a parte superior do reservatório $R$ (câmara C3) ao interior do cubo da turbina, através de um furo $T 2$ feito na cruzeta do controle $T$ de orientação das pás. Esta câmara C3 está sob pressão atmosférica, contendo óleo a certo nível e desempenhando o papel de tanque de expansão do óleo contido no cubo. 
Esta câmara deve ser localizada a um nível tal que a pressão estática garanta a presença de óleo no cubo, sendo suficiente para evitar a entrada de água no interior do mesmo.

Uma vez definido o sistema a ser analisado, é necessário realizar a descrição operacional do sistema, que consiste na elaboração da árvore funcional, conforme a sequência apresentada na Figura 4.1 do Capítulo 4.

A elaboração da árvore funcional permite identificar os sistemas, os quais podem ser divididos em subsistemas, e assim subsequentemente possibilitando a sua decomposição em componentes que estão interligados por um vínculo funcional. Deve-se definir a função principal de cada subsistema e elaborar a árvore funcional correspondente, sendo necessário utilizar as descrições funcionais apresentadas no Apêndice A.

No caso do regulador de velocidade da turbina Kaplan, a árvore funcional é apresentada na Figura 5.4. Sua função mais relevante é: "acionar os mecanismos de controle de vazão por meio de atuadores hidráulicos, permitindo variar a vazão de água através do rotor da turbina conforme a demanda de energia elétrica e mantendo, deste modo, a rotação do eixo da turbina dentro de níveis admissíveis" (VINADE, 2003). Para executar esta função, o sistema precisa de seis subsistemas básicos: sistema de resfriamento, sistema de pressurização de óleo, unidade de controle, unidade de trabalho, sistema de emergência e unidade principal do regulador. A interação e o correto funcionamento destes seis subsistemas, faz com que $\circ$ regulador de velocidade consiga desempenhar sua função principal identificada. A falha de um destes subsistemas pode levar à parada do regulador de velocidade e, consequentemente, à interrupção da geração da energia elétrica, causando perdas econômicas à central hidrelétrica. 
Figura 5-4 Árvore funcional do regulador de velocidade da turbina Kaplan

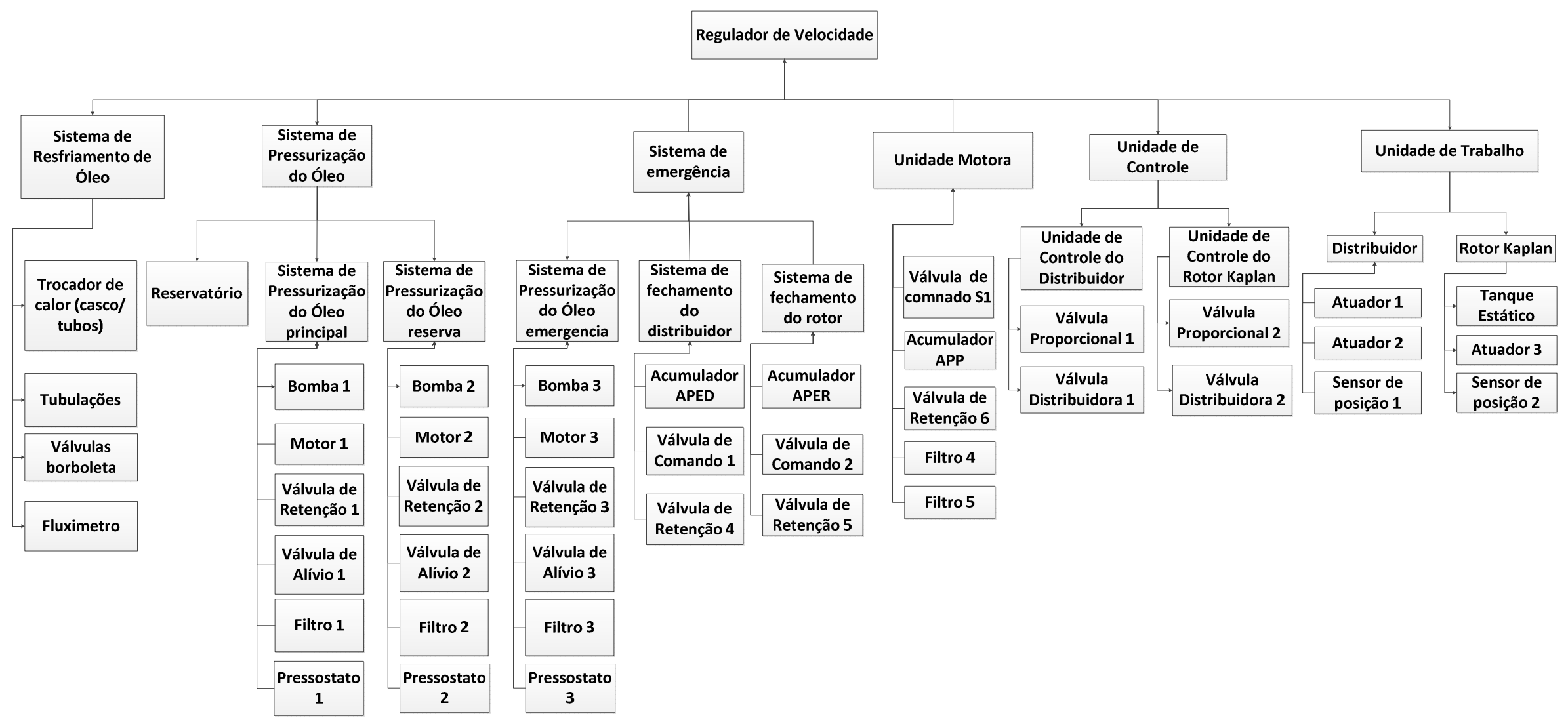


A elaboração da árvore funcional foi baseada no estudo das referências bibliográficas sobre reguladores de velocidades utilizados em usinas hidroelétricas e em estudos de sistemas hidráulicos. Dentre as bibliografias consultadas vale ressaltar Andia (2005), De Negri (2001), Mazzorana (2008), Paes e De Negri (2002), Reivax (2012), Yesid (2006) e Vinade (2003). Além disso, foi de grande valia a utilização dos manuais de operação da própria usina que, por motivos de confidencialidade, não poderão ser apresentados neste trabalho. As informações serviram de auxilio para identificar cada componente que constitui o regulador de velocidade e suas respectivas funções dentro do sistema.

Pode-se destacar que a elaboração da árvore funcional permite que a equipe de análise tenha uma visão funcional do regulador de velocidade.

Uma vez elaborado a árvore funcional é realizada a descrição funcional. A descrição funcional permite definir uma listagem das funções desempenhadas por cada sistema, subsistema e componentes dentro do regulador de velocidade.

\subsubsection{Aquisição do conhecimento para o diagnóstico de falhas.}

Conforme a Figura 4.2, a segunda etapa do método proposto é realizar a aquisição do conhecimento para o diagnóstico de falhas, baseia-se na aplicação da técnica de Estudo de Perigos e Operabilidade (HAZOP). O principal objetivo de aplicar a técnica HAZOP é investigar a fundo e de forma metódica cada segmento de um processo (focalizando os pontos específicos do projeto -nós- um de cada vez), visando descobrir todos os possíveis desvios das condições normais de operação, identificando as causas responsáveis por tais desvios e as respectivas consequências.

Para poder identificar os desvios operacionais, realizou-se um levantamento dos parâmetros de monitoração do regulador de velocidade, o qual permite identificar as faixas dos parâmetros de operação em condição normal. Esta informação foi obtida no manual de operação do hidrogerador e através de entrevistas com profissionais que participam na manutenção do regulador de velocidade e possuem a necessária experiência técnica de campo sobre as falhas deste sistema. 
No regulador de velocidade, os parâmetros operacionais medidos são: o nível de óleo no reservatório, a temperatura do óleo na saída do trocador de calor, a vazão da água de resfriamento, pressão nos acumuladores e na saída das bombas, nível de óleo nos acumuladores, e pressão na entrada e saída dos filtros.

Os níveis aceitáveis para os parâmetros monitorados são:

i. Nível de óleo no reservatório.

- 850 mm - Alarme de nível de óleo alto.

- $650 \mathrm{~mm}$ - Alarme de nível de óleo baixo.

- $450 \mathrm{~mm}$ - Alarme de nível de óleo muito baixo - Sinaliza ao operador e desliga as bombas.

ii. Temperatura do óleo na saída do trocador de calor.

- $>60^{\circ} \mathrm{C}$ - Alarme de temperatura alta.

- $>70{ }^{\circ} \mathrm{C}$ - Alarme de temperatura muito alta - sinaliza ao operador e desliga as bombas.

iii. Vazão de água de resfriamento.

- < 200 litros/min - Alarme de baixa vazão de água.

iv. Pressão no acumulador principal (APP), no acumulador de emergência do distribuidor (APED) e no acumulador de emergência do rotor (APER).

- 26 bar - Alarme de pressão muito alta no acumulador.

- 25 bar - Pressão normal do acumulador

- 22 bar - Alarme de pressão baixa no acumulador (ligar a bomba de reserva)

- 20 bar - Alarme de pressão de óleo muito baixa no acumulador (desligamento da máquina com o emprego dos acumuladores de emergência) 
v. Nível de óleo no acumulador principal (APP), no acumulador de emergência do distribuidor (APED) e no acumulador de emergência do rotor (APER).

- 1950 mm - Alarme de nível de óleo muito alto no acumulador.

- $1800 \mathrm{~mm}$ - Alarme de nível de óleo alto no acumulador (ligar a reposição automática de ar comprimido).

- $1500 \mathrm{~mm}$ - Alarme de nível de óleo baixo no acumulador.

- 570 mm - Alarme de nível de óleo muito baixo no acumulador (fechamento da máquina através dos acumuladores de emergência)

vi. Pressão na entrada e saída dos filtros para identificar a presença de sujeira no filtro. O filtro é dotado de um pressostato, de forma que quando a pressão diferencial atingir 5 bar, o pressostato envia um sinal de alarme de filtro sujo.

Como resultado deste processo da análise dos parâmetros monitorados, foram identificados onze pontos ou nós de referência, como é apresentado na Figura 5.5, e os parâmetros e os desvios associados com as palavras guia são apresentados na Tabela 5.1. Como pode ser observado na Tabela 5.1, as consequências dos desvios são: parada do regulador de velocidade, possível parada do regulador de velocidade, movimentação lenta dos atuadores, perda da precisão do posicionamento dos atuadores e temperatura elevada do óleo. Nos nós 4,5,6, qualquer desvio leva à parada do regulador de velocidade. Isso ocorre porque o regulador de velocidade não pode operar se algum componente do sistema de emergência estiver em estado de falha.

Para cada desvio identificado em cada um dos nós, as causas para os eventos são investigadas através da técnica de Árvores de Falhas. 
Figura 5-5 Diagrama do regulador de velocidade da turbina Kaplan com os nós a serem analisados.

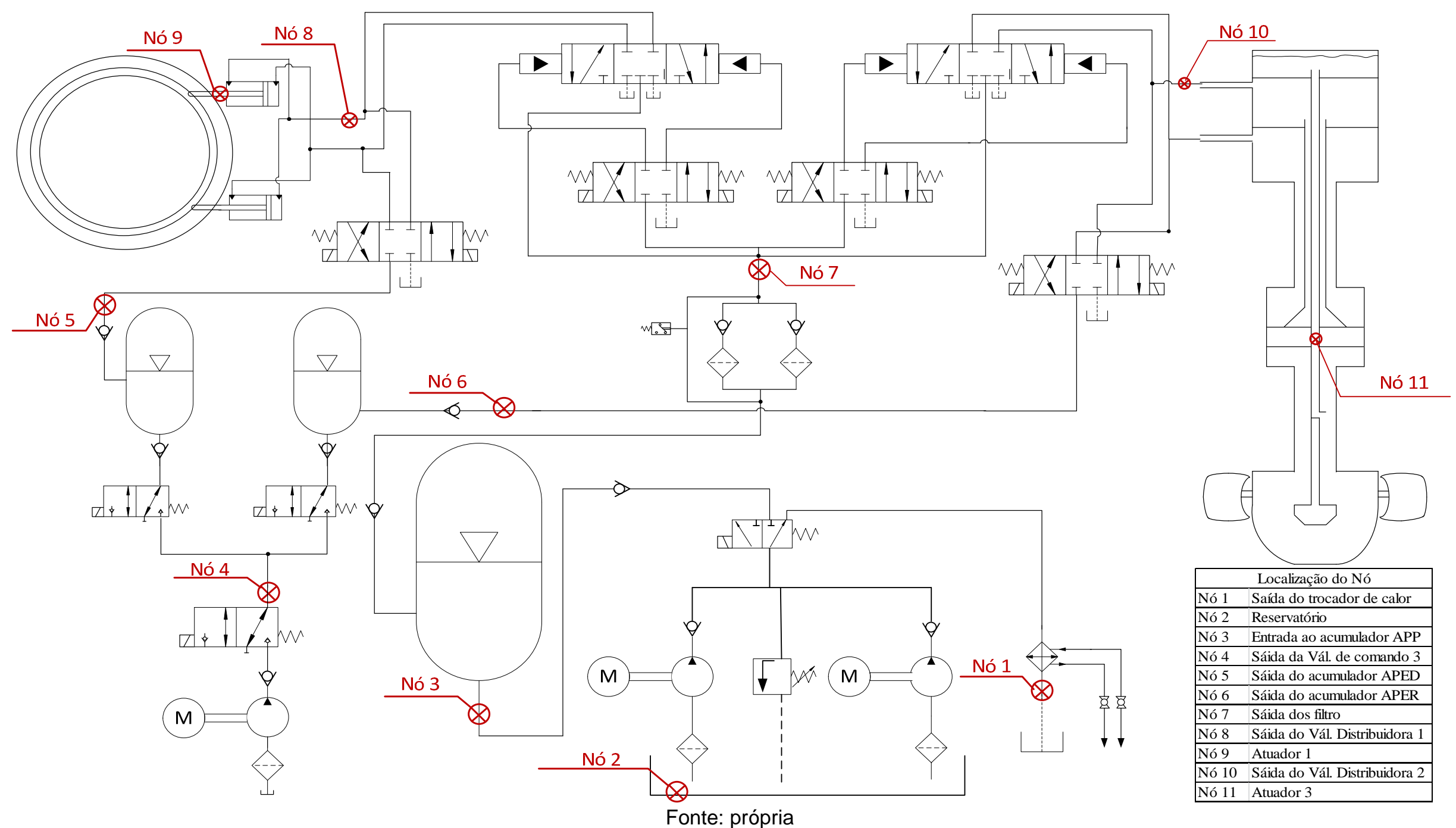


Tabela 5.1 Nós de Referência, Parâmetros, Palavras Guia, Desvios e Consequências - Análise HAZOP

\begin{tabular}{|c|c|c|c|c|}
\hline Nó & Parâmetro & Palavra guia & Desvio & Consequência \\
\hline \multirow{3}{*}{1} & \multirow{3}{*}{ Temperatura } & \multirow{3}{*}{ Mais } & \multirow{3}{*}{ Temperatura alta } & Diminui a viscosidade do óleo \\
\hline & & & & Incremento de vazamentos internos \\
\hline & & & & Possível parada do regulador de velocidade \\
\hline \multirow{3}{*}{2} & \multirow{3}{*}{ Nível } & Nenhum & Não há nível & Indisponibilidade do regulador de velocidade \\
\hline & & \multirow{2}{*}{ Menos } & \multirow{2}{*}{ Nível baixo } & Possível parada do regulador de velocidade \\
\hline & & & & Temperatura elevada do óleo \\
\hline \multirow{8}{*}{3} & \multirow{3}{*}{ Vazão } & Nenhum & Nenhuma vazão & Indisponibilidade do regulador de velocidade \\
\hline & & \multirow{2}{*}{ Menos } & \multirow{2}{*}{ Vazão baixa } & Possível parada do regulador de velocidade \\
\hline & & & & Movimentação lenta dos atuadores \\
\hline & \multirow{5}{*}{ Pressão } & \multirow{3}{*}{ Menos } & \multirow{3}{*}{ Pressão baixa } & Possível parada do regulador de velocidade \\
\hline & & & & Movimentação lenta dos atuadores \\
\hline & & & & Pressão insuficiente no acumulador APP \\
\hline & & \multirow{2}{*}{ Mais } & \multirow{2}{*}{ Pressão alta } & Possível parada do regulador de velocidade \\
\hline & & & & Temperatura elevada do óleo \\
\hline \multirow{4}{*}{$4,5,6$} & \multirow{2}{*}{ Vazão } & Nenhum & Nenhuma vazão & Indisponibilidade do regulador de velocidade \\
\hline & & Menos & Vazão baixa & Indisponibilidade do regulador de velocidade \\
\hline & \multirow{2}{*}{ Pressão } & Menos & Pressão baixa & Indisponibilidade do regulador de velocidade \\
\hline & & Mais & Pressão alta & Indisponibilidade do regulador de velocidade \\
\hline \multirow{8}{*}{$7,8,10$} & \multirow{3}{*}{ Vazão } & Nenhum & Nenhuma vazão & Indisponibilidade do regulador de velocidade \\
\hline & & Menes & Vดา̃̃ hoix & Possível parada do regulador de velocidade \\
\hline & & ivenos & vazau dalxa & Movimentação lenta dos atuadores \\
\hline & & & & Possível parada do regulador de velocidade \\
\hline & & Menos & Pressão baixa & Movimentação lenta dos atuadores \\
\hline & Pressão & & & pressão insuficiente no acumulador APP \\
\hline & & Mais & Prescão alta & Possível parada do regulador de velocidade \\
\hline & & IVtals & riessau alla & Temperatura elevada do óleo \\
\hline & & Nenhum & Nenhuma vazão & Indisponibilidade do regulador de velocidade \\
\hline & Vazão & Menos & Vazão haixa & Possível parada do regulador de velocidade \\
\hline & & inenos & vazao oalxa & Movimentação lenta dos atuadores \\
\hline & & & & Possível parada do regulador de velocidade \\
\hline & & Menos & Pressão baixa & Movimentação lenta dos atuadores \\
\hline 9 & Pressão & & & Pressão insuficiente no acumulador APP \\
\hline & & Mais & Precsão alta & Possível parada do regulador de velocidade \\
\hline & & IVIads & Pressao a alla & Temperatura elevada do óleo \\
\hline & & & & Possível parada do regulador de velocidade \\
\hline & Precisão & Nenhum & Não há precisão & Perda da precisão no posicionamento nos \\
\hline & & & & atuadores do distribuidor \\
\hline & & Nenhum & Nenhuma vazão & Indisponibilidade do regulador de velocidade \\
\hline & Vazão & Menos & Vazão haixa & Possível parada do regulador de velocidade \\
\hline & & IVIEIIOS & vazao baixa & Movimentação lenta dos atuadores \\
\hline & & & & Possível parada do regulador de velocidade \\
\hline & & Menos & Pressão baixa & Movimentação lenta dos atuadores \\
\hline 11 & Pressão & & & Pressão insuficiente no acumulador APP \\
\hline & & Mais & Precsão alta & Possível parada do regulador de velocidade \\
\hline & & Nials & Pressao alta & Temperatura elevada do óleo \\
\hline & & & & Possível parada do regulador de velocidade \\
\hline & Precisão & Nenhum & Não há precisão & Perda da precisão no posicionamento nos \\
\hline & & & & atuadores do rotor \\
\hline
\end{tabular}


Como exemplo da aplicação, pode-se observar na Figura 5.6 a aplicação das técnicas de HAZOP e FTA para o nó 3 . Neste nó se identificaram dois parâmetros, "vazão e pressão", as palavras guias para o parâmetro de vazão foram "nenhuma e baixa", e para o parâmetro pressão as palavras guias foram "baixo e alta", como pode se observar na Tabela 5.1. Os desvios identificados para o nó 3 são: nenhuma vazão, vazão baixa, pressão baixa e pressão alta, de acordo com a Tabela 5.1. Como consequência do desvio, o regulador de velocidade ficaria indisponível, causando perdas econômicas e matérias.

Figura 5-6 Aplicação das técnicas HAZOP e FTA para o nó 3

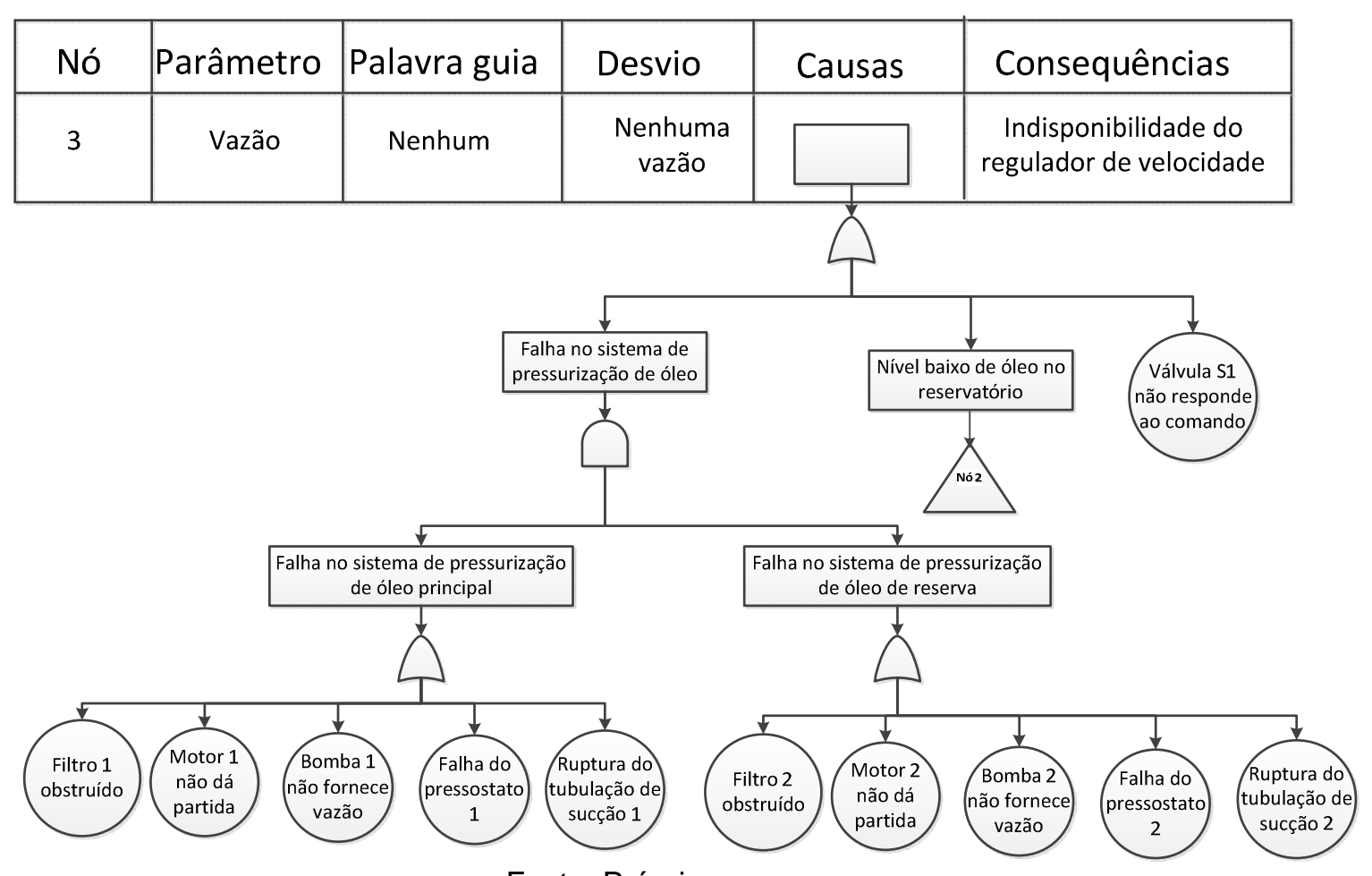

Fonte: Própria

As causas do desvio foram analisadas através da técnica do FTA, que pode ser observada na Figura 5.6. No exemplo, o evento topo é: "nenhuma vazão", que é causada por dois eventos básicos como: baixo nível de óleo no reservatório e válvula S1 não responde ao comando; bem como for um evento intermediário: falha no sistema de pressurização de óleo. Para combinações destes eventos, é utilizada a porta lógica "OU", que significa que a ocorrência de qualquer destes eventos 
mencionados leva ao evento topo. A aplicação das técnicas do HAZOP e FTA para todos os nós é mostrada no Apêndice $B$.

Para o evento intermediário "falha no sistema de pressurização do óleo" que é causado pelas falhas no sistema de pressurização do óleo principal e de reserva. Tais eventos são combinados por uma porta lógica "E", que significa que tem que acontecer a falha simultânea destes sistemas. Para que aconteça uma falha no sistema de pressurização de óleo principal, é preciso ocorrer qualquer um dos eventos básicos como: filtro 1 obstruído, motor elétrico 1 não dá partida, bomba 1 não fornece vazão e falha do pressostato 1. Tais eventos são combinados por uma porta lógica "OU". Para que aconteça uma falha no sistema de pressurização do óleo de reserva tem que ocorrer qualquer dos eventos básicos como: filtro 2 obstruído, motor elétrico 2 não dá partida, bomba 2 não fornece vazão e falha do pressostato 2. Tais eventos são combinados por uma porta lógica "OU".

Uma vez identificados os eventos básicos que levam a ocorrência do desvio, como por exemplo, do nó 2 com o desvio "não tem vazão", tem-se que o evento básico corresponde ao modo de falha de um componente, por essa razão a técnica do FMEA é aplicada para identificar a causa das falhas ou o desvio que levou a ocorrência do modo de falha.

O levantamento das causas da falha é realizado por meio da coleta de informação das referencias bibliográficas, dentro as quais podem se ressaltar as seguintes:

- Manuais técnicos: Parker (1999), Vickers (2013), Applied (2014), Vickers (2014) e Monarch (2014);

- Manuais de manutenção: Ferreiros CAT (2004) e manual de manutenção da hidrelétrica;

- Artigos: Bagnoli (2009), Bonaldi (2008), Frith e Scott (1992), Hugueros (2002), Park (2002), Vinade et al (2001), Zanini (2007);

- Livros: Drapinski (1975), Linsingen (2008); Mobley (2000), Parr (1999), Ravi e Andries (2005). 
Da bibiografia citada, vale apena ressaltar Applied (2014), Ferreiros (2004) e Drapinski (1975), que indicaram as causas de falha de componentes hidráulicos, e os sintomas que estes apresentam em função do desenvolvimento da falha. Parr (1999), Ravi e Andries (2005), e Monarch (2014) possuem capítulos dedicados a troubleshooting em sistemas hidráulicos e sugestões sobre possíveis intervenções nos componentes hidráulicos. Vinade (2003) indica as causas e efeitos dos modos de falhas em sistemas hidráulicos. Frith e Scott (1992) discutiram como a contaminação do óleo hidráulico afeta o desempenho de sistemas hidráulicos.

A técnica do FMEA permitiu gerar um critério para a seleção de políticas de manutenção. Em função de terem sido identificadas as possíveis causas da falha, pode-se preparar recomendações de manutenção que visem reduzir ou mitigar as ocorrências dos modos de falha. No caso de se indicar a realização da manutenção preventiva calcula-se a periocidade.

Como exemplo da aplicação da técnica de Análise de Modos e Efeitos de Falhas utiliza-se o Motor elétrico A.C, considerando o modo de falha "motor elétrico não dá partida", apresentada na Tabela 5.2. A parte complementar das análises FMEA, é indicada no Apêndice $C$.

Tabela 5.2 Aplicação da Análise de Modo e Efeito de Falha para o Motor elétrico AC.

\begin{tabular}{|c|c|c|c|}
\hline \multicolumn{4}{|c|}{ Análise de Modo e Efeito de Falha - FMEA } \\
\hline Componente & Função & $\begin{array}{c}\text { Modo de falha } \\
\text { potencial }\end{array}$ & Causa(s) da falha \\
\hline \multirow{7}{*}{ Motor AC } & & & Disjuntor aberto \\
\hline & Transformar & & Perda do isolamento da bobinas \\
\hline & energia elétrica & Não dá & Sobreaquecimento no motor \\
\hline & em energia & partida & Travamento do eixo do motor \\
\hline & mecânica para & & Ventilação inadequada \\
\hline & o acionamento & & Baixa ou incorreta tensão de alimentação \\
\hline & da bomba & & \\
\hline
\end{tabular}

\subsubsection{Aquisição do conhecimento para seleção das políticas de manutenção.}

Para selecionar as políticas de manutenção mais apropriadas para os modos de falhas identificados foram utilizados os diagramas propostos pela filosofia de 
Manutenção Centrada em Confiabilidade (MOUBRAY, 2000). Para aplicar o diagrama de decisão é preciso realizar a classificação das falhas dos componentes em função das consequências destas sobre o desempenho operacional do sistema. Sob o ponto de vista da tomada de decisão em manutenção, as falhas podem ser funcionais ou potenciais. A falha funcional é definida como a incapacidade de um elemento ou componente de um equipamento satisfazer um funcionamento padrão desejado. A falha potencial é representada pela presença de uma evidência física de que um processo de deterioração de um componente está acontecendo, o qual culminará como uma falha funcional.

Para a elaboração das políticas de manutenção foram tomadas como referências manuais de operação e manutenção, assim como livros de sistemas hidráulicos. Os manuais de operação e manutenção incluem todas as características, informações e desenhos dos componentes. Os manuais incluem a descrição de procedimentos recomendados de operação e manutenção.

Uma vida longa do equipamento hidráulico é conseguida, inicialmente, através de condições de limpeza e lubrificação adequadas e posteriormente com inspeções e ajustes periódicos, eliminando-se desalinhamentos e folgas (DRAPINSKI, 1975).

Um exemplo da aplicação das políticas de manutenção é indicado na Tabela 5.3, tomando como exemplo de aplicação o motor elétrico. A parte complementar das políticas de manutenção, é indicada no Apêndice $D$.

Tabela 5.3 Políticas de manutenção para o Motor elétrico A.C.

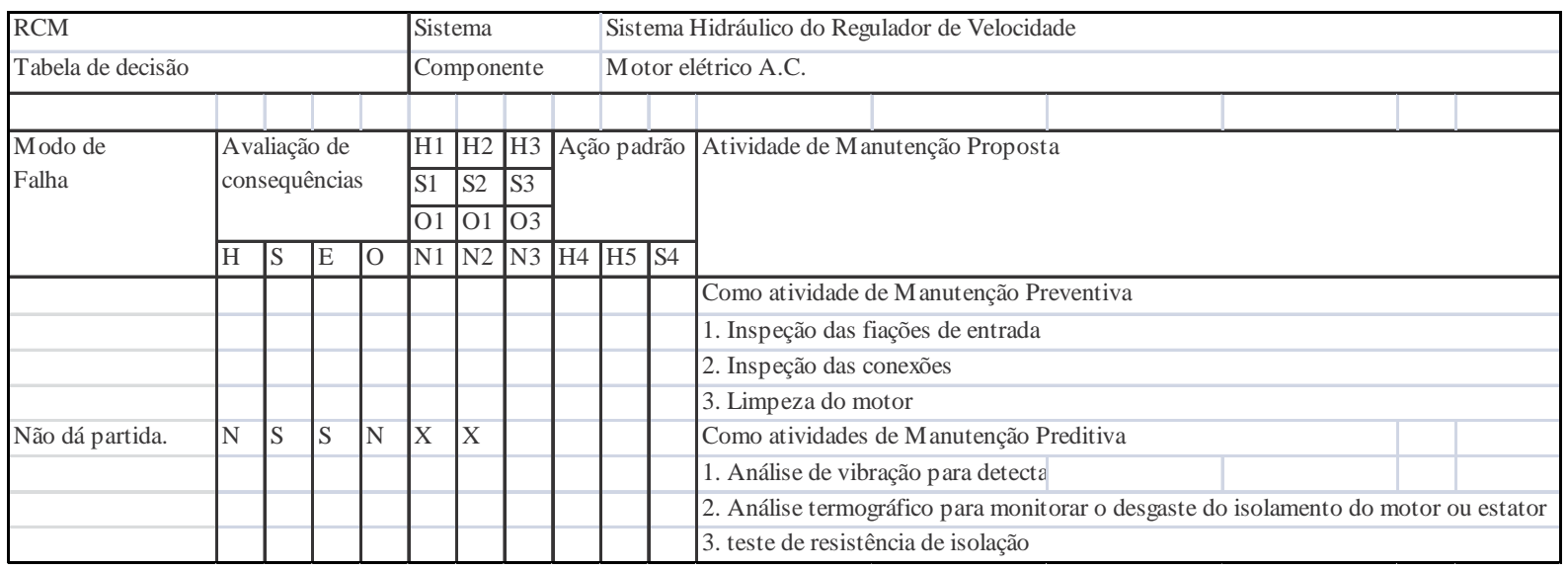


Os sintomas de indicação do desenvolvimento de falhas em componentes hidráulicos estão relacionados com a temperatura excessiva, vazamento, vibração e ruído. Caso seja possível perceber estes efeitos em um componente, há grandes chances de ter encontrando a origem do mau funcionamento do equipamento. Se o mau funcionamento não ocorre, os efeitos de aviso podem ajudar a preveni-los através de ajustes, reparos ou substituição do componente, (VINADE, 2001).

Segundo Jingyi (2006) cerca de $50 \%$ dos problemas encontrados nos sistemas hidráulicos estão relacionados com o óleo hidráulico. Dessa forma, controlando ou eliminando os modos de falhas do óleo hidráulico, pode se evitar um número maior de efeitos indesejáveis no regulador de velocidade.

Os manuais de manutenção recomendam uma realização periódica da análise do óleo. Os testes podem ser realizados para determinar a viscosidade, a contaminação por partículas metálicas e a presença de água no óleo. Seus resultados permitirão que a equipe de manutenção possa identificar a qualidade e 0 estado do fluido hidráulico. A presença de partículas metálicas no fluido pode ser utilizada como indicador da perda de material identificando que algum componente pode estar sofrendo desgaste.

A falha do motor elétrico pode ser associada a falhas mecânicos e/ou elétricas. As principais falhas mecânicas são: falhas de rolamentos e desgaste do isolamento do rotor e estator. A sua manutenção pode ser baseada na substituição ou inspeção programada. A análise termográfica pode ser aplicada para monitorar o envelhecimento do isolamento. No motor elétrico, o padrão de análise da vibração do eixo pode ser utilizado como uma indicação de falha potencial do rolamento.

A falha da bomba pode ser associada ao desgaste que pode causar desbalanceamento e consequentemente vibração do eixo. A utilização de acelerômetros como transdutores de vibração permite 0 uso da monitoração baseada na condição da bomba. Além disso, a análise de ultrassom pode ser aplicada para a detecção de cavitação na bomba.

Recomenda-se o uso da técnica de inspeção termográfica com o objetivo de verificar a temperatura do componente para identificar vazamentos internos em 
válvulas e atuadores hidráulicos. O desgaste da vedação pode ser associado à presença de partículas no óleo hidráulico, causando vazamentos internos ou externos nas válvulas e atuadores.

A falha nas válvulas unidirecional e de alívio podem estar associadas tanto ao desgaste e degradação por fadiga da mola. $O$ uso de inspeção preventiva e substituição programada podem reduzir a frequência de ocorrência de falha.

As falhas nos pressostatos, nos fluxômetros, no medidor diferencial e nos solenoides das válvulas proporcionais, podem estar associadas ao desgaste dos componentes mecânicos e falha do sistema elétrico, recomenda-se realizar a substituição do componente.

Outros elementos importantes no sistema hidráulico são os filtros. O estado da maioria dos filtros é mostrado pela diferença de pressão observada entre a entrada e a saída, a qual indica possível bloqueio dos mesmos. Os filtros devem ser trocados antes que sejam bloqueados ou que ocorra a ruptura do elemento filtrante. A evolução temporal dessa pressão diferencial é um indicativo da ocorrência de depósitos no filtro, podendo ser utilizada como um parâmetro para a aplicação da prática de manutenção preditiva.

\subsubsection{Periocidade da manutenção preventiva}

Uma vez identificadas às políticas de manutenção para cada um dos elementos do sistema hidráulico, são propostas os tempos de intervenção para execução da manutenção preventiva conforme o fluxograma apresentado na Figura 4.6.

Para calcular a periocidade de manutenção preventiva, é importante realizar o levantamento dos parâmetros da distribuição de confiabilidade dos componentes do regulador de velocidade.

Como base de dados foi utilizada a norma Non Electronic Parts Reliability Data (NPRD-95). A distribuição utilizada pela norma para modelar as taxas de falhas dos componentes é a da distribuição Exponencial. A mesma nos fornece informações 
que permitem calcular os parâmetros da distribuição de Weibull a partir do conhecimento do valor de $\beta$, possibilitando estimar o valor de $\eta$ de acordo com cálculos estabelecidos na norma (RAC, 1995).

Como exemplo, é calculada a constante de escala $\eta$ a partir do valor da constante de forma $\beta$ da distribuição de Weibull do atuador hidráulico. $O$ valor de $\beta$ para o atuador é 2 (BLOCH e GEITNER, 2010). Segundo a Norma NPRD-95 podese observar na página 3-3 o Acumulador hidráulico, Unk, DOR 13253-000, No Details, Pop: 11, para o qual lista-se 8 falhas em 0,9636 milhão de partes - operando horas, como apresentado na Figura 5.7.

Figura 5-7 Base de dados da Norma NPDR-95

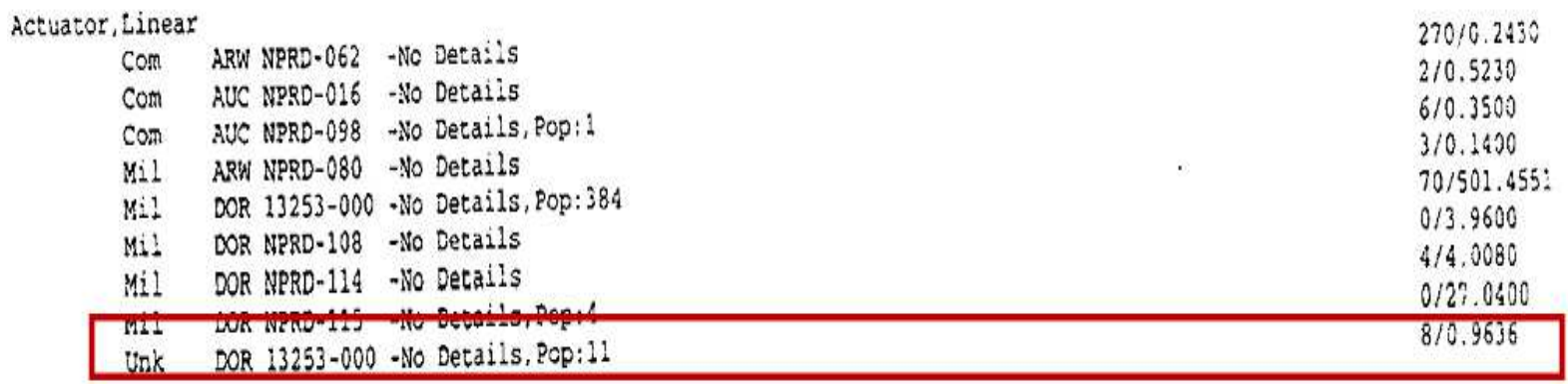

Fonte: NPRD-95 (1995)

Estes dados podem ser convertidos para uma constante de escala $\eta$ da seguinte maneira:

a) Determinar a porcentagem de falha:

$$
\% \text { Falha }=\frac{8}{11}=72,73 \%
$$

b) Converter a porcentagem de falha para relação $t / \propto$ em $t / \eta$ utilizando a Tabela 5.4. Para ingressar na tabela é necessário saber a porcentagem de falha é igual a $72,73 \%$ e a constante de forma $\beta=2$. 
Tabela 5.4 Porcentagem de falha para distribuição de Weibull

\begin{tabular}{|c|c|c|c|c|c|c|}
\hline \multirow[b]{2}{*}{$(t / \alpha)$} & \multicolumn{6}{|c|}{$\beta$} \\
\hline & 1 & 2 & 3 & 4 & 5 & 6 \\
\hline .1 & 10 & 4.1 & 1.3 & .2 & 0 & 0 \\
\hline .2 & 20 & 8.6 & 3.0 & 1.0 & .2 & 0 \\
\hline .3 & 30 & 15 & 6.8 & 3.1 & 1.0 & .7 \\
\hline .4 & 40 & 23 & 13 & 8.1 & 3.7 & 1.7 \\
\hline .5 & 50 & 31 & 20 & 13 & 8.3 & 5.0 \\
\hline .6 & 60 & 41 & 31 & 21 & 15 & 12 \\
\hline 7 & 70 & 52 & 42 & 32 & 27 & 26 \\
\hline .8 & 80 & 62 & 55 & 47 & 29 & 42 \\
\hline 9 & 90 & 75 & 68 & 64 & 47 & 64 \\
\hline 1.0 & 100 & 88 & 82 & 80 & 65 & 85 \\
\hline 1.1 & 110 & 99 & 96 & 93 & 79 & 98 \\
\hline 1.2 & 120 & 109 & 107 & 105 & 87 & 103 \\
\hline 1.3 & 130 & 121 & 117 & 111 & 92 & 106 \\
\hline 1.4 & 140 & 133 & 128 & 119 & 97 & 111 \\
\hline 1.5 & 150 & 145 & 139 & 126 & 105 & 119 \\
\hline 1.6 & 160 & 155 & 149 & 136 & 116 & 129 \\
\hline 1.7 & 170 & 169 & 160 & 148 & 130 & 144 \\
\hline 1.8 & 180 & 180 & 171 & 161 & 145 & 161 \\
\hline 1.9 & 190 & 190 & 192 & 175 & 159 & 176 \\
\hline 2.0 & 200 & 202 & 195 & 189 & 171 & 191 \\
\hline$>2.0$ & \multicolumn{6}{|c|}{ for $(t / \alpha)>2, \%$ failure $=100(t / \alpha)$} \\
\hline
\end{tabular}

$$
\frac{t}{\propto} \cong 0,88
$$

c) Calcular a quantidade de horas operando por partes

$$
\frac{\text { Partes }- \text { horas }}{\text { população }}=\frac{0,9636}{11}=0,0876 \text { milhão horas }
$$

d) Calcular $\eta$

$$
\eta=\frac{\frac{\text { Partes }- \text { horas }}{\text { população }}}{\frac{t}{\alpha}}=\frac{0,0876}{0,88}=0,099261 \text { milhão horas }=99261 \text { horas }
$$

$\mathrm{Na}$ Tabela 5.5 pode-se observar os parâmetros da distribuição de Weibull para os principais componentes do regulador de velocidade, os quais são utilizados para estimar a periocidade da manutenção preventiva. 
Tabela 5.5 Componentes com suas respectivas taxas de falha

\begin{tabular}{|l|c|c|}
\hline \multirow{2}{*}{ Componente } & \multicolumn{2}{|c|}{$\begin{array}{c}\text { Parâmetros da Distribuição de. } \\
\text { Weibull }\end{array}$} \\
\cline { 2 - 3 } & $\beta$ & $\eta$ (horas) \\
\hline Acumulador & 2 & 221430 \\
\hline Bomba & 2.2 & 51389 \\
\hline Atuador & 2 & 99261 \\
\hline Motor & 3 & 101750 \\
\hline Trocador de calor & 3 & 19095 \\
\hline
\end{tabular}

$\mathrm{Na}$ Tabela 5.6 são apresentados os valores de entrada dos parâmetros de distribuição de Weibull para Motor Elétrico. Os valores de custos considerados neste estudo de caso variam conforme 0 valor de $K$ que corresponde à relação entre 0 custo da manutenção corretiva $C_{f}$ e o custo da manutenção preventiva $C p$, para os quais executa se uma análise de sensibilidade de resultados dos tempos de manutenção.

Tabela 5.6- Dados de entrada

\begin{tabular}{|l|l|l|}
\hline Confiabilidade & $\beta$ & 3 \\
\hline \multirow{2}{*}{ Custos } & $\eta$ & 101750 horas \\
\hline & $\mathrm{K}_{=} \mathrm{C}_{f} / \mathrm{C}_{p}$ & $5,10,15$ \\
\cline { 2 - 3 } & $\mathrm{C}_{p}$ & 3000 \\
\hline
\end{tabular}

Nas Tabelas 5.7, 5.8, 5.9, 5.10 e 5.11 são apresentadas as alternativas de intervalos de manutenção expressas em horas, consideradas no modelo para o motor, atuador, bomba, trocador de calor e acumulador respectivamente.

Tabela 5.7 Alternativas dos intervalos de intervenção (Ti) para fazer a manutenção preventiva do motor

\begin{tabular}{|c|c|c|c|c|c|}
\hline Alternativas & $\begin{array}{c}\text { Tempo } \\
\text { (horas) }\end{array}$ & Alternativas & $\begin{array}{c}\text { Tempo } \\
\text { (horas) }\end{array}$ & Alternativas & $\begin{array}{c}\text { Tempo } \\
\text { (horas) }\end{array}$ \\
\hline T1 & 20000 & T11 & 40000 & T21 & 60000 \\
\hline T2 & 22000 & $\mathrm{~T} 12$ & 42000 & $\mathrm{~T} 22$ & 62000 \\
\hline T3 & 24000 & $\mathrm{~T} 13$ & 44000 & $\mathrm{~T} 23$ & 64000 \\
\hline $\mathrm{T} 4$ & 26000 & $\mathrm{~T} 14$ & 46000 & $\mathrm{~T} 24$ & 66000 \\
\hline $\mathrm{T} 5$ & 28000 & $\mathrm{~T} 15$ & 48000 & $\mathrm{~T} 25$ & 68000 \\
\hline $\mathrm{T} 6$ & 30000 & $\mathrm{~T} 16$ & 50000 & $\mathrm{~T} 26$ & 70000 \\
\hline $\mathrm{T} 7$ & 32000 & $\mathrm{~T} 17$ & 52000 & $\mathrm{~T} 27$ & 72000 \\
\hline $\mathrm{T} 8$ & 34000 & $\mathrm{~T} 18$ & 54000 & $\mathrm{~T} 28$ & 74000 \\
\hline $\mathrm{T} 9$ & 36000 & $\mathrm{~T} 19$ & 56000 & $\mathrm{~T} 29$ & 76000 \\
\hline $\mathrm{T} 10$ & 38000 & $\mathrm{~T} 20$ & 58000 & $\mathrm{~T} 30$ & 78000 \\
\hline
\end{tabular}


Tabela 5.8 Alternativas dos intervalos de intervenção (Ti) para fazer a manutenção preventiva do atuador

\begin{tabular}{|c|c|c|c|c|c|}
\hline Alternativas & $\begin{array}{c}\text { Tempo } \\
\text { (horas) }\end{array}$ & Alternativas & $\begin{array}{c}\text { Tempo } \\
\text { (horas) }\end{array}$ & Alternativas & $\begin{array}{c}\text { Tempo } \\
\text { (horas) }\end{array}$ \\
\hline $\mathrm{T} 1$ & 20000 & $\mathrm{~T} 11$ & 40000 & $\mathrm{~T} 21$ & 60000 \\
\hline $\mathrm{T} 2$ & 22000 & $\mathrm{~T} 12$ & 42000 & $\mathrm{~T} 22$ & 62000 \\
\hline $\mathrm{T} 3$ & 24000 & $\mathrm{~T} 13$ & 44000 & $\mathrm{~T} 23$ & 64000 \\
\hline $\mathrm{T} 4$ & 26000 & $\mathrm{~T} 14$ & 46000 & $\mathrm{~T} 24$ & 66000 \\
\hline $\mathrm{T} 5$ & 28000 & $\mathrm{~T} 15$ & 48000 & $\mathrm{~T} 25$ & 68000 \\
\hline $\mathrm{T} 6$ & 30000 & $\mathrm{~T} 16$ & 50000 & $\mathrm{~T} 26$ & 70000 \\
\hline $\mathrm{T} 7$ & 32000 & $\mathrm{~T} 17$ & 52000 & $\mathrm{~T} 27$ & 72000 \\
\hline $\mathrm{T} 8$ & 34000 & $\mathrm{~T} 18$ & 54000 & $\mathrm{~T} 28$ & 74000 \\
\hline $\mathrm{T} 9$ & 36000 & $\mathrm{~T} 19$ & 56000 & $\mathrm{~T} 29$ & 76000 \\
\hline $\mathrm{T} 10$ & 38000 & $\mathrm{~T} 20$ & 58000 & $\mathrm{~T} 30$ & 78000 \\
\hline
\end{tabular}

Tabela 5.9 Alternativas dos intervalos de intervenção (Ti) para fazer a manutenção preventiva do bomba

\begin{tabular}{|c|c|c|c|c|c|}
\hline Alternativas & $\begin{array}{c}\text { Tempo } \\
\text { (horas) }\end{array}$ & Alternativas & $\begin{array}{c}\text { Tempo } \\
\text { (horas) }\end{array}$ & Alternativas & $\begin{array}{c}\text { Tempo } \\
\text { (horas) }\end{array}$ \\
\hline T1 & 5000 & $\mathrm{~T} 11$ & 25000 & $\mathrm{~T} 21$ & 45000 \\
\hline $\mathrm{T} 2$ & 7000 & $\mathrm{~T} 12$ & 27000 & $\mathrm{~T} 22$ & 47000 \\
\hline $\mathrm{T} 3$ & 9000 & $\mathrm{~T} 13$ & 29000 & $\mathrm{~T} 23$ & 49000 \\
\hline $\mathrm{T} 4$ & 11000 & $\mathrm{~T} 14$ & 31000 & $\mathrm{~T} 24$ & 51000 \\
\hline $\mathrm{T} 5$ & 13000 & $\mathrm{~T} 15$ & 33000 & $\mathrm{~T} 25$ & 53000 \\
\hline $\mathrm{T} 6$ & 15000 & $\mathrm{~T} 16$ & 35000 & $\mathrm{~T} 26$ & 55000 \\
\hline $\mathrm{T} 7$ & 17000 & $\mathrm{~T} 17$ & 37000 & $\mathrm{~T} 27$ & 57000 \\
\hline $\mathrm{T} 8$ & 19000 & $\mathrm{~T} 18$ & 39000 & $\mathrm{~T} 28$ & 59000 \\
\hline $\mathrm{T} 9$ & 21000 & $\mathrm{~T} 19$ & 41000 & $\mathrm{~T} 29$ & 61000 \\
\hline $\mathrm{T} 10$ & 23000 & $\mathrm{~T} 20$ & 43000 & $\mathrm{~T} 30$ & 63000 \\
\hline
\end{tabular}

Tabela 5.10 Alternativas dos intervalos de intervenção (Ti) para fazer a manutenção preventiva do trocador de calor

\begin{tabular}{|c|c|c|c|c|c|}
\hline Alternativas & $\begin{array}{c}\text { Tempo } \\
\text { (horas) }\end{array}$ & Alternativas & $\begin{array}{c}\text { Tempo } \\
\text { (horas) }\end{array}$ & Alternativas & $\begin{array}{c}\text { Tempo } \\
\text { (horas) }\end{array}$ \\
\hline T1 & 1000 & $\mathrm{~T} 11$ & 6000 & $\mathrm{~T} 21$ & 11000 \\
\hline $\mathrm{T} 2$ & 1500 & $\mathrm{~T} 12$ & 6500 & $\mathrm{~T} 22$ & 11500 \\
\hline $\mathrm{T} 3$ & 2000 & $\mathrm{~T} 13$ & 7000 & $\mathrm{~T} 23$ & 12000 \\
\hline $\mathrm{T} 4$ & 2500 & $\mathrm{~T} 14$ & 7500 & $\mathrm{~T} 24$ & 12500 \\
\hline $\mathrm{T} 5$ & 3000 & $\mathrm{~T} 15$ & 8000 & $\mathrm{~T} 25$ & 13000 \\
\hline $\mathrm{T} 6$ & 3500 & $\mathrm{~T} 16$ & 8500 & $\mathrm{~T} 26$ & 13500 \\
\hline $\mathrm{T} 7$ & 4000 & $\mathrm{~T} 17$ & 9000 & $\mathrm{~T} 27$ & 14000 \\
\hline $\mathrm{T} 8$ & 4500 & $\mathrm{~T} 18$ & 9500 & $\mathrm{~T} 28$ & 14500 \\
\hline $\mathrm{T} 9$ & 5000 & $\mathrm{~T} 19$ & 10000 & $\mathrm{~T} 29$ & 15000 \\
\hline $\mathrm{T} 10$ & 5500 & $\mathrm{~T} 20$ & 10500 & $\mathrm{~T} 30$ & 15500 \\
\hline
\end{tabular}


Tabela 5.11 Alternativas dos intervalos de intervenção (Ti) para fazer a manutenção preventiva do acumulador

\begin{tabular}{|c|c|c|c|c|c|}
\hline Alternativas & $\begin{array}{c}\text { Tempo } \\
\text { (horas) }\end{array}$ & Alternativas & $\begin{array}{c}\text { Tempo } \\
\text { (horas) }\end{array}$ & Alternativas & $\begin{array}{c}\text { Tempo } \\
\text { (horas) }\end{array}$ \\
\hline T1 & 20000 & $\mathrm{~T} 11$ & 70000 & $\mathrm{~T} 21$ & 120000 \\
\hline $\mathrm{T} 2$ & 25000 & $\mathrm{~T} 12$ & 75000 & $\mathrm{~T} 22$ & 125000 \\
\hline $\mathrm{T} 3$ & 30000 & $\mathrm{~T} 13$ & 80000 & $\mathrm{~T} 23$ & 130000 \\
\hline $\mathrm{T} 4$ & 35000 & $\mathrm{~T} 14$ & 85000 & $\mathrm{~T} 24$ & 135000 \\
\hline $\mathrm{T} 5$ & 40000 & $\mathrm{~T} 15$ & 90000 & $\mathrm{~T} 25$ & 140000 \\
\hline $\mathrm{T} 6$ & 45000 & $\mathrm{~T} 16$ & 95000 & $\mathrm{~T} 26$ & 145000 \\
\hline $\mathrm{T} 7$ & 50000 & $\mathrm{~T} 17$ & 100000 & $\mathrm{~T} 27$ & 150000 \\
\hline $\mathrm{T} 8$ & 55000 & $\mathrm{~T} 18$ & 105000 & $\mathrm{~T} 28$ & 155000 \\
\hline $\mathrm{T} 9$ & 60000 & $\mathrm{~T} 19$ & 110000 & $\mathrm{~T} 29$ & 160000 \\
\hline $\mathrm{T} 10$ & 65000 & $\mathrm{~T} 20$ & 115000 & $\mathrm{~T} 30$ & 165000 \\
\hline
\end{tabular}

No primeiro período de tempo, após a entrada em funcionamento da máquina, considera-se que nenhuma tarefa de manutenção foi executada. Não existe degradação do componente pela ação da manutenção, ou seja, o valor de $i$ é igual a 0 .

A partir do momento em que foi feita a primeira intervenção de manutenção preventiva o componente sofre degradação e os valores de $i$ passam a ter valores inteiros $(i=1,2,3,4)$. Nesse momento os valores de $a_{i}$ e $b_{i}$ são recalculados, pois dependem diretamente do valor de i. A Tabela 5.12 ilustra a função preferência e seus respectivos parâmetros empregados nesta análise.

Tabela 5.12 Função de preferência e características dos critérios.

\begin{tabular}{|l|l|l|}
\hline Características & $\begin{array}{l}\text { R } \\
\text { (confiabilidade) }\end{array}$ & $\begin{array}{l}\text { Cm } \\
\text { (custo de manutenção) }\end{array}$ \\
\hline Maximizar / Minimizar & Maximizar & Minimizar \\
\hline Função Preferência & Linear & Usual \\
\hline Limite de indiferença (q) & 0,001 & - \\
\hline Limite de preferência (p) & 0,01 & - \\
\hline
\end{tabular}

Nas Figuras 5.8, 5.9 e 5.10 apresentam-se os resultados obtidos após a aplicação do método com a variação do valor de $\mathrm{K}$ para o motor. Nestas figuras pode-se observar que os tempos de intervenção mudam para cada nova campanha operacional, considerando a degradação do equipamento e a variação nos pesos dos custos e da confiabilidade. 
Para execução do estudo de seleção do tempo entre ações de manutenção preventiva, considerou-se a variação da preferência do tomador de decisão com relação à importância da confiabilidade e do custo da manutenção ao longo do tempo de operação da máquina. Propõe-se o seguinte critério:

i. Para a seleção do primeiro intervalo de manutenção considera-se que o componente é novo e, portanto a tomada de decisão deve priorizar o custo de manutenção uma vez que a confiabilidade do componente deve ser alta.

ii. Para a seleção do segundo intervalo de manutenção utiliza-se igual importância para confiabilidade e custos, considerando o inicio da degradação do componente.

iii. Para seleção do terceiro intervalo de manutenção dá-se maior importância à confiabilidade, considerando a degradação do componente em função do tempo de uso.

Figura 5-8 Resultados do motor para a manutenção preventiva com degradação, para o valor de K=5.

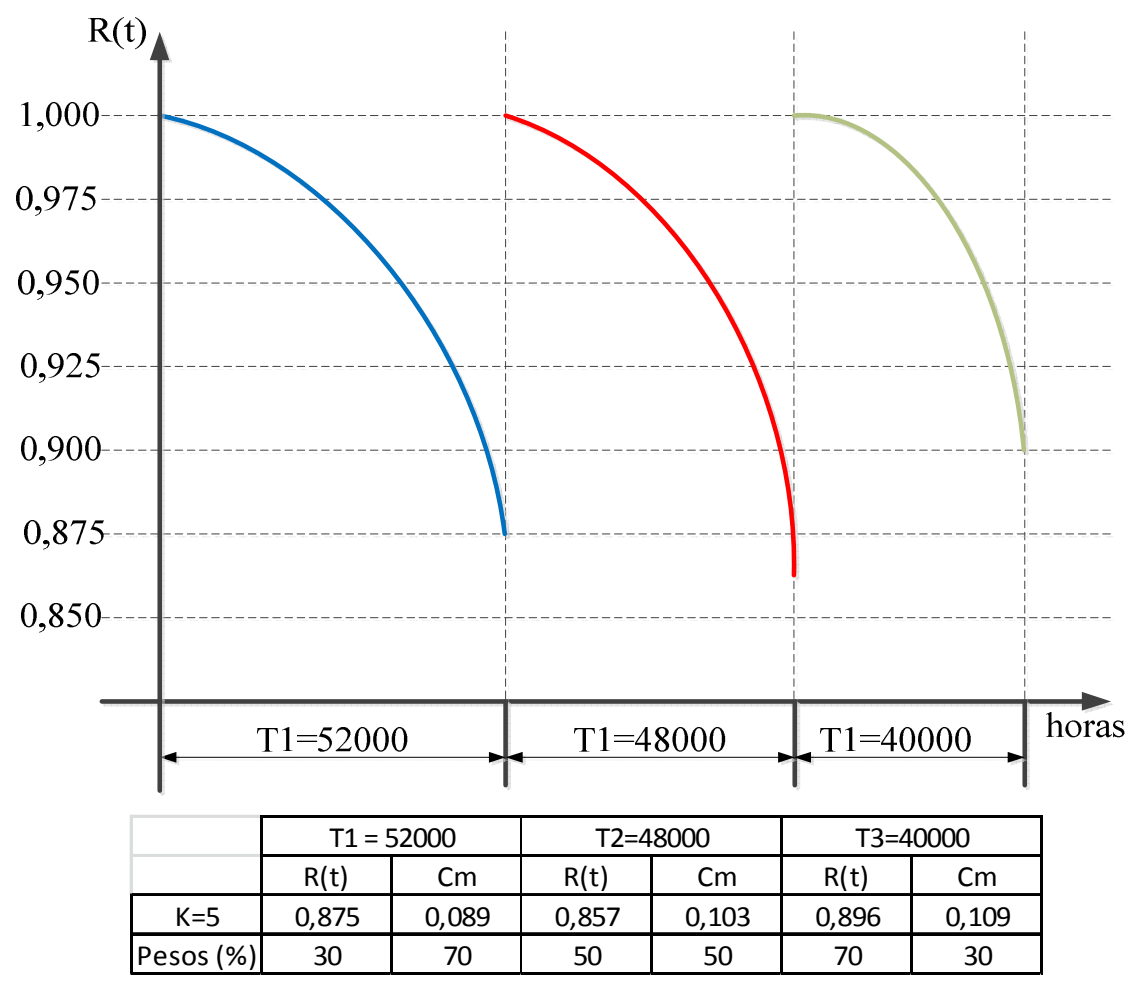

Fonte: Própria 
Figura 5-9 Resultados do motor para a manutenção preventiva com degradação, para o valor de $\mathrm{K}=10$.

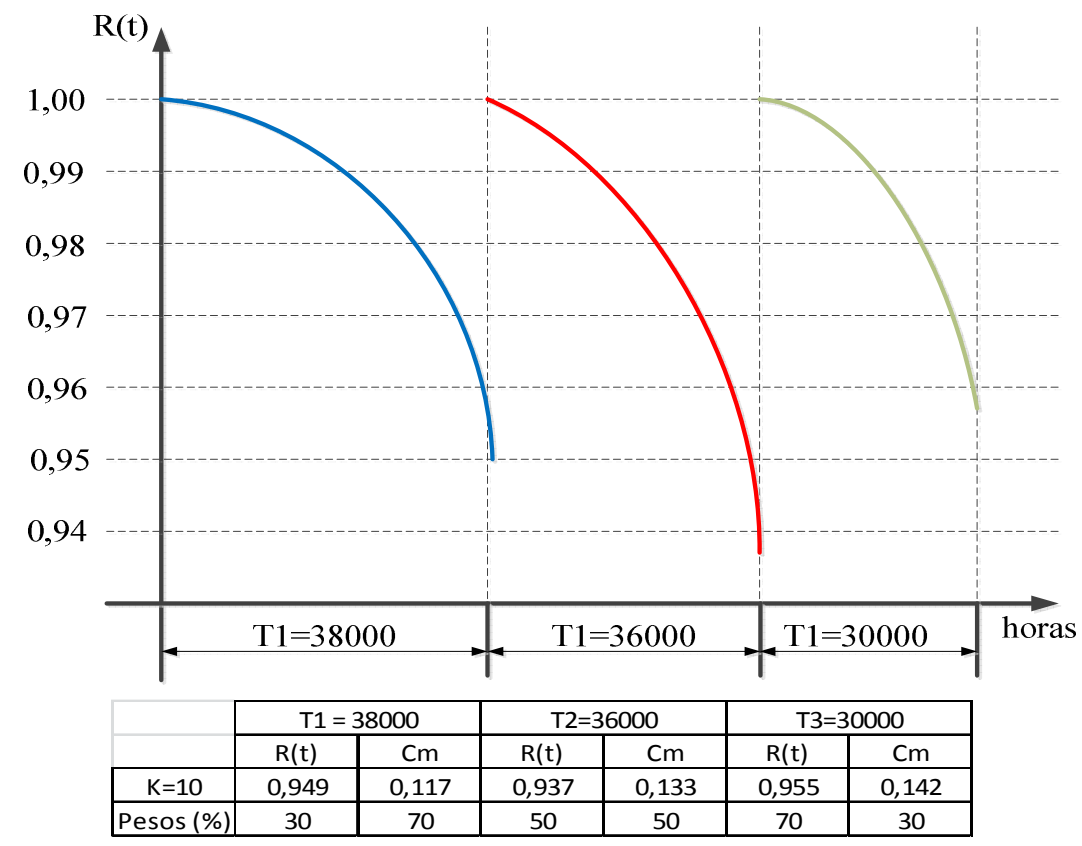

Fonte: Própria

Figura 5-10 Resultados do Motor para a manutenção preventiva com degradação, para o valor de $\mathrm{K}=15$.

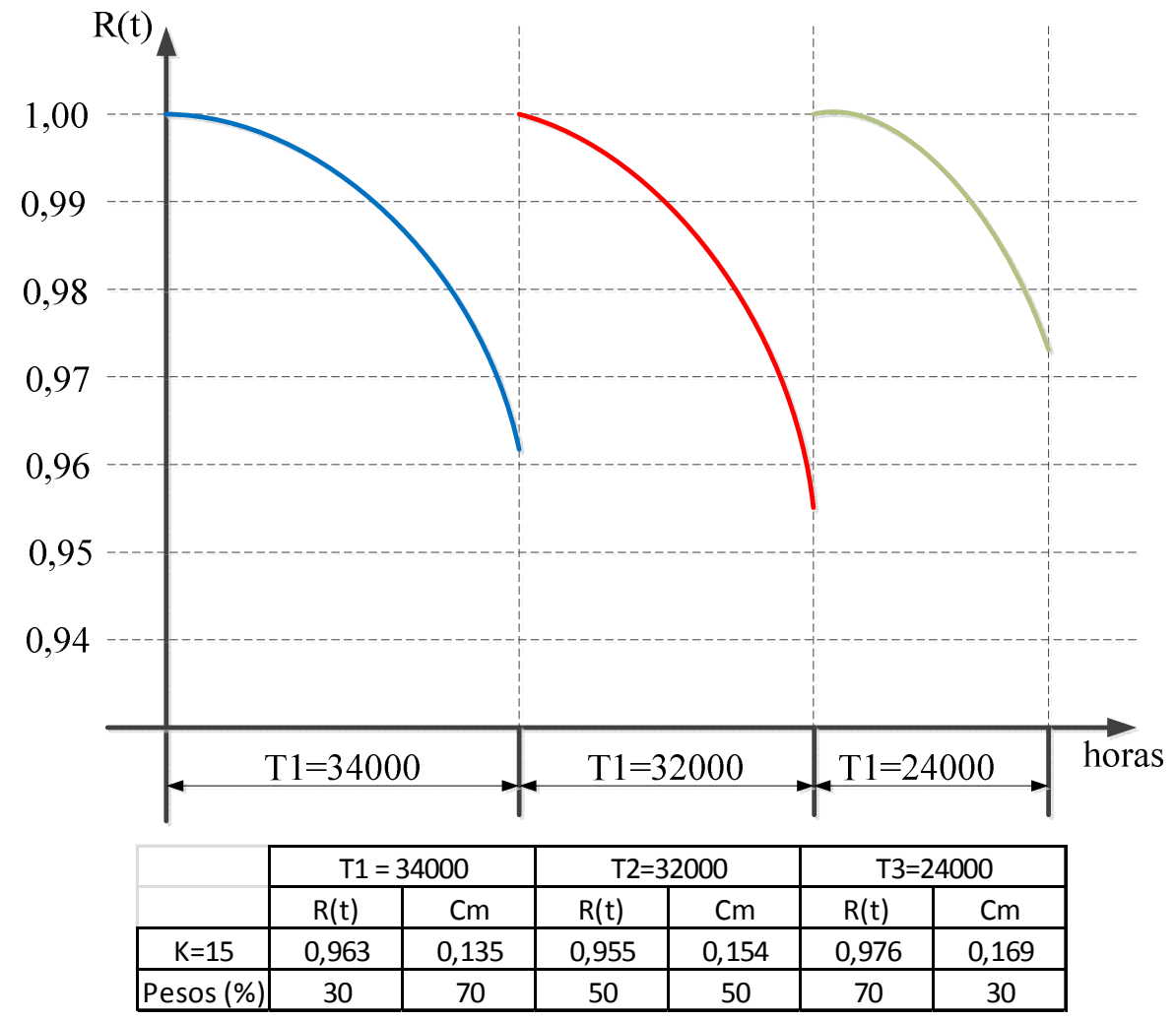

Fonte: Própria 
Do mesmo modo, foram calculados as periocidades da manutenção preventiva com degradação para a bomba, atuador e acumulador, levando em consideração que os valores de $\beta$ e $\eta$ variam para cada componente. Os valores de $\beta$ e $\eta$ da distribuição de Weibull foram apresentados na Tabela 5.5. As funções de preferência e características dos critérios são os mesmos para todos os componentes.

$\mathrm{Na}$ Tabela 5.13 são apresentados os resultados da periocidade (em horas) da manutenção preventiva para a bomba.

Tabela 5.13 Resultados das periocidades da manutenção preventiva da bomba.

\begin{tabular}{|c|c|c|c|c|c|c|}
\hline & \multicolumn{2}{|c|}{$\mathrm{T} 1=25000$} & \multicolumn{2}{|c|}{$\mathrm{T} 2=23000$} & \multicolumn{2}{|c|}{$\mathrm{T} 3=21000$} \\
\hline & $R(t)$ & $\mathrm{Cm}$ & $R(t)$ & $\mathrm{Cm}$ & $R(t)$ & $\mathrm{Cm}$ \\
\hline$K=5$ & 0,815 & 0,222 & 0,794 & 0,257 & 0,810 & 0,270 \\
\hline \multirow[t]{3}{*}{ Pesos (\%) } & 30 & 70 & 50 & 50 & 70 & 30 \\
\hline & \multicolumn{2}{|c|}{$\mathrm{T} 1=17000$} & \multicolumn{2}{|c|}{$\mathrm{T} 2=15000$} & \multicolumn{2}{|c|}{$T 3=15000$} \\
\hline & $R(t)$ & $\mathrm{Cm}$ & $\mathrm{R}(\mathrm{t})$ & $\mathrm{Cm}$ & $R(t)$ & $\mathrm{Cm}$ \\
\hline $\mathrm{K}=10$ & 0,916 & 0,318 & 0,913 & 0,367 & 0,907 & 0,381 \\
\hline \multirow[t]{3}{*}{ Pesos (\%) } & 30 & 70 & 50 & 50 & 70 & 30 \\
\hline & \multicolumn{2}{|c|}{$\mathrm{T} 1=15000$} & \multicolumn{2}{|c|}{$\mathrm{T} 2=13000$} & \multicolumn{2}{|c|}{$\mathrm{T} 3=11000$} \\
\hline & $R(t)$ & $\mathrm{Cm}$ & $R(t)$ & $\mathrm{Cm}$ & $R(t)$ & $\mathrm{Cm}$ \\
\hline $\mathrm{K}=15$ & 0,936 & 0,388 & 0,936 & 0,449 & 0,949 & 0,475 \\
\hline Pesos (\%) & 30 & 70 & 50 & 50 & 70 & 30 \\
\hline
\end{tabular}

$\mathrm{Na}$ Tabela 5.14 são apresentados os resultados da periocidade (em horas) da manutenção preventiva para o atuador.

Tabela 5.14 Resultados das periocidades da manutenção preventiva do atuador.

\begin{tabular}{|c|c|c|c|c|c|c|}
\hline & \multicolumn{2}{|c|}{$\mathrm{T} 1=50000$} & \multicolumn{2}{|c|}{$\mathrm{T} 2=48000$} & \multicolumn{2}{|c|}{ T3=20000 } \\
\hline & $R(t)$ & $\mathrm{Cm}$ & $R(t)$ & $\mathrm{Cm}$ & $R(t)$ & $\mathrm{Cm}$ \\
\hline$K=5$ & 0,776 & 0,124 & 0,736 & 0,143 & 0,926 & 0,200 \\
\hline \multirow[t]{3}{*}{ Pesos (\%) } & 30 & 70 & 50 & 50 & 50 & 50 \\
\hline & \multicolumn{2}{|c|}{$\mathrm{T} 1=34000$} & \multicolumn{2}{|c|}{$\mathrm{T} 2=32000$} & \multicolumn{2}{|c|}{ T3=28000 } \\
\hline & $R(t)$ & $\mathrm{Cm}$ & $R(t)$ & $\mathrm{Cm}$ & $R(t)$ & $\mathrm{Cm}$ \\
\hline $\mathrm{K}=10$ & 0,889 & 0,183 & 0,872 & 0,211 & 0,890 & 0,223 \\
\hline \multirow[t]{3}{*}{ Pesos (\%) } & 30 & 70 & 50 & 50 & 70 & 30 \\
\hline & \multicolumn{2}{|c|}{$\mathrm{T} 1=26000$} & \multicolumn{2}{|c|}{$\mathrm{T} 2=24000$} & \multicolumn{2}{|c|}{$\mathrm{T} 3=24000$} \\
\hline & $R(t)$ & $\mathrm{Cm}$ & $R(t)$ & $\mathrm{Cm}$ & $R(t)$ & $\mathrm{Cm}$ \\
\hline $\mathrm{K}=15$ & 0,934 & 0,228 & 0,926 & 0,262 & 0,920 & 0,273 \\
\hline Pesos (\%) & 30 & 70 & 50 & 50 & 70 & 30 \\
\hline
\end{tabular}


$\mathrm{Na}$ Tabela 5.15 são apresentados os resultados da periocidade (em horas) da manutenção preventiva para o acumulador.

Tabela 5.15 Resultados das periocidades da manutenção preventiva do acumulador.

\begin{tabular}{|c|c|c|c|c|c|c|}
\cline { 2 - 7 } \multicolumn{1}{c|}{} & \multicolumn{2}{c|}{$\mathrm{T} 1=115000$} & \multicolumn{2}{c|}{$\mathrm{T} 2=110000$} & \multicolumn{2}{c|}{$\mathrm{T} 3=20000$} \\
\cline { 2 - 7 } \multicolumn{1}{c|}{} & $\mathrm{R}(\mathrm{t})$ & $\mathrm{Cm}$ & $\mathrm{R}(\mathrm{t})$ & $\mathrm{Cm}$ & $\mathrm{R}(\mathrm{t})$ & $\mathrm{Cm}$ \\
\hline $\mathrm{K}=5$ & 0,764 & 0,055 & 0,724 & 0,064 & 0,976 & 0,166 \\
\hline Pesos (\%) & 30 & 70 & 50 & 50 & 50 & 50 \\
\hline
\end{tabular}

\begin{tabular}{|c|c|c|c|c|c|c|}
\cline { 2 - 7 } \multicolumn{1}{c|}{} & \multicolumn{2}{c|}{$\mathrm{T} 1=75000$} & \multicolumn{2}{c|}{$\mathrm{T} 2=70000$} & \multicolumn{2}{c|}{$\mathrm{T} 3=65000$} \\
\cline { 2 - 7 } \multicolumn{1}{c|}{} & $\mathrm{R}(\mathrm{t})$ & $\mathrm{Cm}$ & $\mathrm{R}(\mathrm{t})$ & $\mathrm{Cm}$ & $\mathrm{R}(\mathrm{t})$ & $\mathrm{Cm}$ \\
\hline $\mathrm{K}=10$ & 0,892 & 0,082 & 0,877 & 0,095 & 0,883 & 0,099 \\
\hline Pesos (\%) & 30 & 70 & 50 & 50 & 70 & 30 \\
\hline
\end{tabular}

\begin{tabular}{|c|c|c|c|c|c|c|}
\cline { 2 - 7 } \multicolumn{1}{c|}{} & \multicolumn{2}{c|}{$\mathrm{T} 1=60000$} & \multicolumn{2}{c|}{$\mathrm{T} 2=55000$} & \multicolumn{2}{c|}{$\mathrm{T3}=55000$} \\
\cline { 2 - 7 } \multicolumn{1}{c|}{} & $\mathrm{R}(\mathrm{t})$ & $\mathrm{Cm}$ & $\mathrm{R}(\mathrm{t})$ & $\mathrm{Cm}$ & $\mathrm{R}(\mathrm{t})$ & $\mathrm{Cm}$ \\
\hline $\mathrm{K}=15$ & 0,929 & 0,102 & 0,922 & 0,118 & 0,916 & 0,123 \\
\hline Pesos (\%) & 30 & 70 & 50 & 50 & 70 & 30 \\
\hline
\end{tabular}

$\mathrm{Na}$ Tabela 5.16 são apresentados os resultados da periocidade (em horas) da manutenção preventiva para o trocador de calor.

Tabela 5.16 Resultados das periocidades da manutenção preventiva do trocador de calor.

\begin{tabular}{|c|c|c|c|c|c|c|}
\hline & \multicolumn{2}{|c|}{$\mathrm{T} 1=9500$} & \multicolumn{2}{|c|}{$T 2=9000$} & \multicolumn{2}{|c|}{$T 3=1500$} \\
\hline & $R(t)$ & $\mathrm{Cm}$ & $R(t)$ & $\mathrm{Cm}$ & $R(t)$ & $\mathrm{Cm}$ \\
\hline $\mathrm{K}=5$ & 0,884 & 0,476 & 0,858 & 0,545 & 0,997 & 2,029 \\
\hline \multirow[t]{3}{*}{ Pesos (\%) } & 30 & 70 & 50 & 50 & 70 & 30 \\
\hline & \multicolumn{2}{|c|}{$\mathrm{T} 1=7500$} & \multicolumn{2}{|c|}{$\mathrm{T} 2=7000$} & \multicolumn{2}{|c|}{$T 3=5500$} \\
\hline & $R(t)$ & $\mathrm{Cm}$ & $R(t)$ & $\mathrm{Cm}$ & $R(t)$ & $\mathrm{Cm}$ \\
\hline $\mathrm{K}=10$ & 0,941 & 0,621 & 0,930 & 0,712 & 0,958 & 0,760 \\
\hline \multirow[t]{3}{*}{ Pesos (\%) } & 30 & 70 & 50 & 50 & 70 & 30 \\
\hline & \multicolumn{2}{|c|}{$\mathrm{T} 1=6500$} & \multicolumn{2}{|c|}{$T 2=5500$} & \multicolumn{2}{|c|}{$T 3=4000$} \\
\hline & $R(t)$ & $\mathrm{Cm}$ & $R(t)$ & $\mathrm{Cm}$ & $R(t)$ & $\mathrm{Cm}$ \\
\hline $\mathrm{K}=15$ & 0,913 & 0,718 & 0,964 & 0,825 & 0,982 & 0,939 \\
\hline Pesos (\%) & 30 & 70 & 50 & 50 & 70 & 30 \\
\hline
\end{tabular}

Realiza-se uma segunda análise de sensibilidade variando o valor de K para 50 , 100 e 500, na estimação da periocidade da manutenção preventiva para o motor elétrico. Na Tabela 5.17 são apresentados os resultados desta análise. O aumento do fator de $\mathrm{K}$ implica em sensível redução dos tempos de intervenção, fato bastante 
logico pois o aumento do custo da consequência da falha (que influencia o custo da manutenção corretiva) exige redução da periocidade de ação de prevenção.

Tabela 5.17 Resultados dos das periocidades da manutenção preventiva do motor elétrico .

\begin{tabular}{|c|c|c|c|c|c|c|}
\hline & \multicolumn{2}{|c|}{$\mathrm{T} 1=23000$} & \multicolumn{2}{|c|}{$\mathrm{T} 2=19000$} & \multicolumn{2}{|c|}{$\mathrm{T} 3=15000$} \\
\hline & $R(t)$ & $\mathrm{Cm}$ & $\mathrm{R}(\mathrm{t})$ & $\mathrm{Cm}$ & $R(t)$ & $\mathrm{Cm}$ \\
\hline $\mathrm{k}=50$ & 0,989 & 0,204 & 0,990 & 0,235 & 0,994 & 0,258 \\
\hline \multirow[t]{3}{*}{ Pesos(\% } & 30 & 70 & 50 & 50 & 70 & 30 \\
\hline & \multicolumn{2}{|c|}{$\mathrm{T} 1=17000$} & \multicolumn{2}{|c|}{$\mathrm{T} 2=16000$} & \multicolumn{2}{|c|}{$\mathrm{T} 3=14000$} \\
\hline & $R(t)$ & $\mathrm{Cm}$ & $\mathrm{R}(\mathrm{t})$ & $\mathrm{Cm}$ & $R(t)$ & $\mathrm{Cm}$ \\
\hline $\mathrm{k}=100$ & 0,995 & 0,258 & 0,994 & 0,293 & 0,995 & 0,312 \\
\hline \multirow[t]{3}{*}{ Pesos(\% } & 30 & 70 & 50 & 50 & 70 & 30 \\
\hline & \multicolumn{2}{|c|}{$\mathrm{T} 1=10000$} & \multicolumn{2}{|c|}{$\mathrm{T} 2=9500$} & \multicolumn{2}{|c|}{$\mathrm{T} 3=9000$} \\
\hline & $R(t)$ & $\mathrm{Cm}$ & $\mathrm{R}(\mathrm{t})$ & $\mathrm{Cm}$ & $R(t)$ & $\mathrm{Cm}$ \\
\hline $\mathrm{k}=500$ & 0,999 & 0,442 & 0,999 & 0,503 & 0,999 & 0,529 \\
\hline Pesos(\% & 30 & 70 & 50 & 50 & 70 & 30 \\
\hline
\end{tabular}

Pode-se observar que os resultados para o tempo entre as ações de manutenção para os componentes: bomba, atuador, motor, trocador de calor e acumulador, variam conforme o valor de K. Quando o valor de K for maior, os tempos de intervenção de manutenção preventiva são menores, pois os custos de manutenção emergencial (corretiva) acabam ficando mais elevados.

\subsection{Desenvolvimento do sistema especialista para o diagnóstico de falhas no regulador de velocidade da turbina Kaplan.}

A estrutura de um sistema especialista é apresentada no Capítulo 3. A primeira etapa apresentada é aquisição do conhecimento, conforme o método proposto neste trabalho. Uma vez adquirido o conhecimento, é possível criar a base do conhecimento, a qual é realizada por meio de árvores de decisão, que é considerada uma forma simples e eficaz de representar o conhecimento. 
As árvores de decisão utilizam a estratégia de dividir um problema complexo em subproblemas mais simples, proporcionando ao pesquisador a possibilidade de acompanhar o procedimento de classificação por meio dos nós da árvore.

Está técnica de inteligência artificial consiste em representar as informações pertinentes a um problema em uma estrutura de árvore, na qual os nós internos representam os testes a serem realizados e os nós folhas as possíveis decisões a serem tomadas.

A árvore de decisão é constituída por um conjunto de regras, ou seja, o conhecimento representado nessas árvores de decisão é representado na forma de regras de classificação do tipo "Se - Então". Sendo assim, cada nó da árvore representará uma condição (antecedente) envolvendo um atributo e um conjunto de valores. Enquanto os nós folhas irão representar às conclusões (consequente), indicam a atribuição de um valor ou conjunto de valores a um atributo do problema (NIKOPOULOS, 1997).

A partir do conhecimento adquirido para a elaboração do sistema especialista, foi possível desenvolver cinco árvores de decisão: o regulador de velocidade não opera, temperatura elevada do óleo, movimentação lenta dos atuadores do distribuidor, movimentação lenta do atuador do rotor e perda da precisão do posicionamento dos atuadores.

Na Figura 5.11 pode-se observar a árvore de decisão para a temperatura elevada do óleo. A árvore é inicializada quando a temperatura do óleo for maior que $60^{\circ} \mathrm{C}$, a qual será indicada pelo sensor de temperatura localizado no reservatório do óleo. As outras árvores de decisão são apresentadas no Apêndice E. 
Figura 5-11 Árvore de decisão para temperatura elevada do óleo.

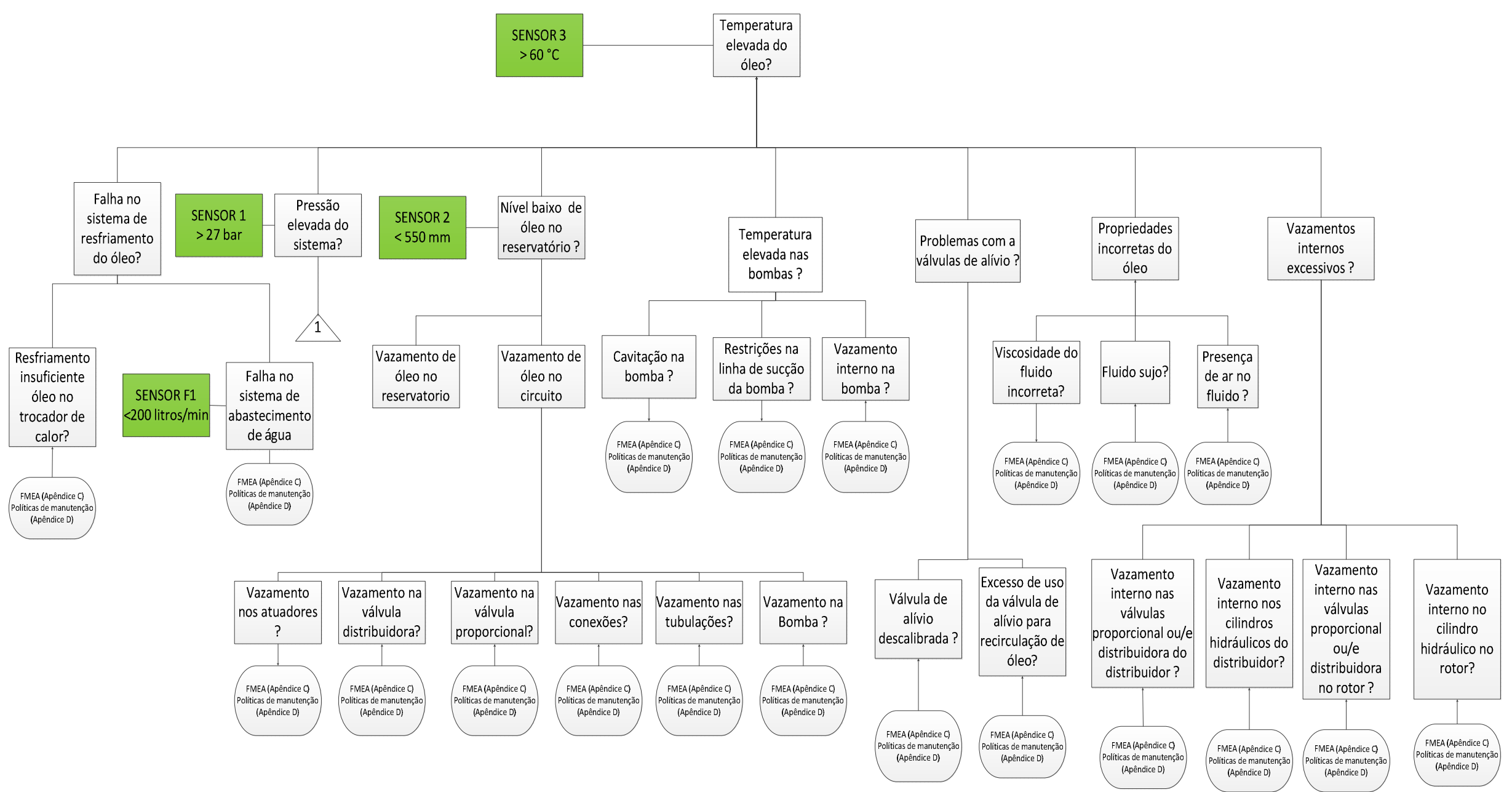

Fonte: Própria 
As árvores de decisão são programadas em CLIPS ("C Language Integrated Production System"). O CLIPS foi desenvolvido no Johnson Space Center da NASA em 1984. O CLIPS é considerado uma ferramenta poderosa para o manuseio de uma dada base que admite três tipos de programação: do conhecimento na forma de regras, orientado por objetos e do conhecimento utilizando procedimentos do tipo funções e sub-rotinas (GIARRATANO, 2004).

O desempenho de um motor de inferência é apontado como um fator-chave que influencia na qualidade do sistema especialista para diagnóstico de falhas do sistema. A direção de inferência utilizado neste trabalho é de encadeamento para atras.

Quando o sistema é inicializado, os parâmetros monitorados são lidos pelo sistema especialista, sendo os parâmetros de entrada inseridos em um arquivo de texto. Quando uma situação anormal for detectada pelo sistema especialista, o mesmo irá ativar a regra a qual inicializará o processo de diagnóstico de falhas (as causas de falhas são pesquisadas pelo motor de inferência) e o sistema tem como objetivo informar que uma falha está acontecendo. Caso o mecanismo de inferência não identifique a falha, se realizará uma série de perguntas para o responsável de operação da máquina. Conforme as respostas obtidas, assim como os dados de monitoramento lidos, o sistema é capaz de identificar a causa da falha ou desvio. Uma vez identificada a causa da falha, o sistema informará as possíveis sugestões de manutenção.

Como ponto de partida, o sistema especialista de diagnóstico de falhas detecta a anormalidade que ocorreu no nível superior, verificando o estado do subsistema funcional ao qual pertence a anormalidade. O diagnóstico é executado no nível superior até que um subsistema funcional com operação anormal seja encontrado. Em seguida, o mesmo desce para o nível inferior com o fim de definir o componente em estado de falha. Esta estratégia de controle reduz o espaço de busca e consumo de tempo. Concentra-se o diagnóstico de falhas em um subsistema rapidamente. Se o resultado do diagnóstico for anormal, a anomalia é analisada até que todas as potenciais causas locais sejam examinadas. Se uma causa local for encontrada, ela aparecerá na lista de fatos e a busca continua até que uma causa básica (por exemplo, trocador de calor tubo-vazamento) for encontrada. As causas encontradas 
e as recomendações sugeridas serão impressas. Com isso, o sistema especialista voltará a realizar o diagnóstico de anormalidades disponíveis na lista de fatos. Quando a lista de fatos for esvaziada, o processo de diagnóstico é finalizado.

Para uma melhor compreensão de como o sistema especialista funciona, um estudo de caso envolvendo uma temperatura de óleo maior que $60^{\circ} \mathrm{C}$ é apresentada. O sistema especialista tem a função de detectar essa anomalia e ativar a primeira regra para ingressar na árvore de decisão a qual foi elaborada para temperatura elevada de óleo. De acordo com a Figura 5.11, pode se observar que alguns parâmetros tem monitoração. Como por exemplo, a pressão elevada no sistema tem que ser maior que 26 bar; o nível de óleo baixo tem que ser menor que $650 \mathrm{~mm}$. E a vazão baixa da água no sistema de resfriamento tem que ser menor que 200 litros/min.

Se a temperatura do óleo for maior que $60^{\circ} \mathrm{C}$ e se alguns dos componentes que são monitoradas apresentam um desvio, o sistema identificará a causa do problema e apresentará as sugestões de manutenção, como se observa na Figura 5.12.

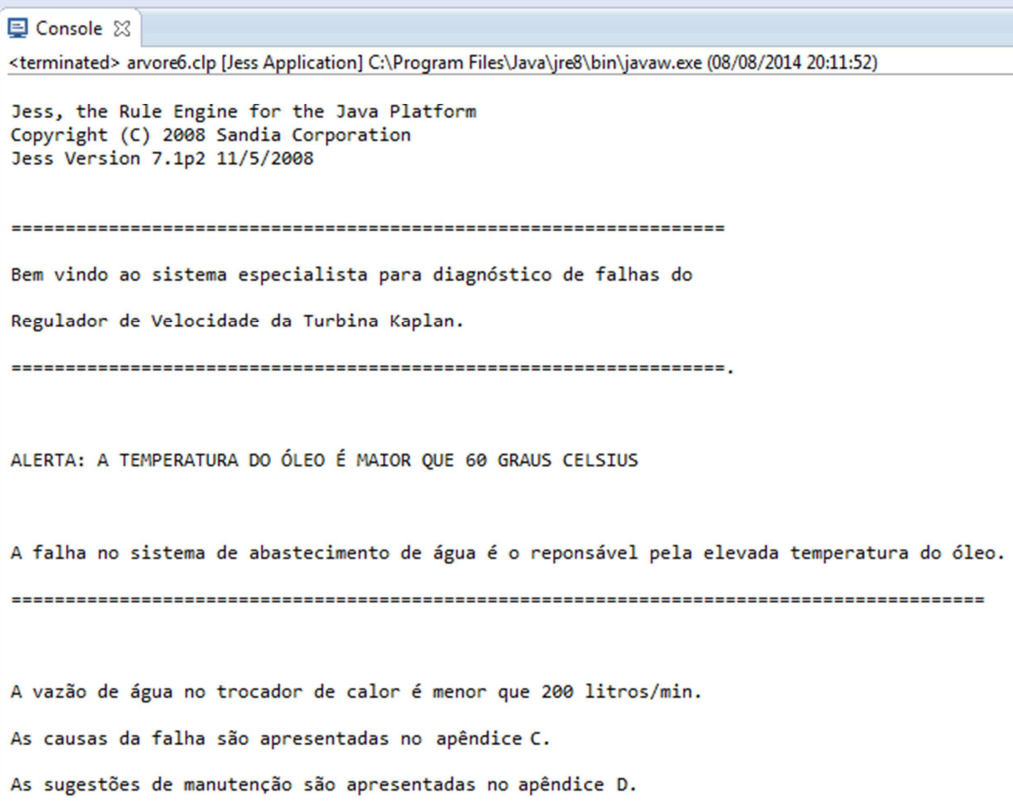

Figura 5-12 O sistema especialista identifica a causa do desvio. 
Se a temperatura do óleo for maior que $60^{\circ} \mathrm{C}$ e não acontece nenhum desvio nos componentes que estão sendo monitorados, o sistema precisará realizar perguntas ao responsável pela operação da máquina a fim de identificar o problema, como se observa na Figura 5.13.

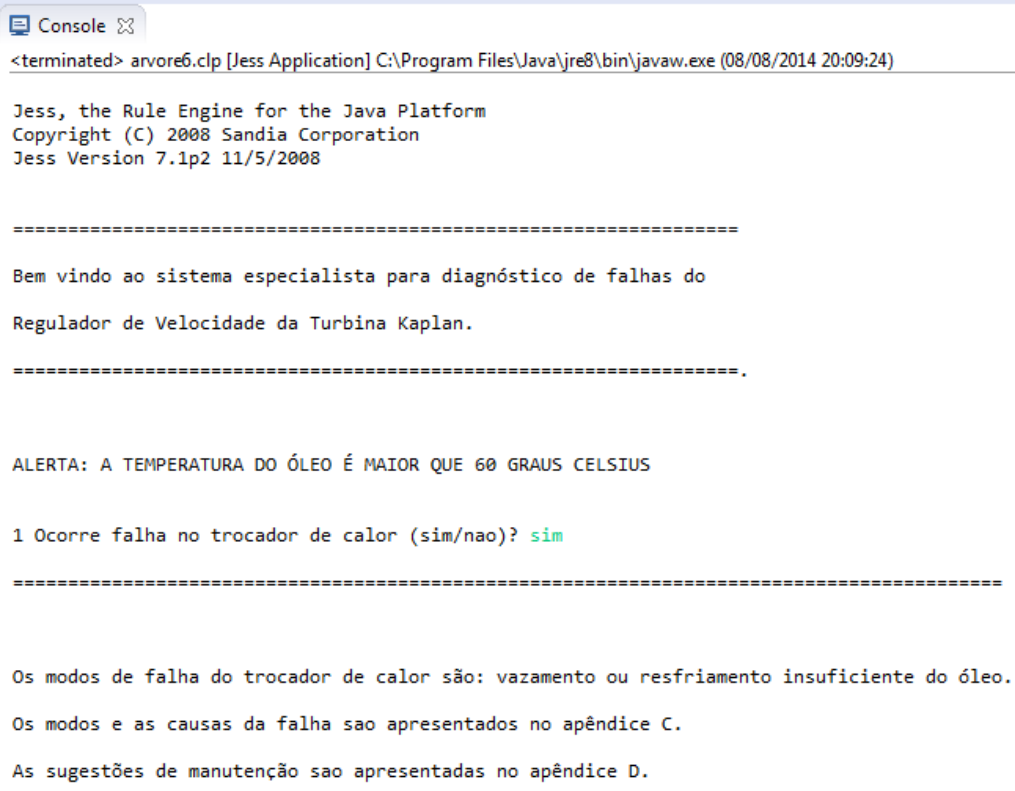

Figura 5-13 O sistema especialista realiza perguntas para identificar a causa do desvio.

Pode-se concluir que se algum equipamento apresenta algum desvio, o sistema especialista poderá identificar a causa do problema, não sendo necessário realizar as perguntas ao operador da máquina. 


\section{VALIDAÇÃO DO MÉTODO.}

A validação do método foi realizada pela comparação do histórico de falhas e diagnose das mesmas registradas na usina hidroelétrica com o levantamento do diagnóstico realizado por meio da aplicação do método proposto.

É importante ressaltar que os equipes de manutenção e de operação da usina em que foi utilizada como caso exemplo não tem um registro completo de todas as ocorrências das falhas do regulador de velocidade.

Atualmente o Operador Nacional de Sistemas Elétrico (ONS) exige o registro das mudanças dos estados operativos e condições operativas das Unidades Geradoras. Todo evento de mudança de estado operativo que caracteriza uma indisponibilidade total ou parcial de uma unidade geradora deverá obrigatoriamente ter seu campo de comentário preenchido com a descrição elucidativa do motivo da indisponibilidade, o qual permite manter um melhor controle sobre as falhas que ocorrem dentro da unidade geradora. Dessa forma, as empresas geradoras de energia elétrica passam a manter um registro detalhado das falhas das máquinas.

Na Tabela 6.1, é apresentado o resultado da filtragem dos dados históricos de falhas da usina, apresentando somente as falhas no sistema hidráulico do regulador de velocidade. Os dados de falhas referem-se ao período operacional compreendido entre o período 01/01/2001 até 27/07/2012.

Cabe ressaltar que todas as informações apresentadas na Tabela 6.1 foram coletadas pelas equipes de manutenção e operação da usina e compreendem apenas as falhas que foram registradas em uma planilha. Não foram consideradas as falhas relatas verbalmente. 
Tabela 6.1 Registro de falhas do regulador de velocidade no período 01/01/2001 até 27/07/2012.

\begin{tabular}{|c|c|c|c|c|c|c|c|c|}
\hline Equipamento & Comentário ONS & Data e Hora Início & Data e Hora Fim & $2^{2}$ nivel & $3^{\circ}$ nivel & $4^{\circ}$ nível & $5^{\circ}$ nivel & $6^{\circ}$ nivel \\
\hline $\begin{array}{l}\text { SPUS_13P8_UG1 } \\
\text { SPUS S13P8 UGG }\end{array}$ & & 02/02/2001 23:08 & 03/02/2001 01:00 & SRV & HID & VASO DE PRESSAO AR OLEO (APP) & & VASO DE PRESSÁO AR ÓLEO (APP) \\
\hline 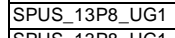 & & 23/04/2001 09:08 & 04/05/2001 10:30 & SRV & & & & SISTEMA DE REGULACÁO DE VELOCIDADE DA UNIDADE GERADORA \\
\hline 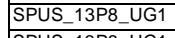 & & 04/05/2001 10:30 & 04/05/2001 17:27 & SRV & HIID & CAIXA DE ÓLEO & BOMBA 1 & BOMBA 1 PRESSÃO PRINCIPAL \\
\hline SPUS_13P8_UG1 & & 12/02/2002 10:38 & 12/02/2002 12:03 & SRV & HIID & VALVULA PROPORCIONAL & & \\
\hline SPUS_13P8_UG1 & & 12/02/2002 13:43 & 12/02/2002 16:52 & SRV & HIID & CAIXA DE OLEO & PRESSOSTATO 1 & \\
\hline SPUS_13P8_UG1 & Vazamento de óleo & 16/04/2002 16:58 & 16/04/2002 17:10 & SRV & HIID & TROCADOR DE CALOR & & \\
\hline SPUS_13P8_UG1 & & $26 / 05 / 200317: 41$ & $28 / 05 / 2003$ 10:30 & SRV & & & & SISTEMA DE REGULACÁO DE VELOCIDADE DA UNIDADE GERADORA \\
\hline SPUS_13P8_UG1 & & 10/07/2003 12:12 & 10/07/2003 19:30 & SRV & HIID & VASO DE PRESSÃO AR ÓLEO (APP) & & ACUMULADOR DE PRESSAO AR ÓLEO PRINCIPAL \\
\hline SPUS_13P8_UG1 & & 10/07/2003 18:04 & 15/07/2003 16:45 & SRV & & & & SISTEMA DE REGULACÁAO DE VELOCIDADE DA UNIDADE GERADORA \\
\hline SPUS_13P8_UG1 & & 19/08/2003 19:24 & 19/08/2003 23:19 & SRV & HIID & CAIXA DE ÓLEO & VALVULA & $\begin{array}{l}\text { LIMITADORA DE PRESSÁO APP } \\
\end{array}$ \\
\hline SPUS_13P8_UG1 & & $27 / 08 / 200304: 33$ & 27/08/2003 05:18 & SRV & HID & VASO DE PRESSÃO AR ÓLEO (APP) & & PRESSÁO DO ACUMULADOR \\
\hline SPUS_13P8_UG1 & & 27/08/2003 05:18 & 28/08/2003 02:38 & & & & & \\
\hline SPUS_13P8_UG1 & & 28/08/2003 02:38 & $28 / 08 / 2003 \quad 10: 25$ & & & & & \\
\hline SPUS_13P8_UG1 & & 28/08/2003 10:25 & $28 / 08 / 2003$ 15:35 & SRV & HID & VASO DE PRESSÃO AR ÓLEO (APP) & & PRESSÃO DO ACUMULADOR \\
\hline SPUS_13P8_UG1 & & 26/11/2003 06:30 & 26/11/2003 15:30 & SRV & HIID & CAIXA DE ÓLEO & BLOCO DE INTERMITENCIA & ELEMENTO LOGGICO \\
\hline SPUS_13P8_UG1 & & $07 / 12 / 200315: 21$ & 07/12/2003 17:01 & SRV & HID & & & SISTEMA HIDRAULICO DE REGULACAO DE VELOCIDADE \\
\hline SPUS_13P8_UG1 & & 23/12/2003 11:38 & 24/12/2003 11:45 & SRV & PRV & QG1-5 & IHM & IHM \\
\hline 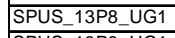 & & $08 / 11 / 200507: 45$ & 08/11/2005 11:10 & SRV & HID & CAIXA DE ÓLEO & VALVULA DE ALIIVIO & LIMITADORA DE PRESSAO \\
\hline SPUS_13P8_UG1 & & $08 / 11 / 200511: 10$ & 20/11/2005 18:27 & & & & & \\
\hline SPUS_13P8_UG1 & $\begin{array}{l}\text { Filtros sujos (MANUTENÇÃO } \\
\text { CORRETIVA) }\end{array}$ & 20/11/2005 18:27 & 20/11/2005 19:55 & SRV & HID & FILTROS & & \\
\hline SPUS_13P8_UG1 & $\begin{array}{l}\text { Redução da vazão de água para o } \\
\text { resfriamento no regulador de velocidade }\end{array}$ & 30/12/2005 06:23 & 03/01/2006 23:19 & & & & & \\
\hline SPUS_13P8_UG1 & $\begin{array}{l}\text { baixa pressão no APP- falha no sistema } \\
\text { de reposiçăo de ar }\end{array}$ & 02/02/2006 09:00 & 02/02/2006 11:11 & SRV & HID & VASO DE PRESSÃO AR ÓLEO (APP) & & \\
\hline SPUS_13P8_UG1 & Vazamento pelo atuador & 27/02/2009 09:35 & 27/02/2009 17:10 & SRV & & & & RESFRIAMENTO DA UNIDADE GERADORA \\
\hline SPUS_13P8_UG1 & Problemas no regulador de velocidade & 08/01/2010 03:58 & 15/01/2010 23:30 & CAU & & & & COMANDO E AUTOMATISMO DA UNIDADE GERADORA \\
\hline SPUS_13P8_UG1 & $\begin{array}{l}\text { Restrição devido vazamento excessivo } \\
\text { no retorno de óleo pelo regulador de } \\
\text { velocidade, pelo circuito de comando }\end{array}$ & 16/03/2010 14:45 & 05/04/2010 23:40 & & & & & \\
\hline SPUS_13P8_UG1 & $\begin{array}{l}\text { Restrição devido vazamento excessivo } \\
\text { no retorno de óleo pelo regulador de } \\
\text { velocidade, pelo circuito de comando } \\
\text { hidráulico do Rotor Kaplan. }\end{array}$ & 26/06/2010 13:18 & 03/12/2010 00:10 & & & & & \\
\hline SPUS_13P8_UG1 & $\begin{array}{l}\text { Restrição devido vazamento excessivo } \\
\text { no retorno de óleo pelo regulador de } \\
\text { velocidade, pelo circuito de comando } \\
\text { hidráulico do Rotor Kaplan. }\end{array}$ & 03/12/2010 01:08 & 16/01/2011 08:35 & & & & & \\
\hline SPUS_13P8_UG1 & $\begin{array}{l}\text { Substituicão da CPU do CLP Principal } \\
\text { do Regulador de Velocidade da UG-22 }\end{array}$ & 29/06/2011 07:32 & 29/06/2011 11:01 & CAU & PCL & PAINEL QG 2-3 & CPU PRINCIPAL & MODULO CPU $700 \mathrm{MHZ}$ \\
\hline SPUS_13P8_UG1 & $\begin{array}{l}\text { 1- pressão baixa no acumulador } \\
\text { principal( APP) ar /óleo da UG; 2- } \\
\text { Ensaios operacionais }\end{array}$ & 27/09/2011 17:42 & 27/09/2011 21:41 & SRV & & VASO DE PRESSÃO AR ÓLEO (APP) & & \\
\hline
\end{tabular}


Conclusão

\begin{tabular}{|c|c|c|c|c|c|c|c|c|}
\hline Equipamento & Comentário ONS & \begin{tabular}{|l|} 
Data e Hora Início \\
\end{tabular} & Data e Hora Fim & $2^{\circ}$ níve & $3^{\circ}$ nivel & $4^{\circ}$ nivel & $5^{\circ}$ nível & $6^{\circ}$ nivel \\
\hline SPUS_13P8_UG1 & $\begin{array}{l}\text { 1- Sobrepressão acumulador principall( } \\
\text { APP) ar /óleo da UG; 2- }\end{array}$ & 27/09/2011 21:41 & 28/09/2011 06:43 & & & & & \\
\hline SPUS_13P8_UG1 & $\begin{array}{l}\text { falha no motor da bomba de regulação } \\
\text { No2; }\end{array}$ & 18/10/2011 08:41 & 18/10/2011 16:52 & SRV & HID & CAIXA DE ÓLEO & MOTOR 2 & BOMBA 2 PRESSÃO RESERVA \\
\hline SPUS_13P8_UG1 & $\begin{array}{l}\text { SGl-036.427-08; Restrição devido } \\
\text { vazamento excessivo no retorno de óleo } \\
\text { pelo regulador de velocidade, mais } \\
\text { especificamente pelo circuito de } \\
\text { comando hidráulico do rotor kaplan. }\end{array}$ & 22/06/2012 07:29 & \begin{tabular}{|l|} 
22/06/2012 23:39 \\
\end{tabular} & & & & & \\
\hline SPUS_13P8_UG1 & $\begin{array}{l}\text { SGI-036.427-08; Restrição devido } \\
\text { vazamento excessivo no retorno de óleo } \\
\text { pelo regulador de velocidade, mais } \\
\text { especificamente pelo circuito de } \\
\text { comando hidráulico do rotor kaplan. }\end{array}$ & 23/06/2012 03:33 & \begin{tabular}{|l|}
$23 / 06 / 2012$ 04:01 \\
\end{tabular} & & & & & \\
\hline SPUS_13P8_UG1 & $\begin{array}{l}\text { SGl-036.427-08; Restrição devido } \\
\text { vazamento excessivo no retorno de óleo } \\
\text { pelo regulador de velocidade, mais } \\
\text { especificamente pelo circuito de } \\
\text { comando hidráulico do rotor kaplan. }\end{array}$ & 23/06/2012 04:01 & \begin{tabular}{|l|}
$|09 / 07 / 2012 ~ 11: 56|$ \\
\end{tabular} & & & & & \\
\hline SPUS_13P8_UG1 & & 27/07/2012 15:11 & 27/07/2012 16:28 & SRV & HID & CAIXA DE ÓLEO & BOMBA 1 & ACIONAMENTO DA INTERMITENCIA \\
\hline SPUS_13P8_UG1 & $\begin{array}{l}\text { Restrição devido vazamento excessivo } \\
\text { no retorno de óleo pelo regulador de } \\
\text { velocidade }\end{array}$ & 27/07/2012 16:28 & \begin{tabular}{|l|}
$01 / 01 / 200100: 00$ \\
\end{tabular} & & & & & \\
\hline
\end{tabular}


Como pode ser observado na Tabela 6.1 foram registrados trinta e nove eventos indesejáveis. Os eventos indesejados que mais aconteceram foram: problemas com a pressão no acumulador APP, vazamentos externos no retorno do óleo ao reservatório e bomba 1. Outros eventos indesejados registrados foram problemas com válvula de alívio, trocador de calor, motor 2 , redução na vazão para o sistema de resfriamento de óleo, filtro obstruído e vazamento no atuador.

Problemas com a pressão baixa no acumulador podem ser causados por falta de reposição de ar no acumulador, folgas nas conexões ou problemas no sistema de pressurização de óleo. De acordo na Tabela 6.1 observa-se que não foram registradas as causas das falhas que levaram a ocorrência da pressão baixa no acumulador. Estes eventos indesejáveis levam à parada do regulador de velocidade, já que o acumulador é o responsável por fornecer pressão e vazão para a movimentação dos atuadores do distribuidor e do rotor. Quando se aplicou o método proposto para aquisição do conhecimento, observou-se que o desvio foi identificado pela análise do HAZOP e FTA e os modos de falha no acumulador foram analisadas pela técnica do FMEA.

O segundo evento que mais aconteceu no regulador de velocidade é o vazamento na linha de retorno ao reservatório. Dependendo do volume do vazamento de óleo, o sensor de nível de óleo localizado no reservatório pode enviar um sinal de alerta, se o nível de óleo for menor que $450 \mathrm{~mm}$, e nesse instante o regulador de velocidade ficará indisponível. Quando foi elaborada a análise para o nó 2 com o desvio "nível baixo de óleo" na aplicação da técnica do FTA identificouse as possíveis causas que levam à ocorrência do evento, e um dos causadores desse evento foi o vazamento na linha de retorno ao reservatório.

O terceiro evento que mais aconteceu é o problema com a bomba 1. De acordo com a Tabela 6.1 pode-se observar que não são especificas as causas da falha na bomba 1. Dependendo dos modos de falha da bomba 1, pode ter como consequência a indisponibilidade do regulador de velocidade ou movimentação lenta dos atuadores.

Observa-se na Tabela 6.1 que foi registrada uma falha na válvula proporcional para a qual não foi comentada a causa e as consequências da falha, além disso, 
não foi especificado se foi à válvula proporcional do distribuidor ou o rotor. Dependendo da falha na válvula pode ocorrer a indisponibilidade do regulador de velocidade ou perda na precisão no posicionamento do atuador do distribuidor ou rotor. Quando foi realizada a análise dos nós 8, 9,10 e 11 se elaborou a análise da técnica do FMEA para as válvulas.

De acordo com a Tabela 6.1 observa-se que foi registrada uma falha na válvula de alívio, porém não foi comentada a causa e as consequências desta falha. Quando se analisou o nó 3 observou-se a presença dessa válvula na análise. Dependendo da falha na válvula de alívio, pode ocasionar a indisponibilidade do regulador de velocidade ou pressão insuficiente do sistema causando a movimentação lenta dos atuadores.

$\mathrm{Na}$ Tabela 6.1 observa-se que foi registrada a falha no motor 2, para a qual não foi comentada a causa e consequências da falha. Quando se analisou o nó 3 se levou em consideração os eventos indesejados no motor 2. Dependendo da falha no motor pode ocorrer a indisponibilidade do regulador de velocidade. Para que aconteça indisponibilidade do regulador de velocidade pela falha do motor 2 (o motor 2 forma parte do sistema de pressurização de óleo de reserva) tem que falhar simultaneamente qualquer componente do sistema de pressurização de óleo principal.

De acordo com a Tabela 6.1 observa-se que foi registrada a falha do filtro, porém não foi comentada a causa e as consequências da falha, além disso, não foi especificada a localização do filtro. No sistema têm-se cinco filtros conforme a Figura 5.1; dois filtros no sistema de pressurização de óleo, um filtro no sistema de pressurização de óleo de emergência e dois filtros nas entradas das válvulas proporcionais. Quando se analisou os nós 3, 4 e 7 observou-se a presença dos filtros nas análises. Dependendo da localização do filtro, a falha deste pode ocasionar a indisponibilidade do regulador de velocidade.

Observa-se na Tabela 6.1 que foi registrado o vazamento do atuador hidráulico para a qual não foi comentada a causa e as consequências da falha, além disso, não foi especificado se foi o atuador do distribuidor ou do rotor. O vazamento de óleo no atuador pode ocasionar a indisponibilidade do regulador de velocidade ou nível 
baixo de óleo no reservatório. O vazamento de óleo no atuador foi analisado no nó 2.

Como último evento registrado na Tabela 6.1 tem-se a falha no trocador de calor e redução na vazão para o sistema de resfriamento de óleo do regulador de velocidade. No trocador de calor foi comentada a presença de vazamento de óleo, e as possíveis causas que levam ao vazamento são folgas nas conexões ou presença de trincas no trocador, como é indicado na análise do nó 1 . Como consequência das falhas no trocador de calor e no sistema de abastecimento de água, haverá a elevação da temperatura de óleo e consequentemente a diminuição da viscosidade do fluido, o qual provocará desgaste excessivo dos componentes mecânicos. Quando a temperatura de óleo chega a $70^{\circ} \mathrm{C}$ será enviado um sinal de alerta e o regulador de velocidade ficará indisponível.

Como se pode observar, os eventos que foram registrados pela área da manutenção da usina foram considerados na aplicação do método proposto para aquisição do conhecimento. Foram realizadas várias simulações, modificando os parâmetros de monitoração e se observou que o sistema especialista conseguiu identificar as falhas registradas no histórico de falhas da usina.

Para validar os resultados obtidos para determinar a periocidade para intervenção da manutenção preventiva, foi realizada a comparação entre os resultados desta tese com os obtidos no artigo apresentado por Chareonsuk et al (1997) e os tempos de manutenção preventiva definidos nos planos de manutenção da usina.

No artigo apresentado por Chareonsuk et al (1997) foram utilizados os mesmos critérios desta análise que são: confiabilidade e custos. Nesse artigo não foi introduzido o modelo de degradação por manutenção imperfeita. A comparação dos resultados será feita quando o equipamento ainda não foi submetido a manutenção preventiva, portanto, a degradação nesse instante de tempo não afeta a taxa de falha e permitirá comparar as periocidades da manutenção preventiva.

O método proposto no Capítulo 4 para calcular o tempo de intervenção de manutenção, não pode ser utilizado para valores de $\beta$ menores que 2. No artigo 
constata-se que o valor $\beta=1,8$. No entanto, é possível comparar o primeiro tempo de intervenção para realização da manutenção preventiva, pois o componente ainda não sofreu degradação, o que permite realizar a validação do cálculo. Na Tabela 6.2 podem ser encontrados os dados de entrada para o cálculo.

Tabela 6.2 Dados de entrada

\begin{tabular}{|l|l|l|}
\hline Confiabilidade & $\beta$ & 1,8 \\
\hline & $\eta$ & 50 horas \\
\hline Custos & $\mathrm{K}=\mathrm{C}_{f} / \mathrm{C}_{\mathrm{p}}$ & 4 \\
\hline
\end{tabular}

As alternativas são: $10,20,30,40,50$ dias. A Tabela 6.3 ilustra a função preferência e seus respectivos parâmetros.

Tabela 6.3 Função de preferência e características dos critérios.

\begin{tabular}{|l|c|c|}
\hline Características & $\begin{array}{c}\mathbf{R} \\
\text { (confiabilidade) }\end{array}$ & $\begin{array}{c}\text { Cm } \\
\text { (custo de manutenção) }\end{array}$ \\
\hline Pesos & $40 \%$ & $60 \%$ \\
\hline Maximizar / Minimizar & Maximizar & Minimizar \\
\hline Função Preferência & Linear & Usual \\
\hline Limite de indiferença (q) & 0,01 & - \\
\hline Limite de preferência (p) & 0,15 & - \\
\hline
\end{tabular}

Com o resultado obtido do modelo de cálculo apresentado no artigo, juntamente com os resultados do método proposto para determinar a periocidade para intervenção de manutenção preventiva, é possível chegar ao mesmo resultado de 30 dias, mostrando que o método proposto está correto.

É importante ressaltar que o responsável da área da manutenção da Usina ajudou na validação dos resultados calculados pelo modelo. Para realizar a avaliação foram utilizados cinco componentes do regulador de velocidade, sendo eles: bomba, motor, atuador, acumulador e trocador. Devido ao acordo de confidencialidade assinado, nesse trabalho só serão apresentados os resultados de avaliação do atuador hidráulico. 
Para o atuador, o modelo desenvolvido neste trabalho indica intervenções de manutenção variando entre 3 e 6 anos, dependendo da relação entre os custos de manutenção corretiva e preventiva, como indicado na Tabela 5.10. No plano da manutenção da usina indica-se a inspeção mecânica a cada 6 anos e revisão mecânica a cada 12 anos. Os resultados obtidos neste projeto são consonantes com o plano da manutenção da usina, pois se considera a falha por desgaste $(\beta=2)$ o que exige recondicionamento mecânico em caso de vazamentos internos e externos. 


\section{CONCLUSÕES}

\subsection{Conclusões}

A execução desta pesquisa proporcionou o desenvolvimento de um método para aquisição do conhecimento integrando as técnicas de análise confiabilidade e risco para o desenvolvimento de um sistema especialista para o diagnóstico de falhas. $O$ método pode ser aplicado em qualquer área da indústria.

O processo de aquisição do conhecimento é uma das principais etapas de desenvolvimento de um sistema especialista e é considerado como um dos estágios mais difíceis e importantes de serem executados. As etapas propostas para aquisição do conhecimento neste trabalho permite ao engenheiro do conhecimento e especialistas adquirir o conhecimento de forma organizada e clara. A qualidade do sistema especialista está relacionada com a qualidade da aquisição do conhecimento.

O método proposto mostrou-se viável para o desenvolvimento do sistema especialista aplicado no diagnóstico de falhas. Ressalta-se a importância de seguir passo a passo as etapas propostas no método, que apresenta a sequência das atividades que permitem fazer a análise detalhada e confiável do sistema, pois são utilizadas numa ordem lógica e organizadas.

A aplicação do método mostrou a inclusão da técnica da árvore funcional como ponto de partida que permite criar uma estrutura funcional do sistema, que pode mapear as relações entre os diversos componentes dentro do sistema. A proposta da árvore funcional já fornece uma representação preliminar dos possíveis cenários de falhas.

Com a aplicação da técnica HAZOP, é possível selecionar os nós a serem analisados e identificar os parâmetros de operação mensuráveis nos mesmos para os quais analisa-se os desvios operacionais. Dos desvios operacionais identificados se conseguirá definir as consequências sobre a operação do sistema. 
A aplicação da técnica FTA permite modelar a ocorrência de eventos simultâneos para identificar as causas dos desvios analisados no HAZOP.

Com a aplicação da técnica FMEA, são fornecidos subsídios para a elaboração de planejamento das ações de manutenção preventivas e preditiva aplicando os diagramas de decisão da filosofia da Manutenção Centrada em Confiabilidade.

O método proposto é diferente dos existentes na literatura pelo fato de integrar e aplicar as técnicas HAZOP, FTA e FMEA para a aquisição do conhecimento para o sistema especialista.

O método para determinar a periocidade da manutenção preventiva considera na degradação do componente e também baseia-se na teoria de multicritério, levando a consideração os critérios de confiabilidade e custo, tendo como objetivo maximizar a confiabilidade e reduzir os custos.

Especificamente com relação ao caso exemplo selecionou-se o regulador de velocidade de turbinas Kaplan. Durante o desenvolvimento deste caso exemplo foi possível verificar que a aplicação deste método precisa de um conjunto de informações bem organizadas para entender a função que cada componente desempenha dentro do regulador de velocidade.

O método foi validado com a comparação do histórico de falhas e, considerandose que os eventos básicos (causadores da falha) registrados no histórico de falhas foram encontrados nos resultados da análise, fato que valida o método. O método para determinar a periocidade para intervenção para manutenção preventiva foi validado através de comparação com os resultados de artigos e com os planos de manutenção da usina.

\subsection{Recomendações para trabalhos futuros}

O método proposto neste trabalho, que foi aplicado no regulador de velocidade, e deve ser aplicado em outros sistemas presente na indústria. Com a aplicação do método em outros tipos de sistema poderá surgir à necessidade de 
incluir outras técnicas de análise de confiabilidade e risco para poder solucionar os problemas do sistema em análise.

O desenvolvimento de um sistema hibrido que integre técnicas de aprendizado de máquina com o método proposto neste trabalho, para poder solucionar diversos problemas no setor industrial, como por exemplo, petroquímica, processos químicos, mineração, entre outras.

Como se observou no estudo de caso, o sistema especialista realiza uma série de perguntas ao responsável da operação da máquina quando não consegue identificar a falha por falta de parâmetros de monitoração. Como trabalhos futuros seria importante melhorar o sistema de monitoração do hidrogerador, o qual permitirá que o sistema especialista tenha mais parâmetros de entrada e reduza o tempo de identificação da falha. As perguntas realizadas pelo sistema especialista podem servir de subsídio para o projeto do sistema de monitoração. 


\section{REFERÊNCIAS BIBLIOGRÁFICAS}

ASSOCIAÇÃO BRASILEIRA DE NORMAS TÉCNICAS. NBR 5462: Confiabilidade e mantenabilidade. Rio de Janeiro, 1994.

AFGAN, N.H. e CARVALHO, M.G. Knowledge-Based Expert System for Fouling Assessment of Industrial Heat Exchangers. Applied Thermal Engineering - 16. pp 203-208. 1996.

AGENCIA NACIONAL DE ENERGIA ELÉTRICA. Resolução n. 161 de abril de 2001. Disponível em: <http://www.aneel.gov.br/>. Acesso em: 9 jun. 2011.

. Resolução n. 328 de 6 de outubro de 1998. Disponível em: <http://www.aneel.gov.br/>. Acesso em: 3 jun. 2011.

. Informações Gerenciais. Disponível em: <http://www.aneel.gov.br/>. Acesso em: 9 jun. 2012.

ALBERT, W.L. e YAO, C.H. Developing a PC-based automated monitoring and control platform for electric power systems. Electric Power Systems Research 64. 2003.

ALENCAR, L. Metodologias de análise de riscos APP \& HAZOP 2005. Disponível em:

$<$ http://professor.ucg.br/SiteDocente/admin/arquivosUpload/13179/material/APP_e_ HAZOP.pdf>. Acesso em: 22 feb. 2012.

ALGAN, N.H. et al. An expert system concept for diagnosis and monitoring of gas turbine combustion chambers. Applied Thermal Engineering - 26. pp. 766 771. 2006.

ALI, M. e KHAMIS, M. TIREDDX: an integrated intelligent defects diagnostic system for tire production and service. Expert system with applications - 24. pp 247-259. 2003. 
ALMEIDA, A.T. Modelagem multicritério para seleção de intervalos de manutenção preventiva baseada na teoria da utilidade multiatributo. Pesquisa operacional-25(1). pp. 69-81, 2005.

ALMEIDA, A.T. Multicriteria Model for selections of preventive maintenance Intervals. Quality and reliability engineering international- 28. pp 585-593. 2012.

APPLIED. Fluid power connection: technical information. Disponível em: $<$ http://www.applied.com> Acesso em: 25 feb. 2014.

ANDIA, C. G. Centrales Eléctricas. $1^{\circ}$ ed. Arequipa: Universidad Católica de Santa Maria, 2005. 420p.

ASHRAFI, N. KUILBOER, J. P. e WAGNER, J.M. Expert systems reliability: A life cycle approach. Information \& Management-28. pp 405-414. 1995.

ASSOCIAÇÃO BRASILEIRA DE NORMAS TÉCNICAS. NBR 5462: Confiabilidade e Mantenabilidade. Rio de Janeiro, 1994.

AWADALLAH, M. Application of Al tools in Fault diagnosis of electrical machines and drives - An overview. IEEE transactions on knowledge and data engineering - 18. pp 245-251. 2003.

AZADEH, A.; EBRAHIMIPOUR, V. E BAVAR, V. A fuzzy inference system for pumpo failure diagnosis to improve maintenance process: The case of a petrochemical industry. Expert Systems with Applications - 37. pp. 627-639. 2010.

AZAIEZ, M.N. A multi-attribute preventive replacement model. Journal of quality in maintenance-8. pp. 213-225. 2002.

BAGNOLI, E. et al. Fatigue failure of a stainless steel wires used in a hydraulic pressure line. Engineering Failure Analysis-16. pp. 1404-1411. 2009.

BONALDI, E. et al. Diagnóstico de falhas em motores de corrente continua. VIII Conferencia internacional de aplicações industriais, Poços Calda, 2008. 
BASSETTO, N.Z. SEPPA - Sistemas Especialistas para Planta de Produção de Álcool. Dissertação de Mestrado apresentada à Faculdade de Engenharia Química - Universidade Estadual de Campinas, Campinas, 91p, 2006.

BATANOV, D. et al. EXPERT-MM: a knowledge-based system for maintenance management. Artificial intelligence in engineering - 8. pp. 283-291. 1993.

BATANOV, D. e Cheng, Z. An object-oriented expert system for fault diagnosis in the ethylene distillation process. Computers in Industry-27. pp 237-249. 1995.

BARTHOLOMEW-BIGGS, M.; ZUO, M. J.; LI, X. Modeling and optimizing sequential imperfect preventive maintenance. Reliability Engineering and System Safety- 94(1), pp. 53-62. 2009.

BARR, A. e FEIGENBAUM, E. The handbook of artificial intelligence. 1st ed. California: William Kaufmann Inc; 1981.

BERRAIS, A. Knowledge-Based expert systems: User interface implications. Advances in Engineering software - 28. pp 31-41. 1997.

BLANNING, R.W. Management Applications of Expert Systems. Information \& Management- 7. pp 311-316. 1984.

BROOKE, P.J. E PAIGE, R.F. Fault trees for security system design and analysis. Computers Security- 22. pp. 256-264. 2003.

BLOCH, H.P.; e GEITNER, F.K. Machinery Failure Analysis and Troubleshooting. $3^{\circ}$ ed. Texas: Gulf Professional Publishing, 1999. 668p.

CARAZAS, F.J.G. Decisões baseadas em Risco-Método aplicado na indústria de geração de energia elétrica para a seleção de equipamentos críticos e políticas de manutenção. Tese de Doutorado apresentada à Escola Politécnica da Universidade de São Paulo, São Paulo, 2011.

CASSANELLI, G. et al. Failure Analysis - assisted FMEA. Microelectronics Reliability - 46. pp 1795-1799. 2006. 
CASTELLANOS, V. et al. Failure analysis expert system for onshore pipelines. Part - I: Structured database and knowledge acquisition. Expert system with applications - 38. pp 11085-11090. 2011.

CASTELLANOS, V. et al. Failure analysis expert system for onshore pipelines. Part - II: End-User interface and algorithm. Expert system with applications - 38. pp 11091-11104. 2011.

CHAN, C. An expert decision support system for monitoring and diagnosis of petroleum production and separation processes. Expert system with applications -29. pp 131-143. 2005.

Chan JK, Shaw L. Modeling repairable systems with failure rates that depend on age and maintenance. IEEE Transactions on Reliability - 42(4). pp 566-71. 1993

CHAU, K.W. e YANG, W.W. A knowledge-based Expert System for Unsteady Open Channel Flow. Engineering application Artificial Intelligence - 5. pp 425-430. 1992.

CHAREONSUK, C.; NAGARUR, N.; TABUCANON, M. A multicriteria approach to the selection of preventive maintenance intervals. International Journal Production Economics-49. pp 55-64, 1997.

CHUNG, H. Y. et al. Diagnostic strategies of a prototype expert system for malfunction diagnosis of primary-side system in nuclear power plant. Electrical Power \& Energy Systems - 14. pp. 284-297. 2002.

COSTA, E. S.C. et al. Sobre os sinais de vibração no monitoramento de unidades hidrogeradores. Congresso Nacional de Engenharia Mecânica, Campina Grande, 2010.

CAVAlCANTE, C. A. V.; AlMeIDA, A. T. Modelo multicritérios de apoio a decisão para o planejamento de manutenção preventiva utilizando PROMETHEE II em situações de incerteza. Revista Pesquisa Operacional, v.25 n.1, p.69-81, Janeiro a Abril de 2005. 
CAVALCANTE, C.A.V.; e ALMEIDA, A.T. A multi-criteria decision-aiding model using PROMETHEE III for preventive maintenance planning under uncertain conditions. Journal of Quality in Maintenance Engineering-13. pp 385- 397. 2007

DRAPINSKI J. Hidráulica e Pneumatica Industrial e móvel. $1^{\circ}$ ed. São Paulo: McGraw-Hill do Brasil. 287p. 1975.

DE NEGRI, V. J. Sistemas Hidráulicos e Pneumáticos para Automação e controle. Florianópolis. 2001. Apostila para disciplina de pós-graduação do Departamento de Engenharia Mecânica. Universidade Federal de Santa Catarina. 2001.

DETROJA, K.P., GUDI, R.D. E PATWARDHAN, S.C. "A possibilistic clustering approach to novel fault detection and isolation". Journal of Process Control - 16, pp. 1055-1073, 2006.

DÍEZ, P. F. Turbinas Hidráulicas. Departamento de Ingeniería Eléctrica y Energética de la Universidad de Catarina, Espanha, 1996. 141p. Disponível em: <http://libros.redsauce.net.>. Acesso em: 16 abr. 2012.

DOCHAIN, D.; et al. Monitoring and control of process and power systems: Towards new paradigms Status report prepared by the IFAC Coordinating committee on Process and Power Systems. Annual Reviews in Control - 30. pp. $69-79.2006$.

DOYEN, L.; GAUDOIN, O. Classes of imperfect repair models based on reduction of failure intensity or virtual age. Reliability Engineering and System Safety-84(1). pp. 45 - 56. 2004.

DUAN, R.; e ZHOU, H. A New Fault Diagnosis Method Based on Fault Tree and Bayesian Networks. Energy Procedia - 17. pp 1376-1382. 2012.

DUARTE, Z. ¿Preventivo, predictivo o correctivo?. Decisión bajo el enfoque de planificación de las acciones de mantenimiento. Uptime Magazine, 2007. Disponível em: <http://confiabilidad.net.>. Acesso em: 28 jul. 2012. 
EBERSBACH, S. e PENG, Z. Expert system development for vibration analysis in machine condition monitoring. Expert system with applications - 34. pp 291299. 2008.

ERICSON, C.A. Hazard Analysis Techniques for System Safety. New Jersey: John Wiley \& Sons, 2005.

FEIGENBAUM E.A. et al. On generality and problem solving: A case study using Dendral program. Machine Intelligence - 6. pp 165-190. 1971.

FERREIROS CAT. Manual técnico para estudiantes, instrucción técnica DMSE0020-2004a. Lima. 173p. 2004.

FILHO, A.C. Sistema especialista para o forjamento a quente de precisão. Teses de Doutorado apresentada à comissão de Pós-Graduação da Faculdade de Engenharia Mecânica FEM- Universidade Estadual de Campinas, Campinas, 145p, 2003.

FLACH, P.A. On the state of art in Machine Learning: a personal review. Departament of Computer Science, University of Bristol. pp 1-24. 2000.

FRITH R.H.; SCOTT W.; Control of solids contamination in hydraulic systemsAn Overview. Wear-165. pp. 69-74. 1993.

FREDERICK, H. Ruled - Based systems. Communications of the ACM - 28. pp 921-932. 1985.

FOULADIRAD, M.; GRALL, A.; DIEULLE, L. On the use of on-line detection for maintenance of gradually deteriorating systems. Reliability Engineering \& System Safety $93,1814-1820.2008$.

GIARRATANO J. Expert Systems: Principles and Programming. 4th ed. New York: Course Technology Inc, 2004

GRAHAM-JONES, P.J. e MELLOR, B.G. Expert and Knowledge-based systems in failure analysis. Engineering Failure Analysis - 2. pp 197-149. 1995. 
GOPALASWAMY, V.; RICE, J.A. \& MILLER, F.G. Transit Vehicle Component Maintenance Policy via Multiple Criteria Decision Making Methods. The Journal of the Operational Research Society, 44(1). pp. 37-50, 1993

GUERREIRO, M.A. Desenvolvimento de um sistema especialista para o projeto de unidades industriais de produção de álcool. Dissertação de Mestrado apresentada à Faculdade de Engenharia Elétrica FEE - Universidade Estadual de Campinas, Campinas, 115p, 1995.

GURTHIER, J. e BROCON, C.B.E. Hydro-Electric Engineering Practice. John Wiley \& Sons, New York. 1965.

HAIMMES, Y. Risk modeling assessment and management. John Wiley \& Sons, New York. 1998.

HAMEED, Z.; et al. Condition monitoring and fault detection of Wind turbines and relates algorithms; A review. Renewable and Sustainable Energy Reviews 13. pp. 1-39. 2009.

HAWKINS, P.G. e WOLLONS, D.J. Failure modes Effects Analysis of Complex Engineering Systems Using Funtional Models. Artificial Intelligence in Engineering-12. p.375-397. 1998.

HELMAN, K.S.; MARÇAL, R.F.M. Método multicritério de apoio à decisão na gestão da manutenção: Aplicação do método ELECTRE I na seleção de equipamentos críticos. Revista gestão industrial-3. pp. 123-134.2007

HIDALGO, E.M.P et al. FMEA and FTA analysis applied to the steering system of LNG carriers for the selection of maintenance policies. Proceeding of the $21^{\text {st }}$ Brazilian Congress of Mechanical Engineering. Natal, Brazil, 2011.

HIGA, K. e LEE, H. A graph - based approach for rule integrity and maintainability in expert system maintenance. Information \& Management - 33 . pp 273-285. 1998. 
HUGUEROS P.S.; NETO W.W. Avaliação de corrosão em trocadores de calor tipo duplo tubo, através da técnica da radiografia computarizada. XXI Congresso Nacional de Ensaios Não Destrutivos, Salvador, 2002.

IEC. International Electrotechnical Commission. Risk Management - Risk Assessment Techniques. IEC/FDIS 31010:2009(E), 2009.

JINGYI, Z. et al. The development and prospect of hydraulic reliability engineering. 2001.

JUNIOR, J.R.F. Sistema especialista para diagnóstico de unidades de disco. Dissertação de Mestrado apresentada à Faculdade de Engenharia Elétrica FEE Universidade Estadual de Campinas, Campinas, 109p, 1988.

KHAN, F.I. Knowledge-based expert system framework, systems, management, and cybernetics. IEEE International Conference- 3. pp 2274-2280. 2005.

KHAN, F.I.; e ABBASI, S.A. Towards automation of HAZOP with a new tool EXPERTOP. Environmental Modelling and Software - 15. pp 67-77. 2000.

KRALJA, B. \& PETROVIC, R. A Multiobjective Optimization Approach to Thermal Generating Units Maintenance Scheduling. European Journal of Operational Research-84(2). pp. 481-493, 1995.

KRISHNASAMY, L.; KHAN, F.; e HADDARA, M. Development of risk-based maintenance (RBM) strategy for a power-generating plant. Journal of Loss Prevention in the Process Industries-18, p. 69-81.2005.

KUMAMOTO, $\mathrm{H}$. et al. Application of expert system techniques to fault diagnosis. The chemical engineering journal -29. pp 1-9. 1984.

KUMAMOTO, $\mathrm{H}$ e HENLEY, E. Probabilistic risk assessment and management for engineer and scientists. $2^{\circ}$ ed. Nova York, 2000. 620pp.

KUSIAK, A.; LI, W.; The prediction and diagnosis of wind turbine faults. Renewable Energy - 36. pp. 16-23. 2010 
KUNZE, U. Condition Telemonitoring and Diagnosis of Power Plants Using Web Technology. Progress in Nuclear Energy - 43.pp 129-136. 2003.

LEITCH, R. Reliability Analysis for Engineers. $1^{\circ}$ ed. Grão-Bretanha: Oxford Press, 1995. 230p.a

LEONE, H. A Knowledge-Based system for HAZOP Studies. The knowledge Representation structure. European Symposium on Computer Aided Process Engineering -6. pp 363-374. 1996.

LEWIS, E. E. Introduction to Reliability Engineering. $2^{\circ}$ ed. New York: John Wiley \& Sons, 1987. 435p.

Li, Z.H.; LIU, M.K. Review of intelligence fault diagnosis in power system. Electric Engineering-8.pp 21-24. 2010.

LIAO, S. Expert system methodologies and applications a decade review from 1995 to 2004. Expert systems and applications - 28. pp 93-103. 2005.

LINSINGEN, I. V. Fundamentos de sistemas hidráulicos. $3^{\circ}$ ed. Florianópolis: UFSC, 2008. 399p.

LOTFI, V. Implementing flexible automation: a multiple criteria decision making approach. International journal of production economics - 38. pp. 255-268. 1995.

LORENA, A.C. e CARVALHO, A.C. Uma introdução às support Vector Machines. Revista de informática teórica e aplicada - 14. pp 43-67.2007

MAHER, M. et al. Tools and techniques for Knowledge Based expert system for engineering design. Adv. Eng. Sofware -6. pp 178-188. 1984.

MALIK, M. Reliable preventive maintenance policy. AlIE Transactions-11(3). pp. 221-228. 1979.

MAGLOGIANNIS, LL.G. Emerging Artificial Intelligence Applications in Computer Engineering: real word Al Systems with applications in EHealth, $\mathrm{HCl}$, 
Information Retrieval and Pervasive Technologies. $1^{\circ}$ ed. New York: IOSS Press INC, 2007. 407p.

MAJSTOROVIC, V.D. e MILACIC, V.R. Expert System for Maintenance in the CIM Concept. Computers in Industry - 15. pp. 83-93. 1990.

NAKAGAWA T. Sequential imperfect preventive maintenance policies. IEEE Transactions on Reliability-37(3). pp 295 - 298. 1988.

MATIJEVICS, I. e JÓZSA, L. An Expert-system-assisted Reliability Analysis of Electric Power Networks. Engineering application Artificial Intelligence - 8. pp 449460. 1995.

MATSATSINIS, N.F.; DOUMPOS, M. e ZOPOUNIDIS, C. Knowledge Acquisition and Representation for Expert System in the Field of Financial Analysis. Expert System With Applications - 12. pp 247-262. 1997.

MAZZORANA, R.H.F. Modelagem dinâmica via fluxo de potência de Reguladores de Velocidade em Usinas Hidroelétricas, 2008. 140p. Dissertação (Mestrado) - Departamento de Engenharia Mecânica, Universidade Federal de Santa Catarina, Florianópolis, 2008.

MEZCUA, B. et al. An expert system development tool for non Al experts. Expert system with applications - 38. pp. 597-609. 2011.

MILLER, D. et al. An Image enhanced, Knowledge based expert system for maintenance Trouble Shooting. Computer in industry - 15. pp 187-202. 1990.

MONARCH. Information and troubleshooting guide. Disponível em: <http://www.monarchhyd.com>. Acesso em: 20 abr. 2014.

MONTILLA, C.A.; ARROYAVE, J.F. e SILVA, C.E. Caso de Aplicación Centrado em la Confiabilidad RCM, previa existencia de Mantenimiento Preventivo. Red de Revistas Científicas de América Latina y el Caribe, España y Portugal, 2007. 
MOUBRAY, J. Reliability Centered Maintenance. $2^{\circ}$ ed. New York: Industrial Press, 2000. 445p.

MOBLEY, R.K. Fluid Power Dynamics. Editora Butterworth-Heinemann, Estados Unidos, 2000.

MULVANEY, D. e BRISTOW, C. A Ruled-Based extension to the C++ language. Software - Practice and experience - 27. pp 747-761. 1997.

NIKOLOPOULOS, C. Expert systems: Introduction to Frist and Second Generation and Hydrid Knowledge Based Systems. 1st ed. New York: Marcel Dekker INC;1997.

NUNES, T.I. Um sistema especialista para verificação de regras de projeto elétrico em circuitos integrados de tecnologia CMOS VLSI. Dissertação de Mestrado apresentada à Faculdade de Engenharia Elétrica FEE - Universidade Estadual de Campinas, Campinas, 147p, 1990.

O'KEEFE, R.M. e PREECE, A.D. The development, validation and implementation of knowledge-based systems. European Journal of Operational Research - 92. pp 458-473. 1996.

O' CONNOR, P.D.T. Practical Reliability Engineering. $2^{\text {nd }}$ Edition. New York: Wiley\&Sons, 500 pp. 1985.

OLIVEIRA, E. C. Detecção de Falhas no Helicóptero 3DOF. Dissertação de Mestrado apresentada a Instituto Tecnológico de Aeronáutica, São José dos Campos, São Paulo, 2010.

PAES, F.H.; e DE NEGRI, V.J. Capacitação industrial para construção de sistemas hidráulicos de controladores de turbinas, projeto PADCT/REIVAX. Florianópolis, 75p. 2002.

PAPADOPOULOS, Y. Model-based system monitoring and diagnosis of failures using statecharts and fault trees. Reliability Engineering and System Safety - 81 . pp 325-341. 2003. 
PARK. M. Fatigue failure of a Hydraulic filter head. Engineering Failure Analysis9. pp. 435-450, 2002.

PARKER. Tecnologia hidráulica industrial. Jacarei. 158p. 1999.

PARR, A.A. Hydraulic and Pneumatic. $1^{\circ}$ ed. New York: Elservier Science \& Technlogy Books, 1999. 249p.

PETROBRAS NBR 2782. Critérios para Aplicação de Técnicas de Avaliação de Riscos. Rio de Janeiro, 2004.

PINHEIRO, H.B. Sistema especialista para Operação de Subestações de Energia Elétrica. Dissertação de Mestrado apresentada à Faculdade de Engenharia Elétrica FEE - Universidade Estadual de Campinas, Campinas, 97p, 1995.

PHAM, H.; WANG, H. Imperfect maintenance. European Journal of Operational Research-94(3), pp 425-438, 1996.

PORCIÚNCULA, G; DE NEGRI V; DIAS A. Reliability of Electro-Hydraulic equipment systematization and analysis. $A B C M$ Symposium Series in Mechatronics-2. p.393-400, 2006.

PUÑAL, A. et al. An expert system for monitoring and diagnosis of anaerobic wastewater treatment plants. Water research - 36. pp 2656-2666. 2002.

QIAN, Y. et al. LUBRES: an expert system development and implementation for real-time fault diagnosis of a lubricating oil refining process. Experts systems with Applications -35. pp. 1252-1266. 2008.

RAC. Nonelectronic Parts Reliability Data. Rome: Rome laboratory, 1995. 1004p.

RAHMAN, S. et al. ExpHazop: Knowledge-based expert system to conduct automated HAZOP. Journal of Loss Prevention in the Process Industries - 22. pp 373-380. 2009. 
RAMASWANY, M. et al. Using Directed hypergraphs to verify Ruled-Based Expert Systems. IEEE transactions on knowledge and data engineering - 9. pp 221237. 1997.

RAO, M.P.; MILLER, D. M. e LIN, B. PET: An expert system for productivity analysis. Experts Systems with Applications - 29. pp 300-309. 2005.

RAUSAND, M. e ARNOLJOT, H. System Reliability Theory, Models, Statistical, Methods and Applications. $2^{\circ}$ ed. New Jersey: John Wiley \& Sons, 2004. 668p.

RAVI, D.; ANDRIES, B. Hydraulic Systems, Operation and troubleshooting for engineers \& technicians, $1^{\circ}$ ed. New York: Elservier Science \& Technlogy Books, 2005. 232p.

REIVAX. Regulador de Velocidade RVX 300. Disponível em: <http://www.reivax.com.br>. Acesso em: 15 de fev. 2012.

REZENDE, S.O. Sistemas inteligentes: fundamentos e aplicações. Editora Manole Ltda. Barueri SP. 2005. 527p.

ROBERT, B. e MARCHE, C. An expert system to assist designers of hydraulic systems. Engineering applications of artificial intelligence -2. 1989.

ROSÁRIO, C.R. Metodologia MACTAC - aquisição de conhecimento tácito coletivo para auxiliar no diagnóstico de causa raiz de defeito em processis industriais utilizando sistema especialista. Dissertação de Mestrado apresentada ao Programa de Pós-Graduação em Sistemas e Processos Industriais Universidade de Santa Cruz do Sul, Santa Cruz do Sul, 148p. 2012.

SAIMURUGAN, M. et al. Multi component fault diagnosis of rotational mechanical system based on decision tree and support vector machine. Expert Systems with Applications-38. pp 3819-3826.2011.

SALAHSHOOR, K.; et al. Fault detection and diagnosis of an industrial steam turbine using fusion of SVM ( support vector machine) and ANFIS (adaptive neuro - fuzzy inference system) classifiers. Energy. pp 1-11. 2010. 
SARANGA, H.; KNEZEVIC, J. Reliability prediction for condition-based maintained systems. Reliability Engineering \& System Safety 71, 219 - 224. 2001.

SILVA, V. Modelo multicritério de decisão em grupo para recuperação da bacia de rio Jaboatão em Pernambuco. 136p. Dissertação (Mestrado) - a Departamento de Engenharia de Produção, Universidade Federal de Pernambuco, Recife, 2012.

SIMANI, S.; PATTON, R. J. Fault diagnosis of an industrial gas turbine prototype using a system identification approach. Control Engineering Practice - 16. pp. 769-786. 2008

SMITH, A. e HINCHCLIFFE, G. RCM Gateway to world class maintenance. $1^{\circ} \mathrm{ed}$. Londres: Elservier Butterworth Heinemann, 2004. 335p.

SMITH, D.J. Reliability, Maintainability and Risk. $6^{\circ}$ ed. Oxford: Butterwoth Heinemann, 2001.

SOLIMAN, A.; RIZZONI, G. e KIM, Y.W. Diagnosis of an automotive emission control system using fuzzy inference. Control Engineering Practice - 7. pp 209216. 1999.

SONG, G. et al. HYDES; A Wed-based hydro turbine fault diagnosis system. Expert System with Application - 34. pp. 764-772. 2008.

SOUZA, G.F.M. e MOLINARI, R. PMR-5235 Fundamentos da Manutenção de Sistemas Mecânicos. São Paulo: EPUSP, 2008. 60p. Apostila para disciplina de Pós-Graduação do Departamento de Engenharia Mecatrônica, PMR-5235. Fundamentos da Manutenção de Sistemas Mecânicos.

SOUZA, G.F.M.. Análise de Confiabilidade Aplicada ao Projeto de Sistemas Mecânicos. São Paulo: EPUSP, 2008. Apostila para disciplina de pós-graduação, do Departamento de Engenharia Mecatrônica, PMR-5201. Análise de Confiabilidade Aplicada ao Projeto de Sistemas Mecânicos. 
STREICHFUSS, M.; BURGWINKEL. An Expert-System machine monitoring and maintenance management system. Control Eng. Practice - 3. pp 1023-1027. 1995.

SUN, W.; CHEN, J. e LI, J. Decision tree and PCA-based fault diagnosis of rotating machinery. Mechanical Systems and Signal Processing - 21. Pp 13001317. 2007.

SUNDARARAJAN, C. Guide to Reliability Engineering. $1^{\circ}$ ed. New York: Van Nostrand Reinhold, 1991. 424p.

SUNJURA, I.S. Um modelo de integração do conhecimento aplicada à diagnose. Dissertação de Mestrado apresentada à comissão de Pós.Graduação da Faculdade de Engenharia Mecânica FEE - Universidade Estadual de Campinas, Campinas, 150p, 1996.

TAl, A. H.; CHAN, L. Y. Maintenance models for a continuously degrading system. Computers \& Industrial Engineering- 58(4), pp 578 - 583. 2010.

TANAKA, $H$. et al. Research and development on expert systems applications to power systems in Japan. Electrical Power \& Energy Systems - 14. pp. 71-85. 1992.

TANG, J. e WANG, Q. Online fault diagnosis and prevention expert systems for dredgers. Expert Systems with Applications - 34. pp 511-521. 2008.

TRAN, V.T.; et al. Fault diagnosis of induction motor based on decision trees and adaptive neuro-fuzzy inference. Expert Systems with Applications-36. pp 1840-1849. 2009.

TONACO, R.P. Metodologia para Desenvolvimento de Base de Conhecimento Aplicada à Manutenção Baseada em Condição de Usinas Hidrelétricas. Dissertação de Mestrado apresentada à Faculdade de Engenharia Mecânica Universidade de Brasília, Brasília, 167p. 2008.

UPADHYAYA, B.R.; ZHAO, K. e LU, B. Fault Monitoring of Nuclear Power Plant Sensors and Field Devices. Progress in Nuclear Energy - 43. pp 337-342. 2003. 
US MIL-STD-1629A. Procedures for Performing a Failure Mode, Effects and Criticality Analysis. Washington, 1977. Disponível em: <http://www.goesr. gov/procurement/antenna_docs/reference/MIL-STD-1629A.pdf>. Acesso em: 10 jan. 2012.

VENKATASUMRAMANIAN, V.; ZHAO, J. e VISWANATHAN, S. Intelligent systems for HAZOP analysis of complex process plants. Computers and Chemical Engineering - 24. pp 2291-2302. 2000.

VICKER. Hydraulic hints \& Troubleshhoting guide. Disponível em: <http://www.eaton.com>. Acesso em: 17 fev. 2013.

- Logical troubleshooting in hydraulic systems. Disponível em: <http://www.eaton.com>. Acesso em: 22 abr. 2014.

VINADE, C.A.C. et al. FMEA aplicado no desenvolvimento de Sistemas Hidráulicos. $3^{\circ}$ Congresso Brasileiro de Gestão de Desenvolvimento de Produto, Florianópolis, 2001.

VINADE, C.A.C. Sistematização do processo de projeto para confiabilidade e mantenabilidade aplicado a Sistemas Hidráulicos e implementação de um sistema especialista. 2003. 233p. Dissertação (Doutorado) - Departamento de Engenharia Mecânica, Universidade Federal de Santa Catarina, Florianópolis, 2003.

WANG, Y. et al. Research on Fault diagnosis Expert system based on the neural network and the fault tree technology. Procedia Engineering - 3. pp. 1206-1210. 2012.

WIJAVA, A.R; KUMAR, U. Robust-optimum multi-attribute age-based replacement policy. Journal of quality in maintenance-8. pp. 325-343. 2012.

XENOS, H. G. Gerenciamento a Manutenção Preditiva. $1^{\circ}$ Ed. Rio de Janeiro: INDG, 2004. 302p. 
$\mathrm{XIA}, \mathrm{T}$; et al. Modeling and optimizing maintenance schedule for energy systems subject to degradation. Computers \& Industrial Engineering- 63(3). pp 607-614. 2012.

YAMAKI, C.K. Combinando avaliação parcial e introdução automática de controle para aumentar a eficiência de sistemas especialistas. Dissertação de Mestrado apresentada ao Instituto de Matemática, Estatística e Ciência da Computação - Universidade Estadual de Campinas, Campinas, 184p, 1990.

YANG, B.S.; HAN, T. e KIM, Y.S. Integration of ART-Kohonen neural network and case-based reasoning for intelligent fault diagnosis. Expert Systems with Applications -26. pp 387-395. 2004.

YESID, E. A. M. Desenvolvimento de um sistema servopneumático para Regulação Velocidade de turbinas em pequenas centrais Hidroelétricas. 2006. 150p. Dissertação (Mestrado) - Departamento de Engenharia Mecânica,

ZANINI, L.C. et al. Minimização do desgaste erosivo corrosivo em trocadores de calor de usinas termoelétricas a carvão. Laboratório de Síntese de Complexos Multifuncionais, Universidade do Extremo Sul Catarinense. 2007.

ZHI-LING, Y. et al. Expert System of Fault Diagnosis for Gear Box in Wind Turbine. Systems Engineering Procedia - 4. pp 189-195. 2012.

ZHOU, X.; XI, L.; LEE, J. Reliability-centered predictive maintenance scheduling for a continuously monitored system subject to degradation. Reliability Engineering and System Safety, 92(4), 530 - 534. 2007.

ZHOU, Q. et al. A monitoring and diagnosis expert system for carbon dioxide capture. Expert system with applications - 36. pp 1621-1631. 2009. 


\section{ANEXO A: MÉTODO PROMETHEE II}

\section{A.1. Método PROMETHEE II}

O método PROMETHEE (Preference ranking organization method for enrichment evaluations) foi apresentado por Brans e Vincke em 1984. O método é utilizado para o apoio de tomada de decisão e consiste em construir uma relação sobre classificação valorada (SILVA, 2008).

O objetivo do Método PROMETHEE é proporcionar aos decisores um melhor entrosamento e entendimento da metodologia de apoio à decisão com a qual estarão envolvidos. Esta abordagem faz uso abundante do conceito pseudocritério, já que constrói o grau de superação entre cada par de ações ordenadas levando em conta a diferença de pontuação que essas ações possuem a respeito de cada atributo considerado no critério de decisão.

Este método destaca-se por buscar envolver conceitos e parâmetros, os quais têm alguma interpretação física ou econômica, facilmente entendida pelo decisor, tendo sido descrito numa quantidade considerável de trabalhos e aplicado com sucesso em vários problemas de diferentes naturezas (ALMEIDA e COSTAS, 2002).

O método PROMETHEE é usado para resolver um problema multicritério com número $\mathrm{K}$ de critérios e um conjunto $\mathrm{A}$ de alternativas, como se pode observar na Equação A.1. (CHAREONSUK et al, 1997):

$$
\operatorname{Maximizar}\left\{f_{1}(x), f_{2}(x), \ldots, f_{k}(x), \mid x \varepsilon A\right\},
$$

onde $\mathrm{A}$ é um conjunto de alternativas, e, $\mathrm{f}_{1}(\mathrm{x}), \mathrm{i}=1, \ldots, \mathrm{k}$ é o conjunto de critérios para cada alternativa a ser avaliada.

A estrutura de preferência do método PROMETHEE é baseado em comparações de pares. Neste caso, o desvio entre as duas avaliações das alternativas de um critério específico é considerado. Para cada critério a função preferência específica $\mathrm{Pj}$ ( ) deve ser definida. Esta função é usada para calcular a intensidade de preferência associada com o desvio ou diferença dj( ) entre as 
avaliações no critério fj( ) para um par de alternativas. Quanto maior for o desvio, maior é a preferência.

$$
P_{j}(a, b)=P_{j}\left[d_{j}(a, b)\right]
$$

onde se considera $d_{j}(a, b)=f_{j}(a)-f_{j}(b)$, para critérios que sejam maximizados, e $d_{j}(a, b)=f_{j}(b)-f_{j}(a)$ para critérios a serem minimizados.

O método PROMETHEE permitir a escolha entre seis critérios generalizados para definir a função preferência e identificar a intensidade da preferência. Conforme a maneira com que preferência do decisor aumenta com a diferença entre o desempenho das alternativas para cada critério $\left[g_{j}(a)-g_{j}(b)\right]$, ele pode definir uma função $P(a, b)$ que assume valores entre 0 e 1 . Os critérios generalizados são mostrados na Figura A.1. Da Figura A.1 pode-se observar que devem ser utilizados dois parâmetros q e p. Onde q representa um limite de indiferença, o maior valor para $\left[g_{j}(a)-g_{j}(b)\right]$, abaixo do qual há uma indiferença, e $p$ representa o limite de preferência, o menor valor para $\left[g_{j}(a)-g_{j}(b)\right]$, acima do qual há uma preferência estrita (CALVANCATE e COSTAS, 2006).

Figura A.1 Formas para a função preferência.

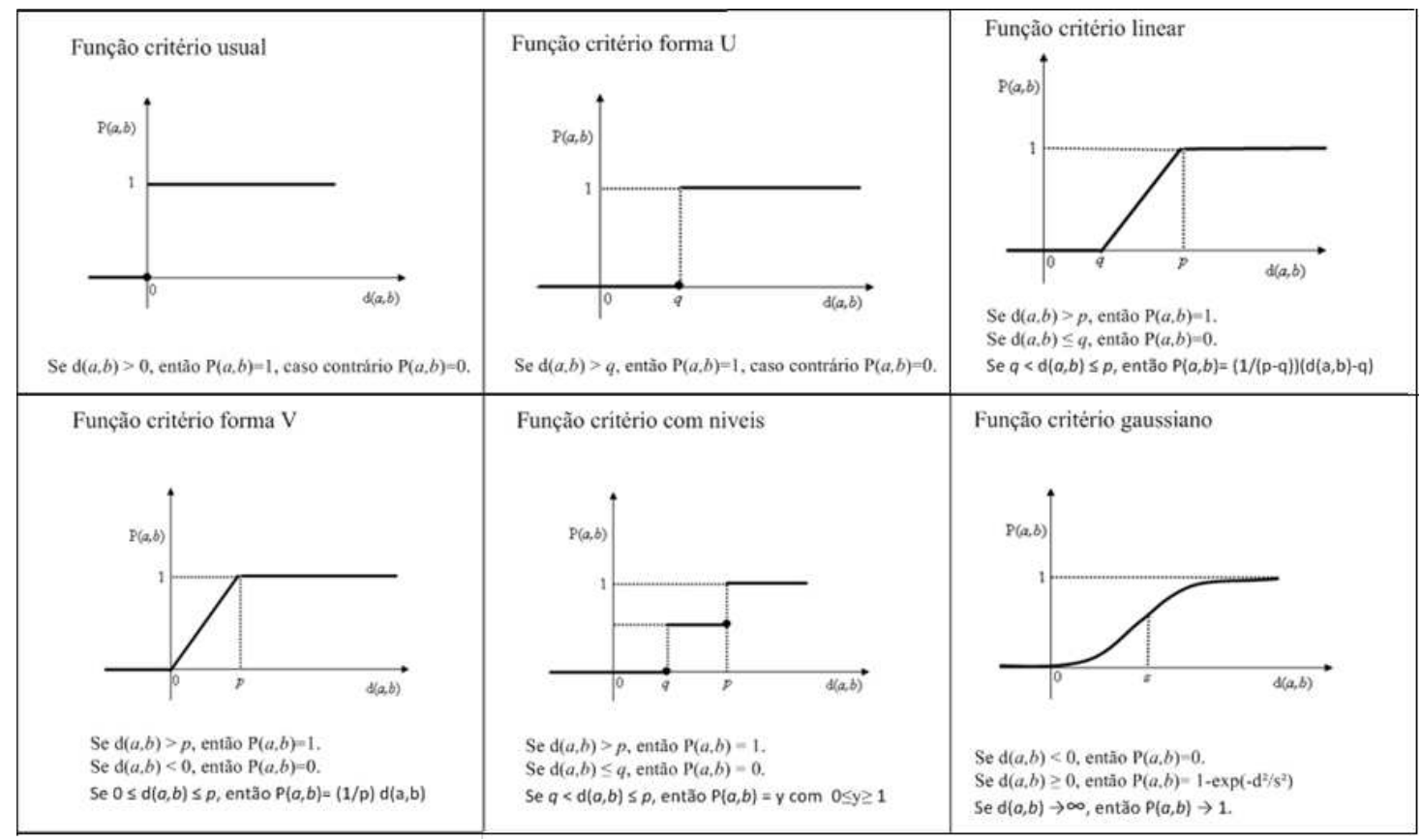


Identificados as intensidades de preferência (que representa o grau de preferência da ação a em relação $a$ b) e os pesos para cada um dos critérios pelos decisores, é feito o calculo do índice de preferência. O índice de preferência define uma relação de preferência valorada que pode ser utilizada na ordenação de alternativas. Além disso, o índice de preferência é um parâmetro que mede a intensidade de preferência de uma alternativa sobre outra levando em consideração todos os critérios. O calculo é representado pela Equação A.3 (CHAREONSUK et al , 1997).

$$
\Pi(a, b)=\sum_{j=1}^{k} w_{j} P_{j}(a, b)
$$

onde $\pi(a, b)$ é o grau de hierarquia e $w_{j}$ é o peso dado para o critério $j$. Os pesos são obtidos a partir do decisor e eles encontram-se normalizados para resumir a unidade.

O índice de preferência ponderado possui as seguintes propriedades:

$$
\begin{gathered}
\pi(a, b)=0 \\
0 \leq \pi(a, b) \leq 1
\end{gathered}
$$

Interpretação:

$\pi(a, b) \approx 0$ denota uma preferência fraca da a sobre $b ;$

$\pi(a, b) \approx 1$ denota uma preferência forte da a sobre $b$.

Calculado os índices de preferência serão feitos os calculados do índice de preferência positivo $\emptyset^{+}(a)$, e o índice de preferência negativo. $\emptyset^{-}(a)$.

O índice de preferência positivo, $\emptyset^{+}(a)$ representa a média de índices de preferência de uma alternativa a sobre todas as outras alternativas do conjunto $A$. Quanto maior $\emptyset^{+}(a)$, melhor a alternativa. $O$ índice de preferência positivo é dado pela Equação A.4. 


$$
\emptyset^{+}(\mathrm{a})=\frac{1}{\mathrm{n}-1} \sum_{\mathrm{x} \varepsilon \mathrm{A}} \Pi(\mathrm{x}, \mathrm{a})
$$

onde $\mathrm{n}$ é o número de alternativas.

O índice de preferência positivo, $\emptyset^{-}$(a) representa a media de índices de preferência de todas as sobre as alternativas a. Quanto menor $\emptyset^{-}(\mathrm{a})$, melhor a alternativa. $O$ índice de preferência negativo é dado pela Equação A.5:

$$
\emptyset^{-}(\mathrm{a})=\frac{1}{\mathrm{n}-1} \sum_{\mathrm{x \varepsilon A}} \Pi(\mathrm{x}, \mathrm{a})
$$

A classificação total do conjunto de alternativas é obtido através da diferença entre os índices de preferência positivo e negativo, para cada alternativa, onde deste modo, todas as alternativas são comparáveis segundo a Equação A.6.

$$
\emptyset(a)=\emptyset^{+}(a)+\emptyset^{-}(a)
$$

\section{A.2. Referências Bibliográficas}

ALMEIDA, A, COSTAS. A. Modelo de decisão multicritério para priorização de sistemas de informação com base no método PROMETHEE. Gestão \& Produção -9. pp. 201-214. 2002.

CAVALCANTE, C.; COSTAS, A. Multicriteria model of preventive maintenance. Brazilian journal of operations \& production management -3. pp 71-86. 2006.

CHAREONSUK, C.; NAGARUR, N.; TABUCANON, M. A multicriteria approach to the selection of preventive maintenance intervals. Int. J. Production Economics 49, pp 55-64, 1997.

SILVA, V. Modelo multicritério de decisão em grupo para recuperação da bacia de rio Jaboatão em Pernambuco. 136p. Dissertação (Mestrado) - a Departamento de Engenharia de Produção, Universidade Federal de Pernambuco, Recife, 2012. 


\section{ANEXO B: REGULADOR DE VELOCIDADE}

Este capítulo tem por objetivo principal reunir e apresentar os principais fundamentos e definições necessárias ao desenvolvimento do estudo proposto sobre reguladores de velocidade. Na primeira etapa, são apresentados os conceitos básicos relacionados com a geração de energia hidrelétrica, buscando identificar os principais componentes de uma instalação, e em particular, o regulador de velocidade, apresentando sua configuração física e definindo suas funções dentro do sistema hidrogerador.

\section{B.1 Centrais Hidrelétricas}

As centrais hidrelétricas produzem energia elétrica a partir de energia mecânica gerada em turbinas hidráulicas. Estas, por sua vez, acionam um gerador elétrico. Um aspecto interessante das centrais hidrelétricas é sua versatilidade de configurações, permitindo desde micro e pico centrais geradoras de alguns watts até grandes hidrelétricas, com capacidade para produzir vários gigawatts.

De acordo com Andia (2005) uma central hidrelétrica é um agrupamento de componentes que tem como principal objetivo transformar a energia potencial hidráulica de um rio ou de uma represa em energia elétrica. Uma central hidrelétrica apresenta alguns sistemas típicos, os quais são: barragem, tomada d'água, conduto forçado, casa de máquina ou casa de Força, canal de Restituição de Água. Na Figura B.1 tem-se uma representação esquemática de uma central hidrelétrica.

Figura B.1 Usina Hidrelétrica.

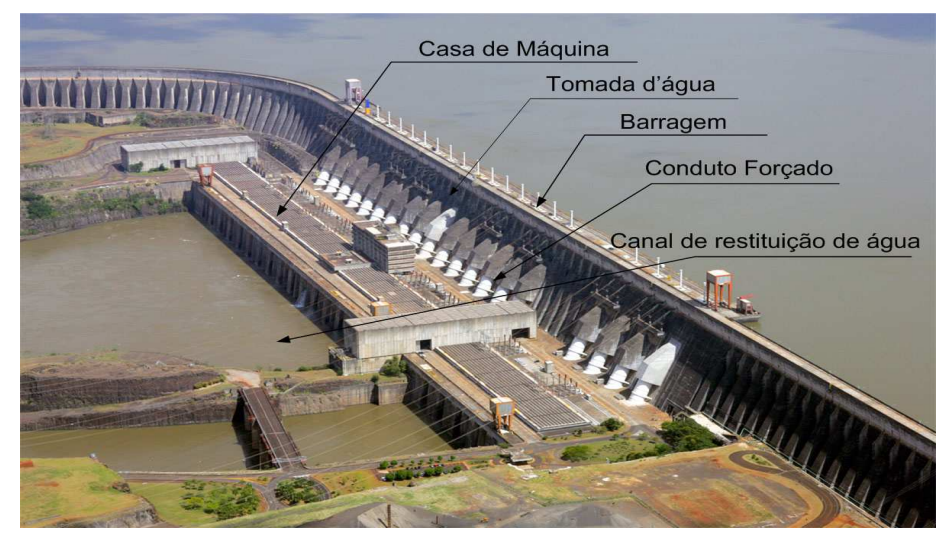

Fonte: Itaipu (2012). 
Na barragem a água do rio é represada para gerar a queda d'água, como função principal. O conduto forçado tem por objetivo permitir o fluxo de água captado na tomada d'água (fazendo a distribuição da água para as diversas máquinas) até a caixa espiral da turbina. No conduto forçado tem-se uma válvula de bloqueio, do tipo borboleta, cuja função é bloquear o fluxo de água na entrada da caixa espiral da turbina, não só em operações de manutenção, mas também em caso de parada de emergência da unidade hidrogeradora.

A casa de máquinas é constituída pela turbina, gerador, regulador de velocidade, regulador de tensão, serviços auxiliares e entre outros. A turbina é o sistema responsável pela transformação de energia potencial hidráulica em energia mecânica, devendo operar de forma contínua, com uma rotação pré-estabelecida, dependente da frequência exigida na geração e do número de pólos do gerador, com o objetivo de manter as características de frequência exigidas pelo sistema de distribuição de energia elétrica. Para garantir a execução de sua função principal, a turbina é composta por uma série de sub-sistemas, dentre os quais podem ser destacados: o rotor, o eixo, a caixa espiral, o pré-distribuidor e o distribuidor propriamente dito, Gurthier and Brocon (1965). O gerador é responsável pela transformação de energia mecânica em energia elétrica. Para executar esta função deve haver um campo magnético girante no interior do gerador, o qual induz à ação de corrente e tensão em um conjunto de bobinas fixas, montadas em uma estrutura concêntrica com o eixo girante do gerador, responsável pela geração do campo magnético. Para executar esta função, o gerador é composto por uma série de equipamentos: rotor, estator, sistema de refrigeração e sistema de excitação (IZENA et al, 2006).

\section{B.2 Turbinas Hidráulicas}

As turbinas hidráulicas desempenham um papel fundamental na geração da energia em uma usina hidrelétrica, pois viabilizam a transformação da energia hidráulica, do escoamento, em energia mecânica através do rotor hidráulico, pela utilização de diferenças entre dois níveis de água. Essa diferença entre dois níveis de água é usualmente obtida pela construção da barragem, cuja altura dependerá das condições do local. A variedade de combinações de alturas e descargas em 
instalações hidrelétricas permite uma grande variação dos tipos de turbinas hidráulicas. As turbinas são classificadas como turbinas de reação e de ação (DIEZ, 1996).

Turbinas de reação: quando escoamento através do rotor ocorre com variação de pressão estática. Essas turbinas são as mais usuais no Brasil e cobrem uma faixa de quedas médias (10 a $200 \mathrm{~m}$ ) para as instalações hidrelétricas. As turbinas que se enquadram nesta definição são as turbinas Francis, Kaplan e Bulbo.

Turbinas de ação: quando escoamento através do rotor ocorre sem variação de pressão estática. Essas turbinas são operadas sobre pressão atmosférica por um jato livre, são menos usuais no Brasil e cobrem uma faixa de quedas maiores (acima de $200 \mathrm{~m}$ ) para as instalações hidrelétricas. As turbinas que se enquadram nesta definição são as turbinas Pelton.

A seguir são apresentadas as características dos principais tipos de turbinas hidráulicas.

As turbinas PELTON são assim chamadas devido ao nome de seu idealizador, Allan Lester Pelton, que em 1880 pôs em funcionamento o primeiro rotor com tipo Pelton. Este modelo de turbina, utilizado para quedas elevadas, pode ser instalado em centrais com quedas d'água entre 100 a 1.800 metros como por exemplo, instalações nos Alpes europeus onde a altura chega a quase 1.800 metros. As turbinas Pelton são constituídas de uma roda munida de pás dispostas em círculo (rotor) e de um injetor (ou mais de um) que desempenha o papel do distribuidor, que pode ser horizontal ou vertical. Cada pá é formada de duas conchas dispostas simetricamente em relação ao plano mediano da roda (plano de simetria perpendicular ao eixo de rotação) (ALSTOM, 2013; GURTHIER e BROCON, 1965). A Figura B.2 mostra esquematicamente uma turbina Pelton com quatros injetores. $O$ rotor da turbina Pelton é acionado direcionando-se o jato d'água contra as pás, através de injetores, de forma a aproveitar a grande quantidade de movimento da água. (ALSTOM, 2012; GURTHIER e BROCON, 1965) 
Figura B.2 Turbina Pelton.

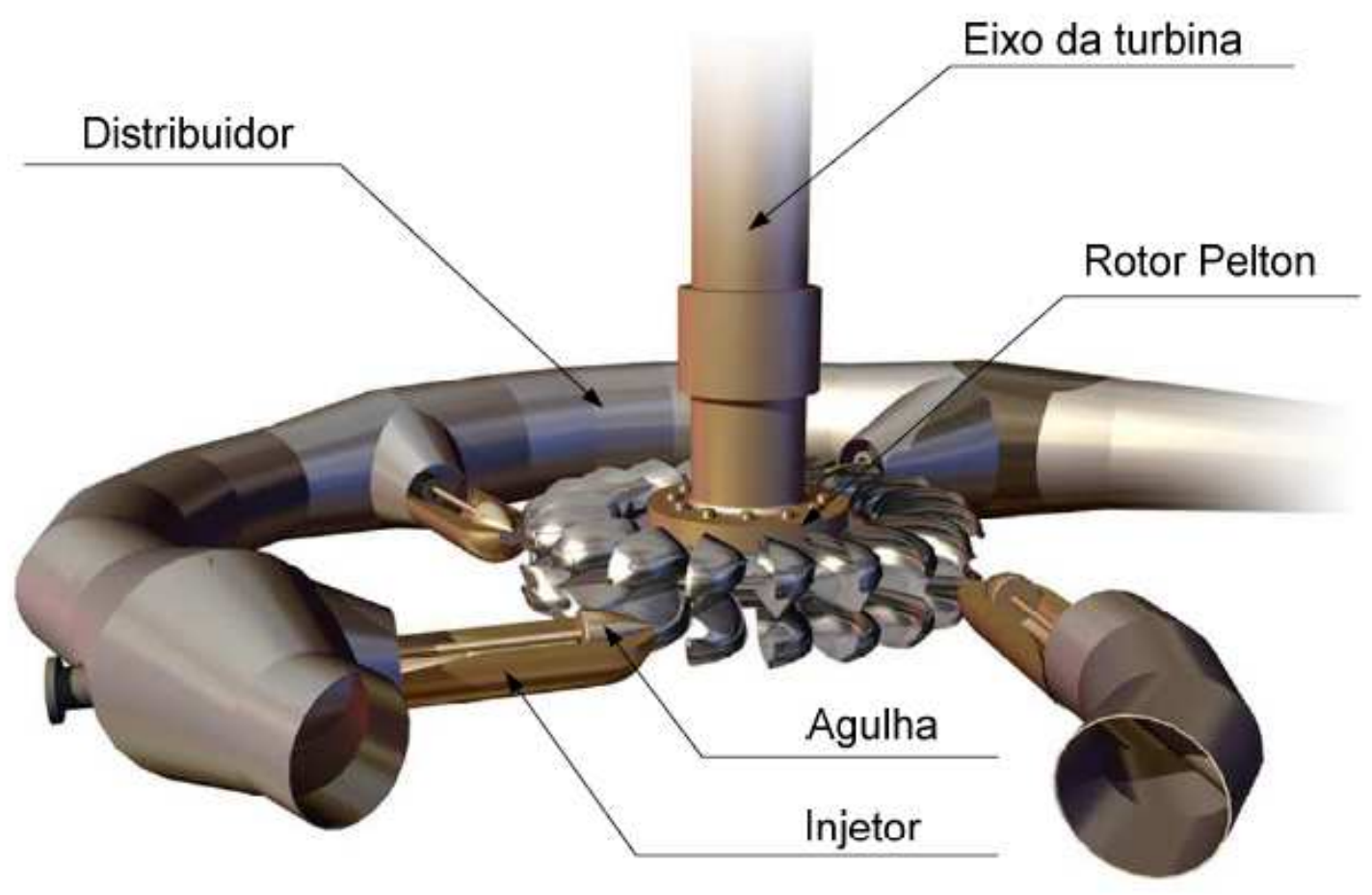

Fonte: Alstom (2012).

As turbinas FRANCIS recebem seu nome em referência ao engenheiro inglês James Bicheno Francis (1812-1892) que as idealizou, em meados do século XIX, quando foram utilizadas em instalações hidrelétricas nos Estados Unidos. Desde a sua primeira concepção muitos aperfeiçoamentos foram feitos, em termos hidráulicos, mecânicos e de instalação (DIEZ, 1996). Atualmente, este é o tipo de turbina mais utilizada na geração de hidroeletricidade no Brasil. As turbinas Francis atingem seus melhores valores de rendimento para quedas que variam de 10 até 200 metros, podendo atingir eficiências de até 94\% (GURTHIER e BROCON, 1965). Basicamente, a turbina Francis é composta por uma caixa espiral, distribuidor, rotor e tubo de sucção. Nas turbinas Francis o fluxo de água que passa pela turbina provém do conduto forçado, entrando na caixa espiral, sendo então direcionado pelas pás do distribuidor até atingir as pás do rotor, levando a água até o tubo de sucção que a drena para o canal de saída da turbina, conforme a Figura B.3. 


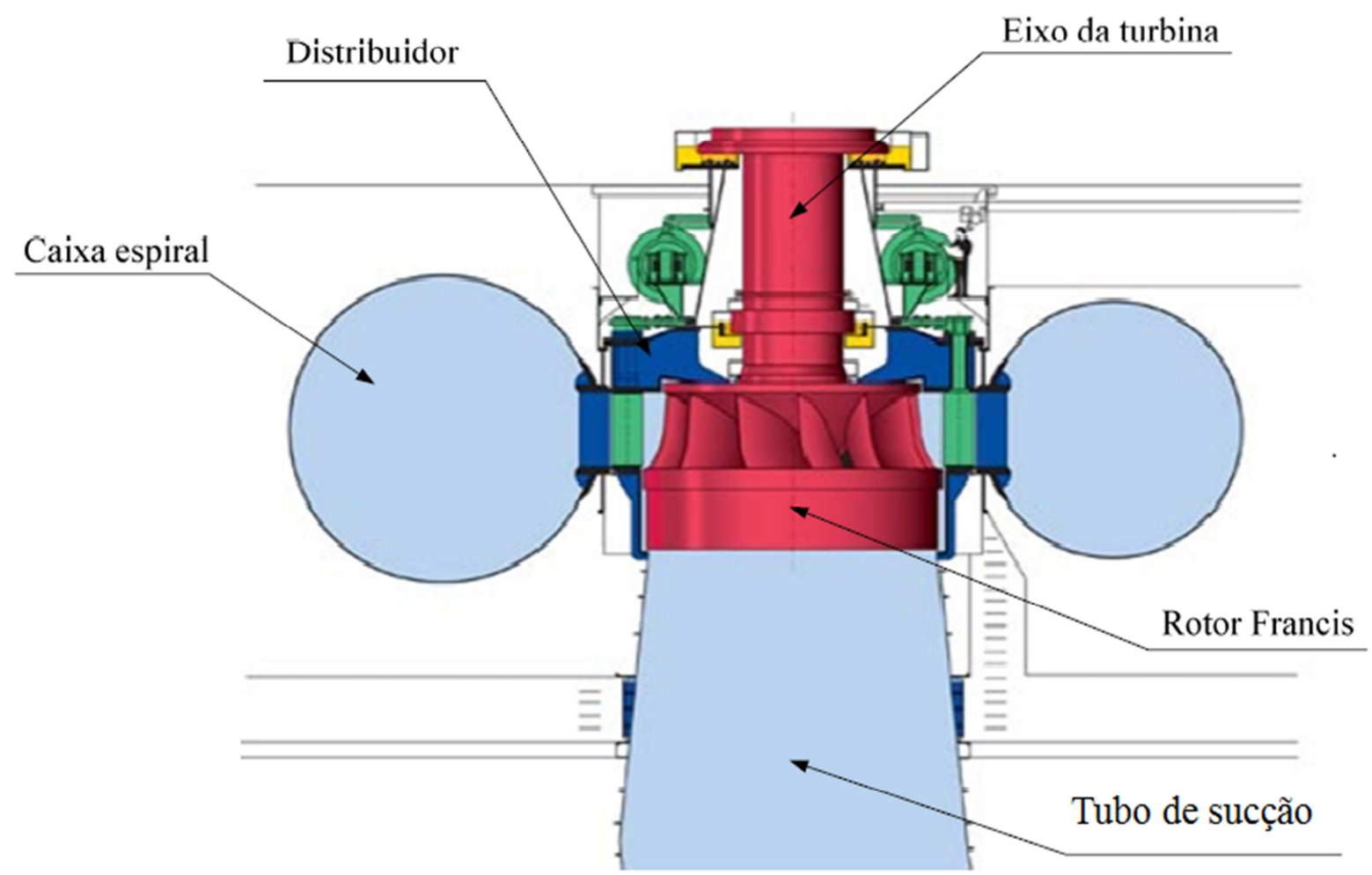

Fonte: Voiht (2012).

As turbinas KAPLAN foram concebidas pelo engenheiro austríaco Victor Kaplan (1876-1934) que, por meio de estudos teóricos e experimentais, criou um novo tipo de turbina a partir das turbinas hélice, com a possibilidade de variar o passo das pás. Surge então a turbina hélice de pás reguláveis (DIEZ, 1996). A turbina Kaplan é caracterizada pela utilização de um rotor que se assemelha aos hélices de navios. Nestas máquinas de reação, o fluxo escoa na direção axial do rotor (ALSTOM, 2012). Estas máquinas operam com grande vazão de água e baixa queda d'água (entre 10 e 60 metros). O rotor da turbina Kaplan possui mecanismo interno de movimentação das pás (estas pás são movimentadas através de um sistema de êmbolo e manivelas montado dentro do cubo do rotor), que opera em função da magnitude da vazão de água e é regulado pelas palhetas diretoras. São máquinas de dupla regulação, conjugando a posição das pás do rotor e a abertura das palhetas para obter elevada eficiência em toda faixa operacional. A Figura B.4 apresenta a configuração básica de uma turbina Kaplan. 
Figura B.4 Turbina Kaplan.

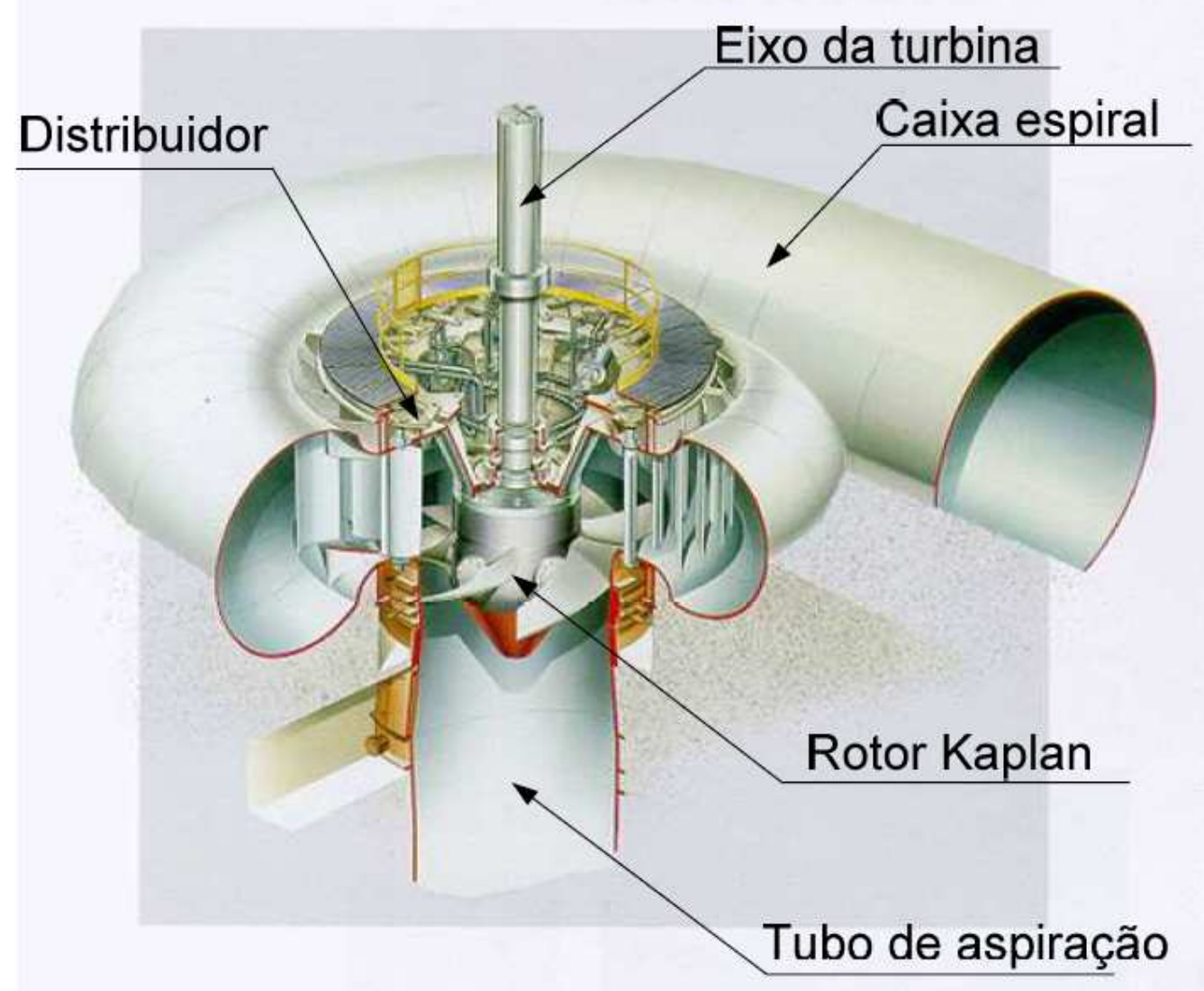

Fonte: Alstom (2013).

\section{B.3 Regulador de Velocidade}

Dentre os subsistemas que atuam conjuntamente com a turbina hidráulica, o regulador de velocidade tem a função principal de atuar no sentido de aumentar ou diminuir a potência gerada pela turbina quando a velocidade ou frequência se afasta do valor de referência. Em função da demanda do sistema, o sistema regulador da turbina atua sobre a posição das pás do distribuidor controlando a abertura e consequentemente a vazão que chega ao rotor, fazendo com que o hidrogerador gere apenas a energia elétrica necessária para o consumo (ANDIA, 2005). O regulador de velocidade tem que manter a rotação da turbina constante para que 0 gerador forneça energia ao sistema elétrico na frequência de $60 \mathrm{~Hz}$.

O regulador de velocidade é constituído por um conjunto de dispositivos e mecanismos que detecta a variação de velocidade do eixo da turbina e a corrige, por 
exemplo, por meio da variação de posição dos servomotores (atuador hidráulico) que age sobre $o$ anel distribuidor que está interligado às pás direcionais em turbinas do tipo Francis e Kaplan.

No projeto do regulador de velocidade, há um ponto que é conhecido como ponto de operação sem carga, que é o ponto específico de abertura das pás do distribuidor, previsto pelo projeto, que determina o ponto onde o sistema gera a força suficiente apenas para vencer os esforços de atrito gerados pela rotação da turbina. É o regulador que propicia a partida da unidade levando-a desde a rotação nula até a rotação nominal através da abertura do distribuidor da turbina. A parada da turbina também cabe ao regulador (JANG, 1995).

Os reguladores de velocidade não só controlam a potência gerada para um determinado local, mas também podem fazer parte de um grupo maior de unidades de geração, em que é exigida alta disponibilidade, devido às solicitações imediatas de geração de potência extra. Eles também permitem prevenir a sobrecarga do rotor da turbina devido ao excesso de velocidade (é o fenômeno que ocorre quando o rotor da turbina atinge uma velocidade de rotação muito acima da projetada, em torno de 10\%) (MAZZORANA, 2008).

Segundo Yesid (2006) e (JANG, 1995), o regulador de velocidade deve realizar várias funções além de ajustar o servomotor a fim de regular a frequência da variação de tensão e corrente elétrica de forma aceitável. Podem-se destacar as seguintes funções:

- Permitir a sincronização do gerador ao sistema no menor tempo possível;

- Dar partida na máquina acelerando-a até a velocidade nominal sem causar danos na turbina (tensões nas pás) no menor tempo possível;

- Ajustar o ângulo das pás do rotor para operação com o máximo rendimento (turbinas Kaplan), em função da altura de queda e abertura do distribuidor;

- Em rejeição brusca de carga, promover o fechamento do distribuidor sem que a sobrepressão do duto e da caixa espiral, subpressão da sucção e 
sobrevelocidade da máquina superem os níveis garantidos pelo fabricante da turbina e do gerador;

- Em condições especiais, colocar limites máximos de geração (limitador eletrônico e/ou mecânico, de potência e/ou posição do servomotor);

- Na falha completa de todas as fontes de alimentação de potência elétrica, promover o fechamento total do distribuidor ou bloqueá-lo e mantê-lo numa posição fixa enquanto é feita a manutenção, sem desligar a máquina do sistema;

- Fornecer indicações confiáveis da velocidade da máquina desde zero (unidade parada, deslocamento mínimo do rotor) até $10 \%$ de sobrevelocidade, para atuação de proteções de sobrevelocidade confiáveis em caso de falha do regulador automático;

- E finalmente, como última atribuição do regulador de velocidade, este deve ser capaz de ajustar a potência ativa para o caso de tomada ou alívio de carga do sistema elétrico e promover abertura ou fechamento automático do distribuidor nos casos de subfreqüência ou sobrefreqüência, respectivamente, conforme sua característica de estatismo.

O regulador de velocidade é composto por três subsistemas: sistema de controle do regulador de velocidade (sistema de controle), sistema hidráulico e o distribuidor. A seguir são apresentadas cada um dos subsistemas.

\section{B.3.1 Sistema de controle do Regulador de Velocidade.}

Antigamente, o regulador de velocidade era composto por dispositivos mecânicos ou hidráulicos que constituíam o sistema de controle do regulador. Conforme a Figura B.5, pode-se observar que o transdutor eletromecânico é comandado por um motor elétrico. Ao transdutor eletromecânico está acoplada uma haste de realimentação da posição do servomotor. A atuação do variador na articulação e consequentemente na válvula é comandada por um motor acoplado a um parafuso de rosca sem fim (DE NEGRI, 2001). 
Figura B.5 Sistema mecânico hidráulico simplificado de um regulador de velocidade convencional.

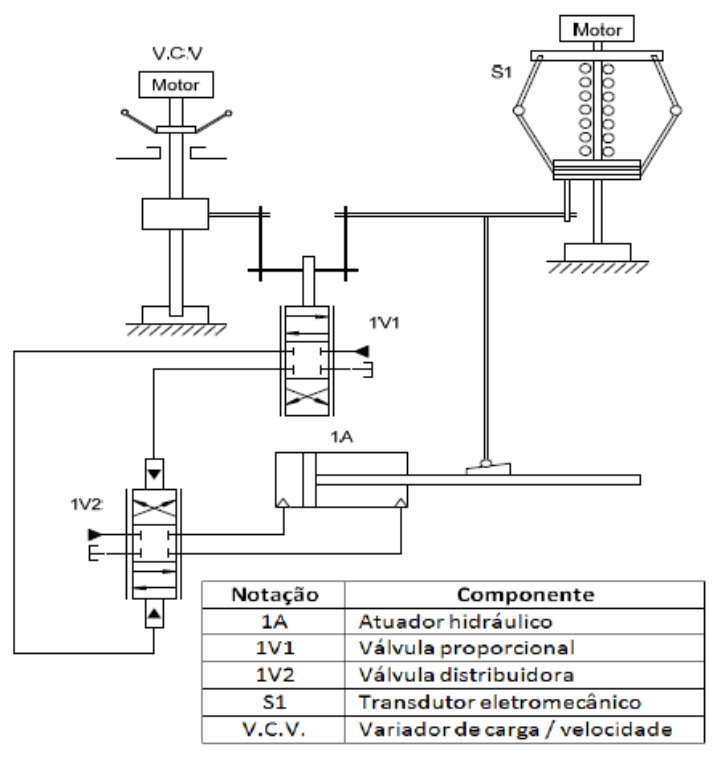

Fonte: De Negri (2001).

Na Figura B.6 está representado um regulador de velocidade moderno em que se substituiu o regulador mecânico por um eletrônico, e um transdutor eletromecânico por um transdutor de posição do tipo LVDT (Transdutor Indutivo de Posição) e a articulação mecânica de medição e atuação foram substituídas por sinais elétricos do tipo corrente ou tensão.

Figura B.6 Sistema mecânico e eletro - hidráulico simplificado de um regulador de velocidade moderno.

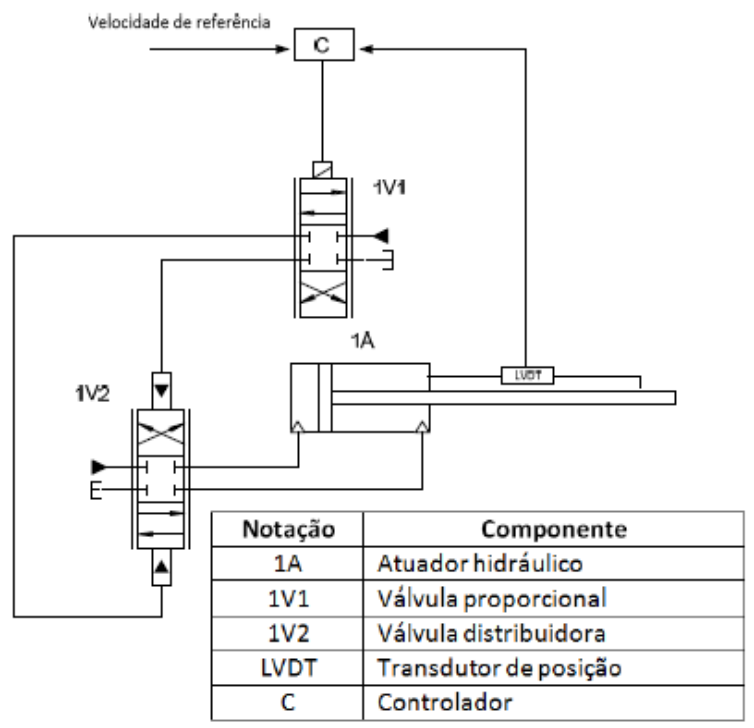

Fonte: De Negri (2001). 
Os sistemas de controles utilizam sensores de frequência e tensão elétrica. As medidas são introduzidas no controlador e são comparadas com os valores de frequência e tensão elétrica desejada. Para o caso de ser necessário aumentar ou diminuir a frequência ou tensão elétrica, um sinal será emitido à válvula proporcional pilotada por solenoide, o qual ativará a válvula distribuidora e comandará o atuador hidráulico para aumentar ou diminuir $o$ ingresso de água na turbina e, consequentemente, restabelecer sua velocidade.

Como exemplo, o regulador de velocidade RVX300 (REIVAX, 2013) recebe sinais lógicos de comando e controle, informações de frequência, potência, posição do distribuidor (e das pás, caso seja do tipo Kaplan), gerando um sinal analógico de controle que, amplificado, comanda as válvulas proporcionais, que acionam as válvulas distribuidoras e os servomotores da turbina.

A Figura B.7 mostra que o regulador pode possuir duas CPUs, uma principal e outra de retaguarda, aumentando a confiabilidade. A comutação de principal para retaguarda é automática, caso ocorra falha na CPU principal, falha na fonte de alimentação ou perda do sinal de frequência da máquina.

Figura B.7 Regulador de velocidade RVX 300 (REIVAX, 2013)

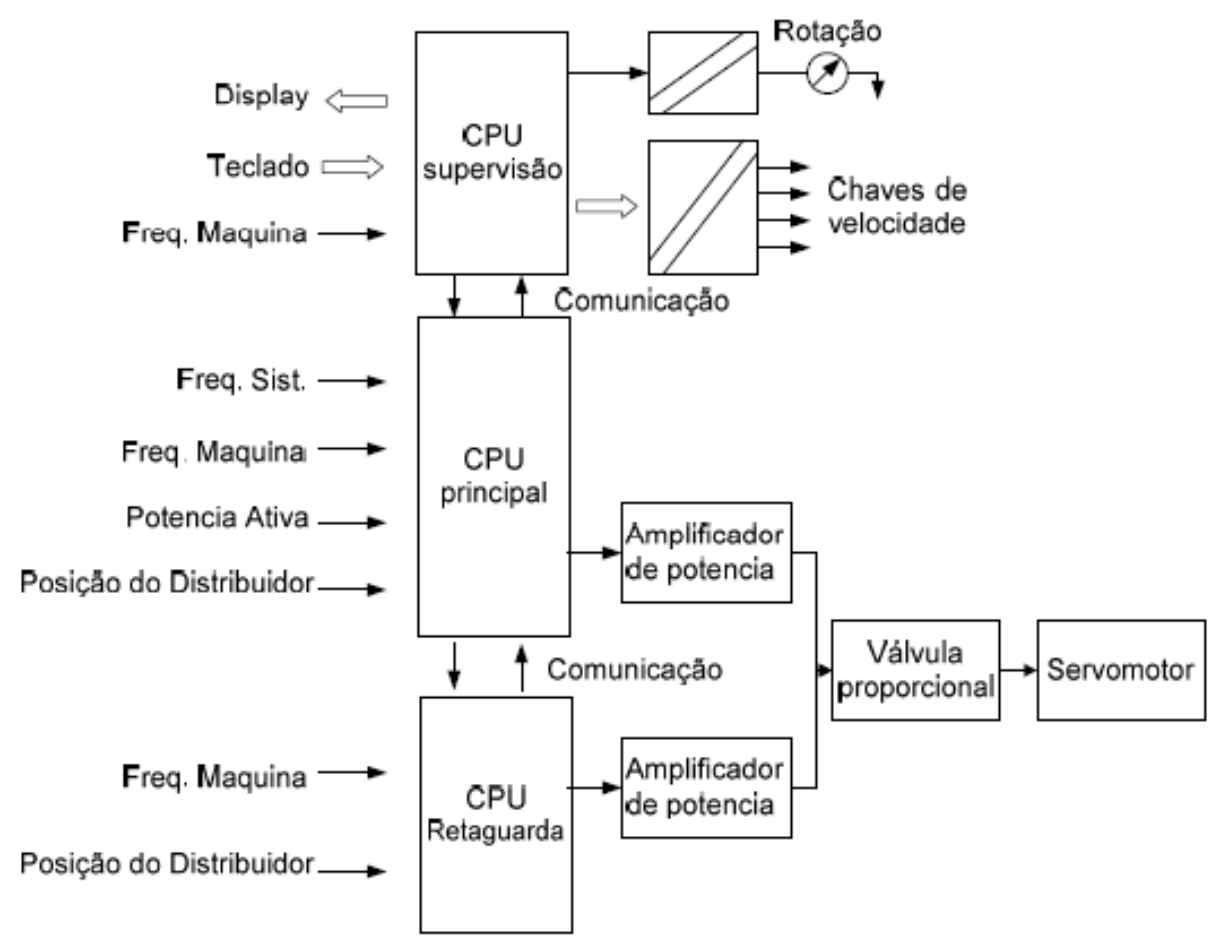

Fonte: Reivax (2013). 
Além disso, a interface Homem - Máquina do regulador RVX300 permite ao usuário acessar e alterar os parâmetros do regulador acompanhando, através de registros gráficos coloridos de alta resolução, o desempenho da máquina como é mostrado na Figura B.8. A Interface Homem-Máquina (IHM) faz a supervisão e o controle local ou remoto de toda a unidade geradora, dispensando a interface convencional com chaves e indicadores (REIVAX, 2013).

Figura B.8 Interface homem-máquina.

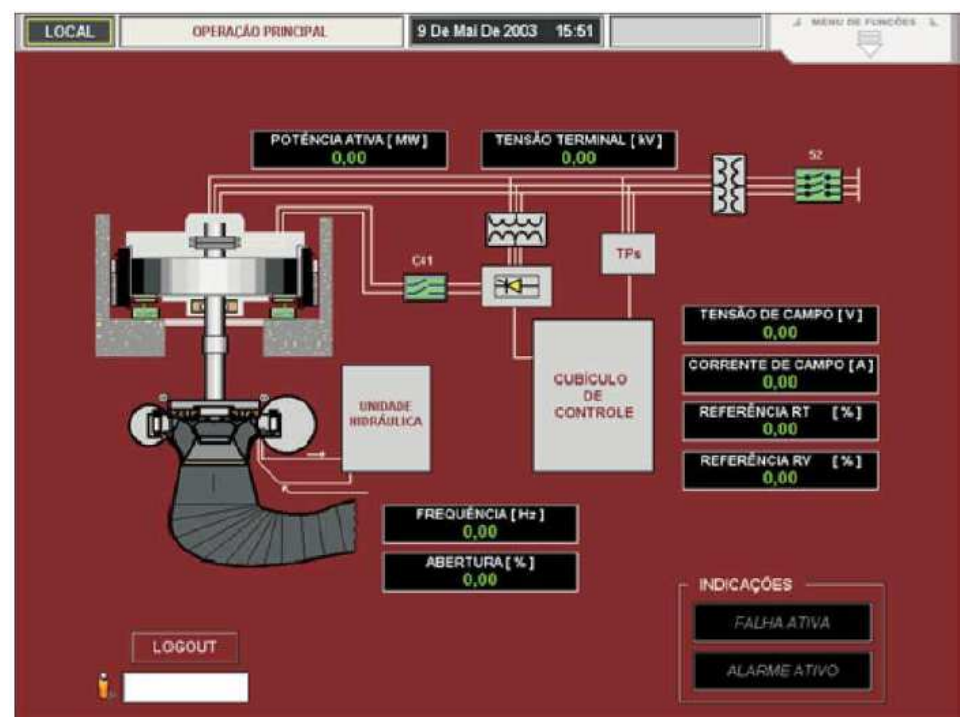

Fonte: Reivax (2013).

\section{B.3.2 Sistema eletro-hidráulico para controle de posição}

Os sistemas hidráulicos encontram aplicação em praticamente todos os ramos de engenharia: maquinários agrícolas, hidráulica industrial, aplicações navais, aeronáutica, geração de energia, entre outros. Isso ocorre devido a algumas vantagens como a versatilidade de sua configuração, precisão no controle de dispositivos mecânicos pesados e os sistemas hidráulicos podem ser comandados por sinais com baixo consumo de energia (PORCIÚNCULA et al., 2006; LINSINGEN, 2008; GAULTENEY, STANLEY e OOMS, 1989).

Quando se faz necessário movimentar grandes massas ou realizar grandes esforços, os sistemas eletro-hidráulicos combinam as vantagens próprias dos circuitos hidráulicos, quais sejam, capacidade, pequena inércia e rápida resposta 
com o pequeno erro e versatilidade na medição, transmissão e processamento dos sinais elétricos (DE NEGRI, 2001; LINSINGEN, 2008).

Os mecanismos de natureza eletro-hidráulicos são comandados por sinais de baixo consumo de energia e controlam com precisão os movimentos de cilindros e motores hidráulicos de mecânica pesada. Além disso, possuem enorme versatilidade devido a uma variedade de configurações, sobretudo no processamento de sinais que podem ser diferentemente projetados para a obtenção da atuação hidráulica desejada. Na Figura B.9 pode ser visto um diagrama típico de um sistema de controle de posição eletro-hidráulico que pode ser empregado em reguladores de velocidades.

O sistema hidráulico do regulador de velocidade é constituído pelos seguintes componentes, conforme indicado na Figura B.9: reservatório de óleo, filtro, motor, bomba, válvula de alívio, válvula proporcional, válvula distribuidora e atuadores ou servomotores. Todos os equipamentos estão interligados por tubulações rígidas e mangueiras.

Figura B.9 Diagrama do sistema hidráulico do regulador de velocidade.

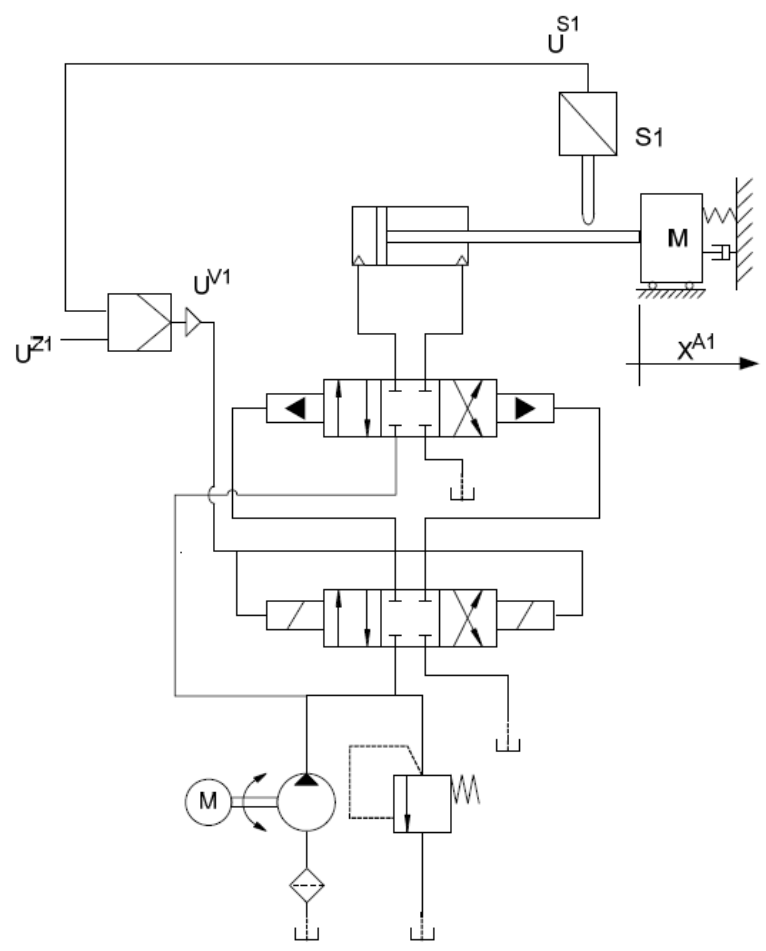

Fonte: De Negri (2001). 
No sistema acima, a razão de se utilizar uma válvula proporcional em conjunto com uma válvula distribuidora é a limitação da força que o solenóide é capaz de suportar enquanto este tipo de válvula está totalmente aberta. Para movimentar os atuadores hidráulicos dos reguladores de velocidade nas hidrelétricas, é necessário grandes vazões e um solenóide não é capaz de vencer as forças de escoamento do carretel causadas pelo escoamento nas câmaras das válvulas, razão pela qual é usada uma válvula proporcional pilotada por solenóide acoplada a uma válvula distribuidora (DE NEGRI, 2001).

De acordo com Porciúncula et al. (2006), a posição desejada para o cilindro é estabelecida pela tensão de referência $\left(U^{Z 1}\right)$ que, através do controlador, gera uma tensão de comando $\left(\mathrm{U}^{\mathrm{V} 1}\right)$ na válvula direcional proporcional, produzindo o deslocamento do carretel. Isso provocará um fluxo através da válvula que promove uma variação de pressão na câmara do cilindro, resultando no movimento da massa (M) que é medida pelo sensor de posição $(\mathrm{S} 1)$ produzindo uma voltagem $\left(\mathrm{U}^{\mathrm{S1}}\right)$. Esta voltagem $\left(U^{S 1}\right)$, com um sinal oposto ao da voltagem de referência $\left(U^{Z 1}\right)$, fornece uma realimentação sobre a posição. Ao alcançar a posição desejada, vai-se anular a voltagem de comando da válvula $\left(\mathrm{U}^{\mathrm{V} 1}\right)$ indicando que a posição da haste $\left(\mathrm{X}^{\mathrm{A} 1}\right)$ corresponde exatamente à posição desejada.

Os atuadores hidráulicos ou servomotores são empregados para o deslocamento da agulha do injetor e do defletor das turbinas Pelton e também podem ser utilizados para o deslocamento do distribuidor em turbinas de reação. No caso da turbina Kaplan também são utilizados para o movimento das pás do rotor.

Servomotores se adéquam a cada aplicação, dependendo do tipo de turbina e de características especiais de cada máquina. $O$ atuador vem com transdutor de posição integrado, assim o regulador faz seu controle de posição através de válvula proporcional. Para potências não muito grandes ( $P \leq 10.000 \mathrm{~kW})$ pode se empregar somente um servomotor de duplo efeito, como mostrado na Figura B.10 (a), entretanto, para turbinas de médio e grande porte $(P>10.000 \mathrm{~kW})$, utilizam-se os servomotores de duplo efeito, como mostrado na Figura B.10 (b). 
Figura B.10 a) Deslocamento do distribuidor por um servomotor; (b) deslocamento do distribuidor com dois servomotores

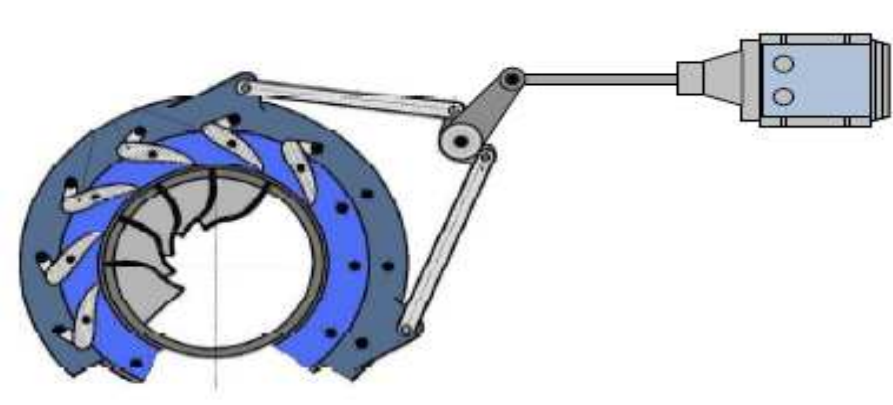

(a)

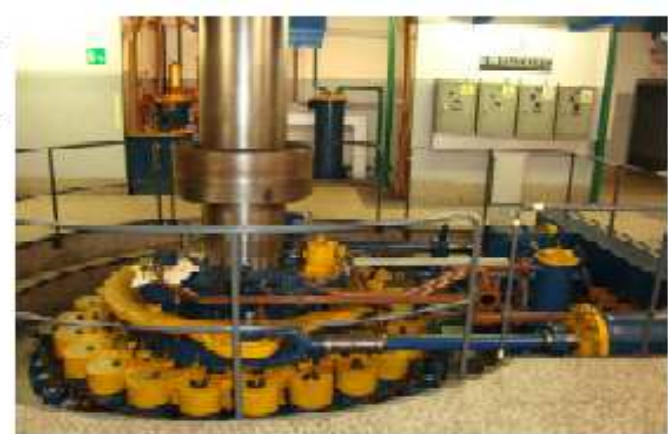

(b)

Fonte: DIÉZ (1996) e Andia (2005).

\section{B.3.3 Distribuidor}

O distribuidor é utilizado nas turbinas de reação e tem como objetivo conduzir a água em direção às pás do rotor regulando a vazão e modificando, desta forma, a potência da turbina, ajustando-se as possíveis variações de carga na rede (DIEZ, 1996; ANDIA, 2005). O distribuidor é constituído de um conjunto de pás diretrizes (direcionais) móveis dispostas ao redor do rotor, as quais giram simultaneamente com mesmo ângulo, possibilitando a passagem da descarga requerida ou interrompendo-a quando necessário. Para cada valor de descarga, o ângulo das pás diretrizes mais conveniente de entrada de água no rotor é o que gera um escoamento com mínima perda hidráulica.

O anel que comanda as bielas das pás, chamado anel de regularização, é comandado por um eixo devido ao uso de bielas que the permitem efetuar um movimento de rotação de pequena amplitude. Esse mecanismo foi proposto por Fink, sendo indicado na Figura B.11. O anel recebe o comando para a regulagem do fluxo de água de alimentação transmitido pelos servomotores colocados no plano do anel de regulação, que provocarão o movimento do anel movendo as pás para a abertura ou ângulo desejado. 
Figura B.11. Sistema mecânico do distribuidor Fink.

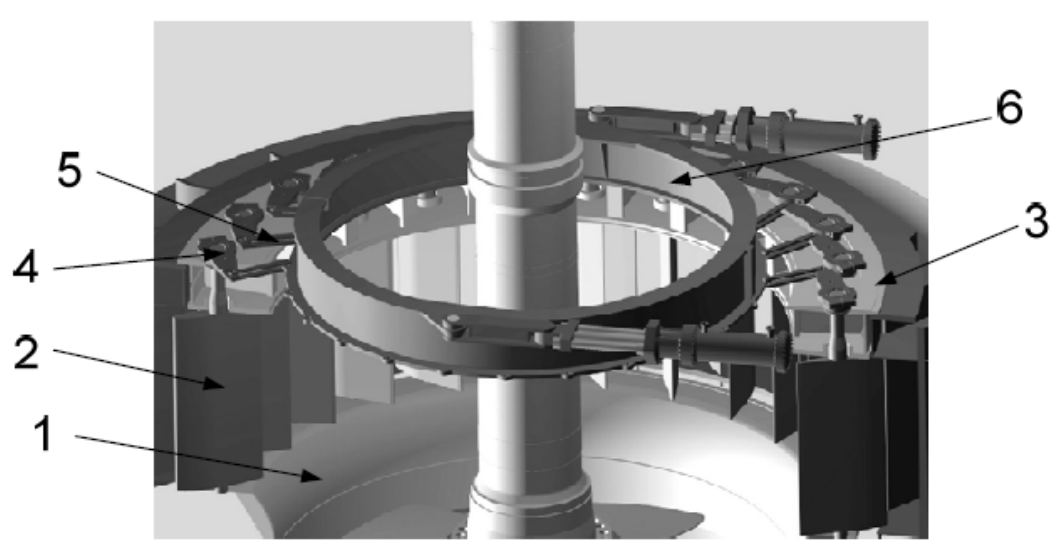

Fonte: Mazzorana (2008).

A Figura B.11 apresenta os componentes que formam parte do sistema mecânico do distribuidor: 1 - anel inferior onde são montadas as pás; 2 - pás direcionais encaixadas entre os anéis inferior e superior; 3 - anel superior; 4 -manivela soldada às pás; 5 - bielas ajustáveis ligadas em uma extremidade às manivelas e na outra ao anel distribuidor; 6 - anel de regulação, responsável pela rotação e movimento simultâneo de todas as pás direcionais do distribuidor na mesma proporção (MAZZORANA, 2008).

\section{B.4 Regulação dos tipos de turbinas com os Reguladores de Velocidade}

\section{B.4.1 Regulação da turbina Pelton.}

Na Figura B.12 apresenta-se o regulador de velocidade na turbina Pelton, a ação do regulador é feita sobre a válvula da agulha do injetor e também no defletor. Em tais circunstâncias, estas turbinas dispõem da denominada dupla regulação, que estabelece uma exata correspondência entre a posição da válvula da agulha e o defletor.

Caso a carga demandada ao grupo gerador diminua bruscamente ou ocorra uma falha na turbina, o defletor intervém, desviando parte do jato em direção ao exterior do rotor; posteriormente, e de forma lenta, se realiza a aproximação da agulha em direção à boca do injetor, com o que se evita efeitos prejudiciais ocasionados pela possível presença do golpe de aríete, especialmente se as tubulações forçadas 
forem de grande diâmetro, caso mais provável, por tratar-se da alimentação da turbina Pelton.

Ao aumentar a potência solicitada da usina, o defletor se afasta do jato de água e, ao mesmo tempo, a agulha se separa do orifício da agulheta, permitindo maior vazão de água em direção à turbina (ANDIA, 2005).

Figura B.12 Sistema de regulação da turbina Francis

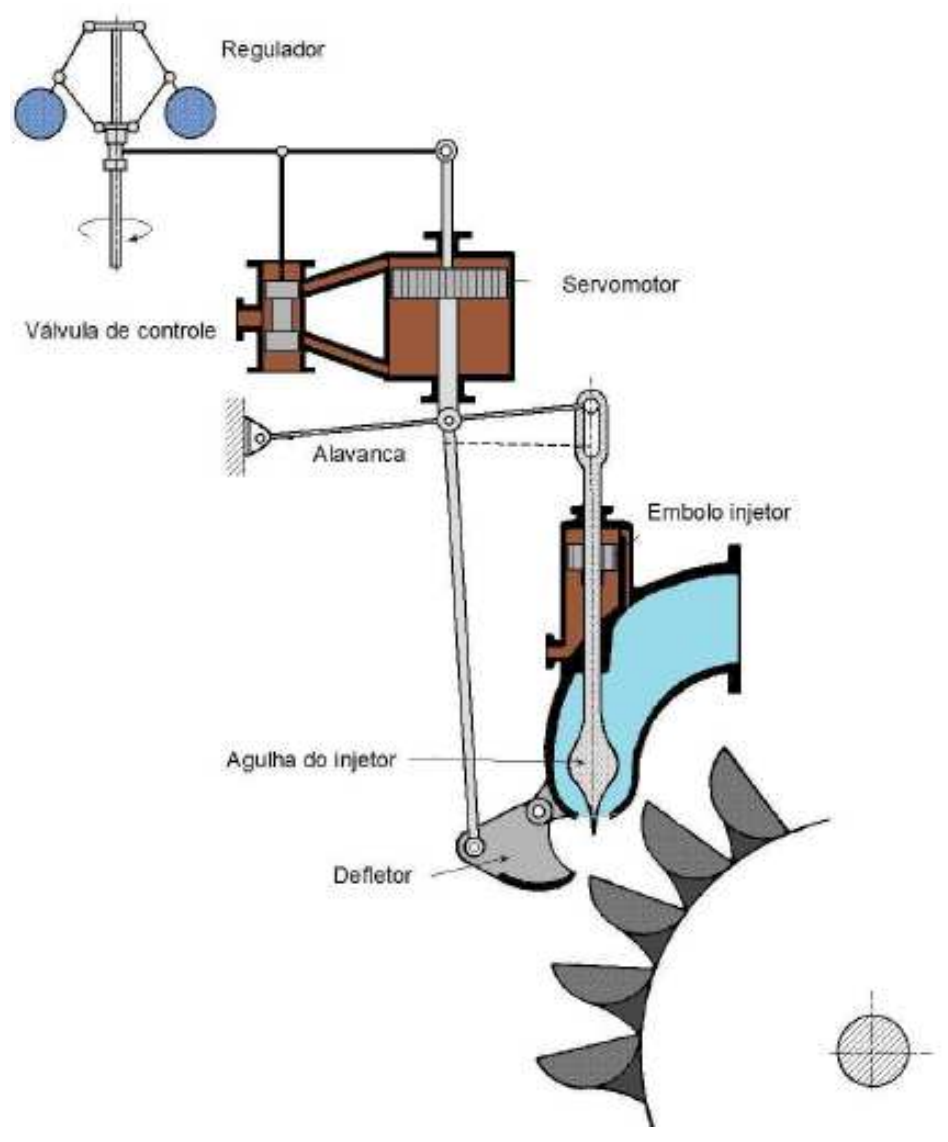

Fonte: Andia (2005).

\section{B.4.2 Regulação das turbinas Francis.}

No caso das turbinas Francis, o controle de vazão ocorre geralmente pela atuação dos servomotores que movimentam o anel do distribuidor. O distribuidor é um anel de pás ajustáveis que envolvem o rotor da turbina. Para alterar a velocidade de rotação da turbina é necessário modificar o ângulo das pás do distribuidor para modificar a passagem de água pelo rotor. $O$ movimento das pás do distribuidor é realizado por um anel de regulação, ligado às pás por um sistema biela-manivela. $A$ 
força necessária para movimentar o anel de regulação (e, por conseguinte as pás do distribuidor) é considerável, sendo usualmente necessário o uso de dois servomotores para este fim. Após a passagem da água pelo distribuidor, esta impacta diretamente com as pás do rotor, onde a potência hidráulica é transformada em potência mecânica (YESID, 2006), de acordo com a Figura B.13.

Figura B.13 Sistema de regulação da turbina Francis.

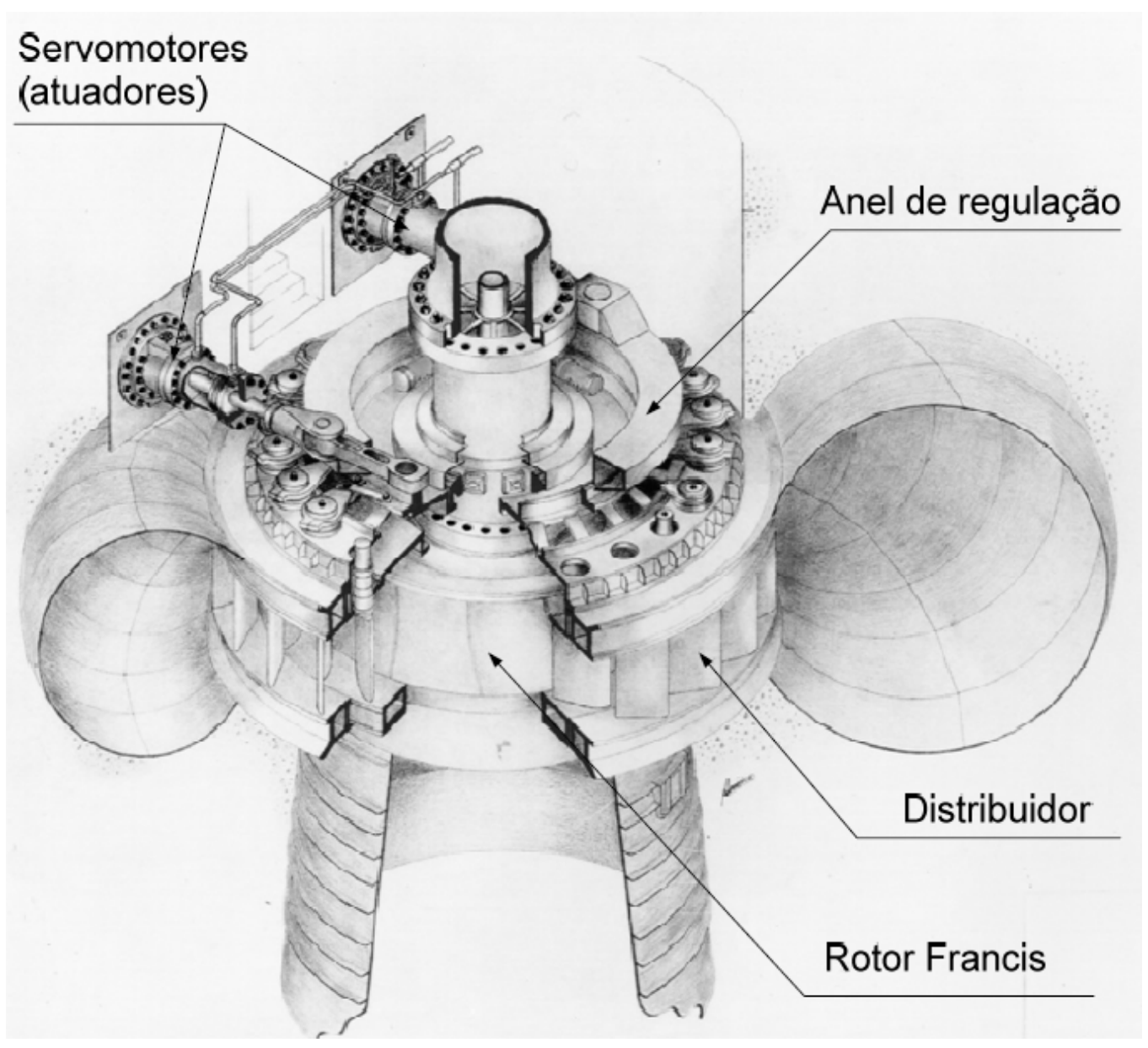

Fonte: Massorana (2008).

O rotor é o elemento mais importante da turbina, cuja função é converter a energia hidráulica em trabalho mecânico. Sua geometria e dimensões são definidas a partir das características do projeto, como vazão e altura nominais. Sua fabricação exige cuidados especiais, pois a eficiência da turbina está diretamente relacionada ao desempenho do seu rotor. A Figura B.14 mostra o rotor de uma turbina Francis. 
Figura B.14 Rotor da Turbina Francis.

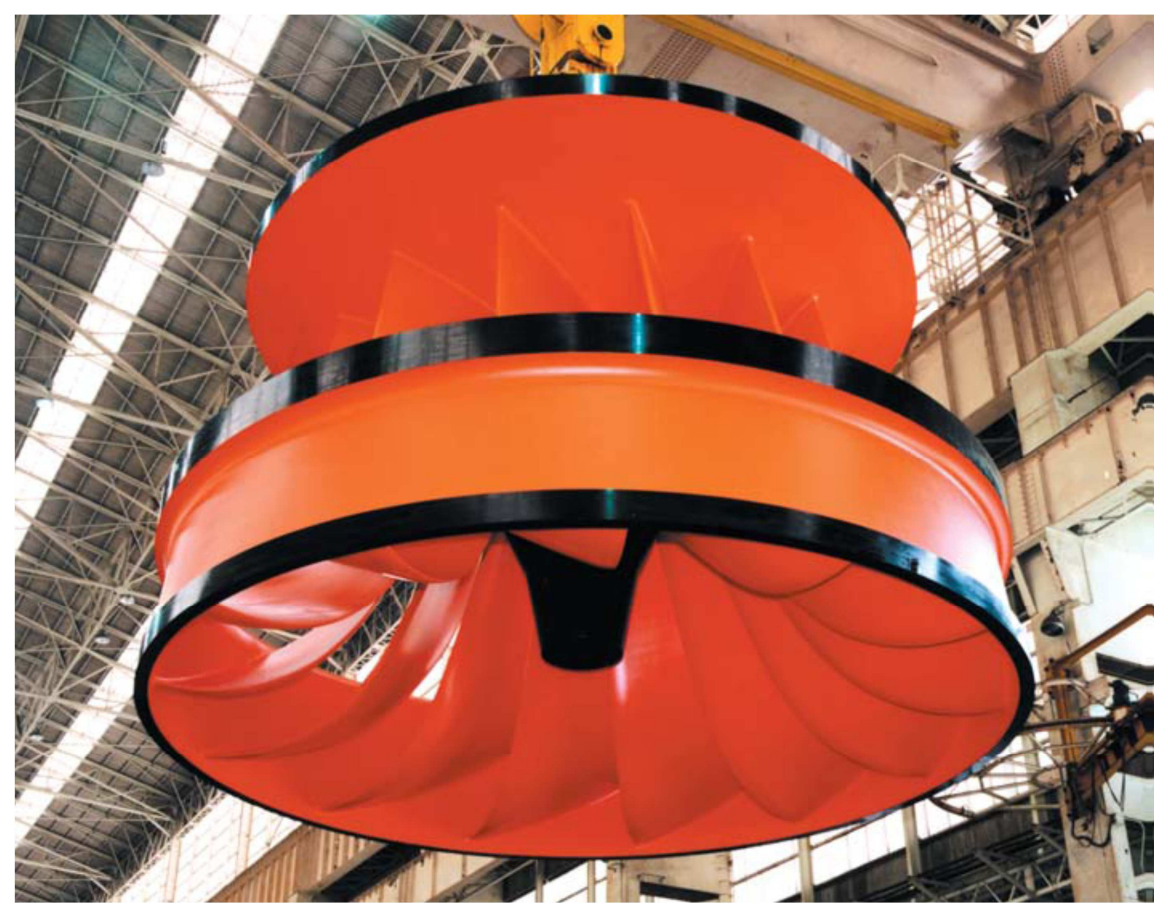

Fonte: Andia (2005).

\section{B.4.3 Regulação da Turbina Kaplan}

As turbinas Kaplan dispõem de um sistema de regulação mais complexo, já que temos dois sistemas de controle: um que controla o ângulo das pás do distribuidor (tem o mesmo princípio de funcionamento do sistema de regulação da turbina Francis); no outro sistema de controle existe um servomotor interno no eixo da turbina responsável pela variação do ângulo das pás do rotor (ANDIA, 2005). Usualmente, os rotores Kaplan têm de quatro a seis pás como pode ser observado na Figura 2.15. A relação correta entre o ângulo das pás do rotor e a vazão de água admitida pelo distribuidor da turbina é determinada por um mecanismo de cames operadas por um servomotor, que por sua vez é comandada a partir do regulador de velocidade. 
Figura B.15 Rotor da Turbina Kaplan.

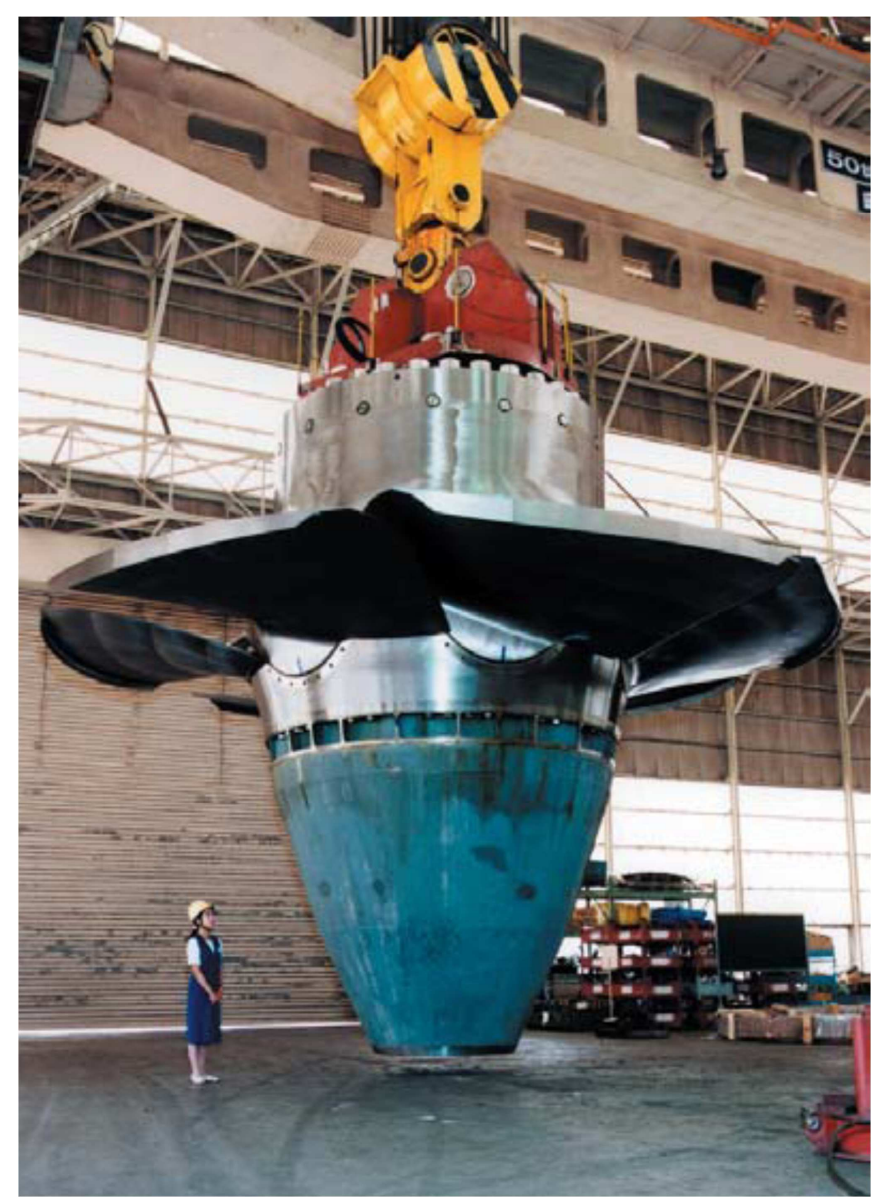

Fonte: Toshiba (2004)

A posição das pás do distribuidor, que controlam o fluxo de água de entrada para a turbina, pode ser ajustada em conjunto com as angulação das pás do rotor, com o objetivo de assegurar máxima eficiência de operação.

$\mathrm{Na}$ Figura B.16 mostra-se um diagrama do mecanismo de regulação das pás móveis do rotor Kaplan. Cada pá estende-se através de um eixo, que penetra dentro do cubo, perpendicularmente ao eixo de rotação da turbina. Cada eixo da pá articula em dois pontos de apoio $\mathrm{P} 1$ e P2, sendo que a alavanca $L$ regula a orientação das pás que, por sua vez, é fixada ao eixo da roda. 
Figura B.16 Mecanismo de regulação das pás da turbina Kaplan
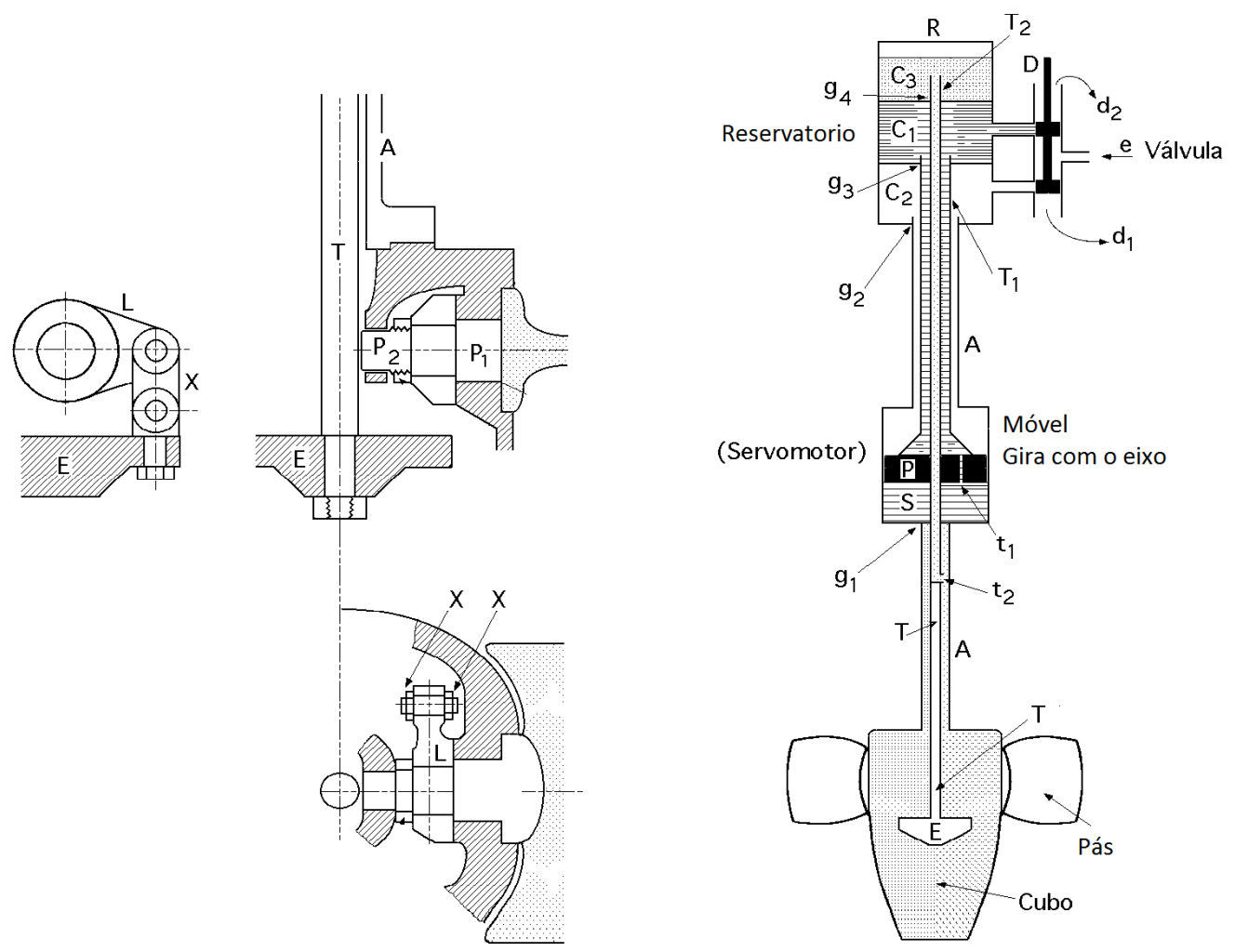

Fonte: Diez (1996)

As bielas $\mathrm{X}$ colocadas na extremidade da alavanca $\mathrm{L}$ estão ligadas ao eixo através de um suporte $E$, todos os quais são acionados por uma haste que passa pelo interior do eixo $A$, de modo que qualquer deslocamento axial desta haste provoca uma rotação simultânea do todas as pás. Todo o mecanismo de regulação é banhado em óleo a certa pressão, fornecendo a lubrificação necessária para todos os rolamentos e conexões, e não permitindo a entrada de água no interior do cubo.

A haste T é acionada por um servomotor $\mathrm{S}$ que gira em conjunto com o eixo, acima deste está localizado um tanque estático $\mathrm{R}$ (pode ser observado na Figura B.17 mais detalhadamente, geralmente é instalado no topo do gerador), no qual as câmaras $C 1$ e C2 estão ligados a uma válvula hidráulica $D$ de uma entrada e duas saídas. No interior do eixo A se encontram dois tubos concêntricos T1 e T2 por onde passa o óleo pressurizado. $\mathrm{O}$ tubo entre o eixo e T1 permite a comunicação entre câmara $\mathrm{C} 1 \mathrm{com}$ a parte inferior do servomotor através do furo t1 feito no pistão 
$\mathrm{P}$ que age direitamente sobre a haste $\mathrm{T}$ de regulação.

Como se trata de peças rotativas, atenção deve ser dada às vedações g2, g3 e g4 para prevenir a perda ou a fuga de óleo entre as várias câmaras que estão a pressões diferentes. Do mesmo modo, o conjunto formado pelo pistão $P$, a haste $T$ e os tubos T1 e T2 localizado dentro do eixo da turbina são lubrificadas pelo óleo. A vedação g1 evita a comunicação desde a parte interior do cubo da turbina para a parte baixa do pistão $\mathrm{P}$ do servomotor, que está a uma pressão variável.

Figura B. 17 Tanque estático

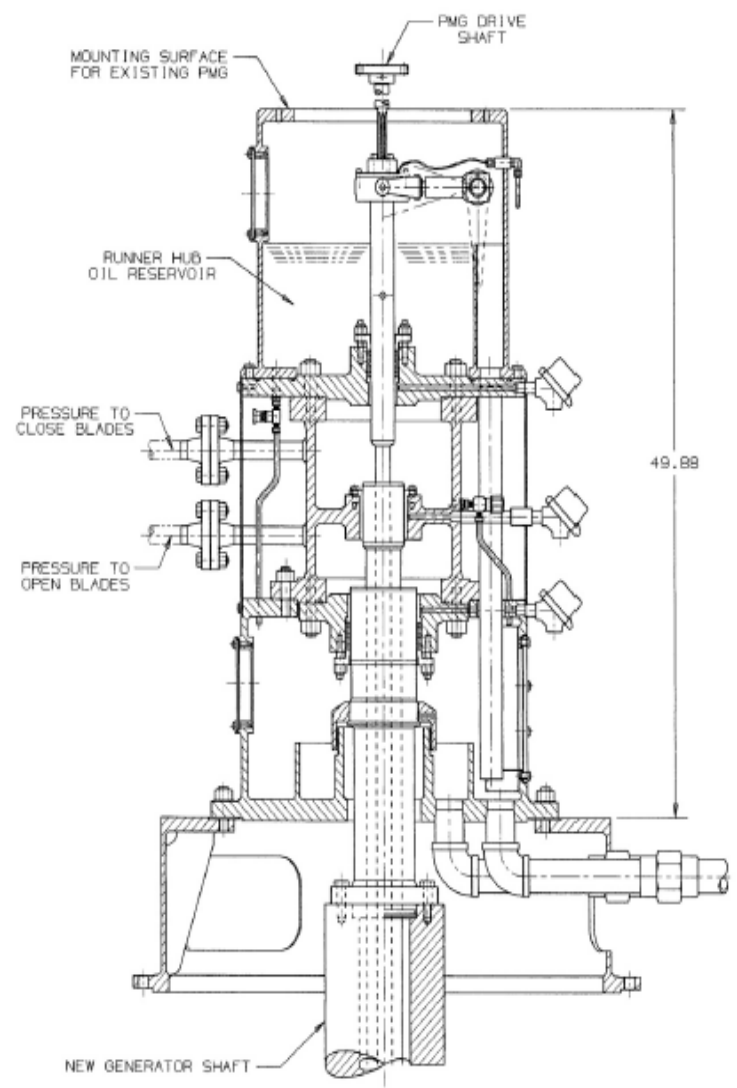

Fonte: Andia (2005).

Dependendo da posição do distribuidor de óleo $\mathrm{D}$ pode ser colocada uma das faces do pistão $\mathrm{P}$ em comunicação com a chegada de óleo com a pressão do tubo de entrada, enquanto o outro lado do pistão $\mathrm{P}$ está com a pressão de descarga. $\mathrm{O}$ tubo T2 liga a parte superior do reservatório R (câmara C3) ao interior do cubo da turbina, através de um furo T2 feito na cruzeta do controle $\mathrm{T}$ de orientação das pás. Esta câmara C3 está à pressão atmosférica, contendo óleo a um certo nível, 
e desempenha o papel de tanque de expansão do óleo contido no cubo, sendo este o volume de óleo em função da posição das pás.

Esta câmara deve ser localizada a um nível tal que a pressão estática garanta a presença de óleo no cubo, e seja suficiente para evitar a entrada de água no interior do cubo. O servomotor $S$ pode estar posicionado no eixo da turbina, no eixo do gerador, ou dentro do rotor Kaplan como é mostrada na Figura B.18.

Figura B.18 Posicionamento do servomotor do rotor Kaplan.
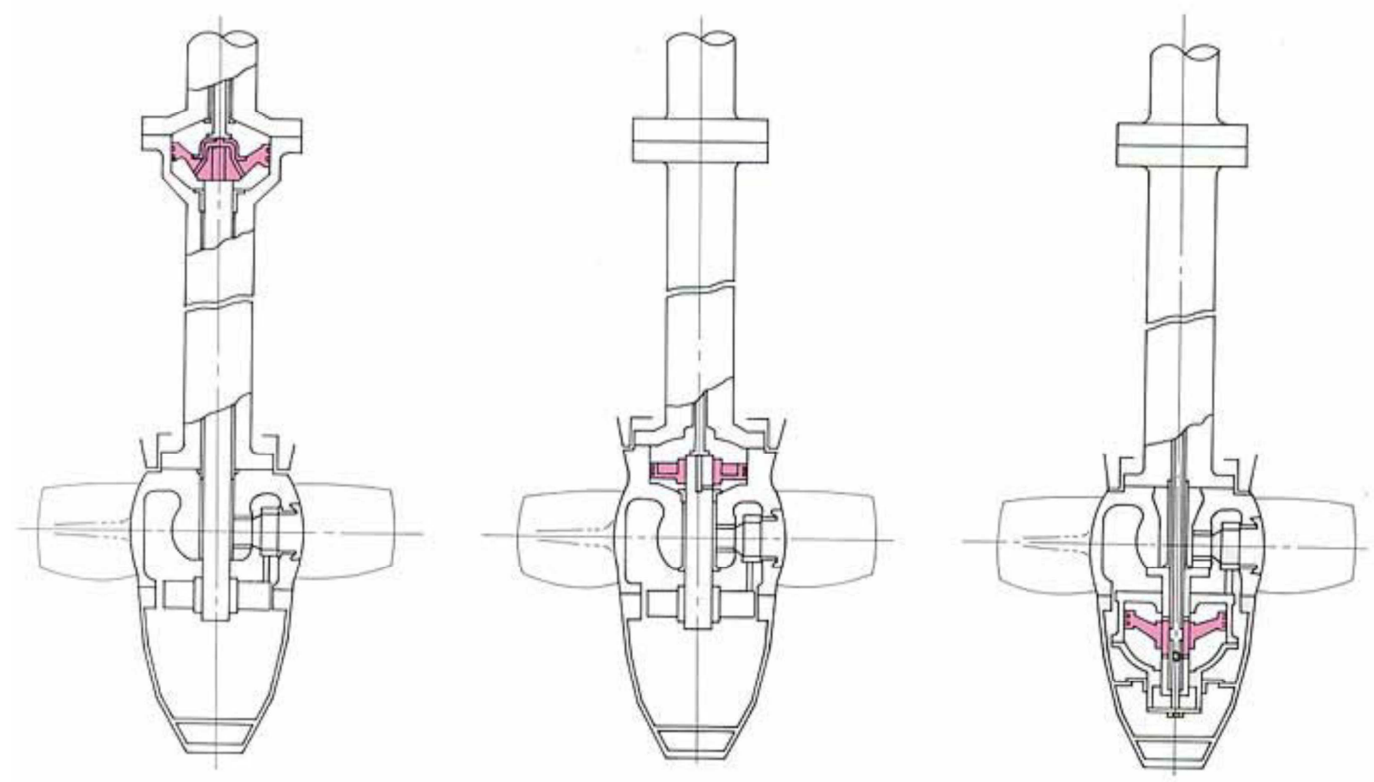

Fonte: Toshiba (2004)

\section{B.5 Referências bibliográficas}

ALSTOM. Disponível em: <http://www.alstom.com.br>. Acesso em: 16 de mar. 2013.

ANDIA, C. G. Centrales Eléctricas. $1^{\circ}$ ed. Arequipa: Universidad Católica de Santa Maria, 2005. 420p.

DE NEGRI, V. J. Sistemas Hidráulicos e Pneumáticos para Automação e controle. Florianópolis. 2001. Apostila para disciplina de pós-graduação do Departamento de Engenharia Mecânica. Universidade Federal de Santa Catarina. 2001.

DíEZ, P. F. Turbinas Hidráulicas. Departamento de Ingeniería Eléctrica y 
Energética de la Universidad de Catarina, Espanha, 1996. 141p. Disponível em: <http://libros.redsauce.net.>. Acesso em: 16 abr. 2012.

GAULTNEY, L.D.; HARLOW, S.D. e OOMS, W. An Expert System for Troubleshooting Tractor Hydraulic Systems. Computer and Electronics in Agriculture - 3. pp 177-187. 1989.

GURTHIER, J. e BROCON, C.B.E. Hydro-Electric Engineering Practice. John Wiley \& Sons, New York. 1965.

ITAIPU. Disponível em: <http://www.itaipu.gov.br>. Acesso em: 16 jun. 2012.

IZENA, A. et al. Practical Hydraulic Turbine Model. Institute of Electrical and Electronics Engineers (IEEE), 2006.

JANG, J. Design of an Optimal Robust Governor for Hydraulic Turbine Generating Units. IEEE Transactions on Energy Conversion - 10. pp 188-194. 1995.

LINSINGEN, I. V. Fundamentos de sistemas hidráulicos. $3^{\circ}$ ed. Florianópolis: UFSC, 2008. 399p.

MAZZORANA, R.H.F. Modelagem dinâmica via fluxo de potência de Reguladores de Velocidade em Usinas Hidroelétricas, 2008. 140p. Dissertação (Mestrado) - Departamento de Engenharia Mecânica, Universidade Federal de Santa Catarina, Florianópolis, 2008.

PORCIÚNCULA, G; DE NEGRI V; DIAS A. Reliability of Electro-Hydraulic equipment systematization and analysis. $A B C M$ Symposium Series in Mechatronics-2. p.393-400, 2006.

REIVAX. Regulador de Velocidade RVX 300. Disponível em: <http://www.reivax.com.br>. Acesso em: 15 de fev. 2013.

TOSHIBA. Hydraulic turbine. 2004. 40p.

VOITH HYDRO. Disponível em: <http://www.voithhydro.com>. Acesso em: 10 fev. 2012.

YESID, E. A. M. Desenvolvimento de um sistema servopneumático para Regulação Velocidade de turbinas em pequenas centrais Hidroelétricas. 2006. 150p. Dissertação (Mestrado) - Departamento de Engenharia Mecânica, 


\section{APÊNDICE A: DESCRIÇÃO FUNCIONAL}

I. Sistema de Resfriamento de óleo.

Função Primária: Manter o óleo dentro das faixas de temperatura especificada.

I.1 Trocado de calor (casos/tubos).

Função Primária: Resfriar o óleo do circuito hidráulico.

I.2. Tubulação.

Função Primária: Encaminha o fluxo de água

I.3. Fluxômetro.

Função Primária: indicar a vazão de água

II. Sistema de pressurização de óleo.

Função Primária: Fornecer óleo pressurizado para o acumulador APP

II.1 Sistema de pressurização de óleo principal.

Função Primária: Fornecer óleo pressurizado para o acumulador APP.

II.1.1. Bomba hidráulica 1.

Função Primária: Converter energia mecânica em hidráulica fazendo os fluidos escoarem.

II.1.2. Motor elétrico A.C.1.

Função Primária: Transformar energia elétrica em energia mecânica para o acionamento da bomba.

II.1.3. Válvula de alívio 1.

Função Primária: Limita a pressão do sistema

II.1.4. Filtro 1.

Função Primária: manter o fluido livre de partículas estranhas.

II.1.5. Pressostato 1.

Função Primária: Medir a pressão na saída da bomba 1

II.1.6. Válvula unidirecional 1: 
Função Primária: Permite um fluido escoar em uma só direção e proteger a bomba de golpe de aríete.

II.2 Sistema de pressurização de óleo reserva.

Função Primária: Fornecer óleo pressurizado para a acumulador APP quando o sistema principal falha ou uma queda brusca de pressão.

II.2.1. Bomba hidráulica 2.

Função Primária: Converter energia mecânica em hidráulica fazendo os fluidos escoarem.

II.2.2. Motor elétrico A.C.2.

Função Primária: Transformar energia elétrica em energia mecânica para o acionamento da bomba.

II.2.3. Válvula de alívio 2.

Função Primária: Limita a pressão do sistema

II.2.4. Filtro 2.

Função Primária: manter o fluido livre de partículas estranhas.

II.2.5. Pressostato 2.

Função Primária: Acionar as bombas em caso de queda brusca de pressão.

II.2.6. Válvula unidirecional 2:

Função Primária: Permite um fluido escoar em uma só direção e proteger a bomba de golpe de aríete.

II.3 Reservatório.

Função Primária: Medir a pressão na saída da bomba 2.

III. Sistema de emergência.

Função Primária: realizar o fechamento do distribuidor e rotor em caso de emergência. 
III.1 Sistema de pressurização de óleo de emergência.

Função Primária: Fornecer óleo pressurizado para os acumuladores APED e APER.

III.1.1. Bomba hidráulica 3.

Função Primária: Converter energia mecânica em hidráulica fazendo os fluidos escoarem.

III.1.2. Motor elétrico A.C.3.

Função Primária: Transformar energia elétrica em energia mecânica para o acionamento da bomba.

III.1.3. Válvula de alívio 3.

Função Primária: Limita a pressão do sistema

III.1.4. Filtro 3.

Função Primária: Manter o fluido livre de partículas estranhas.

III.1.5. Pressostato 3.

Função Primária: Medir a pressão na saída da bomba 3.

III.2 Sistema de fechamento do distribuidor

Função Primária: Fornecer óleo pressurizado para os acumuladores APED.

III.2.1. Acumulador APED.

Função Primária: Fornecer vazão e pressão para o fechamento do distribuidor .

III.2.2. Válvula de comando 1.

Função Primária: Receber a sinal elétrico do sistema de controle e deixa que o óleo encha o acumulador APED .

III.2.3. Válvula unidirecional 4:

Função Primária: Permite um fluido escoar em uma só direção e proteger a bomba de golpe de aríete.

III.2.4. Válvula proporcional 3. 
Função Primária: Receber a sinal do sistema de controle e permitir o fechamento do distribuidor.

III.3 Sistema de fechamento do rotor

Função Primária: Fornecer óleo pressurizado para os acumuladores APER

III.2.1. Acumulador APER.

Função Primária: Fornecer vazão e pressão para o fechamento do rotor .

III.2.2. Válvula de comando 2.

Função Primária: Receber a sinal elétrico do sistema de controle e deixa que o óleo encha o acumulador APER.

III.2.3. Válvula unidirecional 5:

Função Primária: Permite um fluido escoar em uma só direção e proteger a bomba de golpe de aríete.

III.2.4. Válvula proporcional 4.

Função Primária: Receber a sinal do sistema de controle e permitir o fechamento do rotor.

IV. Unidade motora.

Função Primária: Fornecer a vazão e pressão para a movimentação dos atuadores do distribuidor e rotor.

IV.1 Acumulador APP.

Função Primária: Fornecer a vazão e pressão para a movimentação dos atuadores do distribuidor e rotor.

IV.2 Válvula de comando S1.

Função Primária: Receber a sinal do sistema de controle para permitir que o óleo a pressão encha o acumulador APP e permitir a recirculação do óleo para o sistema de resfriamento.

IV.3. Válvula unidirecional 6: 
Função Primária: Permite um fluido escoar em uma só direção.

IV.4. Filtro 3:

Função Primária: manter o fluido livre de partículas estranhas.

IV.5. Filtro 4:

Função Primária: manter o fluido livre de partículas estranhas.

IV.6. Sistema de Pressão Diferencial:

Função Primária: Monitor a pressão diferencial para indicar quando o filtro está entupido.

V. Unidade de Controle.

Função Primária: Receber a sinal do sistema de controle para movimentar os atuadores do distribuidor e rotor.

V.1 Unidade de controle do distribuidor.

Função Primária: Receber a sinal do sistema de controle para movimentar os atuadores do distribuidor.

V.1.1. Válvula proporcional 1.

Função Primária: Receber a sinal do sistema de controle para comandar a válvula distribuidora 1.

V.1.2. Válvula distribuidora 1.

Função Primária: Receber a sinal da válvula proporcional e controla o movimento dos atuadores do distribuidor.

V.2 Unidade de controle do rotor.

Função Primária: Receber a sinal do sistema de controle para movimentar os atuadores do rotor.

V.1.1. Válvula proporcional 2.

Função Primária: Receber a sinal do sistema de controle para comandar a válvula distribuidora 2 .

V.1.2. Válvula distribuidora 2. 
Função Primária: Receber a sinal da válvula proporcional e controla o movimento dos atuadores do rotor.

VI. Unidade de trabalho.

Função Primária: Movimentar o anel do distribuidor e as pás do rotor.

VI.1 Unidade de controle do distribuidor.

Função Primária: Movimentar o anel do distribuidor.

VI.1.1. Atuador 1.

Função Primária: Movimentar o anel do distribuidor.

VI.1.2. Atuador 2.

Função Primária: Movimentar o anel do distribuidor.

VI.1.3. Sensor de posição.

Função Primária: Indicar a posição da haste do atuador 1.

VI.2 Unidade de controle do rotor.

Função Primária: Movimentar as pás do rotor.

Vl.1.1. Atuador 1.

Função Primária: Movimentar as pás do rotor.

VI.1.2. Tanque estático.

Função Primária: Armazenar o óleo. 


\section{Apêndice B: Aplicação do HAZOP e FTA}

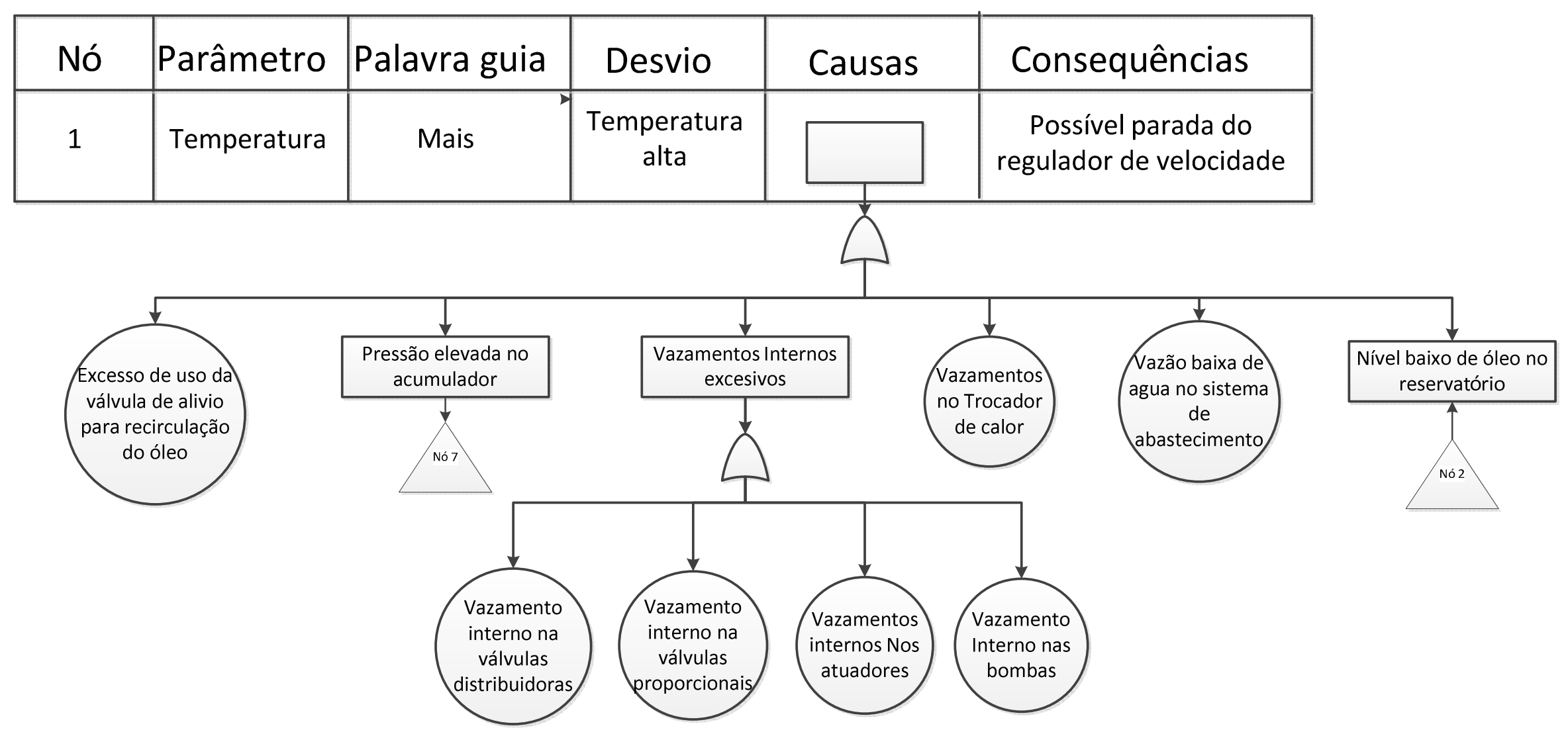




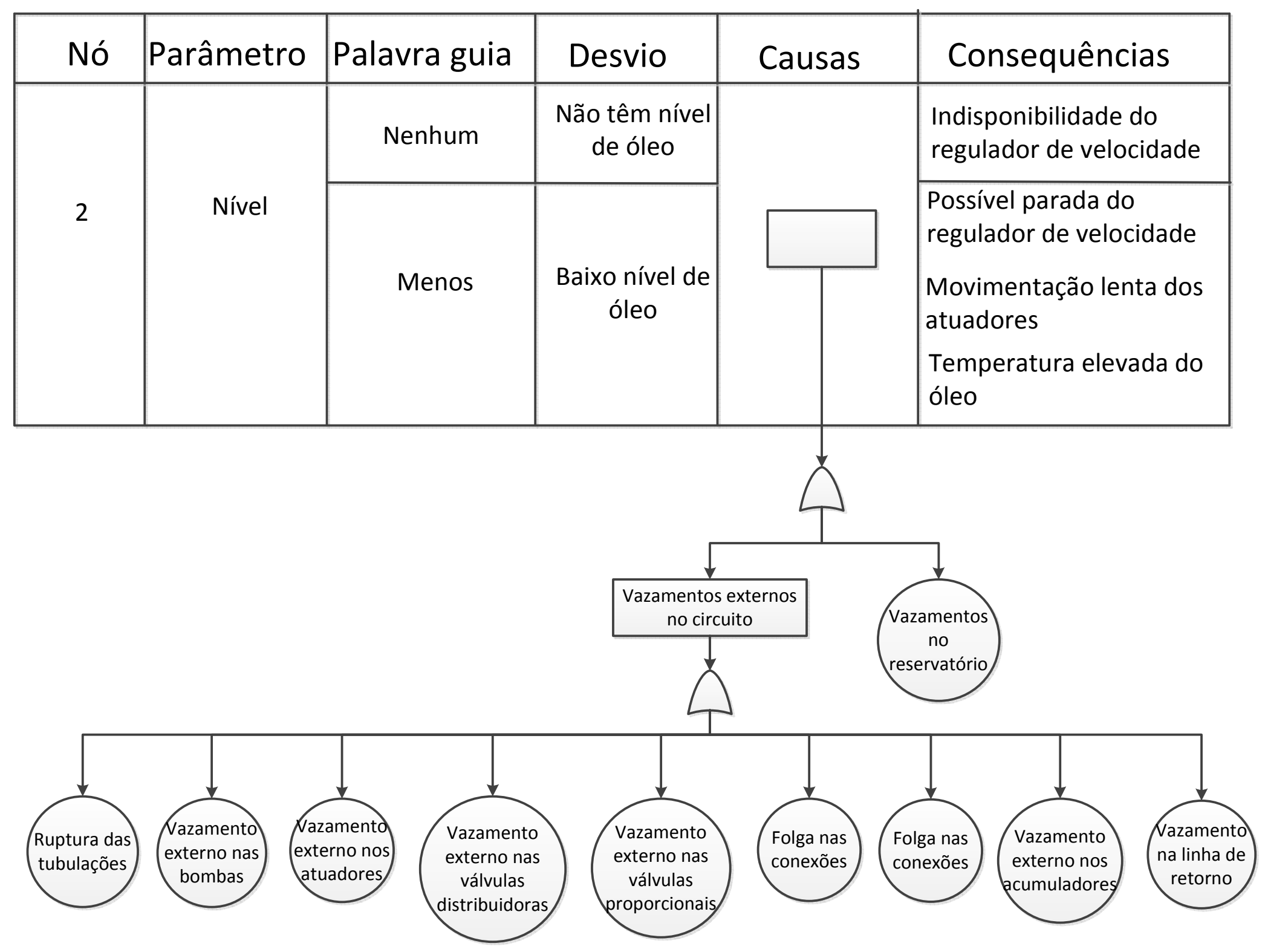




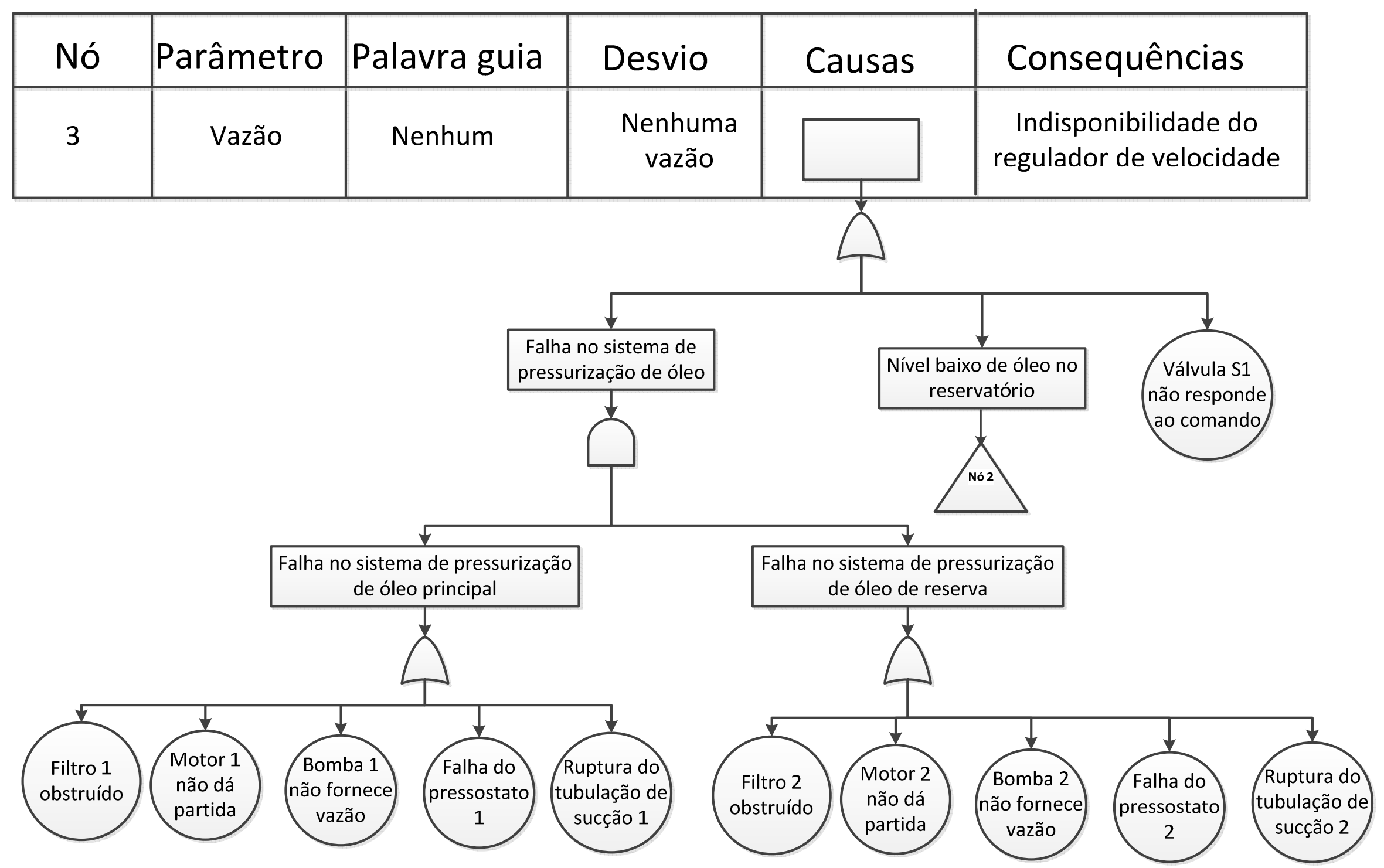




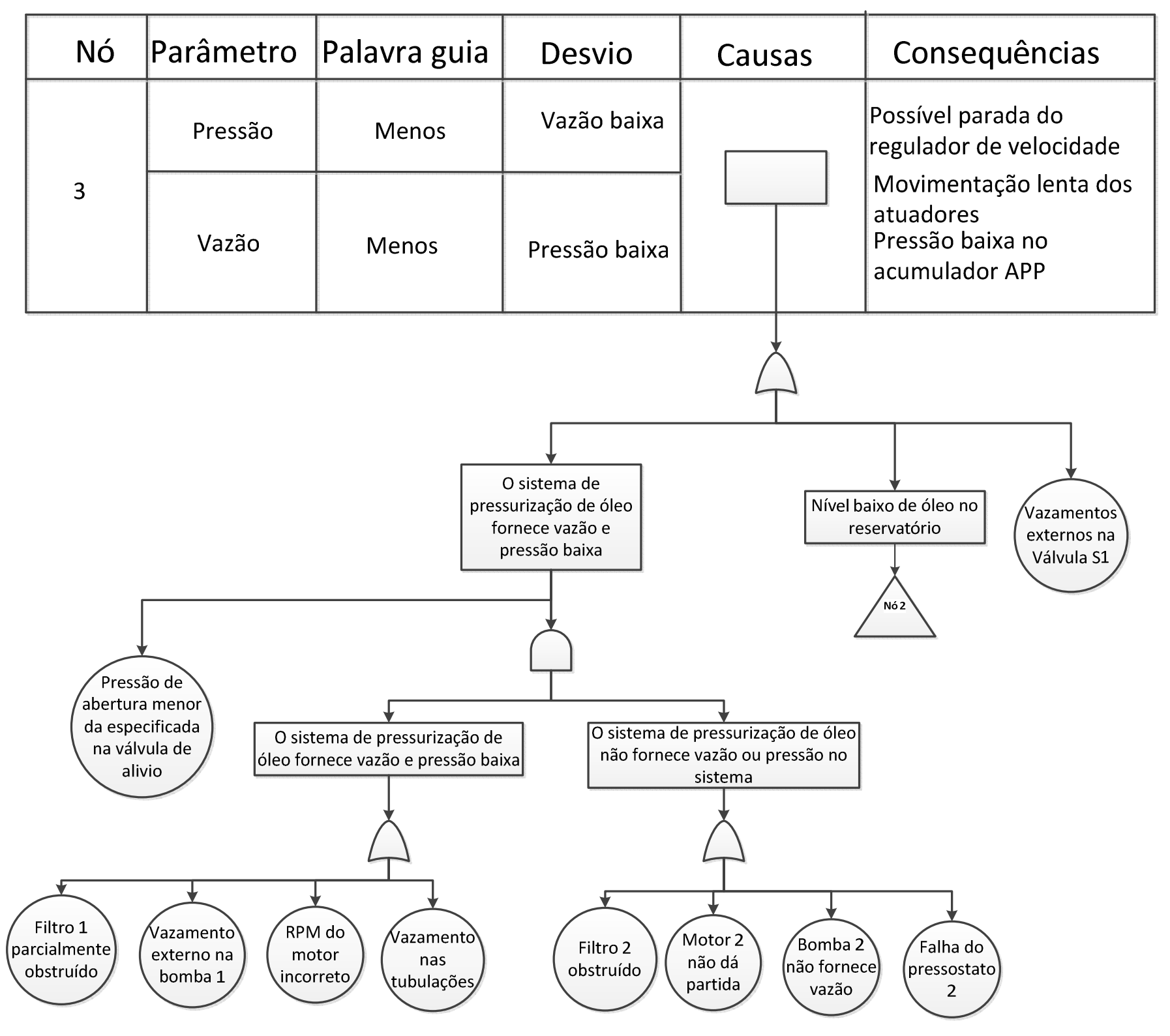




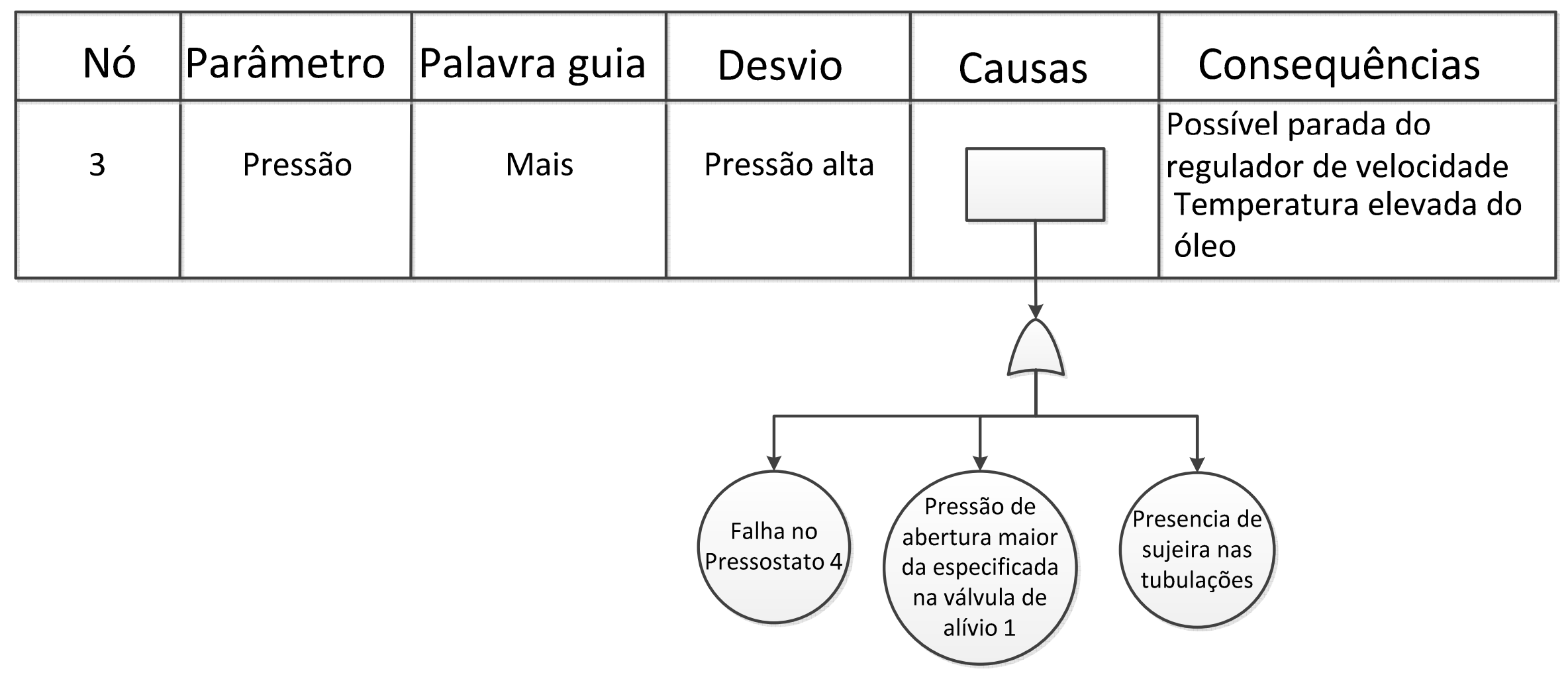




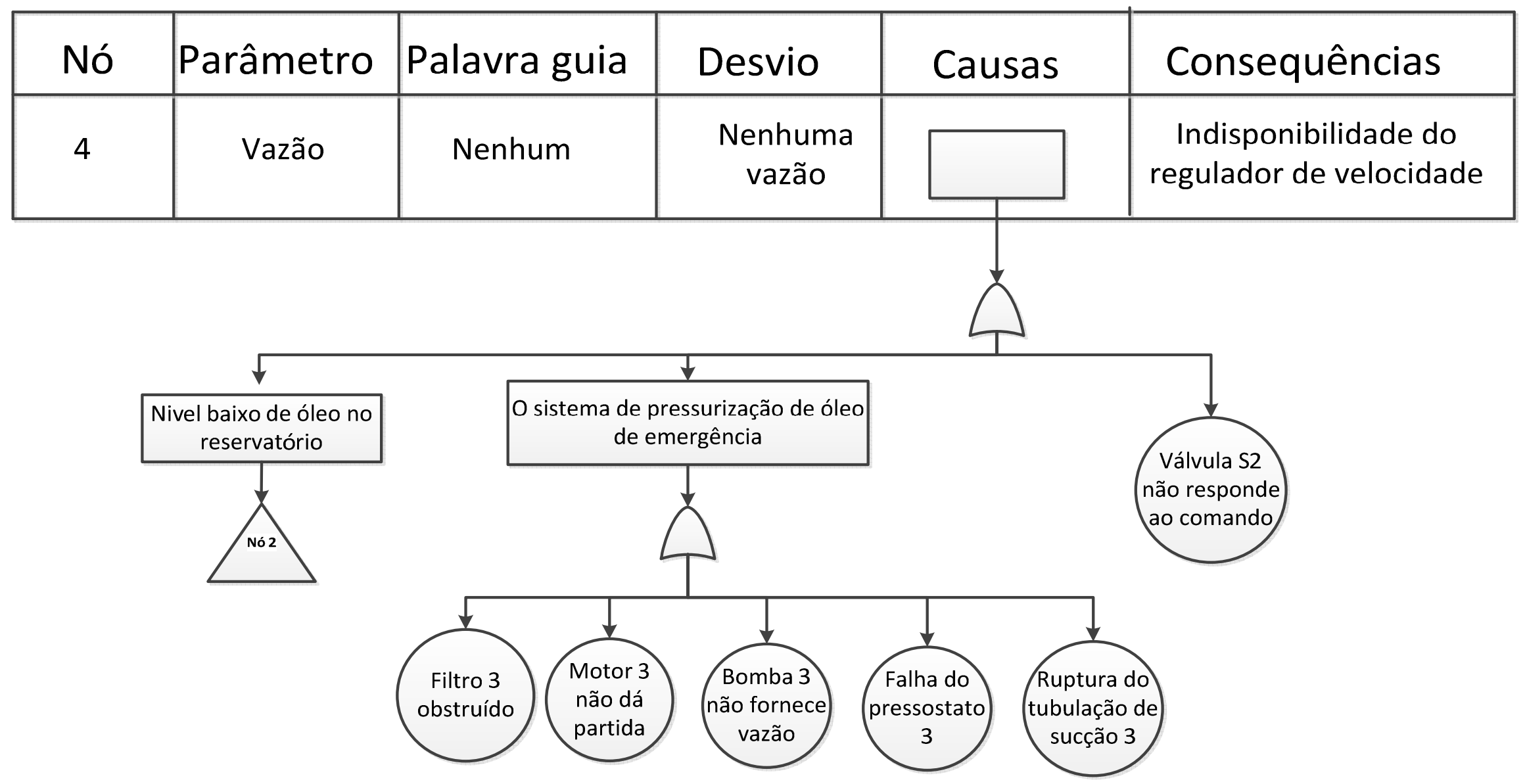




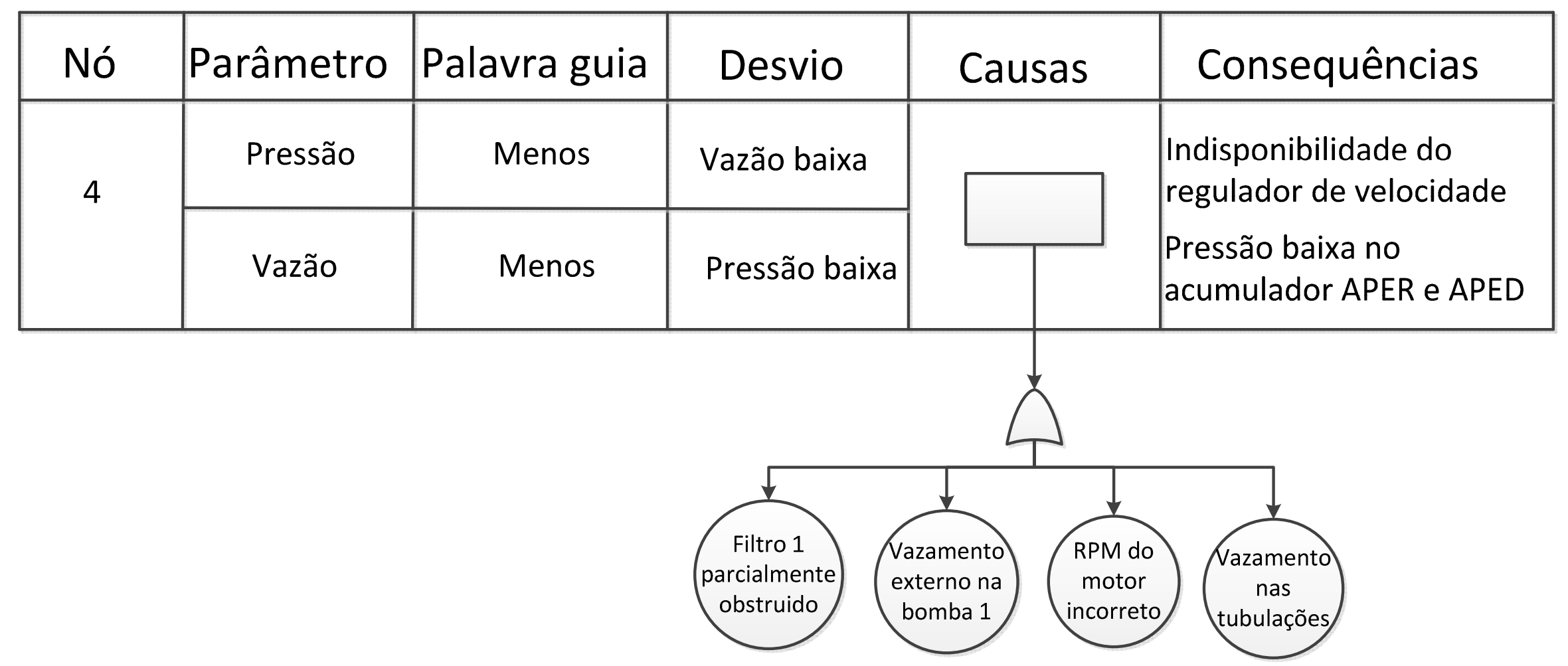




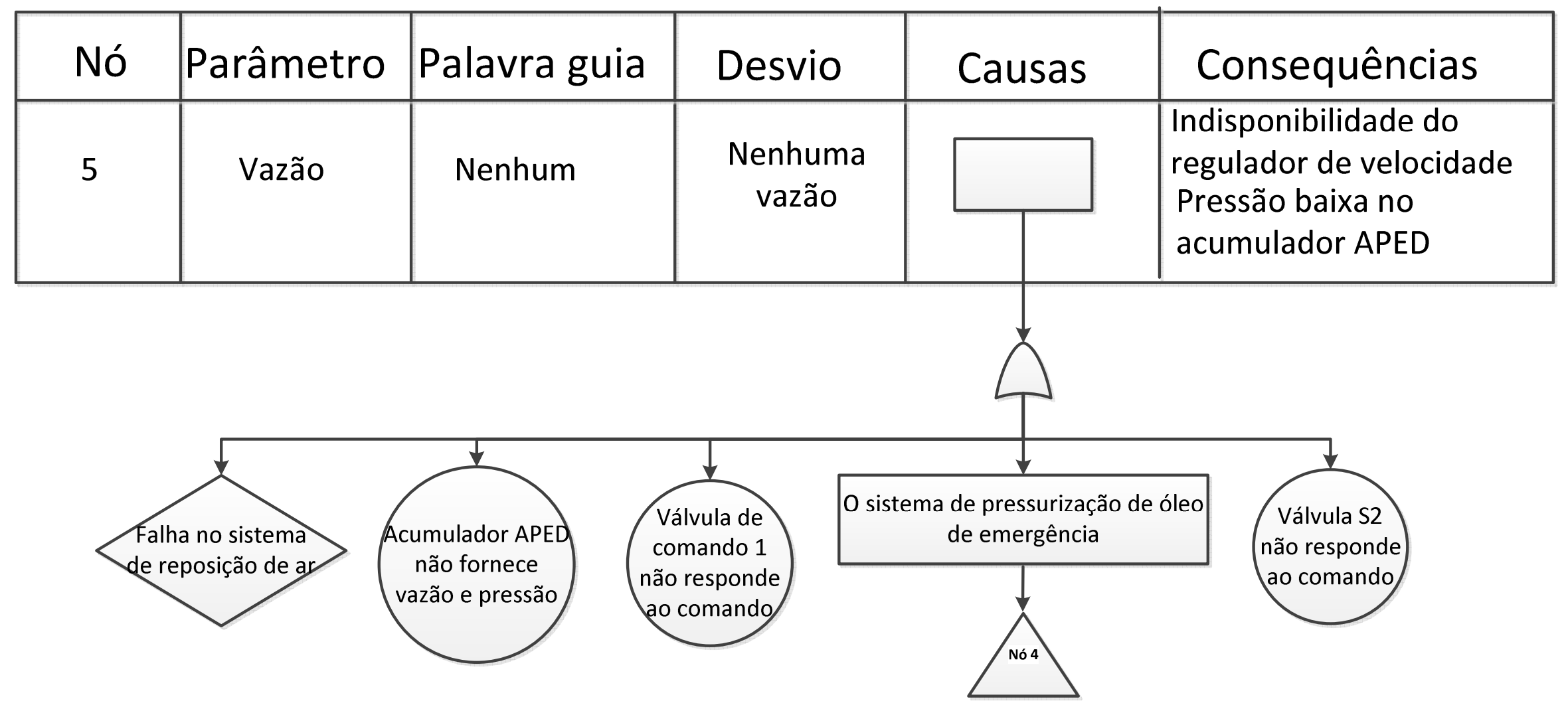




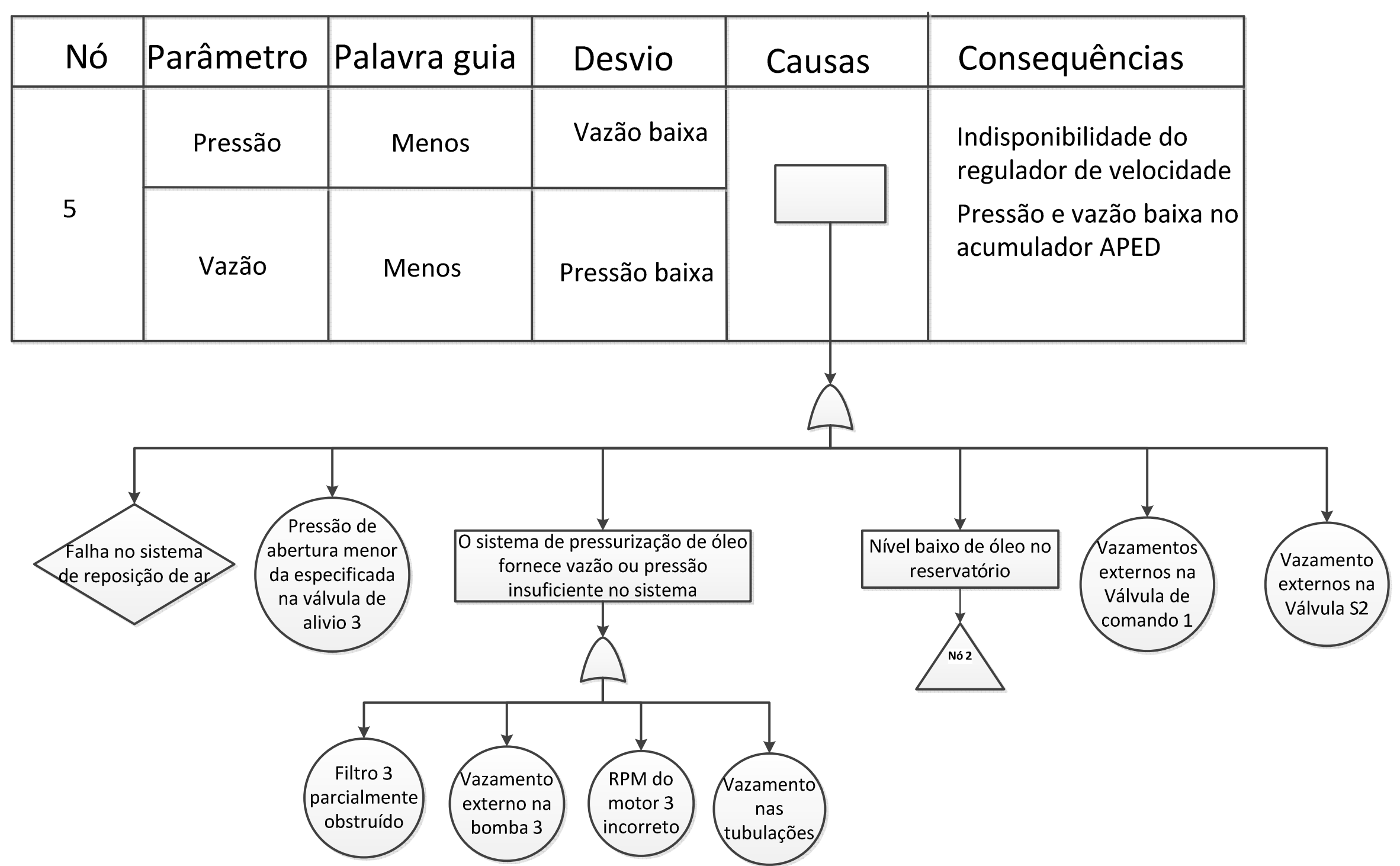




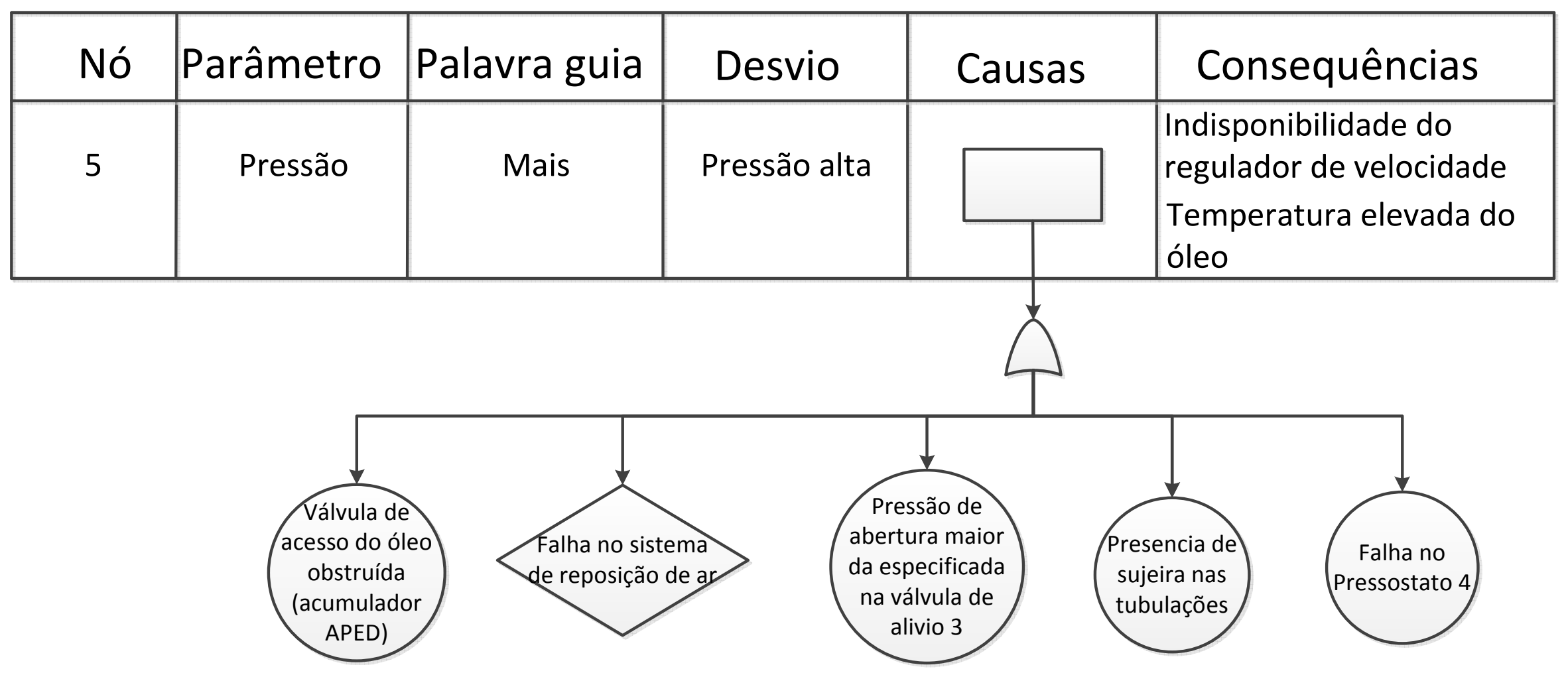




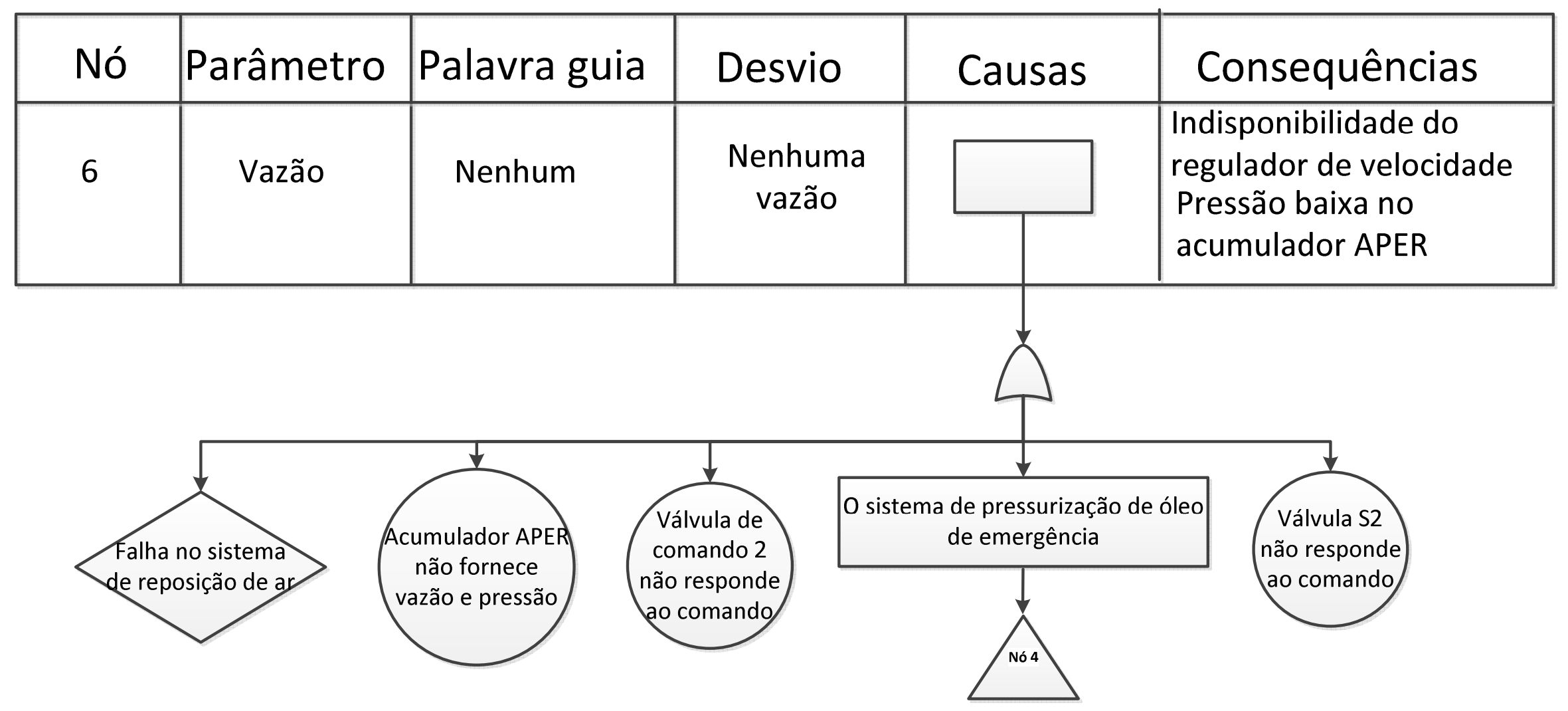




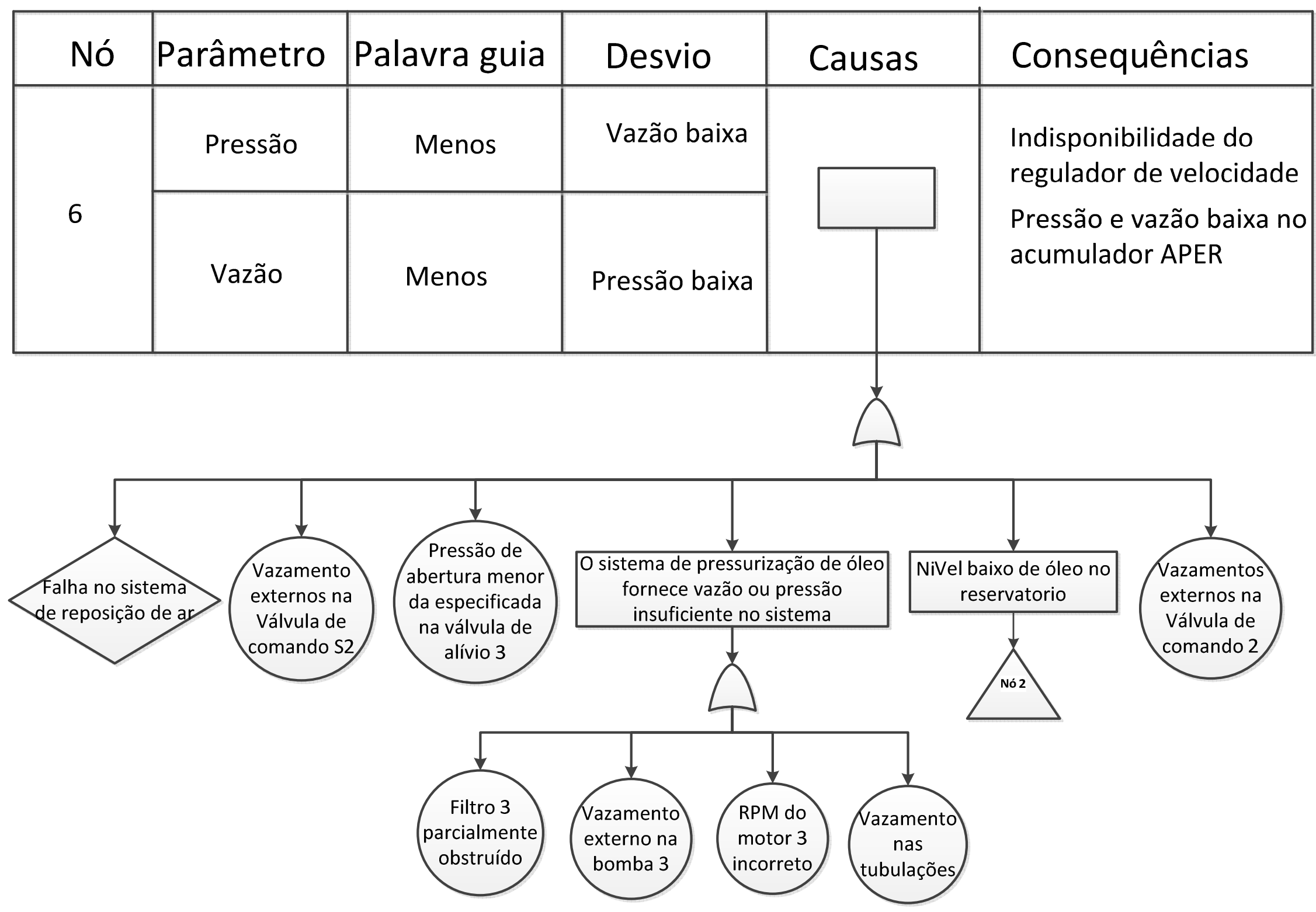




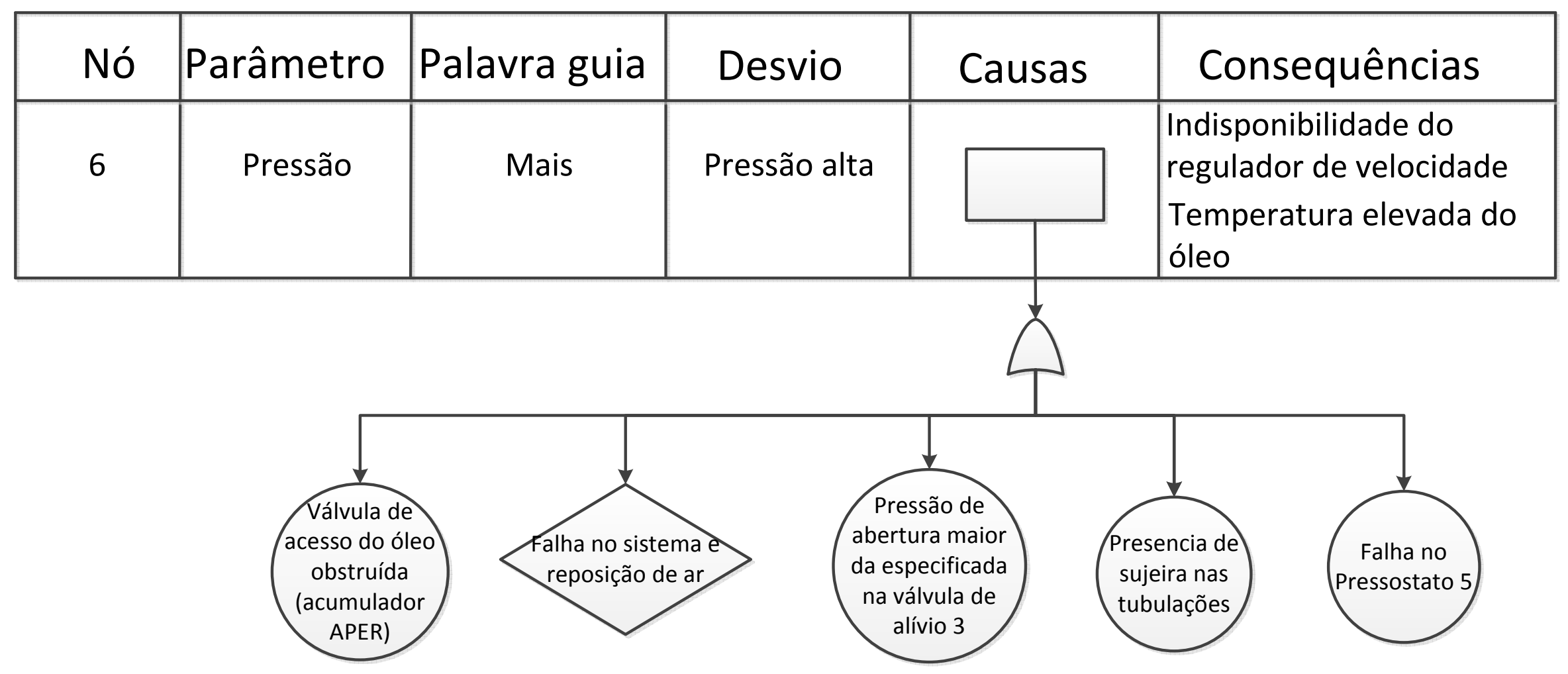




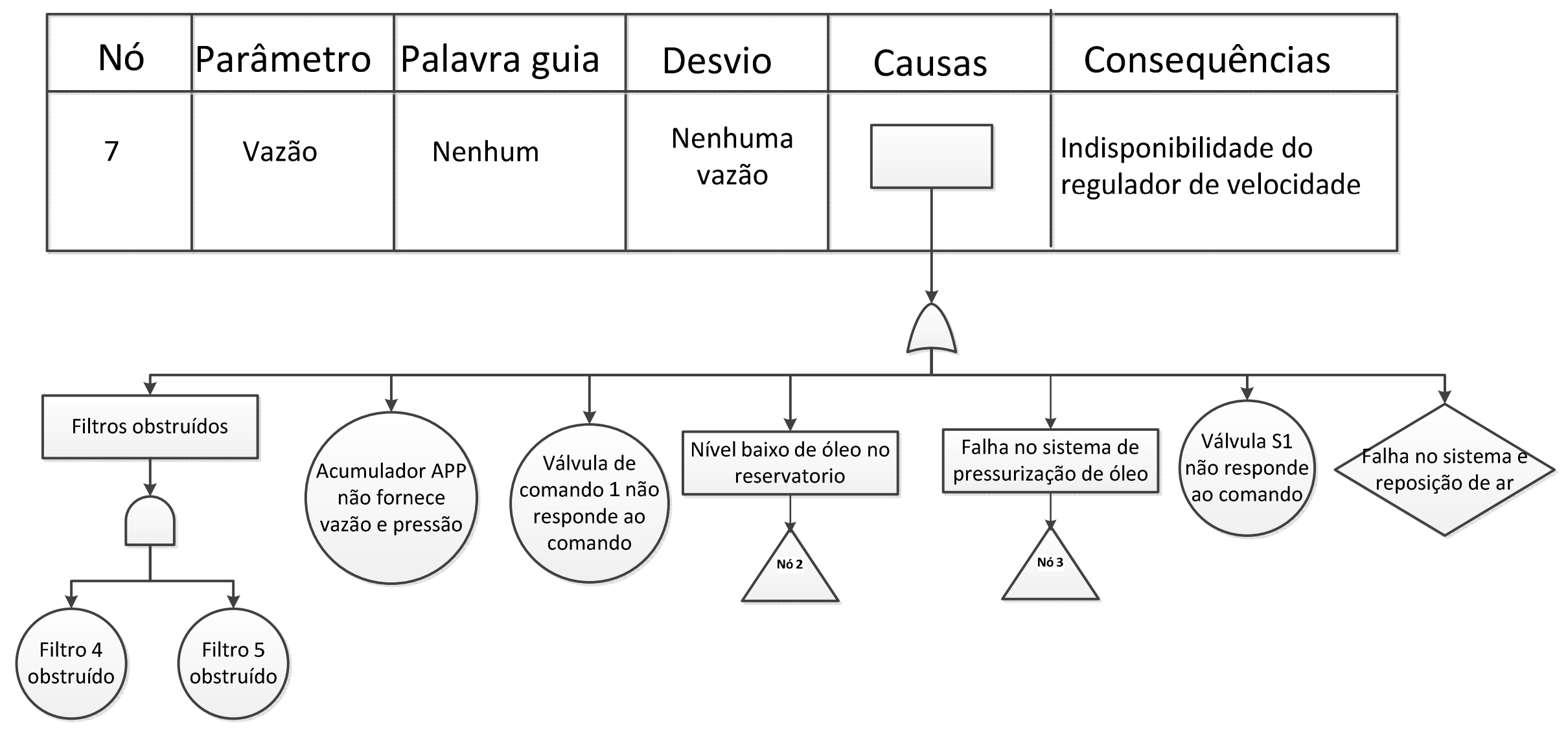




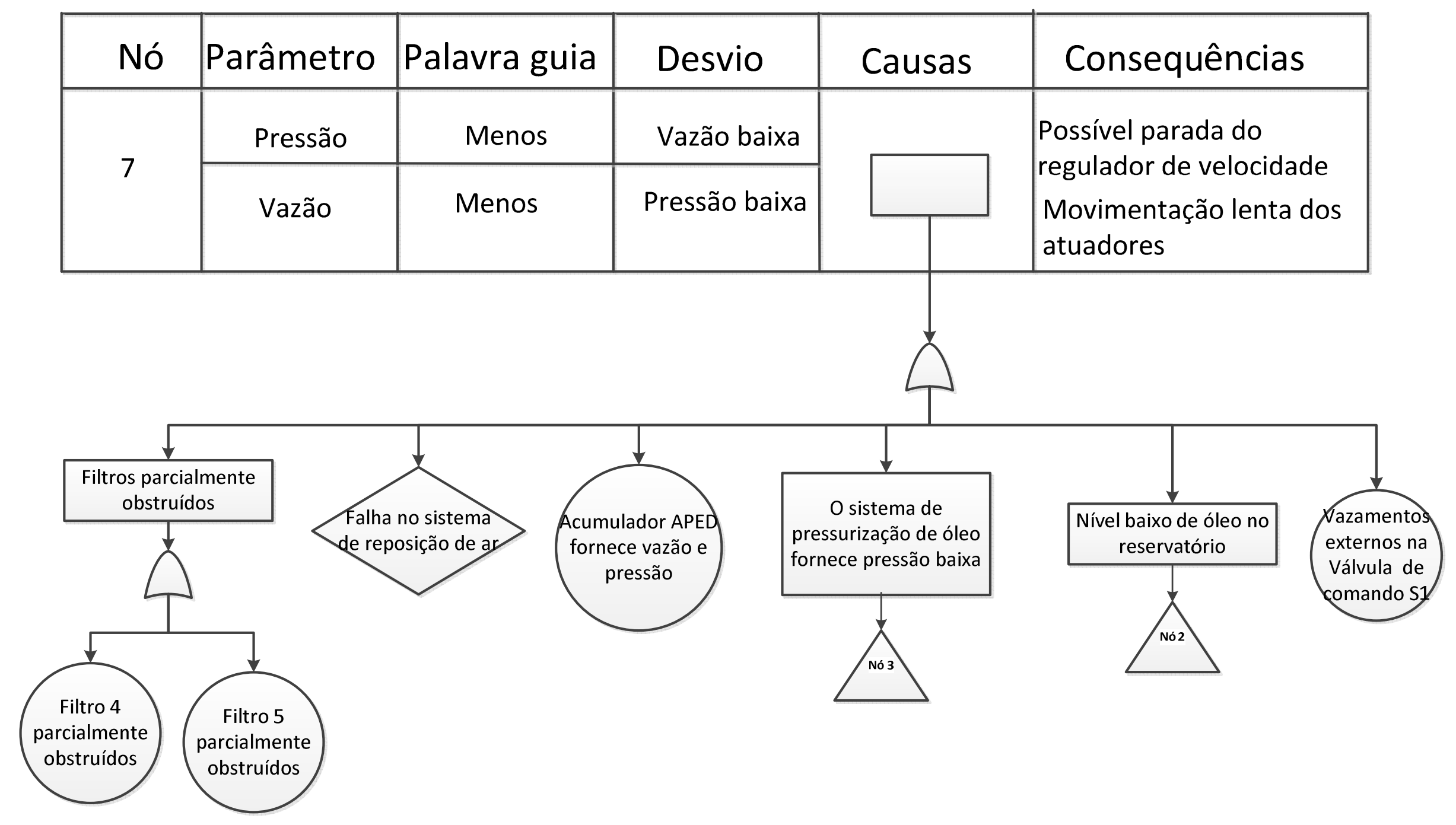




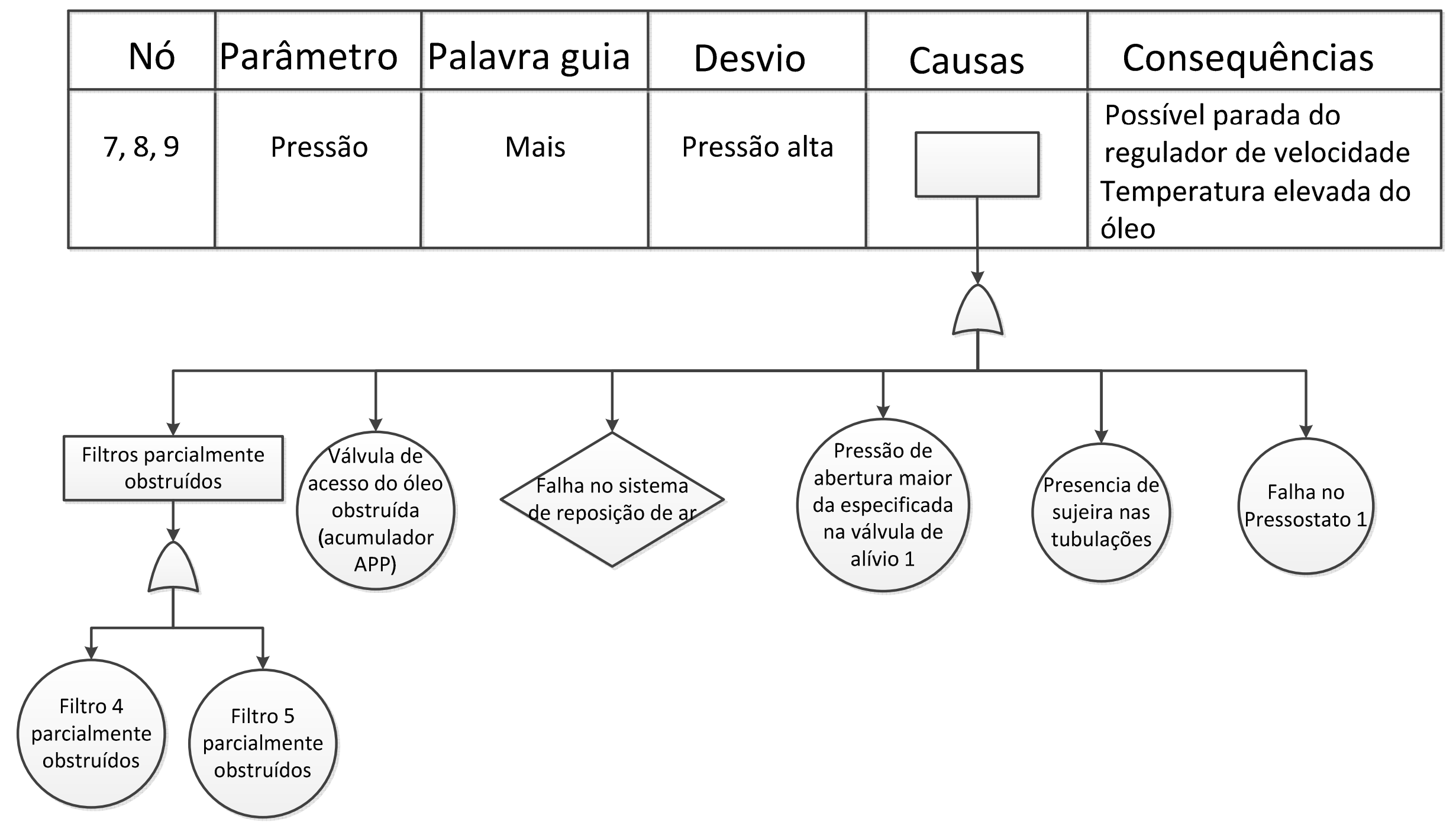




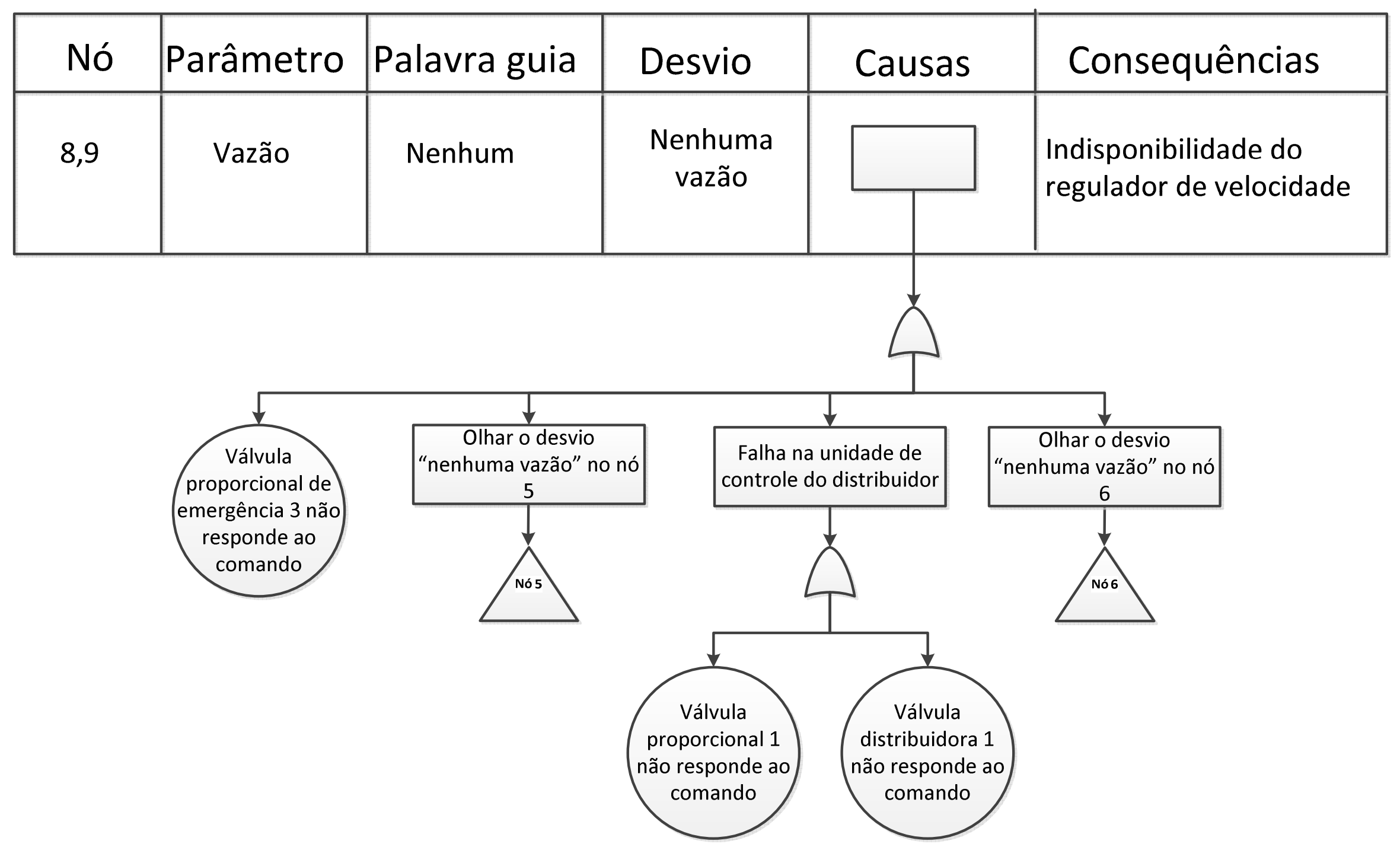




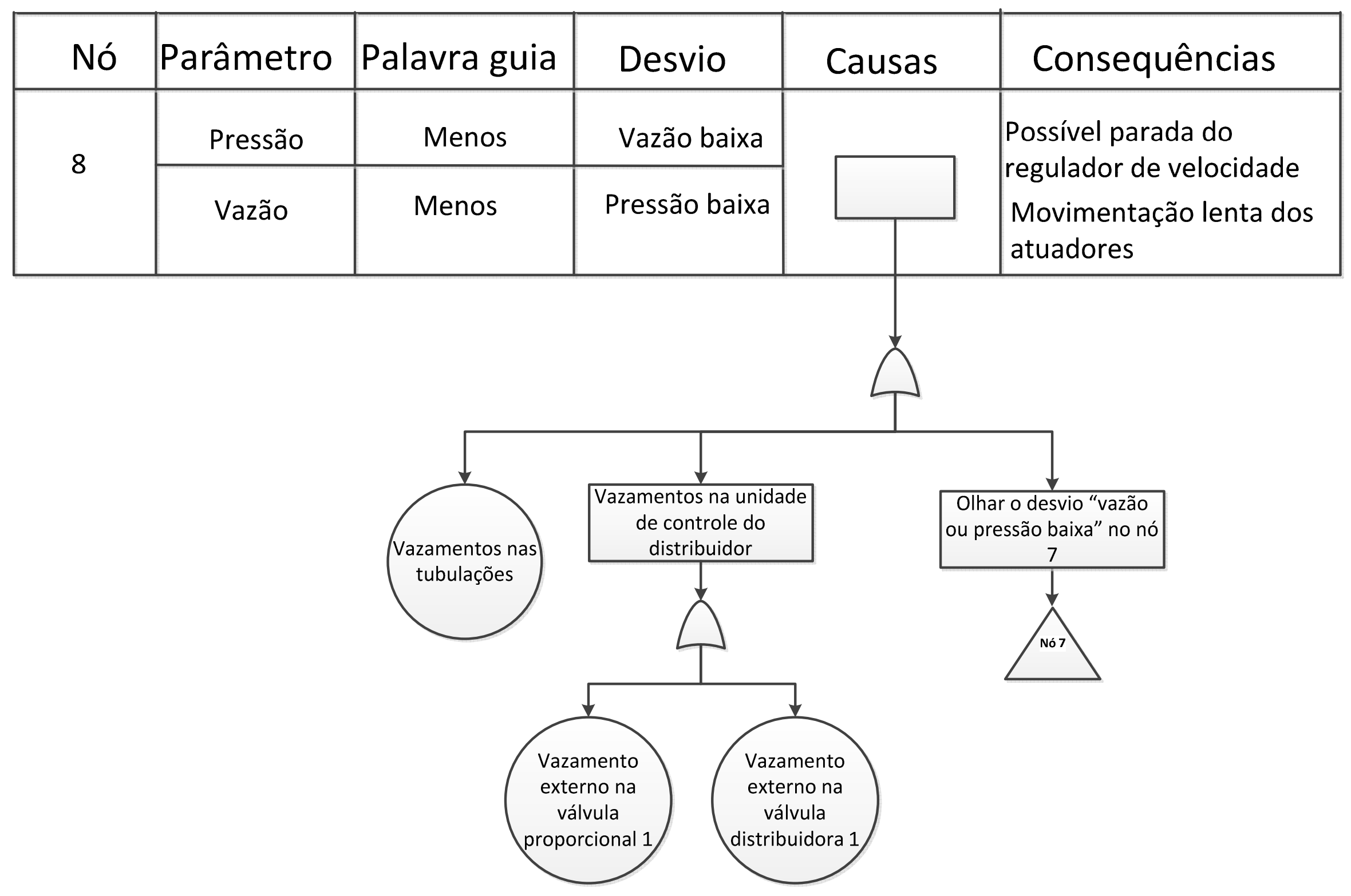




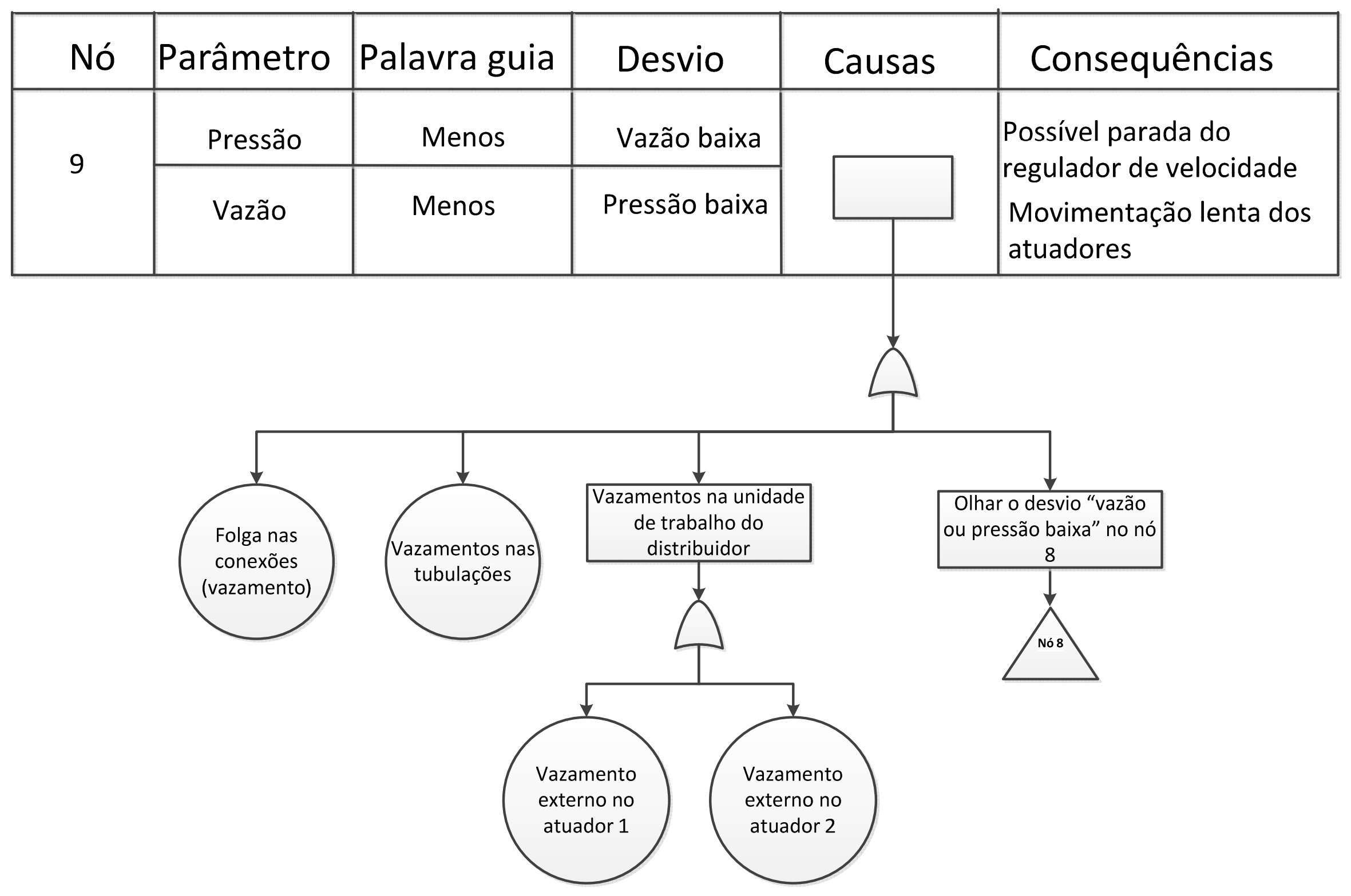




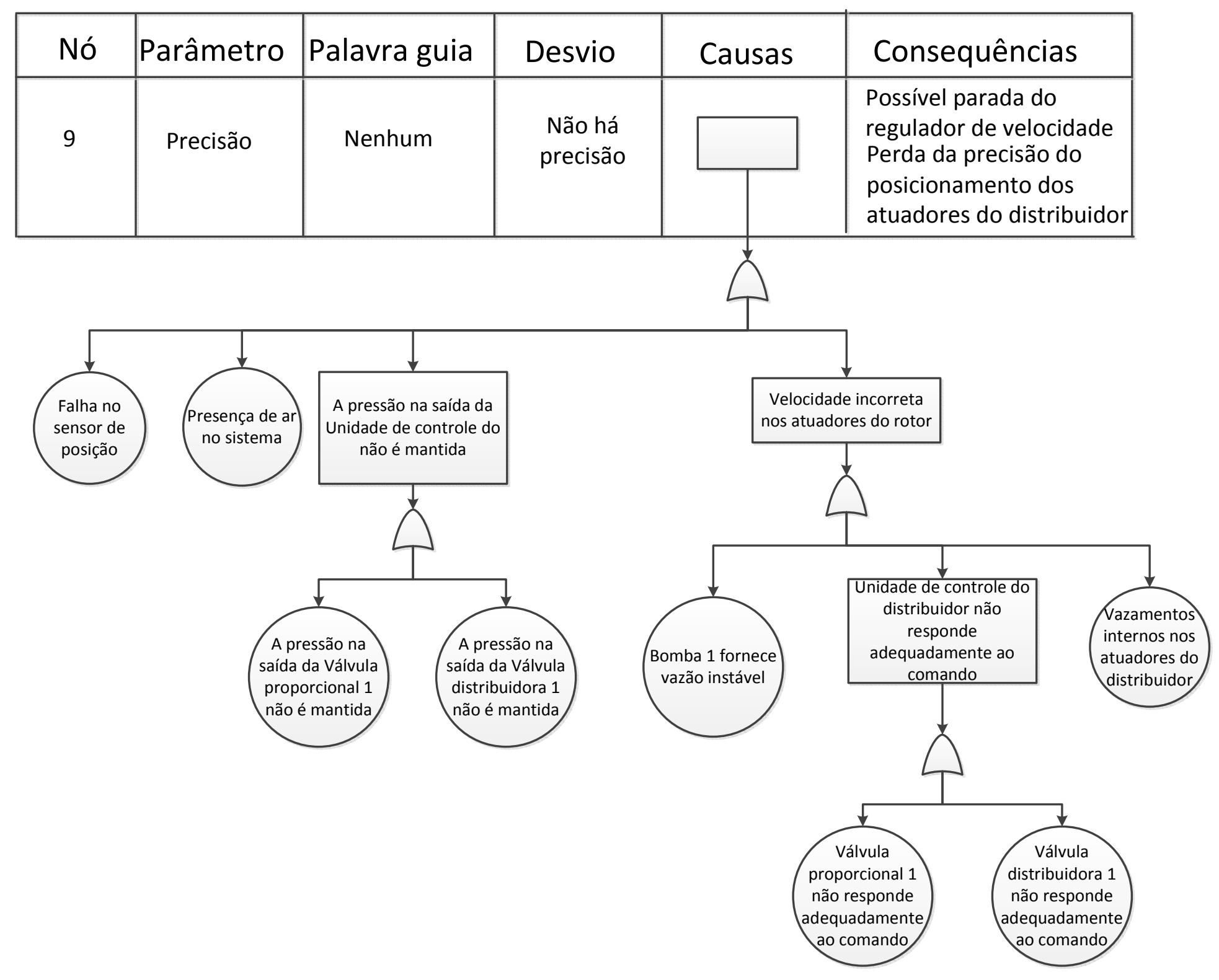




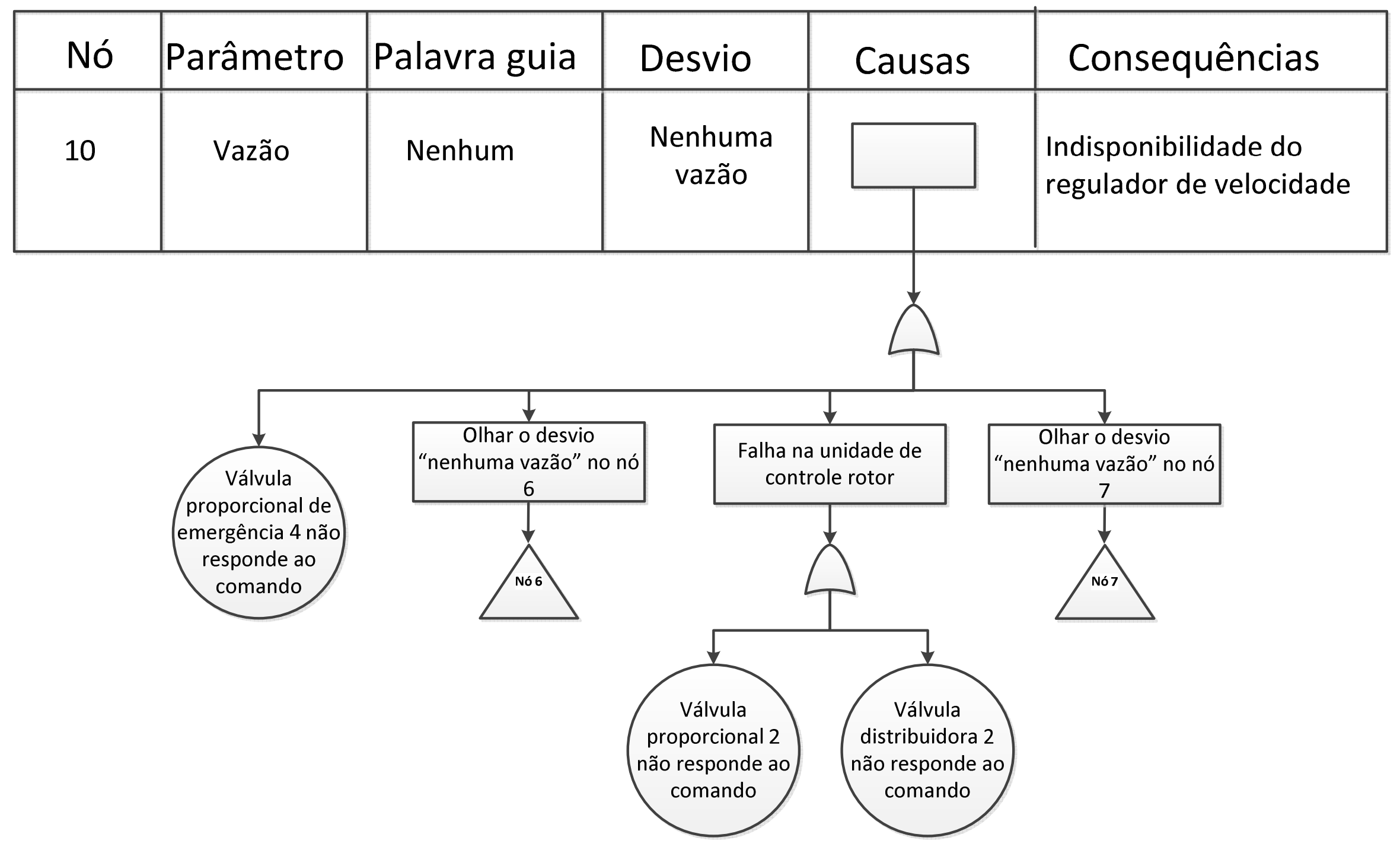




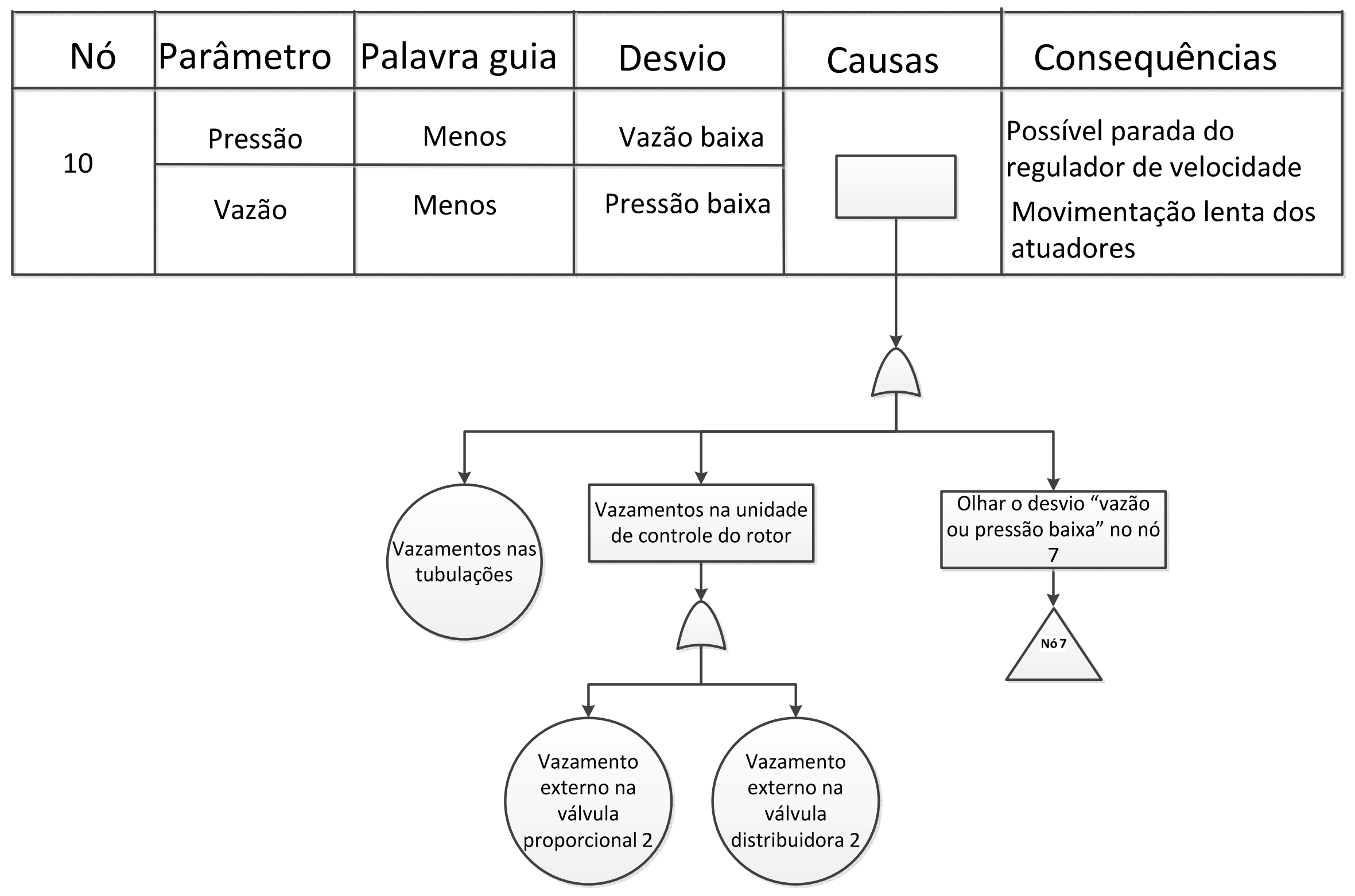




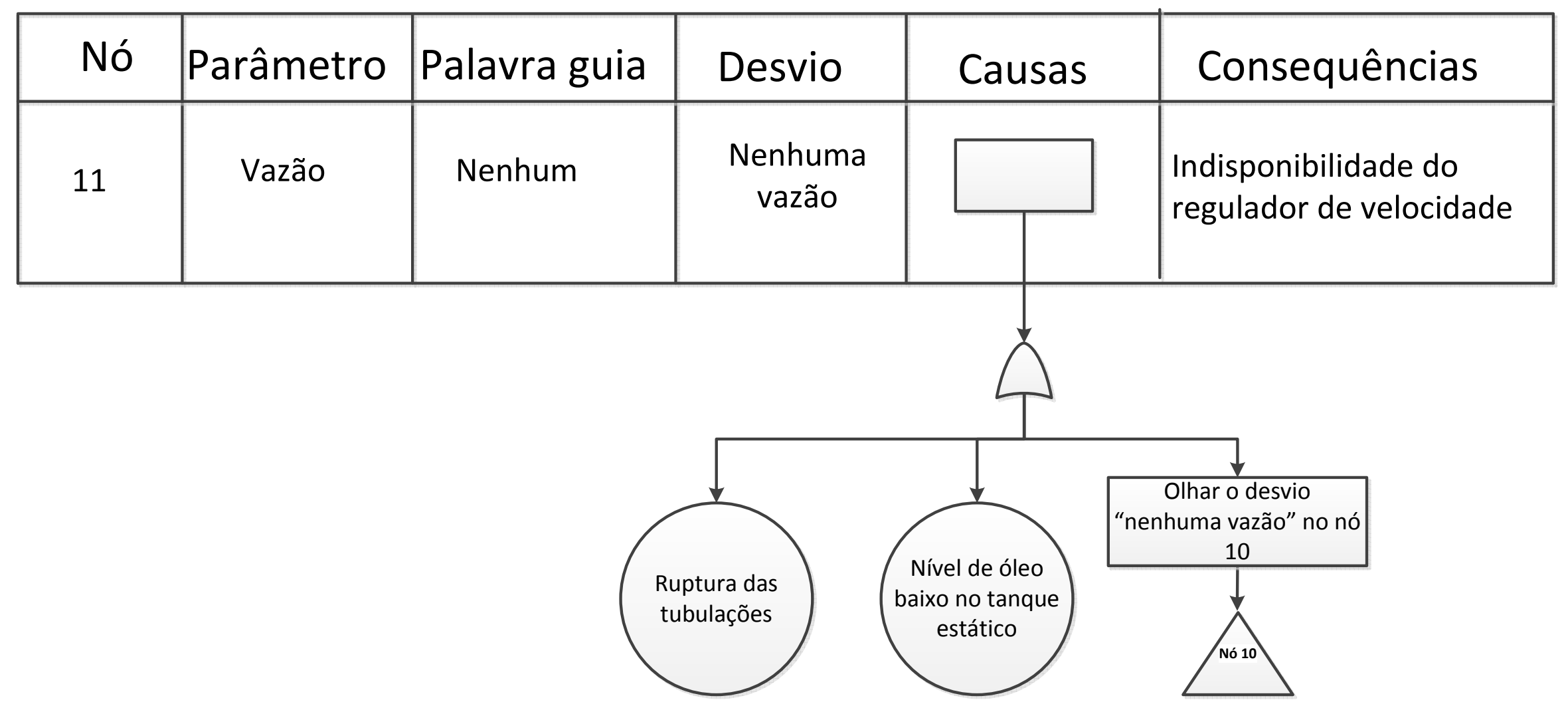




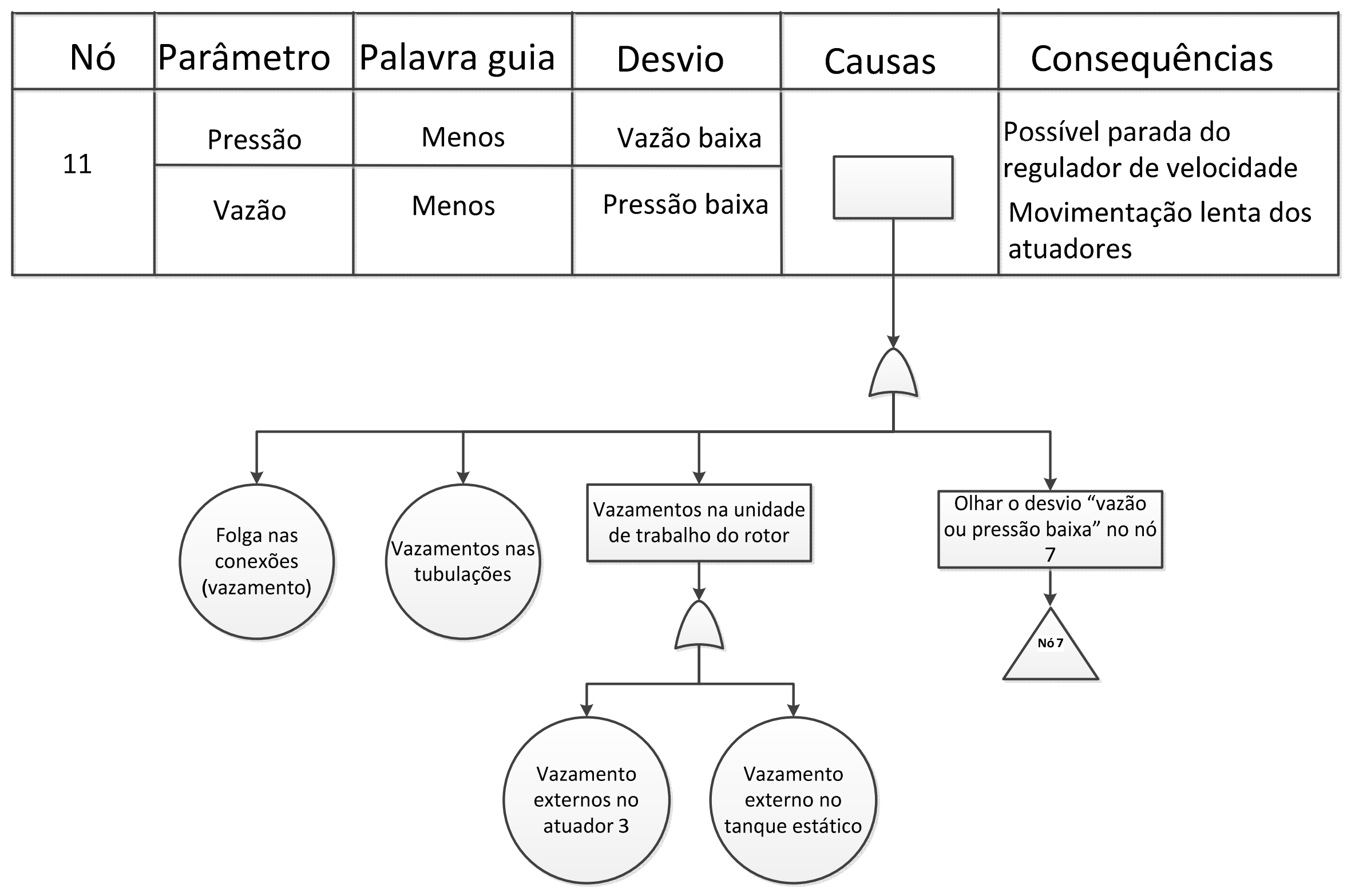




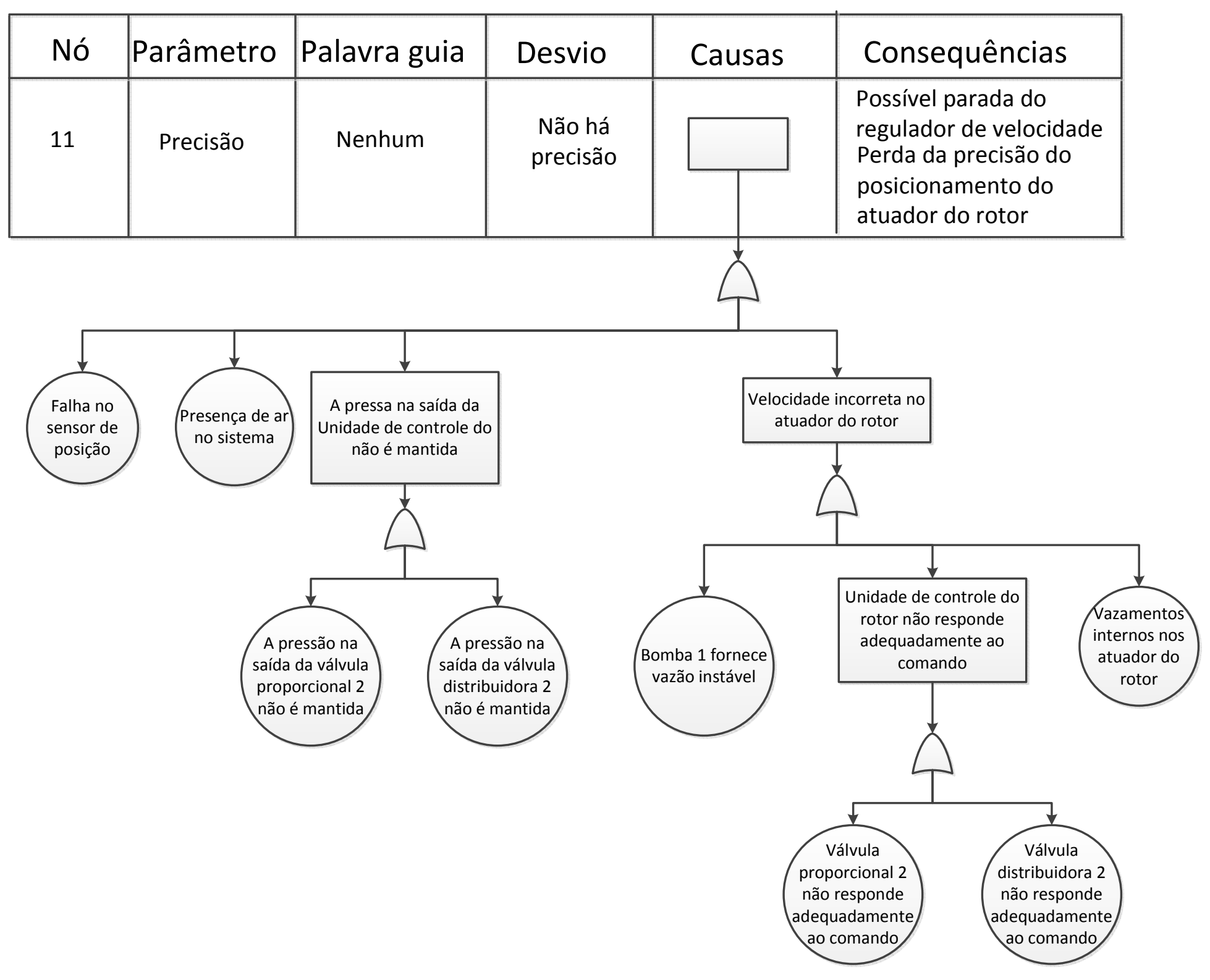


Apêndice C: Análise de Modos e Efeitos de Falha

\begin{tabular}{|c|c|c|c|}
\hline \multicolumn{4}{|c|}{ Análise de Modo e Efeito de Falha - FMEA } \\
\hline Componente: & \multicolumn{3}{|l|}{ Motor AC } \\
\hline \multicolumn{4}{|l|}{ Sistema: } \\
\hline \multicolumn{4}{|l|}{ Equipe: } \\
\hline \multicolumn{4}{|l|}{ Responsável: } \\
\hline \multirow[t]{4}{*}{ Componente } & Função & $\begin{array}{c}\text { Modo de falha } \\
\text { potencial }\end{array}$ & Causa(s) da falha \\
\hline & & & Disjuntor aberto \\
\hline & Transformar & & Perda do isolamento da bobinas \\
\hline & energia elétrica & Não dá & Sobreaquecimento no motor \\
\hline \multirow[t]{4}{*}{ Motor AC } & em energia & partida & Travamento do eixo do motor \\
\hline & mecânica para & & Ventilação inadequada \\
\hline & o acionamento & & Baixa ou incorreta tensão de alimentação \\
\hline & da bomba & & \\
\hline
\end{tabular}

\begin{tabular}{|l|l|}
\hline \multicolumn{2}{|c|}{ Análise de Modo e Efeito de Falha - FMEA } \\
\hline Componente: & Filtro \\
\hline Sistema: & Regulador de velocidade \\
\hline Equipe: & \\
\hline Responsável: & \\
\hline
\end{tabular}

\begin{tabular}{|c|c|c|c|}
\hline Componente & Função & $\begin{array}{c}\text { Modo de falha } \\
\text { potencial }\end{array}$ & Causa(s) da falha \\
\hline \multirow{9}{*}{ Filtro } & \multirow{9}{*}{$\begin{array}{c}\text { Manter o fluido } \\
\text { livre de } \\
\text { partículas } \\
\text { estranhas }\end{array}$} & \multirow{4}{*}{$\begin{array}{c}\text { Ruptura do } \\
\text { elemento filtrante }\end{array}$} & Falha na seleção do filtro \\
\hline & & & Desgaste do papel do elemento filtrante \\
\hline & & & Vazão muito elevada para o filtro \\
\hline & & & Aumento da pressão por acumulo de sujeira \\
\hline & & \multirow{5}{*}{ Filtro entupido } & Viscosidade alta do fluido \\
\hline & & & Falta de limpeza do reservatório \\
\hline & & & Filtro não é limpo ou trocado conforme \\
\hline & & & intervalos recomendados pelo fabricante \\
\hline & & & Falha na seleção do filtro \\
\hline
\end{tabular}




\begin{tabular}{|c|c|c|c|}
\hline \multicolumn{4}{|c|}{ Análise de Modo e Efeito de Falha - FMEA } \\
\hline Componente: & \multicolumn{3}{|c|}{ Bomba de deslocamento positivo } \\
\hline Sistema: & \multicolumn{3}{|c|}{ Regulador de velocidade } \\
\hline \multicolumn{4}{|l|}{ Equipe: } \\
\hline \multicolumn{4}{|l|}{ Responsável: } \\
\hline Componente & Função & $\begin{array}{c}\text { Modo de falha } \\
\text { potencial }\end{array}$ & Causa(s) da falha \\
\hline \multirow{17}{*}{$\begin{array}{l}\text { Bomba de } \\
\text { deslocamento } \\
\text { positivo }\end{array}$} & \multirow{17}{*}{$\begin{array}{l}\text { Converter } \\
\text { energia } \\
\text { mecânica em } \\
\text { hidráulica, } \\
\text { fazendo o óleo } \\
\text { escoar }\end{array}$} & \multirow{6}{*}{$\begin{array}{l}\text { Incapacidade de } \\
\text { bombear }\end{array}$} & Travamento do eixo da bomba \\
\hline & & & Bloqueio total da linha de sucção \\
\hline & & & Falta ou falha de lubrificação levando \\
\hline & & & ao emperramento \\
\hline & & & Ruptura da linha de sucção \\
\hline & & & Falha na montagem da bomba \\
\hline & & \multirow{11}{*}{$\begin{array}{l}\text { Bombeamento com } \\
\text { condições que não } \\
\text { atendem à } \\
\text { especificações de } \\
\text { operação }\end{array}$} & Falha na lubrificação \\
\hline & & & Vazamentos causados por montagem \\
\hline & & & imprópria e falhas dos retentores ou conexões \\
\hline & & & Desgaste abrasivo, provocado por óleo \\
\hline & & & contaminado \\
\hline & & & Folgas excessivas ou com variações devido \\
\hline & & & aos erros de montagem \\
\hline & & & Cavitação ou aeração, provocados por nível \\
\hline & & & de óleo insuficiente, viscosidade de óleo fora \\
\hline & & & das especificações e restrição na entrada. \\
\hline & & & Pressão de sucção insuficiente (NPSH) \\
\hline
\end{tabular}

\begin{tabular}{|c|c|c|c|}
\hline \multicolumn{4}{|c|}{ Análise de Modo e Efeito de Falha - FMEA } \\
\hline Componente: & \multicolumn{3}{|l|}{ Válvula de alivio } \\
\hline Sistema: & \multicolumn{3}{|c|}{ Regulador de velocidade } \\
\hline \multicolumn{4}{|l|}{ Equipe: } \\
\hline \multicolumn{4}{|l|}{ Responsável: } \\
\hline \multirow[t]{4}{*}{ Componente } & Função & $\begin{array}{l}\text { Modo de falha } \\
\text { potencial }\end{array}$ & Causa(s) da falha \\
\hline & & & Quebra da mola \\
\hline & & Não regula a & Quebra do pistão \\
\hline & Limitar a & pressão & Desgaste do parafuso \\
\hline Válvula de & pressão do & & Vazamento de óleo \\
\hline \multirow[t]{4}{*}{ alívio } & sistema & & Desgaste da mola \\
\hline & & Pressão de abertura & Calibração errada da válvula \\
\hline & & errada & Acumulo de sujeira na válvula \\
\hline & & & Desgaste da válvula \\
\hline
\end{tabular}




\begin{tabular}{|c|c|c|c|}
\hline \multicolumn{4}{|c|}{ Análise de Modo e Efeito de Falha - FMEA } \\
\hline Componente: & \multicolumn{3}{|l|}{ Atuador } \\
\hline Sistema: & \multicolumn{3}{|c|}{ Regulador de velocidade } \\
\hline \multicolumn{4}{|l|}{ Equipe: } \\
\hline \multicolumn{4}{|l|}{ Responsável: } \\
\hline Componente & Função & $\begin{array}{c}\text { Modo de falha } \\
\text { potencial }\end{array}$ & Causa(s) da falha \\
\hline \multirow{26}{*}{ Atuador } & \multirow{26}{*}{$\begin{array}{c}\text { Transformar } \\
\text { força, potência } \\
\text { ou energia } \\
\text { hidráulica em } \\
\text { força, potência } \\
\text { ou energia } \\
\text { mecânica }\end{array}$} & \multirow{5}{*}{$\begin{array}{l}\text { Atuador fica sim } \\
\text { movimento }\end{array}$} & Temperatura fora da faixa permissível: expansão \\
\hline & & & térmica das partes móveis \\
\hline & & & Fluido com concentração alta de contaminantes \\
\hline & & & Vedações com ruptura \\
\hline & & & Emperramento do embolo ou do haste do cilindro \\
\hline & & \multirow{6}{*}{ Velocidade incorreta } & Desgaste excessivo da camisa, pistões ou anéis \\
\hline & & & Folga excessiva dos anéis do pistão \\
\hline & & & Retentores com aperto insuficiente \\
\hline & & & Viscosidade elevada do óleo \\
\hline & & & \begin{tabular}{|l|} 
Vazamentos internos no atuador \\
\end{tabular} \\
\hline & & & Ingresso de ar no sistema \\
\hline & & \multirow{5}{*}{ Movimento Pulsante } & Presença de ar no sistema \\
\hline & & & Amassaduras na camisa \\
\hline & & & Excesso de ajuste dos amortecedores \\
\hline & & & do fim do curso \\
\hline & & & Sulcos na camisa ou pistão \\
\hline & & \multirow{5}{*}{ Vazamento externo } & Estiramento de tirantes ou parafusos \\
\hline & & & Desgaste de retentor \\
\hline & & & Presença de trincas na camisa \\
\hline & & & Montagem incorreta do retentor \\
\hline & & & Cilindro desalinhado \\
\hline & & \multirow{5}{*}{ Falta de força } & Vazamentos internos no atuador \\
\hline & & & Presença de ar no sistema \\
\hline & & & Cilindro desalinhado \\
\hline & & & Válvula de alivio esta calibrada incorretamente \\
\hline & & & Nível de óleo insuficiente no reservatório \\
\hline
\end{tabular}




\begin{tabular}{|c|c|c|c|}
\hline \multicolumn{4}{|c|}{ Análise de Modo e Efeito de Falha - FMEA } \\
\hline Componente: & \multicolumn{3}{|l|}{ Válvula distribuidora } \\
\hline Sistema: & \multicolumn{3}{|l|}{ Regulador de velocidade } \\
\hline \multicolumn{4}{|l|}{ Equipe: } \\
\hline \multicolumn{4}{|l|}{ Responsável: } \\
\hline Componente & Função & $\begin{array}{l}\text { Modo de falha } \\
\text { potencial }\end{array}$ & Causa(s) da falha \\
\hline \multirow{26}{*}{$\begin{array}{c}\text { Válvula } \\
\text { distribuidora }\end{array}$} & \multirow{26}{*}{$\begin{array}{c}\text { Receber a sinal da } \\
\text { válvula proporcional e } \\
\text { controlar o movimento } \\
\text { dos atuadores. } \\
\text { Fornecer a potencia } \\
\text { hidráulica necessária } \\
\text { para manobrar o } \\
\text { atuador }\end{array}$} & \multirow{9}{*}{$\begin{array}{l}\text { Válvula não responde } \\
\text { ao comando }\end{array}$} & Excessivo ajuste do anéis que imobiliza o eixo \\
\hline & & & da válvula \\
\hline & & & Mola quebrada \\
\hline & & & Fluido com viscoso elevada \\
\hline & & & Retentor desgastado \\
\hline & & & Travamento do carretel \\
\hline & & & Corpo estranho encunhado entre o carretel e a \\
\hline & & & carcaça \\
\hline & & & Piloto hidráulico obstruído \\
\hline & & \multirow{4}{*}{$\begin{array}{c}\text { Válvula não responde } \\
\text { adequadamente ao } \\
\text { comando }\end{array}$} & Bolsa de ar no óleo \\
\hline & & & Piloto hidráulico parcialmente obstruído \\
\hline & & & Vazamento na válvula permitindo a passagem de \\
\hline & & & pressão para o lado oposto \\
\hline & & \multirow{5}{*}{ Vazamento externo } & Pressão elevada no sistema \\
\hline & & & Parafusos esticados \\
\hline & & & Falta de retentor ou de junta \\
\hline & & & Elementos de vedação desgastados \\
\hline & & & Porosidade ou trincas na carcaça \\
\hline & & \multirow{6}{*}{ Vazamento Interno } & Retentores desgastados \\
\hline & & & Desgaste do carretel ou carcaça \\
\hline & & & Falta de caneletas no carretel \\
\hline & & & Falta de assentamento por presença de partículas \\
\hline & & & aderidas \\
\hline & & & Deformação da carcaça por erro de montagem \\
\hline & & \multirow{2}{*}{$\begin{array}{l}\text { A pressão na saída da } \\
\text { válvula não é mantida }\end{array}$} & Presença de ar dentro da válvula \\
\hline & & & Restrições na linha de dreno \\
\hline
\end{tabular}




\begin{tabular}{|c|c|c|c|}
\hline \multicolumn{4}{|c|}{ Análise de Modo e Efeito de Falha - FMEA } \\
\hline Componente: & \multicolumn{3}{|c|}{ Tubos,mangueiras,conexões } \\
\hline Sistema: & \multicolumn{3}{|c|}{ Regulador de Velocidade } \\
\hline \multicolumn{4}{|l|}{ Equipe: } \\
\hline \multicolumn{4}{|l|}{ Responsável: } \\
\hline \multirow[t]{4}{*}{ Componente } & Função & $\begin{array}{c}\text { Modo de falha } \\
\text { potencial }\end{array}$ & Causa(s) da falha \\
\hline & & & Pressão muito elevada \\
\hline & & & Temperatura elevada \\
\hline & Encaminhar o & & Desgaste erosivo causado por fluido \\
\hline Tubos, & fluido hidráulico & & quente com impacto de partículas \\
\hline mangueiras & entre os & Ruptura & Fatiga/envelhecimento \\
\hline \multirow[t]{4}{*}{ conexões } & componentes & & Corrosão das paredes da tubulação \\
\hline & do circuito & & Falha no projeto \\
\hline & hidráulico & & Presença de trincas \\
\hline & & & Montagem ou instalação incorreta \\
\hline
\end{tabular}

\begin{tabular}{|l|l|}
\hline \multicolumn{2}{|c|}{ Análise de Modo e Efeito de Falha - FMEA } \\
\hline Componente: & Válvula antiretomo \\
\hline Sistema: & Regulador de velocidade \\
\hline Equipe: & \\
\hline Responsável: & \\
\hline
\end{tabular}

\begin{tabular}{|c|c|c|l|}
\hline Componente & Função & $\begin{array}{c}\text { Modo de falha } \\
\text { potencial }\end{array}$ & \multicolumn{1}{c|}{ Causa(s) da falha } \\
\hline & Permitir a passagem & & \\
Válvula & do fluido & Passagem do fluido em & Desgaste da mola \\
\cline { 4 - 4 } antiretomo & somente em & ambaste do assentamento as direções & Elementos de vedação danificados \\
\cline { 4 - 4 } & uma direção & & Desgaste do corpo da válvula \\
\hline
\end{tabular}




\begin{tabular}{|l|l|}
\hline \multicolumn{2}{|c|}{ Análise de Modo e Efeito de Falha - FMEA } \\
\hline Componente: & Válvula Proporcional \\
\hline Sistema: & Regulador de velocidade \\
\hline Equipe: & \\
\hline Responsável: & \\
\hline
\end{tabular}

\begin{tabular}{|c|c|c|c|}
\hline Componente & Função & $\begin{array}{c}\text { Modo de falha } \\
\text { potencial }\end{array}$ & Causa(s) da falha \\
\hline & & & Queima do solenoide \\
\hline & & & Cabos elétricos desgastados \\
\hline & & & Partículas Aderidas entre o carretel e o agulheiro \\
\hline & & & causando que o carretel se trave (solenoide) \\
\hline & & & Excessivo ajuste do anéis que imobiliza \\
\hline & & & o eixo da válvula \\
\hline & & & Mola quebrada, ajuste incorreto \\
\hline & Receber o sinal & Válvula não & Fluido altamente viscoso \\
\hline \multirow{23}{*}{$\begin{array}{c}\text { Válvula } \\
\text { Proporcional }\end{array}$} & do Regulador de & responde ao & Retentor desgastado \\
\hline & velocidade & comando & Falha no regulador de velocidade \\
\hline & eletrônica e & & eletrônica \\
\hline & comandar a & & Dutos obstruídos ou quebrados \\
\hline & válvula & & Corpo estranho encunhado entre o \\
\hline & distribuidora. & & carretel e a carcaça \\
\hline & & Válvula não & Bolsa de ar no óleo \\
\hline & & responde & Frequência e voltagem incorretos no solenoide \\
\hline & & adequadamente ao & Vazamento na válvula permitindo a passagem \\
\hline & & comando & de pressão para o lado. \\
\hline & & & Parafusos esticados \\
\hline & & & Falta de retentor ou de junta \\
\hline & & Vazamento Externo & Porosidade ou trincas na carcaça \\
\hline & & & Deformação da carcaça por erro de montagem \\
\hline & & & Elementos de vedação desgastados \\
\hline & & \multirow{6}{*}{ Vazamento Interno } & Retentores desgastados \\
\hline & & & Desgaste do carretel ou carcaça \\
\hline & & & Falta de caneletas no carretel \\
\hline & & & Falta de assentamento por presença de partículas \\
\hline & & & aderidas \\
\hline & & & Deformação da carcaça por erro de montagem \\
\hline & & \multirow{2}{*}{$\begin{array}{l}\text { A pressão na saída da } \\
\text { válvula não é mantida }\end{array}$} & Presença de ar dentro da válvula \\
\hline & & & Restrições na linha de dreno \\
\hline
\end{tabular}




\begin{tabular}{|l|l|}
\hline \multicolumn{2}{|c|}{ Análise de Modo e Efeito de Falha - FMEA } \\
\hline Componente: & Fluído Hidráulico \\
\hline Sistema: & Regulador de velocidade \\
\hline Equipe: & \\
\hline Responsável: & \\
\hline
\end{tabular}

\begin{tabular}{|c|c|c|c|}
\hline Componente & Função & $\begin{array}{l}\text { Modo de falha } \\
\text { potencial }\end{array}$ & Causa(s) da falha \\
\hline & & & Baixa temperatura do meio ambiente \\
\hline & & Variação da & Fluído inadequado \\
\hline & Lubrificar, & viscosidade: & Falha no Aquecedor ( em ambientes muitos frios) \\
\hline & dissipar o calor & Alta Viscosidade & Falha na seleção do fluido \\
\hline Fluido & $\mathrm{e}$ & & Falha no trocador de calor \\
\hline \multirow[t]{5}{*}{ Hidráulico } & transmitir a & & Contaminação por água \\
\hline & potência & Variação da & Falta de limpeza do reservatório \\
\hline & & viscosidade: & Falha no posicionamento do defletor \\
\hline & & Baixa Viscosidade & Falha na seleção do fluido \\
\hline & & & Duto de entrada e retorno no reservatório muito próximos \\
\hline
\end{tabular}

\begin{tabular}{|l|l|}
\hline \multicolumn{2}{|c|}{ Análise de Modo e Efeito de Falha - FMEA } \\
\hline Componente: & Reservatório \\
\hline Sistema: & Regulador de velocidade \\
\hline Equipe: & \\
\hline Responsável: & \\
\hline
\end{tabular}

\begin{tabular}{|c|c|c|c|}
\hline Componente & Função & $\begin{array}{c}\text { Modo de falha } \\
\text { potencial }\end{array}$ & Causa(s) da falha \\
\hline & Armazenar o óleo. & & \\
\hline & Ajudar a purgar & & Falha de projeto \\
\hline & o fluido dos & Redução muito & Falha no ajuste na linha de dreno \\
\hline \multirow{4}{*}{ Reservatório } & contaminantes & acentuada do nível de & Tampa de limpeza mal fachada \\
\hline & Ajudar a & óleo no reservatório & Presença de trincas \\
\hline & dissipar o calor & & \\
\hline & do fluido & & \\
\hline
\end{tabular}




\begin{tabular}{|l|l|}
\hline \multicolumn{2}{|c|}{ Análise de Modo e Efeito de Falha - FMEA } \\
\hline Componente: & Válvula de Comando \\
\hline Sistema: & Regulador de velocidade \\
\hline Equipe: & \\
\hline Responsável: & \\
\hline
\end{tabular}

\begin{tabular}{|c|c|c|c|}
\hline Componente & Função & $\begin{array}{l}\text { Modo de falha } \\
\text { potencial }\end{array}$ & Causa(s) da falha \\
\hline & & & Falha do solenoide \\
\hline & & & Partículas Aderidas entre o carretel e o agulheiro \\
\hline & & & causando que o carretel se trave \\
\hline & Receber a sinal & & Excessivo ajuste do anéis que imobiliza \\
\hline & do sistema de & & o eixo da válvula \\
\hline Válvula & controle & Válvula não & Mola quebrada ou ajuste incorreto \\
\hline \multirow[t]{5}{*}{ de comando } & para permitir & responde ao & Fluido altamente viscoso \\
\hline & o abastecimento & comando & Retentor desgastado \\
\hline & de óleo no & & Falha do controle eletrônico \\
\hline & acumulador & & Corpo estranho encunhado entre o \\
\hline & & & carretel e a carcaça \\
\hline
\end{tabular}

\begin{tabular}{|c|c|c|c|}
\hline \multicolumn{4}{|c|}{ Análise de Modo e Efeito de Falha - FMEA } \\
\hline Componente: & \multicolumn{3}{|c|}{ Trocador de calor (casco/tubos) } \\
\hline Sistema: & \multicolumn{3}{|c|}{ Regulador de velocidade } \\
\hline \multicolumn{4}{|l|}{ Equipe: } \\
\hline \multicolumn{4}{|l|}{ Responsável: } \\
\hline \multirow[t]{4}{*}{ Componente } & Função & $\begin{array}{c}\text { Modo de falha } \\
\text { potencial }\end{array}$ & Causa(s) da falha \\
\hline & & & Vazão de água insuficiente \\
\hline & & Resfriamento & Área de transferência de calor \\
\hline & & insuficiente do óleo & insuficiente \\
\hline \multirow{10}{*}{$\begin{array}{c}\text { Trocador de } \\
\text { calor } \\
\text { (casco/tubos) }\end{array}$} & & & Presença de sujeira \\
\hline & Resfriar o óleo & & Aumento da resistencia termica \\
\hline & & & (incrustações na parede) \\
\hline & & & Corrosão dos tubos \\
\hline & & Incapacidade parcial & Desgaste erosivo \\
\hline & & para resfriar óleo & Aumento da resistencia termica \\
\hline & & & (incrustações na parede) \\
\hline & & & Falha no sistema de abastecimento de água \\
\hline & & & Presença de trincas \\
\hline & & & Tubos rachados \\
\hline
\end{tabular}




\begin{tabular}{|l|l|}
\hline \multicolumn{2}{|c|}{ Análise de Modo e Efeito de Falha - FMEA } \\
\hline Componente: & Pressostato \\
\hline Sistema: & Regulador de velocidade \\
\hline Equipe: & \\
\hline Responsável: & \\
\hline
\end{tabular}

\begin{tabular}{|c|c|c|c|}
\hline Componente & Função & $\begin{array}{l}\text { Modo de falha } \\
\text { potencial }\end{array}$ & Causa(s) da falha \\
\hline & & & Tensão de alimentação excede a \\
\hline & Enviar sinal & & tensão nominal \\
\hline & para acionar & & Corto circuito \\
\hline & as bombas em & Falta de indicação & Falta de abastecimento de energia \\
\hline \multirow[t]{4}{*}{ Pressostato } & caso de queda & e comando & Quebra da mola \\
\hline & brusca de & & Falha no micro interruptor \\
\hline & pressão & & Golpes de pressão hidráulica \\
\hline & & & Cabos desgastados ou desligados \\
\hline
\end{tabular}

\begin{tabular}{|c|c|c|c|}
\hline \multicolumn{4}{|c|}{ Análise de Modo e Efeito de Falha - FMEA } \\
\hline Componente: & \multicolumn{3}{|l|}{ Medidor diferencial } \\
\hline Sistema: & \multicolumn{3}{|c|}{ Regulador de velocidade } \\
\hline \multicolumn{4}{|l|}{ Equipe: } \\
\hline \multicolumn{4}{|l|}{ Responsável: } \\
\hline \multirow[t]{2}{*}{ Componente } & Função & $\begin{array}{l}\text { Modo de falha } \\
\text { potencial }\end{array}$ & Causa(s) da falha \\
\hline & $\begin{array}{c}\text { Registrar a pressão } \\
\text { diferencial para }\end{array}$ & & Falha no elemento mecânico \\
\hline \multirow{2}{*}{ Medidor diferencial } & determinar quando o & Não registra pressão & Falha no elemento eletrônico \\
\hline & filtro está entupido & diferencial & Quebra ou desgaste da mola \\
\hline
\end{tabular}




\begin{tabular}{|c|c|c|c|}
\hline \multicolumn{4}{|c|}{ Análise de Modo e Efeito de Falha - FMEA } \\
\hline Componente: & \multicolumn{3}{|l|}{ Acumulador } \\
\hline Sistema: & \multicolumn{3}{|c|}{ Regulador de velocidade } \\
\hline \multicolumn{4}{|l|}{ Equipe: } \\
\hline \multicolumn{4}{|l|}{ Responsável: } \\
\hline \multirow[t]{5}{*}{ Componente } & Função & $\begin{array}{l}\text { Modo de falha } \\
\text { potencial }\end{array}$ & Causa(s) da falha \\
\hline & & & Falha na válvula de acesso de óleo \\
\hline & & Não fornece vazão & Ruptura da bexiga \\
\hline & Fornecer vazão e & e pressão & Presença de trincas na armadura \\
\hline & pressão & & Falha no sistema de reposição de ar comprimido \\
\hline \multirow[t]{8}{*}{ Acumulador } & para abrir ou & & Falha na válvula de carga do ar \\
\hline & fechar & & Pressão de carga insuficiente \\
\hline & distribuidor & & Obstrução da válvula de acesso de óleo \\
\hline & ou rotor & & Vazamentos internos ou externos \\
\hline & & Fornece vazão e & Desgaste da vedação \\
\hline & & pressão insuficiente & Pressão de carga excessiva provocara \\
\hline & & & atraso do óleo e diminuição do volume \\
\hline & & & admitido \\
\hline
\end{tabular}

\begin{tabular}{|c|c|c|c|}
\hline \multicolumn{4}{|c|}{ Análise de Modo e Efeito de Falha - FMEA } \\
\hline Componente: & \multicolumn{3}{|l|}{ Fluxômetro } \\
\hline Sistema: & \multicolumn{3}{|c|}{ Regulador de velocidade } \\
\hline \multicolumn{4}{|l|}{ Equipe: } \\
\hline \multicolumn{4}{|l|}{ Responsável: } \\
\hline Componente & Função & $\begin{array}{c}\text { Modo de falha } \\
\text { potencial }\end{array}$ & Causa(s) da falha \\
\hline & Registrar um fluxo & & Falha no elemento mecânico \\
\hline Fluxômetro & $\begin{array}{c}\text { de água com vazão } \\
\text { pré-definida no }\end{array}$ & Não indica o fluxo & Falha no elemento eletrônico \\
\hline & resfriador & & \\
\hline
\end{tabular}




\begin{tabular}{|c|c|c|c|}
\hline \multicolumn{4}{|c|}{ Análise de Modo e Efeito de Falha - FMEA } \\
\hline Componente: & \multicolumn{3}{|c|}{ Sistema de abastecimento de água } \\
\hline Sistema: & \multicolumn{3}{|c|}{ Regulador de velocidade } \\
\hline \multicolumn{4}{|l|}{ Equipe: } \\
\hline \multicolumn{4}{|l|}{ Responsável: } \\
\hline Componente & Função & $\begin{array}{c}\text { Modo de falha } \\
\text { potencial }\end{array}$ & Causa(s) da falha \\
\hline Sistema de & Abastecer de água & & Folgas nas conexões \\
\hline abastecimento & ao trocador & Vazão de água menor & Obstrução parcial das tubulações \\
\hline \multirow[t]{2}{*}{ de água } & de calor & que a especificada & Presença de trincas nas tubulações \\
\hline & & & Ruptura das tubulações \\
\hline
\end{tabular}




\section{Apêndice D: Politicas de manutenção.}

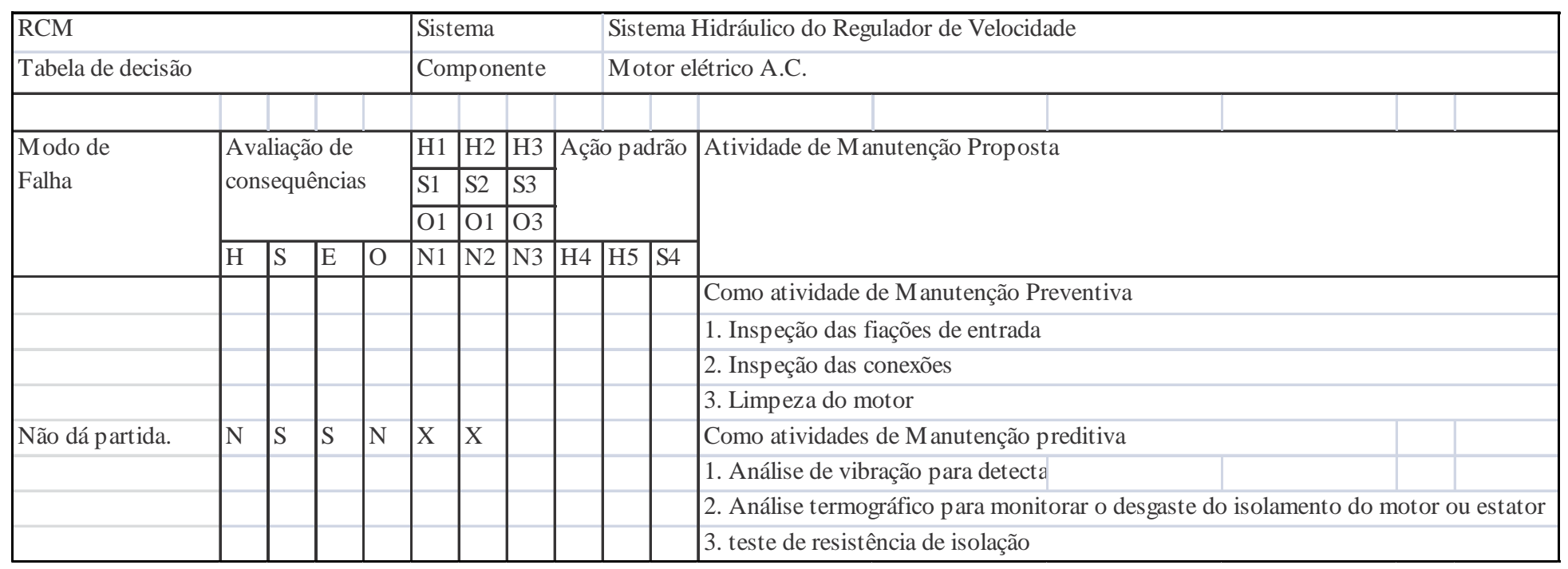




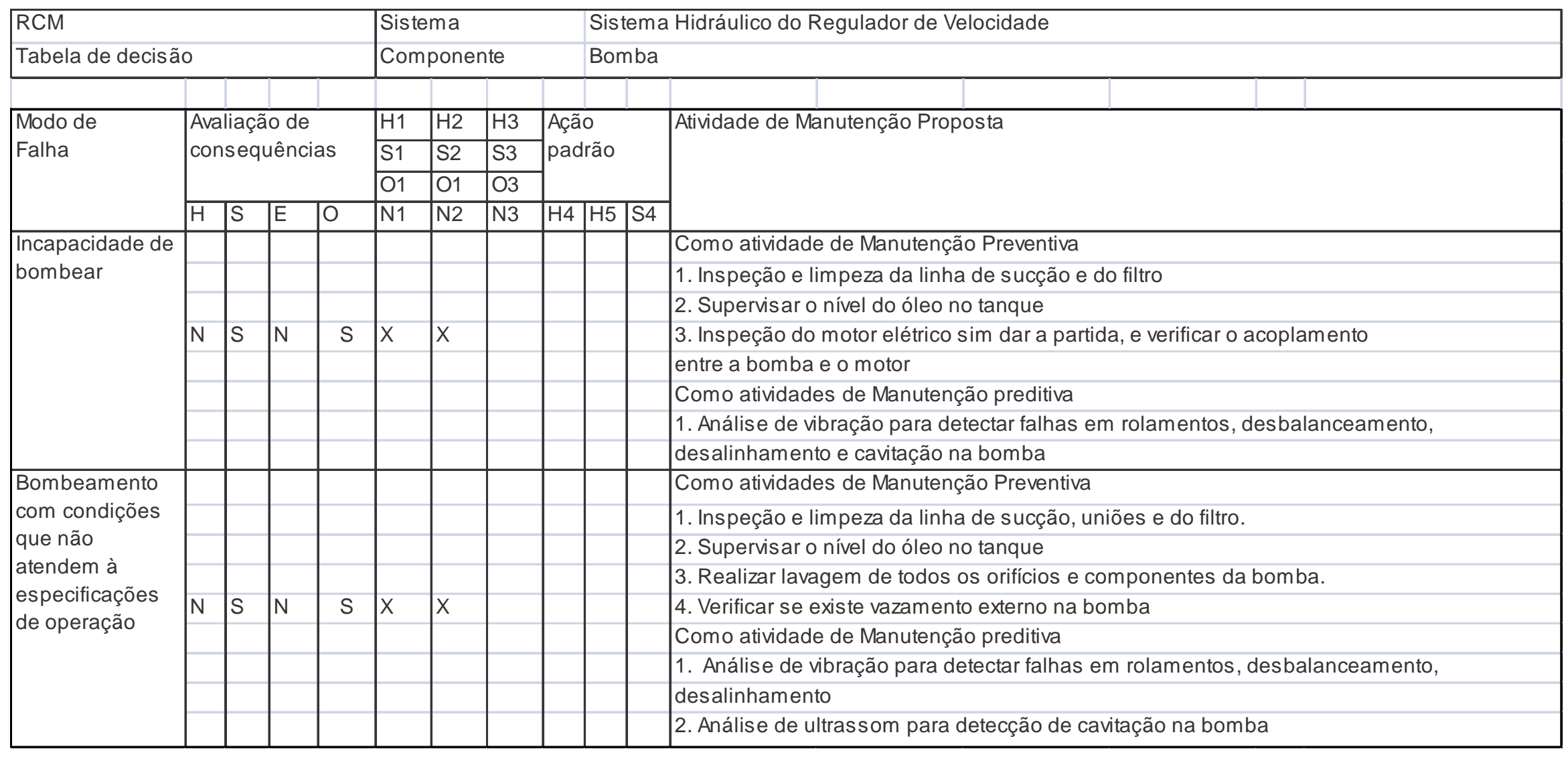




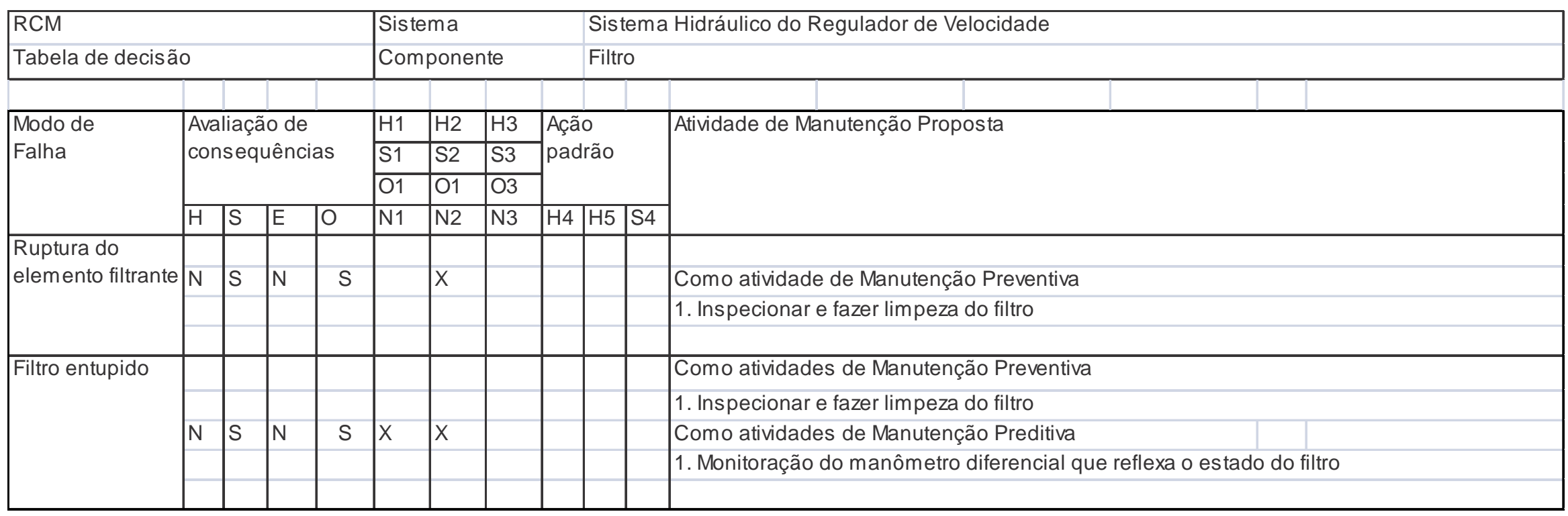




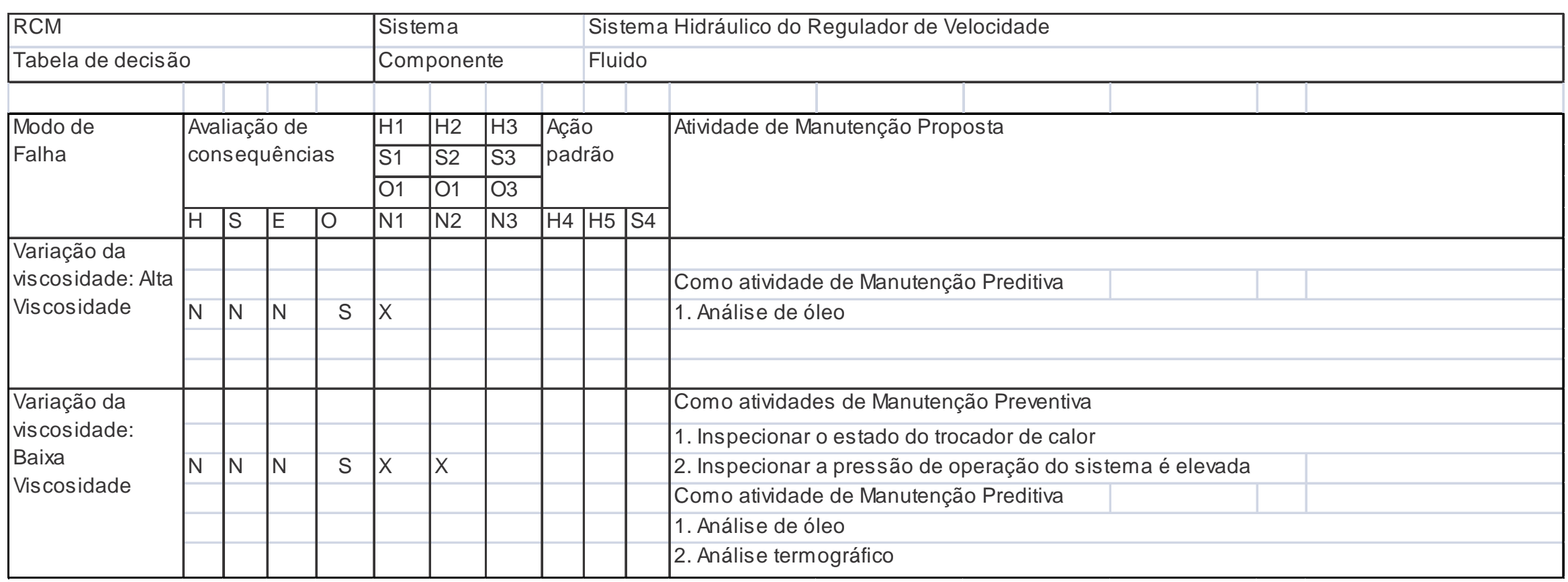




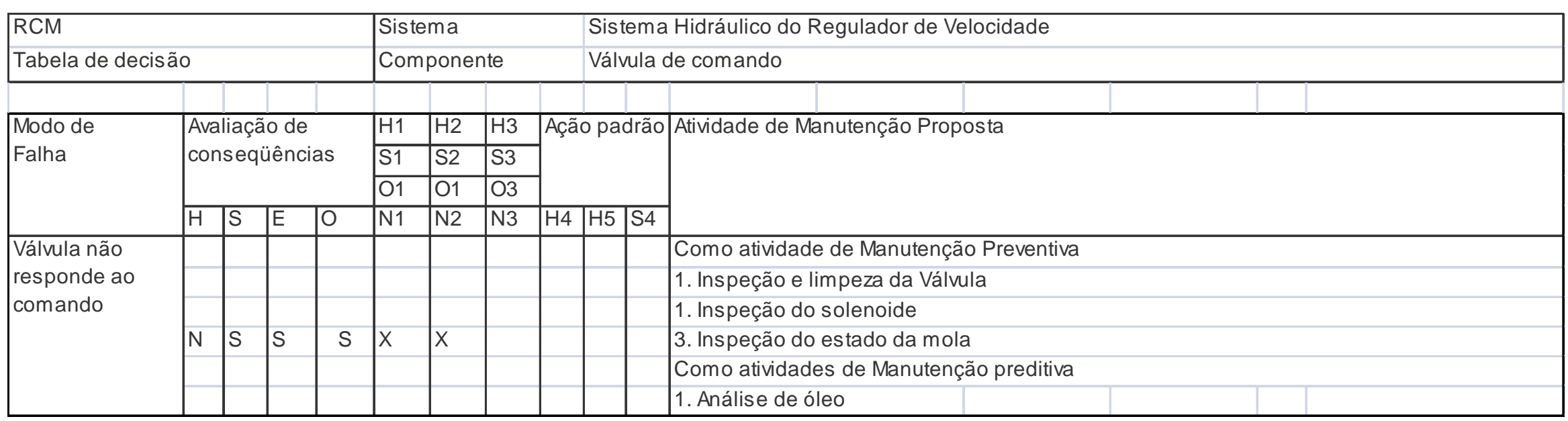




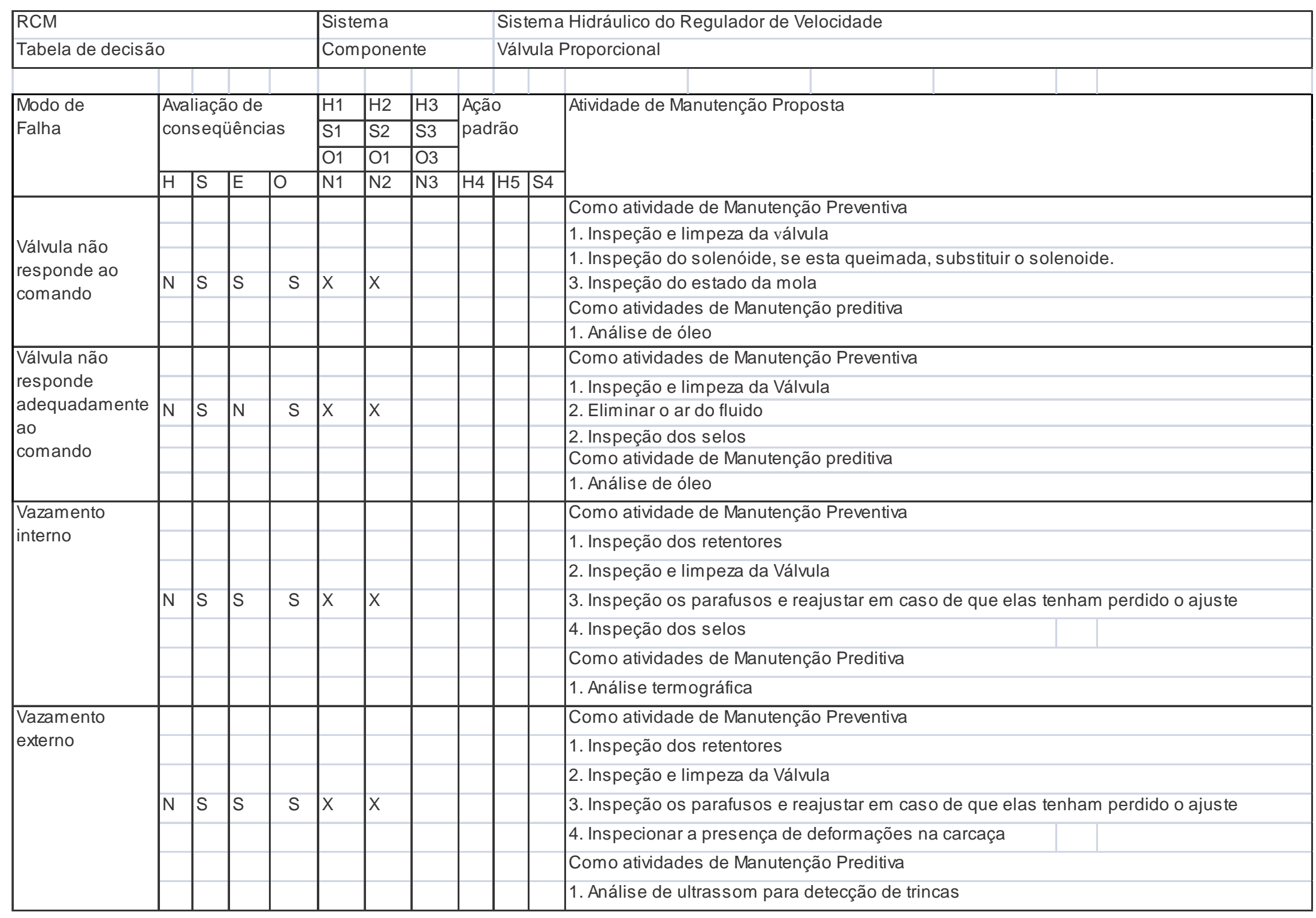




\begin{tabular}{|c|c|c|c|c|c|c|c|c|c|c|c|c|}
\hline \multirow{2}{*}{\multicolumn{5}{|c|}{$\begin{array}{l}\text { RCM } \\
\text { Tabela de decisão }\end{array}$}} & \multicolumn{4}{|c|}{ Sistema } & \multicolumn{4}{|c|}{ Sistema Hidráulico do Regulador de Velocidade } \\
\hline & & & & & \multicolumn{4}{|c|}{ Componente } & \multicolumn{4}{|c|}{ Válvula Distribuidora } \\
\hline \multirow{4}{*}{$\begin{array}{l}\text { Modo de } \\
\text { Falha }\end{array}$} & \multirow{3}{*}{\multicolumn{4}{|c|}{$\begin{array}{l}\text { Avaliação de } \\
\text { consequências }\end{array}$}} & $\mathrm{H} 1$ & $\mathrm{H} 2$ & $\mathrm{H} 3$ & \multirow{3}{*}{\multicolumn{3}{|c|}{$\begin{array}{l}\text { Ação } \\
\text { padrão }\end{array}$}} & \multirow{4}{*}{\multicolumn{2}{|c|}{ Atividade de Manutenção Proposta }} \\
\hline & & & & & S1 & S2 & S3 & & & & & \\
\hline & & & & & O1 & O1 & $\mathrm{O} 3$ & & & & & \\
\hline & $\mathrm{H}$ & S & $\mathrm{E}$ & $\mathrm{O}$ & $\mathrm{N} 1$ & N2 & N3 & $\mathrm{H} 4$ & H5 & S4 & & \\
\hline \multirow{6}{*}{$\begin{array}{l}\text { Válvula não } \\
\text { responde ao } \\
\text { comando }\end{array}$} & & & & & & & & & & & \multicolumn{2}{|l|}{ Como atividade de Manutenção Preventiva } \\
\hline & & & & & & & & & & & \multicolumn{2}{|l|}{ 1. Inspeção e limpeza da Válvula } \\
\hline & & & & & & & & & & & \multicolumn{2}{|l|}{ 1. Inspeção e limpeza do piloto hidráulico } \\
\hline & $N$ & S & S & S & $x$ & $x$ & & & & & \multicolumn{2}{|c|}{ 3. Inspeção do estado da mola, se está quebrada, substituir a mola } \\
\hline & & & & & & & & & & & \multicolumn{2}{|l|}{ Como atividades de Manutenção preditiva } \\
\hline & & & & & & & & & & & \multicolumn{2}{|l|}{ 1. Análise de óleo } \\
\hline \multirow{6}{*}{\begin{tabular}{|l|} 
Válvula não \\
responde \\
adequadamente \\
ao \\
comando
\end{tabular}} & & & & & & & & & & & \multicolumn{2}{|l|}{ 1. Inspeção e limpeza da Válvula } \\
\hline & & & & & & & & & & & \multicolumn{2}{|l|}{ 2. Eliminar o ar do fluido } \\
\hline & $\mathrm{N}$ & S & $\mathrm{N}$ & S & $x$ & $\mathrm{X}$ & & & & & \multicolumn{2}{|l|}{ 2. Inspeção dos selos } \\
\hline & & & & & & & & & & & \multicolumn{2}{|l|}{ Como atividade de Manutenção Preditiva } \\
\hline & & & & & & & & & & & \multicolumn{2}{|l|}{ 1. Análise de óleo } \\
\hline & & & & & & & & & & & & \\
\hline \multirow{7}{*}{\begin{tabular}{|l} 
Vazamento \\
externo
\end{tabular}} & & & & & & & & & & & \multicolumn{2}{|l|}{ Como atividade de Manutenção Preventiva } \\
\hline & & & & & & & & & & & \multicolumn{2}{|l|}{ 1. Inspeção dos retentores } \\
\hline & & & & & & & & & & & \multicolumn{2}{|l|}{ 2. Inspeção e limpeza da Válvula } \\
\hline & $\mathrm{N}$ & S & S & S & $\mathrm{x}$ & $\mathrm{X}$ & & & & & \multicolumn{2}{|c|}{ 3. Inspeção os parafusos e reajustar em caso de que elas tenham perdido o ajuste } \\
\hline & & & & & & & & & & & 4. Inspecionar a pres ença de deformações na carcaça & \\
\hline & & & & & & & & & & & Como atividades de Manutenção Preditiva & \\
\hline & & & & & & & & & & & 1. Análise de ultrassom para detecção de trincas & \\
\hline Vazamento & & & & & & & & & & & Como atividade de Manutenção Preventiva & \\
\hline interno & & & & & & & & & & & 1. Inspeção dos retentores & \\
\hline & & & & & & & & & & & 2. Inspeção e limpeza da Válvula & \\
\hline & $\mathrm{N}$ & S & S & S & $x$ & $x$ & & & & & 3. Inspeção os parafusos e reajustar em caso de que e & nham perdido o ajuste \\
\hline & & & & & & & & & & & 4. Inspeção dos selos & \\
\hline & & & & & & & & & & & Como atividades de Manutenção Preditiva & \\
\hline & & & & & & & & & & & 1. Análise termográfica & \\
\hline
\end{tabular}




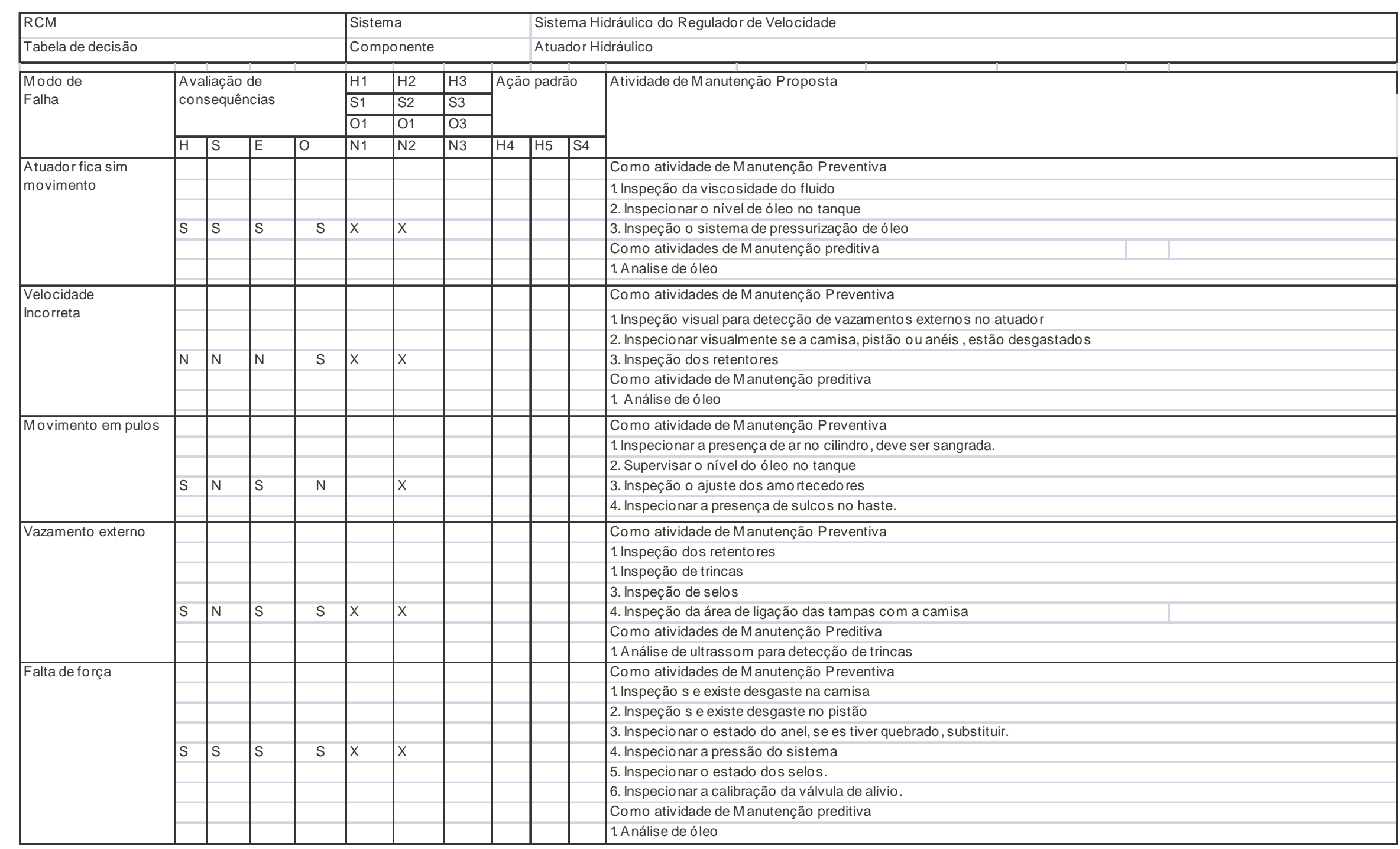




\begin{tabular}{|l|l|l|}
\hline RCM & Sistema & Sistema Hidráulico do Regulador de Velocidade \\
\hline Tabela de decisão & Componente & Acumulador \\
\hline
\end{tabular}

\begin{tabular}{|c|c|c|c|c|c|c|c|c|c|c|c|}
\hline \multirow{4}{*}{$\begin{array}{l}\text { Modo de } \\
\text { Falha }\end{array}$} & \multirow{2}{*}{\multicolumn{4}{|c|}{$\begin{array}{l}\text { Avaliação de } \\
\text { consequências }\end{array}$}} & $\mathrm{H} 1$ & $\mathrm{H} 2$ & $\mathrm{H} 3$ & \multirow{2}{*}{\multicolumn{3}{|c|}{ Ação padrão }} & \multirow[t]{4}{*}{ Atividade de Manutenção Proposta } \\
\hline & & & & & S1 & S2 & S3 & & & & \\
\hline & & & & & 10 & ו & & \multirow[b]{2}{*}{$\mathrm{H} 4$} & \multirow[b]{2}{*}{ H5 } & \multirow[b]{2}{*}{ S4 } & \\
\hline & $\mathrm{H}$ & S & E & $\mathrm{O}$ & N1 & N2 & N3 & & & & \\
\hline \multirow{7}{*}{$\begin{array}{l}\text { Não fornece } \\
\text { vãzao e pressão }\end{array}$} & & & & & & & & & & & Como atividade de Manutenção Preventiva \\
\hline & & & & & & & & & & & 1. Inspecionar vazamentos \\
\hline & & & & & & & & & & & 2. Inspeção da bexiga no caso de estar furada, substituir a bexiga. \\
\hline & $\mathrm{N}$ & S & $\mathrm{N}$ & S & $\mathrm{X}$ & $\mathrm{X}$ & & & & & 3. Inspeção da pressão de carga do acumulador \\
\hline & & & & & & & & & & & 4. Limpeza do acumulador \\
\hline & & & & & & & & & & & Como atividades de Manutenção preditiva \\
\hline & & & & & & & & & & & 1. Análise de óleo \\
\hline \multirow{8}{*}{$\begin{array}{l}\text { Fornece vazão e } \\
\text { pressão } \\
\text { insuficiente }\end{array}$} & & & & & & & & & & & Como atividade de Manutenção Preventiva \\
\hline & & & & & & & & & & & 1. Inspecionar vazamentos \\
\hline & & & & & & & & & & & 2. Inspeção da bexiga no caso de estar furada, substituir a bexiga. \\
\hline & $\mathrm{N}$ & S & $\mathrm{N}$ & S & $x$ & $\mathrm{X}$ & & & & & 3. Inspeção da pressão de carga do acumulador \\
\hline & & & & & & & & & & & 4. Limpeza do acumulador \\
\hline & & & & & & & & & & & Como atividades de Manutenção preditiva \\
\hline & & & & & & & & & & & 1. Análise de óleo \\
\hline & & & & & & & & & & & 2. Análise de ultrasom para identificar presença de trincas \\
\hline
\end{tabular}




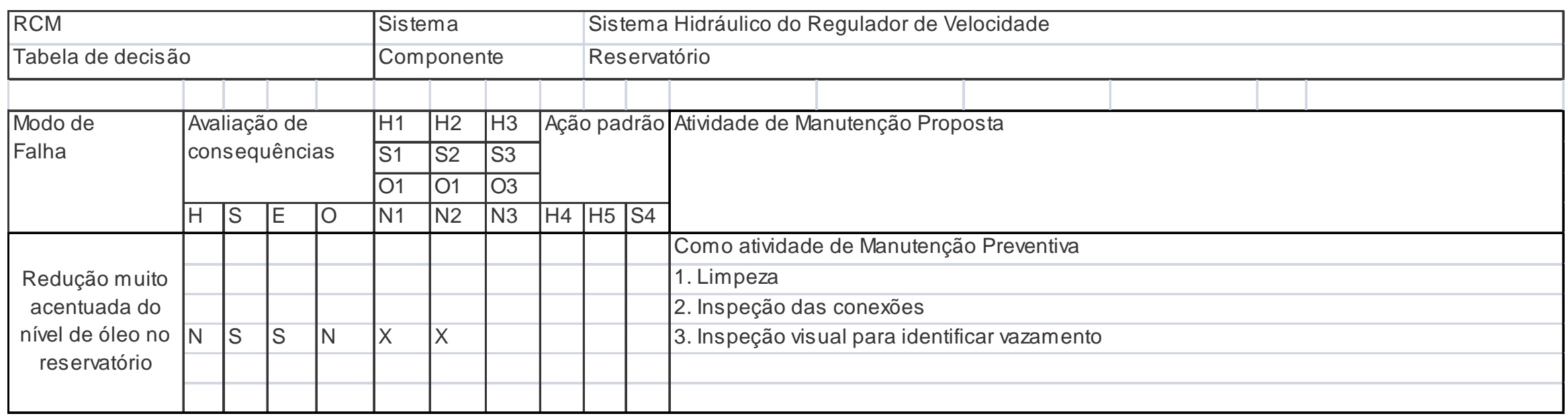

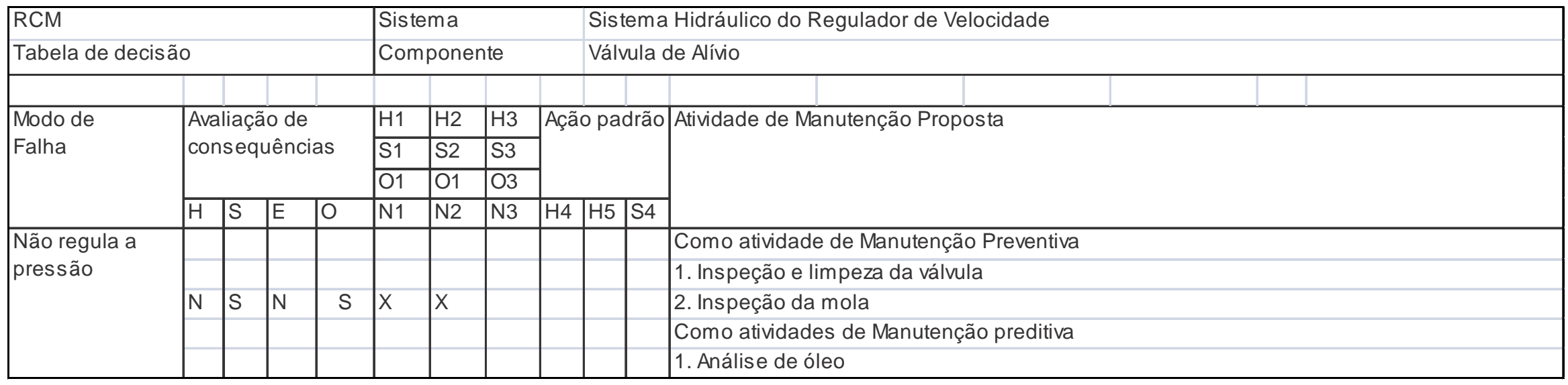




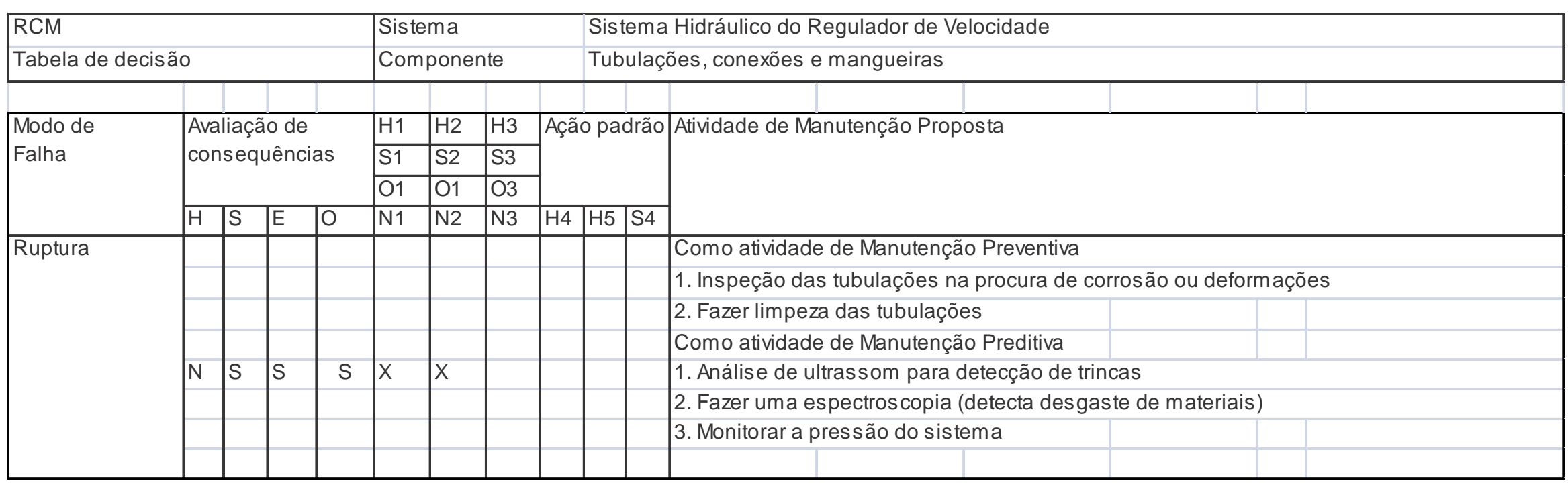




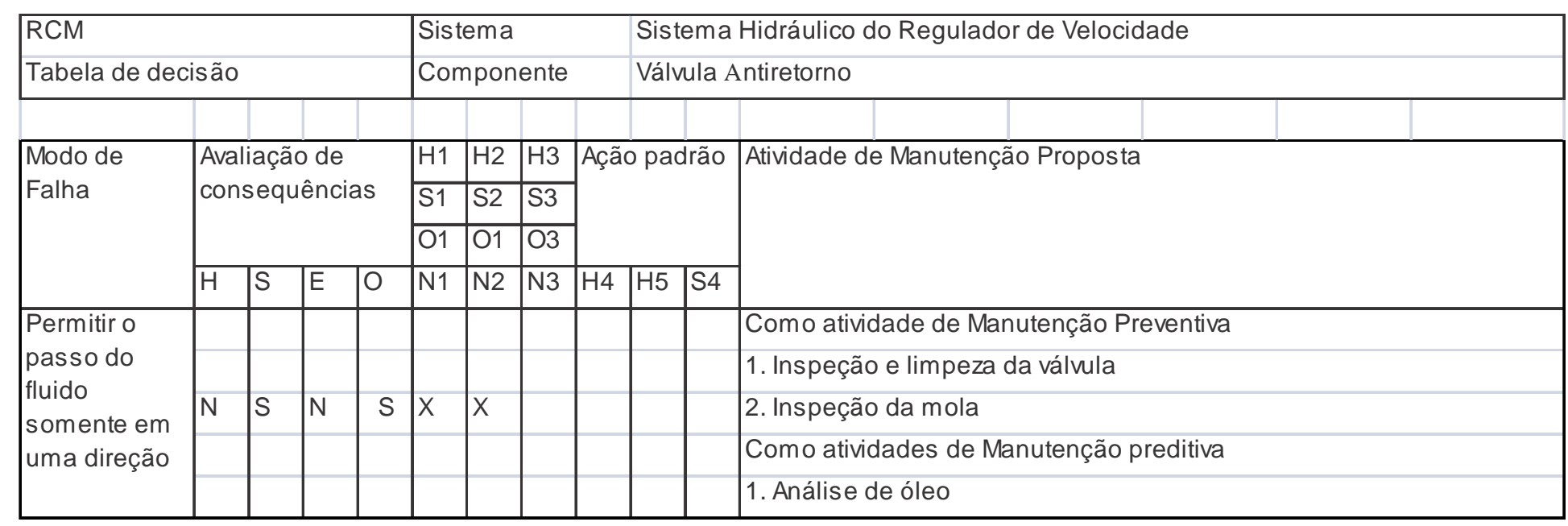

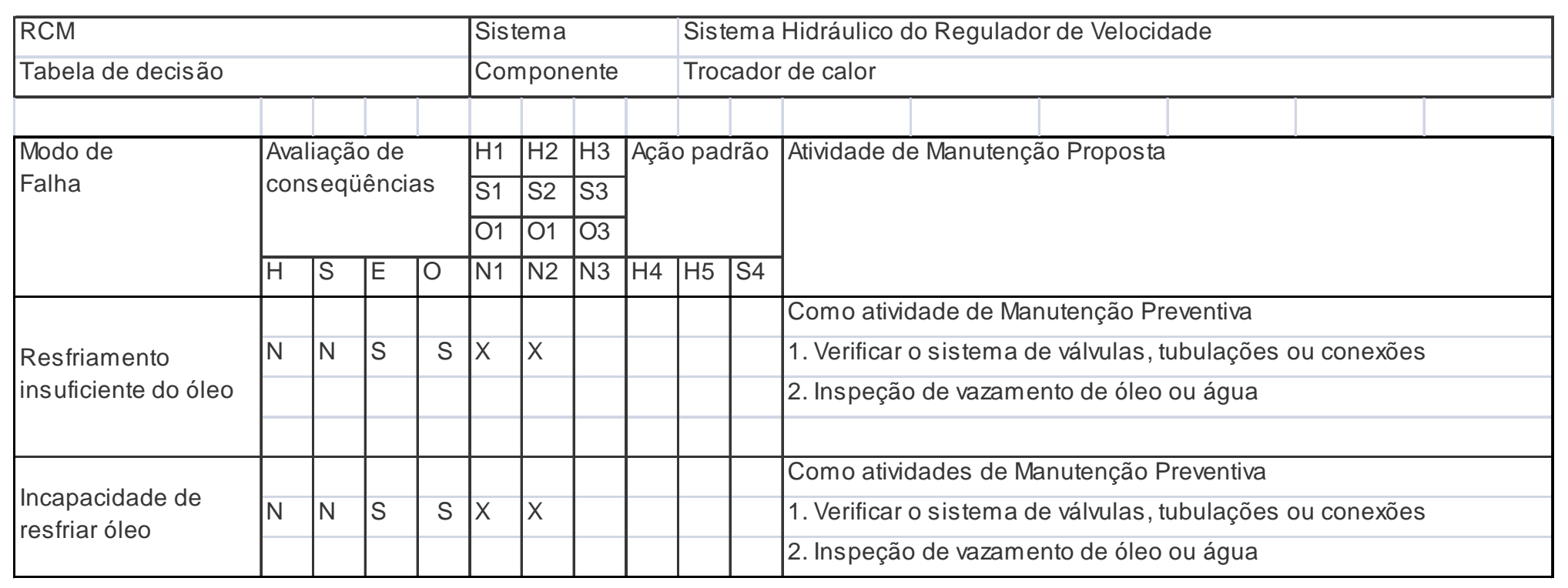




\section{Apêndice D: Árvores de decisão}

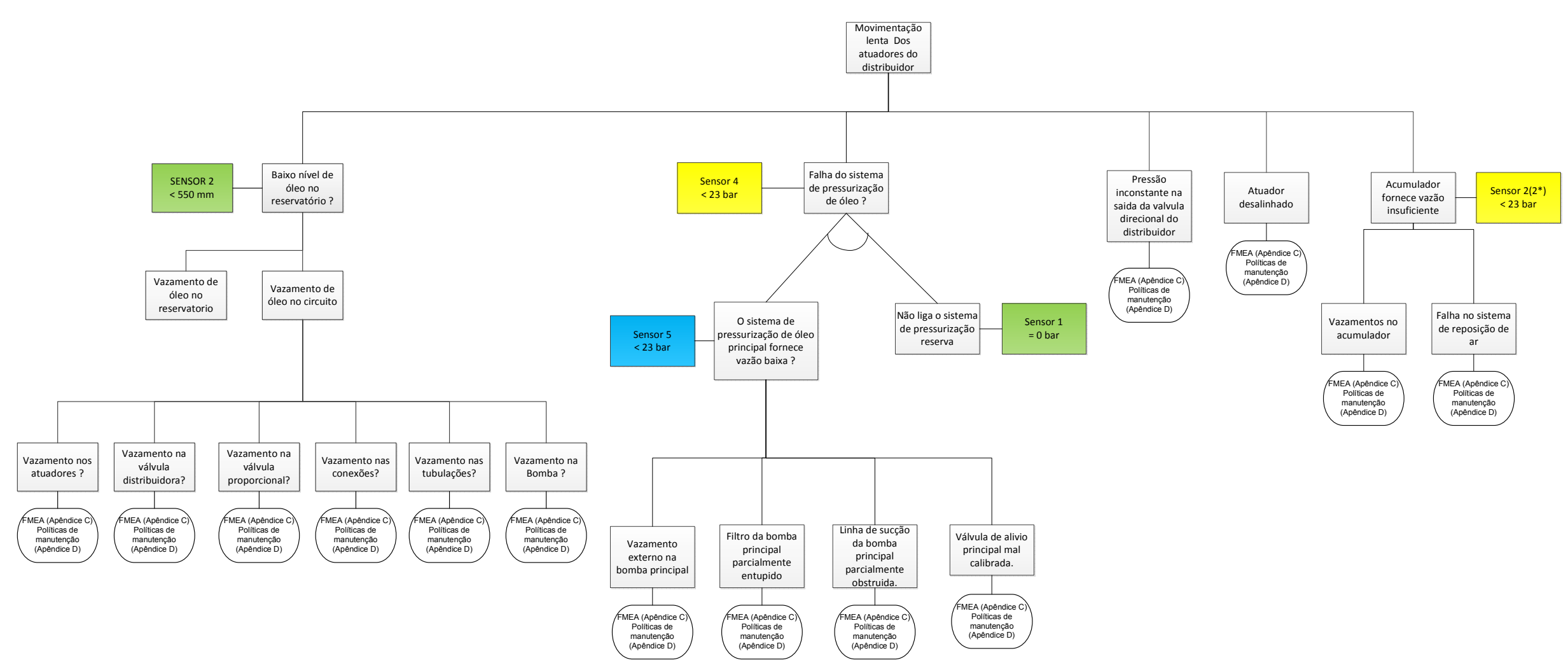




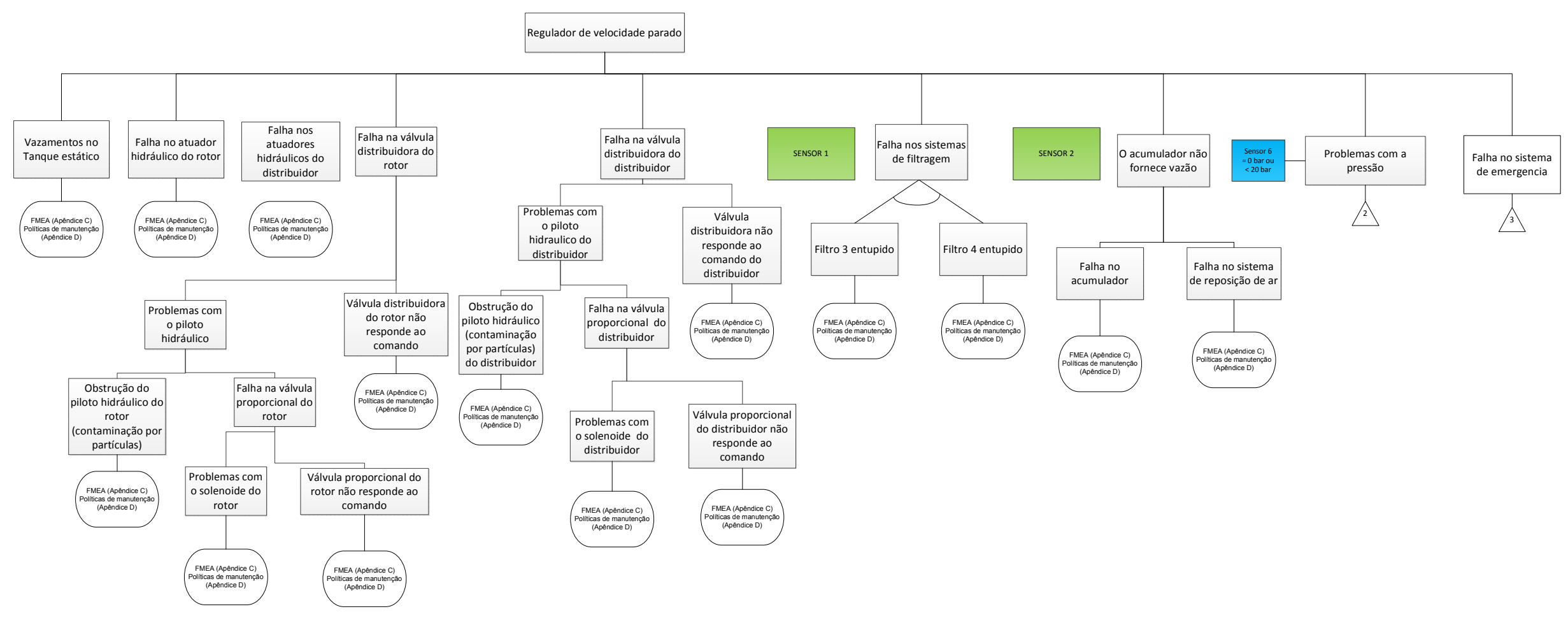




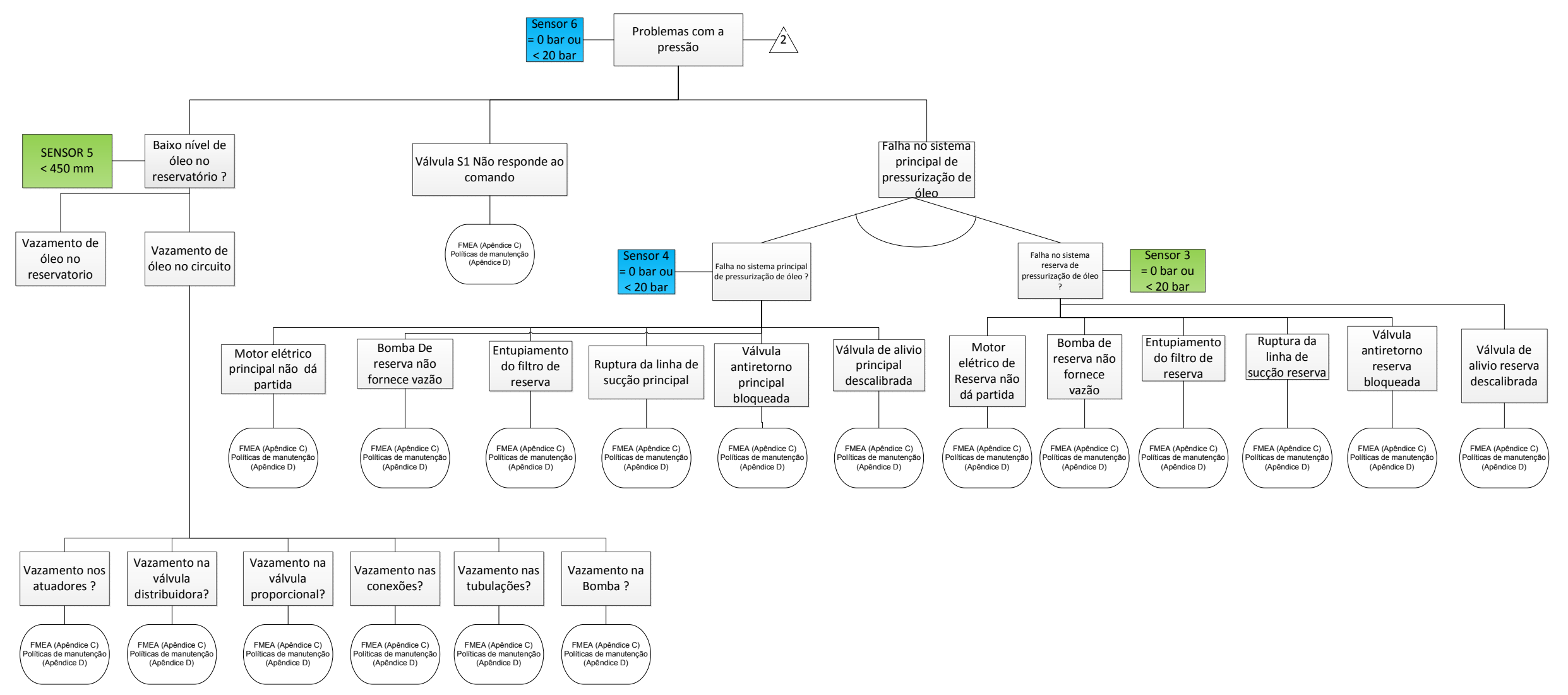




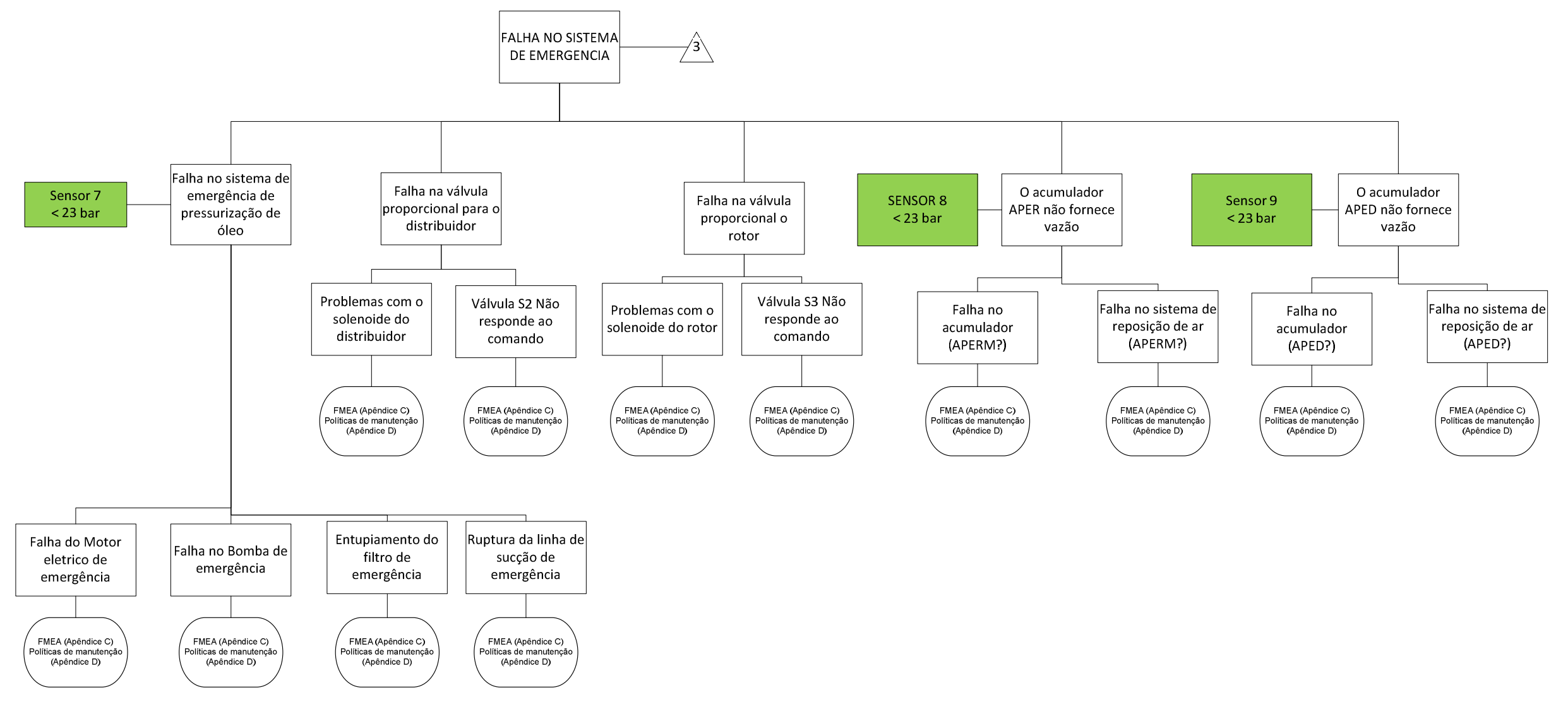




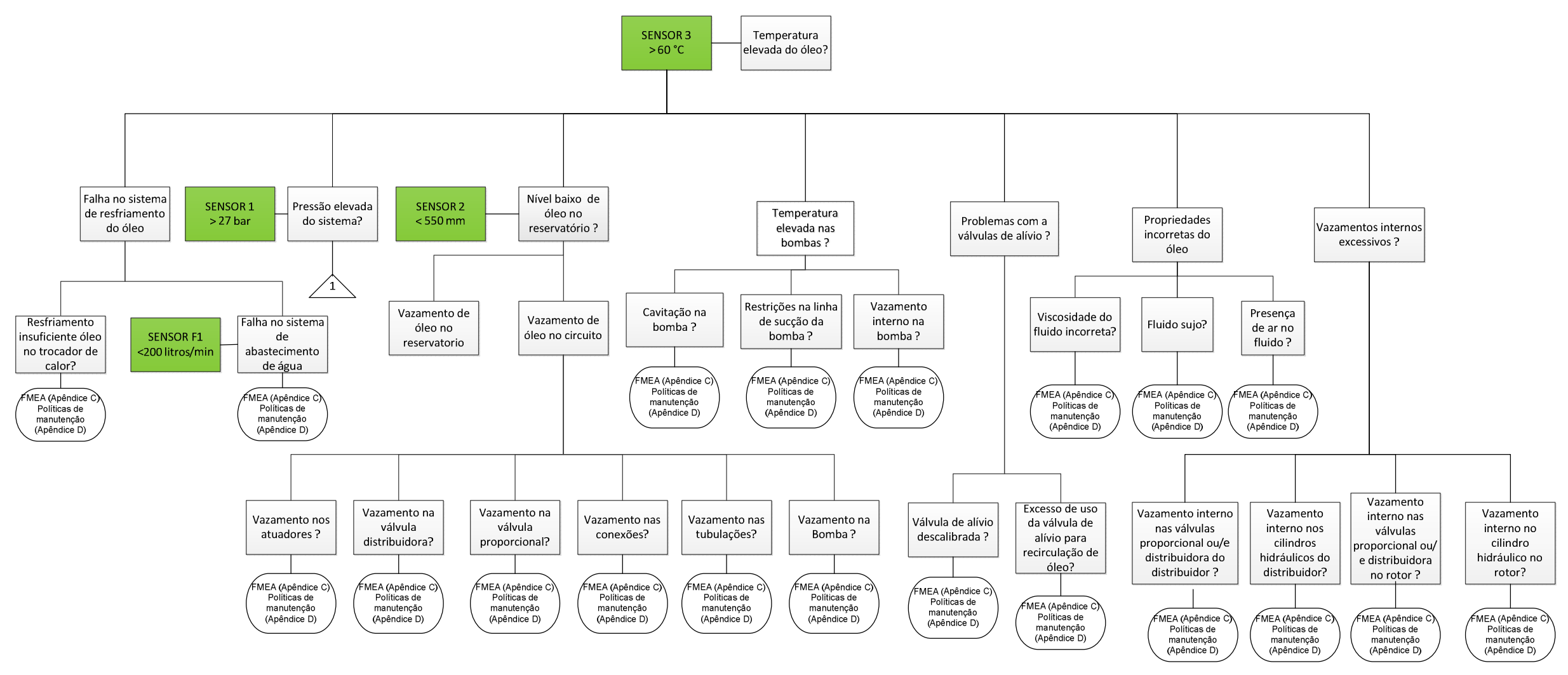




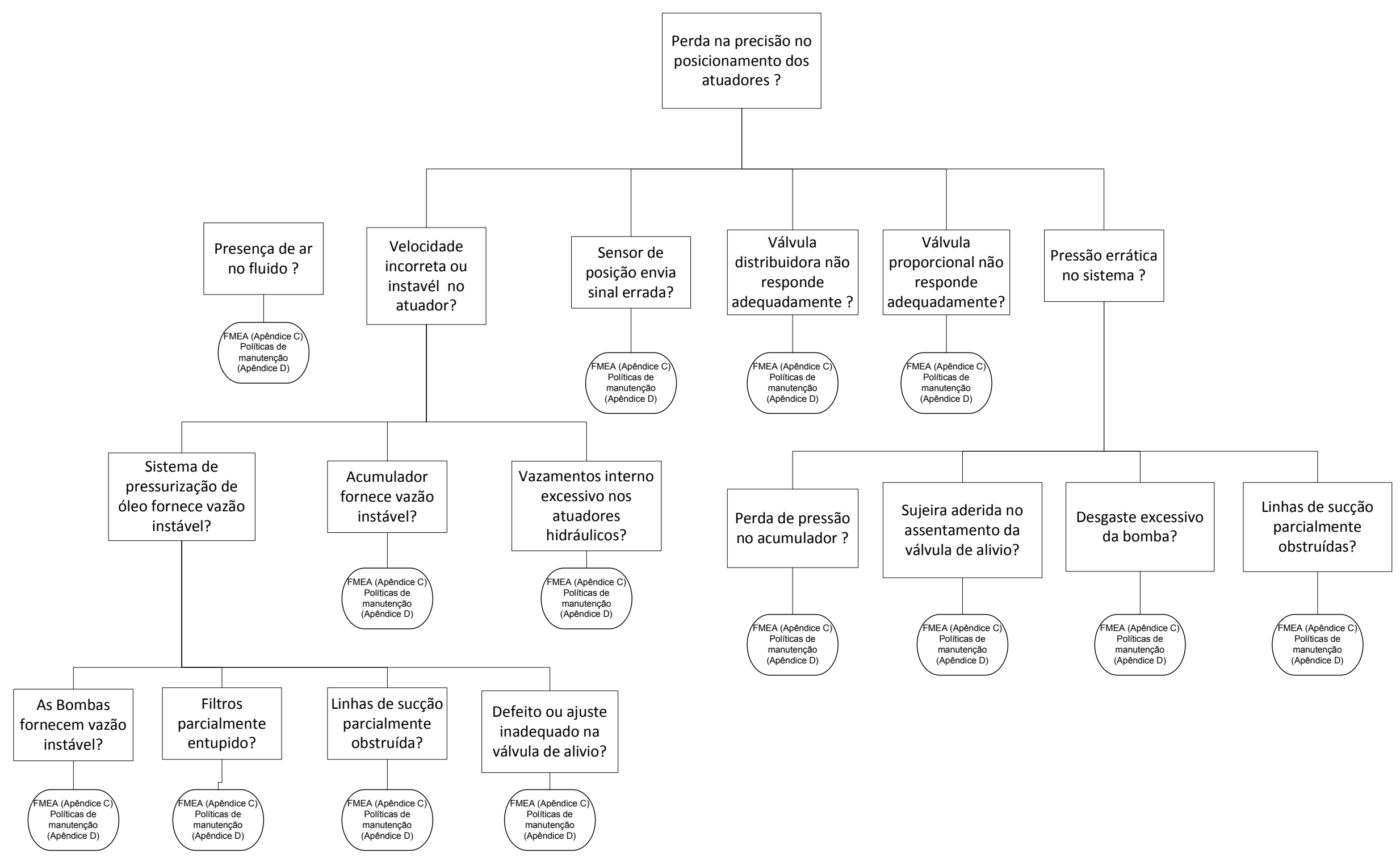




\section{Apêndice F: Código de programação em Clips}

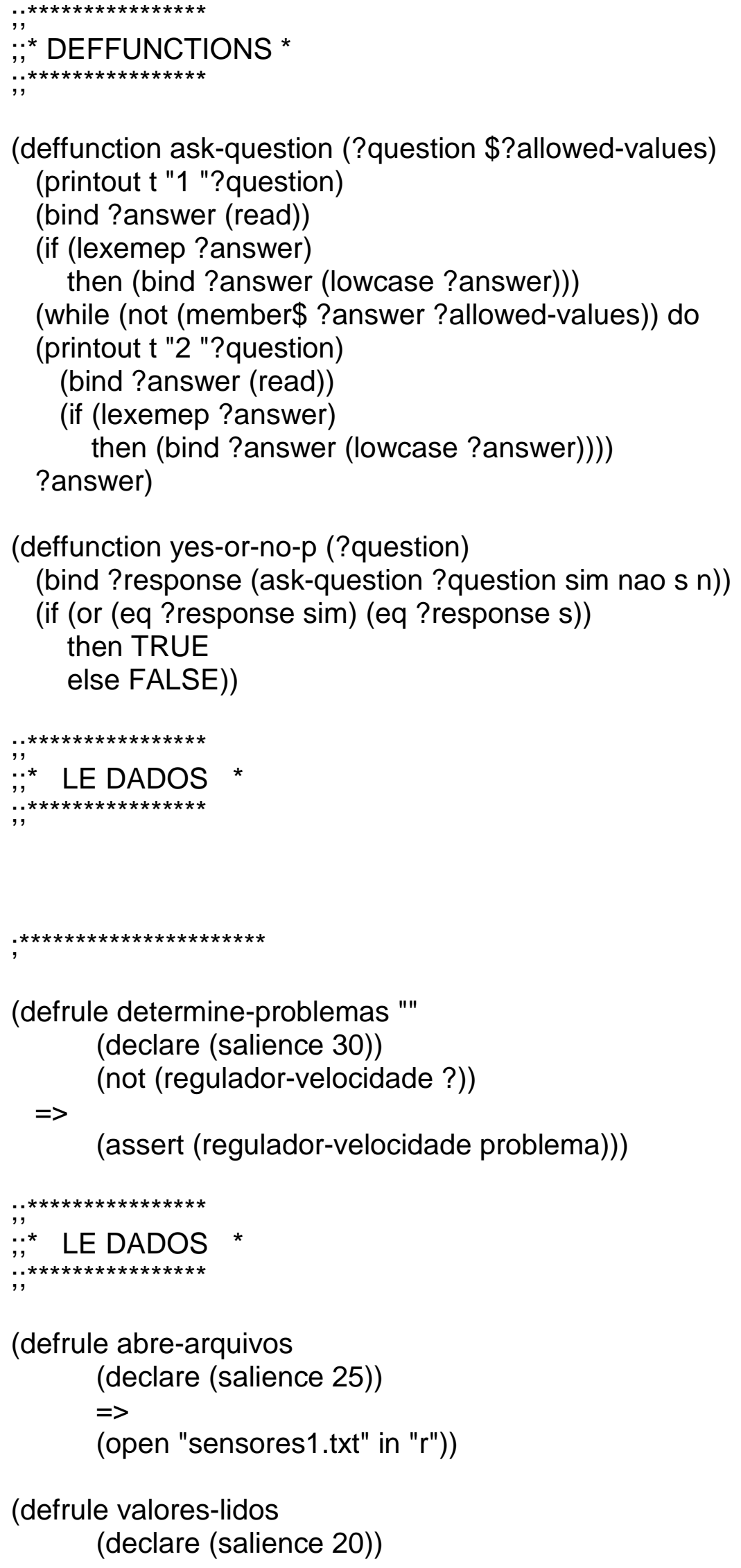

(defrule abre-arquivos

(declare (salience 25))

$=>$

(open "sensores1.txt" in "r"))

(defrule valores-lidos

(declare (salience 20)) 
(not (S1 ?))

(not (S2 ?))

(not (S3 ?))

(not (S4 ?))

(not (S5 ?))

(not (S6 ?))

(not (S11?))

$($ not $(\mathrm{S} 12 ?))$

(not (S13?))

$\Rightarrow$

(bind ?S1 (read in))

(bind ?S2 (read in))

(bind ?S3 (read in))

(bind ?S4 (read in))

(bind ?S5 (read in))

(bind ?S6 (read in))

(bind ?S11 (read in))

(bind ?S12 (read in))

(bind ?S13 (read in))

(assert (b ?S1))

(assert (c ?S2))

(assert (d ?S3))

(assert (e ?S4))

(assert (f ?S5))

(assert (g ?S6))

(assert (h ?S11))

(assert (i ?S12))

(assert (j ?S13)))

(defrule fecha-arquivos

(declare (salience 15))

$=>$

(close in))

Determinar Sensores

(defrule determine-sensores "'"

(declare (salience 10))

(b ?x)

(c ?y)

(d ?z)

(e ?t)

(f ?u)

(g ?v)

(h ?w)

(i ?p)

(j ?q)

(not (sistema-filtragem ?)) 
(not (vazao-acumulador ?))

(not (vazao-sistema ?))

(not (vazao-bomba-principal ?))

(not (vazao-bomba-reserva ?))

(not (sistema-emergencia-pressurizacao-oleo ?))

(not (vazao-acumulador-APERM ?))

(not (vazao-acumulador-APED ?))

$=>$

(if (> ?x 5) then (assert (sistema-filtragem falha))else (assert (sistemafiltragem OK))(assert (filtros OK)))

(if (< ?y 23) then (assert (vazao-acumulador problema))else (assert (vazao-acumulador OK))(assert (acumulador OK))(assert (sistema-reposicao-ar $\mathrm{OK}))$

(if $(<? z 23)$ then (assert (vazao-sistema problema))else (assert (vazaosistema OK)))

(if $(<$ ?t 23) then (assert (vazao-bomba-principal problema)(sistemaprincipal-pressurizacao-oleo falha))else (assert(vazao-bomba-principal OK))(assert (motor-eletrico-principal OK))(assert(bomba-principal OK))(assert(filtro-principal OK))(assert (linha-succao-principal OK)))

(if (< ?u 23) then (assert (vazao-bomba-reserva problema)(sistemareserva-pressurizacao-oleo falha)) else(assert(vazao-bomba-reserva OK))(assert (motor-eletrico-reserva OK))(assert(bomba-reserva OK))(assert(filtro-reserva OK))(assert (linha-succao-reserva OK)))

(if (< ?v 450) then (assert (nivel-oleo-reservatorio baixo)) else (assert(nivel-oleo-reservatorio OK)))

(if ( $<$ ?w 24) then (assert (sistema-emergencia-pressurizacao-oleo falha)) (assert (sistema-emergencia falha)) else (assert(sistema-emergenciapressurizacao-oleo OK)))

(if $(<$ ?p 20) then (assert (vazao-acumulador-APERM falha)) (assert (sistema-emergencia falha)) else (assert(vazao-acumulador-APERM OK)))

(if (< ?q 20) then (assert (vazao-acumulador-APED falha)) (assert (sistema-emergencia falha)) else (assert(vazao-acumulador-APED OK))))

(defrule determine-sistema-pressurizacao-oleo-inicial "'"

(declare (salience 5))

(regulador-velocidade problema)

(vazao-bomba-principal problema)

(vazao-bomba-reserva problema)

(not (sistema-pressurizacao-oleo ?))

$=>$

(assert (sistema-pressurizacao-oleo falha))) 
(defrule determine-sistema-emergencia "'"

(regulador-velocidade problema)

(sistema-filtragem OK)

(vazao-acumulador OK)

(vazao-sistema OK)

(vazao-bomba-principal OK)

(vazao-bomba-reserva OK)

(not (sistema-emergencia ?))

$=>$

(if (yes-or-no-p "Ocorre falha no sistema de emergencia (sim/nao)? ")

then (assert (sistema-emergencia falha))

else (assert (sistema-emergencia OK))))

(defrule determine-motor-eletrico-emergencia "'"

(regulador-velocidade problema)

(sistema-emergencia falha)

(sistema-emergencia-pressurizacao-oleo falha)

(not (motor-eletrico-emergencia ?))

$=>$

(if (yes-or-no-p "Ocorre falha no motor eletrico de emergencia (sim/nao)? ") then (assert (motor-eletrico-emergencia falha)(tem-reparo sim))

else (assert (motor-eletrico-emergencia OK))))

(defrule determine-bomba-emergencia "'"

(regulador-velocidade problema)

(sistema-emergencia falha)

(sistema-emergencia-pressurizacao-oleo falha)

(not (bomba-emergencia ?))

$=>$

(if (yes-or-no-p "Ocorre falha na bomba de emergencia (sim/nao)? ") then (assert (bomba-emergencia falha)(tem-reparo sim))

else (assert (bomba-emergencia OK))))

(defrule determine-filtro-emergencia "'"

(regulador-velocidade problema)

(sistema-emergencia falha)

(sistema-emergencia-pressurizacao-oleo falha)

(not (filtro-emergencia ?))

$=>$

(if (yes-or-no-p "Ocorre falha no filtro de emergencia (sim/nao)? ") then (assert (filtro-emergencia falha)(tem-reparo sim))

else (assert (filtro-emergencia OK))))

(defrule determine-linha-succao-emergencia "'"

(regulador-velocidade problema)

(sistema-emergencia falha)

(sistema-emergencia-pressurizacao-oleo falha)

(not (linha-succao-emergencia ?))

$=>$

(if (yes-or-no-p "Ocorre falha na linha de succao de emergencia (sim/nao)? ") 
then (assert (linha-succao-emergencia falha)(tem-reparo sim)) else (assert (linha-succao-emergencia OK))))

(defrule determine-valvula-proporcional-distribuidor-emergencia (regulador-velocidade problema)

(sistema-emergencia falha)

(not (valvula-proporcional-distribuidor-emergencia ?))

$$
=>
$$

(if (yes-or-no-p "Ocorre falha na valvula proporcional de emergencia do distribuidor (sim/nao)?")

then (assert (valvula-proporcional-distribuidor-emergencia falha)) else (assert (valvula-proporcional-distribuidor-emergencia OK))))

(defrule determine-solenoide-distribuidor-emergencia

(regulador-velocidade problema)

(sistema-emergencia falha)

(valvula-proporcional-distribuidor-emergencia falha)

(not (solenoide-distribuidor-emergencia ?))

$$
=>
$$

(if (yes-or-no-p "Ocorre falha no solenoide de emergencia do distribuidor (sim/nao)? ")

then (assert (solenoide-distribuidor-emergencia falha)(tem-reparo $\operatorname{sim}))$

$$
\text { else (assert (solenoide-distribuidor-emergencia OK)))) }
$$

(defrule determine-valvulaS2

(regulador-velocidade problema)

(sistema-emergencia falha)

(valvula-proporcional-distribuidor-emergencia falha)

(not (valvulaS2 ?))

$=>$

(if (yes-or-no-p "Ocorre falha na valvula S2 (sim/nao)? ")

then (assert (valvulaS2 falha)(tem-reparo sim))

else (assert (valvulaS2 OK))))

(defrule determine-valvula-proporcional-rotor-emergencia

(regulador-velocidade problema)

(sistema-emergencia falha)

(not (valvula-proporcional-rotor-emergencia ?))

$$
=>
$$

(if (yes-or-no-p "Ocorre falha na valvula proporcional de emergencia do rotor (sim/nao)? ")

then (assert (valvula-proporcional-rotor-emergencia falha))

else (assert (valvula-proporcional-rotor-emergencia OK))))

(defrule determine-solenoide-rotor-emergencia

(regulador-velocidade problema)

(sistema-emergencia falha)

(valvula-proporcional-rotor-emergencia falha)

(not (solenoide-rotor-emergencia ?)) 


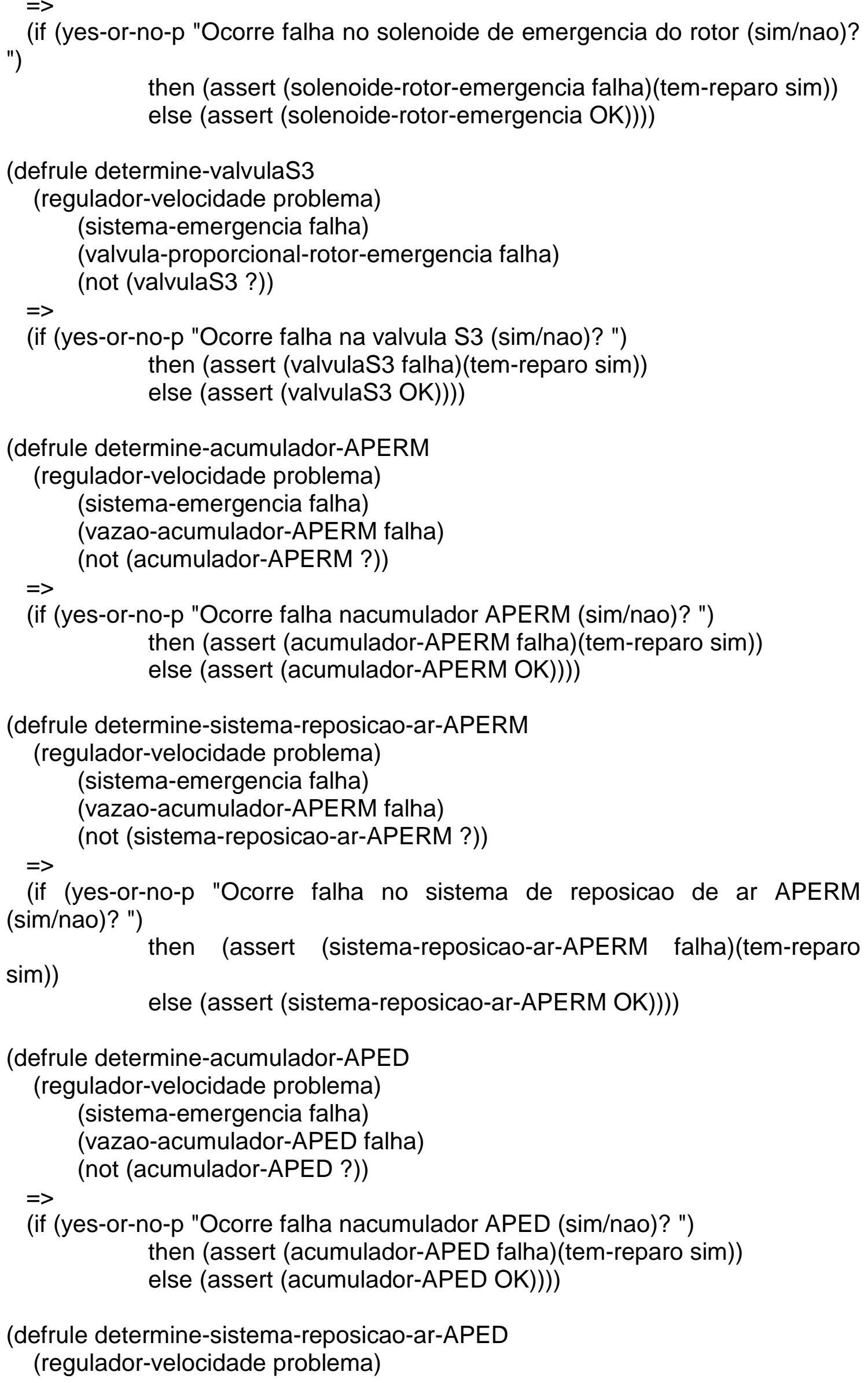




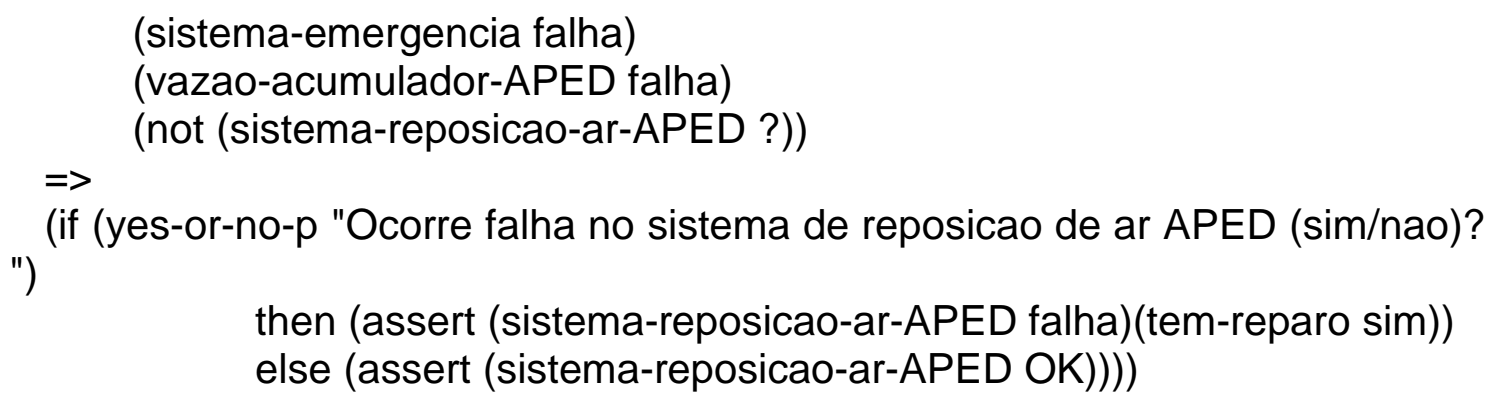

(defrule determine-valvula-distribuidora-rotor "'"

(regulador-velocidade problema)

(sistema-filtragem OK)

(vazao-acumulador OK)

(vazao-sistema OK)

(vazao-bomba-principal OK)

(vazao-bomba-reserva OK)

(sistema-emergencia OK)

(not (valvula-distribuidora-rotor ?))

$=>$

(if (yes-or-no-p "Ocorre falha na valvula distribuidora do rotor (sim/nao)? ")

then (assert (valvula-distribuidora-rotor falha))

else (assert (valvula-distribuidora-rotor OK)))) 
(defrule determine-piloto-hidraulico-rotor "'"

(regulador-velocidade problema)

(valvula-distribuidora-rotor falha)

(sistema-filtragem OK)

(vazao-acumulador OK)

(vazao-sistema OK)

(not (piloto-hidraulico-rotor ?))

$=>$

")

(if (yes-or-no-p "Ocorre problema com o piloto hidraulico do rotor (sim/nao)?

then (assert (piloto-hidraulico-rotor falha))

else (assert (piloto-hidraulico-rotor OK))))

(defrule determine-valvula-distribuidora-responde-comando-rotor "'"

(regulador-velocidade problema)

(valvula-distribuidora-rotor falha)

(sistema-filtragem OK)

(vazao-acumulador OK)

(vazao-sistema OK)

(not (valvula-distribuidora-responde-comando-rotor ?))

$=>$

(if (yes-or-no-p "A valvula distribuidora responde ao comando do rotor (sim/nao)?")

responde))

then (assert (valvula-distribuidora-responde-comando-rotor responde))))

else (assert (valvula-distribuidora-responde-comando-rotor nao-

(defrule determine-obstrucao-piloto-hidraulico-rotor "'"

(regulador-velocidade problema)

(valvula-distribuidora-rotor falha)

(piloto-hidraulico-rotor falha)

(sistema-filtragem OK)

(vazao-acumulador OK)

(vazao-sistema OK)

(not (obstrucao-piloto-hidraulico-rotor ?))

$=>$

(if (yes-or-no-p "O piloto hidraulico do rotor esta obstruido (sim/nao)? ")

then (assert (obstrucao-piloto-hidraulico-rotor obstruido)(tem-

reparo $\operatorname{sim})$ )

else (assert (obstrucao-piloto-hidraulico-rotor OK))))

(defrule determine-valvula-proporcional-rotor "'"

(regulador-velocidade problema)

(valvula-distribuidora-rotor falha)

(piloto-hidraulico-rotor falha)

(sistema-filtragem OK)

(vazao-acumulador OK)

(vazao-sistema OK) 
(not (valvula-proporcional-rotor ?))

$=>$

(if (yes-or-no-p "Ocorre falha na valvula proporcional do rotor (sim/nao)? ") then (assert (valvula-proporcional-rotor falha))

else (assert (valvula-proporcional-rotor OK))))

(defrule determine-solenoide-rotor "'"

(regulador-velocidade problema)

(valvula-distribuidora-rotor falha)

(piloto-hidraulico-rotor falha)

(valvula-proporcional-rotor falha)

(sistema-filtragem OK)

(vazao-acumulador OK)

(vazao-sistema OK)

(not (solenoide-rotor ?))

$=>$

(if (yes-or-no-p "Ocorre falha no solenoide do rotor (sim/nao)? ")

then (assert (solenoide-rotor falha) (tem-reparo sim))

else (assert (solenoide-rotor OK))))

(defrule determine-valvula-proporcional-rotor-responde-comando "'

(regulador-velocidade problema)

(valvula-distribuidora-rotor falha)

(piloto-hidraulico-rotor falha)

(valvula-proporcional-rotor falha)

(sistema-filtragem OK)

(vazao-acumulador OK)

(vazao-sistema OK)

(not (valvula-proporcional-rotor-responde-comando ?))

$=>$

(if (yes-or-no-p "A valvula proporcional do rotor responde ao comando (sim/nao)? ")

responde))

then (assert (valvula-proporcional-rotor-responde-comando

responde) (tem-reparo sim))))

(defrule determine-valvula-distribuidora-rotor-responde-comando "'"

(regulador-velocidade problema)

(valvula-distribuidora-rotor falha)

(sistema-filtragem OK)

(vazao-acumulador OK)

(vazao-sistema OK)

(not (valvula-distribuidora-rotor-responde-comando ?))

$=>$

(if (yes-or-no-p "A valvula distribuidora do rotor responde ao comando (sim/nao)?")

responde))

then (assert (valvula-distribuidora-rotor-responde-comando 
else (assert (valvula-distribuidora-rotor-responde-comando naoresponde) (tem-reparo sim))))

(defrule determine-atuador-hidraulico-1 "'"

(regulador-velocidade problema)

(sistema-filtragem OK)

(vazao-acumulador OK)

(vazao-sistema OK)

(vazao-bomba-principal OK)

(vazao-bomba-reserva OK)

(sistema-emergencia OK)

(not (atuador-hidraulico-1 ?))

$\Rightarrow$

(if (yes-or-no-p "Ocorre falha nos atuadores hidraulicos do distribuidor (sim/nao)?")

then (assert (atuador-hidraulico-1 falha) (tem-reparo sim))

else (assert (atuador-hidraulico-1 OK))))

(defrule determine-valvula-distribuidora-distribuidor "'"

(regulador-velocidade problema)

(sistema-filtragem OK)

(vazao-acumulador OK)

(vazao-sistema OK)

(vazao-bomba-principal OK)

(vazao-bomba-reserva OK)

(sistema-emergencia OK)

(not (valvula-distribuidora-distribuidor ?))

$=>$ ")

(if (yes-or-no-p "Ocorre falha na valvula distribuidora do distribuidor(sim/nao)?

then (assert (valvula-distribuidora-distribuidor falha))

else (assert (valvula-distribuidora-distribuidor OK))))

(defrule determine-piloto-hidraulico-distribuidor "'"

(regulador-velocidade problema)

(valvula-distribuidora-distribuidor falha)

(sistema-filtragem OK)

(vazao-acumulador OK)

(vazao-sistema OK)

(not (piloto-hidraulico-distribuidor ?))

$\Rightarrow$

(if (yes-or-no-p "Ocorre problema com o piloto hidraulico do distribuidor (sim/nao)?")

then (assert (piloto-hidraulico-distribuidor falha))

else (assert (piloto-hidraulico-distribuidor OK))))

(defrule determine-valvula-distribuidora-responde-comando-distribuidor "'"

(regulador-velocidade problema)

(valvula-distribuidora-rotor falha)

(sistema-filtragem OK) 
(vazao-acumulador OK)

(vazao-sistema OK)

(not (valvula-distribuidora-responde-comando-distribuidor ?))

$=>$

(if (yes-or-no-p "A valvula distribuidora responde ao comando do distribuidor (sim/nao)?")

responde))

then (assert (valvula-distribuidora-responde-comando-distribuidor

else (assert (valvula-distribuidora-responde-comando-distribuidor nao-responde) (tem-reparo sim))))

(defrule determine-obstrucao-piloto-hidraulico-distribuidor "'"

(regulador-velocidade problema)

(valvula-distribuidora-rotor falha)

(piloto-hidraulico-distribuidor falha)

(sistema-filtragem OK)

(vazao-acumulador OK)

(vazao-sistema OK)

(not (obstrucao-piloto-hidraulico-distribuidor ?))

$=>$

(if (yes-or-no-p "O piloto hidraulico do distribuidor esta obstruido (sim/nao)? ") then (assert (obstrucao-piloto-hidraulico-distribuidor obstruido) (tem-reparo sim)) else (assert (obstrucao-piloto-hidraulico-distribuidor OK))))

(defrule determine-valvula-proporcional-distribuidor "'"

(regulador-velocidade problema)

(valvula-distribuidora-distribuidor falha)

(piloto-hidraulico-distribuidor falha)

(sistema-filtragem OK)

(vazao-acumulador OK)

(vazao-sistema OK)

(not (valvula-proporcional-distribuidor ?))

$=>$

(if (yes-or-no-p "Ocorre falha na valvula proporcional do distribuidor (sim/nao)?")

then (assert (valvula-proporcional-distribuidor falha))

else (assert (valvula-proporcional-distribuidor OK))))

(defrule determine-solenoide-distribuidor "'"

(regulador-velocidade problema)

(valvula-distribuidora-distribuidor falha)

(piloto-hidraulico-distribuidor falha)

(valvula-proporcional-distribuidor falha)

(sistema-filtragem OK)

(vazao-acumulador OK)

(vazao-sistema OK)

(not (solenoide-distribuidor ?))

$=>$

(if (yes-or-no-p "Ha problemas com o solenoide do distribuidor (sim/nao)? ") 
then (assert (solenoide-distribuidor falha) (tem-reparo sim)) else (assert (solenoide-distribuidor OK))))

(defrule determine-valvula-proporcional-distribuidor-responde-comando "' (regulador-velocidade problema)

(valvula-distribuidora-distribuidor falha)

(piloto-hidraulico-distribuidor falha)

(valvula-proporcional-distribuidor falha)

(sistema-filtragem OK)

(vazao-acumulador OK)

(vazao-sistema OK)

(not (valvula-proporcional-distribuidor-responde-comando ?))

$=>$

(if (yes-or-no-p "A valvula proporcional do distribuidor responde ao comando (sim/nao)?")

responde))

then (assert (valvula-proporcional-distribuidorr-responde-comando

else (assert (valvula-proporcional-distribuidor-responde-comando nao-responde) (tem-reparo sim))))

(defrule determine-valvula-distribuidora-distribuidor-responde-comando "'"

(regulador-velocidade problema)

(valvula-distribuidora-distribuidor falha)

(piloto-hidraulico-distribuidor falha)

(valvula-proporcional-distribuidor falha)

(sistema-filtragem OK)

(vazao-acumulador OK)

(vazao-sistema OK)

(not (valvula-proporcional-distribuidor-responde-comando ?))

$=>$

(if (yes-or-no-p "A valvula proporcional do distribuidor responde ao comando (sim/nao)? ")

responde))

then (assert (valvula-distribuidora-distribuidorr-responde-comando

else (assert (valvula-distribuidora-distribuidor-responde-comando nao-responde) (tem-reparo sim))))

(defrule determine-filtros "'"

(regulador-velocidade problema)

(sistema-filtragem falha)

(not (filtros ?))

$=>$

(assert (filtros falha) (tem-reparo sim)))

(defrule determine-vazao-acumulador "'"

(regulador-velocidade problema)

(not (vazao-acumulador ?))

$=>$

(if (yes-or-no-p "O acumulador fornece vazao (sim/nao)? ")

then (assert (vazao-acumulador OK)) 


$$
\text { else (assert (vazao-acumulador problema)))) }
$$

(defrule determine-acumulador "'"

(regulador-velocidade problema)

(vazao-acumulador problema)

(not (acumulador ?))

$=>$

(if (yes-or-no-p "O acumulador esta com problema (sim/nao)? ")

then (assert (acumulador falha)(tem-reparo sim))

else (assert (acumulador OK))))

(defrule determine-sistema-reposicao-ar "'"

(regulador-velocidade problema)

(vazao-acumulador problema)

(not (sistema-reposicao-ar ?))

$=>$

")

(if (yes-or-no-p "O sistema de reposicao de ar esta com problema (sim/nao)?

then (assert (sistema-reposicao-ar falha)(tem-reparo sim))

else (assert (sistema-reposicao-ar OK))))

(defrule determine-vazao "'"

(regulador-velocidade problema)

(vazao-sistema problema)

(not (vazao ?))

$=>$

$$
\text { (assert (vazao nao-tem))) }
$$

(defrule determine-valvulaS1 "'"

(regulador-velocidade problema)

(vazao-sistema problema)

(vazao nao-tem)

(not (valvulaS1?))

$=>$

(if (yes-or-no-p "A valvula S1 responde ao comando (sim/nao)? ")

then (assert (valvulaS1 responde))

else (assert (valvulaS1 nao-responde)(tem-reparo sim))))

(defrule determine-vazamento-oleo-reservatorio "'"

(regulador-velocidade problema)

(nivel-oleo-reservatorio baixo)

(not (vazamento-oleo-reservatorio ?))

$=>$

(if (yes-or-no-p "Ocorre vazamento de oleo no reservatorio (sim/nao)? ") then (assert (vazamento-oleo-reservatorio ocorre))(assert (tem-

reparo $\operatorname{sim})$ )

else (assert (vazamento-oleo-reservatorio nao-ocorre))))

(defrule determine-vazamento-oleo-circuito "'

(regulador-velocidade problema) 
(nivel-oleo-reservatorio baixo)

(not (vazamento-oleo-circuito ?))

$=>$

(if (yes-or-no-p "Ocorre vazamento de oleo no circuito (sim/nao)? ")

then (assert (vazamento-oleo-circuito ocorre))

else (assert (vazamento-oleo-circuito nao-ocorre))))

(defrule determine-vazamento-atuadores "'"

(regulador-velocidade problema)

(nivel-oleo-reservatorio baixo)

(vazamento-oleo-circuito ocorre)

(not (vazamento-atuadores ?))

$=>$

(if (yes-or-no-p "Ocorre vazamento de oleo nos atuadores (sim/nao)? ")

then (assert (vazamento-atuadores ocorre))(assert (tem-reparo

$\operatorname{sim}))$

else (assert (vazamento-atuadores nao-ocorre))))

(defrule determine-vazamento-valvula-distribuidora "'"

(regulador-velocidade problema)

(nivel-oleo-reservatorio baixo)

(vazamento-oleo-circuito ocorre)

(not (vazamento-valvula-distribuidora ?))

$=>$ ")

(if (yes-or-no-p "Ocorre vazamento de oleo na valvula distribuidora (sim/nao)?

reparo $\operatorname{sim})$ )

then (assert (vazamento-valvula-distribuidora ocorre))(assert (tem-

else (assert (vazamento-valvula-distribuidora nao-ocorre))))

(defrule determine-vazamento-valvula-proporcional "'"

(regulador-velocidade problema)

(nivel-oleo-reservatorio baixo)

(vazamento-oleo-circuito ocorre)

(not (vazamento-valvula-proporcional ?))

$=>$ ")

(if (yes-or-no-p "Ocorre vazamento de oleo na valvula proporcional (sim/nao)?

reparo $\operatorname{sim})$ )

then (assert (vazamento-valvula-proporcional ocorre))(assert (tem-

else (assert (vazamento-valvula-proporcional nao-ocorre))))

(defrule determine-vazamento-conexoes "'"

(regulador-velocidade problema)

(nivel-oleo-reservatorio baixo)

(vazamento-oleo-circuito ocorre)

(not (vazamento-conexoes ?))

$=>$

(if (yes-or-no-p "Ocorre vazamento de oleo nas conexoes (sim/nao)? ") 
$\operatorname{sim}))$

then (assert (vazamento-conexoes ocorre))(assert (tem-reparo else (assert (vazamento-conexoes nao-ocorre))))

(defrule determine-vazamento-tubulacoes "'"

(regulador-velocidade problema)

(nivel-oleo-reservatorio baixo)

(vazamento-oleo-circuito ocorre)

(not (vazamento-tubulacoes ?))

$=>$

(if (yes-or-no-p "Ocorre vazamento de oleo nas tubulacoes (sim/nao)? ") then (assert (vazamento-tubulacoes ocorre))(assert (tem-reparo $\operatorname{sim}))$

else (assert (vazamento-tubulacoes nao-ocorre))))

(defrule determine-vazamento-bomba "'"

(regulador-velocidade problema)

(nivel-oleo-reservatorio baixo)

(vazamento-oleo-circuito ocorre)

(not (vazamento-bomba ?))

$=>$

(if (yes-or-no-p "Ocorre vazamento de oleo na bomba (sim/nao)? ")

then (assert (vazamento-bomba ocorre))(assert (tem-reparo sim))

else (assert (vazamento-bomba nao-ocorre))))

(defrule determine-sistema-pressurizacao-oleo "'"

(regulador-velocidade problema)

(vazao-sistema problema)

(vazao nao-tem)

(not (sistema-pressurizacao-oleo ?))

$=>$

")

(if (yes-or-no-p "Ocorre falha no sistema de pressurizacao de oleo (sim/nao)?

then (assert (sistema-pressurizacao-oleo falha)) (assert (sistemaprincipal-pressurizacao-oleo falha)) (assert (sistema-reserva-pressurizacaooleo falha))

else (assert (sistema-pressurizacao-oleo OK))))

(defrule determine-valvula-anti-retorno-principal "'"

(regulador-velocidade problema)

(vazao-sistema problema)

(vazao nao-tem)

(sistema-pressurizacao-oleo falha)

(sistema-principal-pressurizacao-oleo falha)

(not (valvula-anti-retorno-principal ?))

$=>$

(if (yes-or-no-p "A valvula anti-retorno principal esta bloqueada (sim/nao)? ") then (assert (valvula-anti-retorno-principal bloqueada) (tem-reparo $\operatorname{sim}))$

else (assert (valvula-anti-retorno-principal OK)))) 
(defrule determine-valvula-alivio-principal "'"

(regulador-velocidade problema)

(vazao-sistema problema)

(vazao nao-tem)

(sistema-pressurizacao-oleo falha)

(sistema-principal-pressurizacao-oleo falha)

(not (valvula-alivio-principal ?))

$=>$

(if (yes-or-no-p "A valvula de alivio principal esta descalibrada (sim/nao)? ") then (assert (valvula-alivio-principal descalibrada) (tem-reparo $\operatorname{sim}))$ else (assert (valvula-alivio-principal OK))))

(defrule determine-motor-eletrico-principal "'"

(regulador-velocidade problema)

(vazao-sistema problema)

(vazao nao-tem)

(sistema-pressurizacao-oleo falha)

(sistema-principal-pressurizacao-oleo falha)

(vazao-bomba-principal problema)

(not (motor-eletrico-principal ?))

$=>$

(if (yes-or-no-p "O motor eletrico principal apresenta problema (sim/nao)? ") then (assert (motor-eletrico-principal falha) (tem-reparo sim)) else (assert (motor-eletrico-principal OK))))

(defrule determine-bomba-principal "'"

(regulador-velocidade problema)

(vazao-sistema problema)

(vazao nao-tem)

(sistema-pressurizacao-oleo falha)

(sistema-principal-pressurizacao-oleo falha)

(vazao-bomba-principal problema)

(not (bomba-principal ?))

$=>$

(if (yes-or-no-p "A bomba principal apresenta problema (sim/nao)? ")

then (assert (bomba-principal falha) (tem-reparo sim))

else (assert (bomba-principal OK))))

(defrule determine-entupimento-filtro-principal "'"

(regulador-velocidade problema)

(vazao-sistema problema)

(vazao nao-tem)

(sistema-pressurizacao-oleo falha)

(sistema-principal-pressurizacao-oleo falha)

(vazao-bomba-principal problema)

(not (entupimento-filtro-principal ?))

$=>$

(if (yes-or-no-p "O filtro principal esta entupido (sim/nao)? ") 
$\operatorname{sim}))$

then (assert (entupimento-filtro-principal entupido) (tem-reparo else (assert (entupimento-filtro-principal OK))))

(defrule determine-linha-succao-principal "'"

(regulador-velocidade problema)

(vazao-sistema problema)

(vazao nao-tem)

(sistema-pressurizacao-oleo falha)

(sistema-principal-pressurizacao-oleo falha)

(vazao-bomba-principal problema)

(not (linha-succao-principal ?))

$=>$

(if (yes-or-no-p "Ha rupturas na linha de succao principal (sim/nao)? ")

then (assert (linha-succao-principal entupido) (tem-reparo sim))

else (assert (linha-succao-principal OK))))

(defrule determine-motor-eletrico-reserva "'"

(regulador-velocidade problema)

(vazao-sistema problema)

(vazao nao-tem)

(sistema-pressurizacao-oleo falha)

(sistema-principal-pressurizacao-oleo falha)

(vazao-bomba-principal problema)

(not (motor-eletrico-reserva ?))

$=>$

(if (yes-or-no-p "O motor eletrico reserva apresenta problema (sim/nao)? ")

then (assert (motor-eletrico-reserva falha) (tem-reparo sim))

else (assert (motor-eletrico-reserva OK))))

(defrule determine-bomba-reserva "'"

(regulador-velocidade problema)

(vazao-sistema problema)

(vazao nao-tem)

(sistema-pressurizacao-oleo falha)

(sistema-principal-pressurizacao-oleo falha)

(vazao-bomba-principal problema)

(not (bomba-reserva ?))

$=>$

(if (yes-or-no-p "A bomba reserva apresenta problema (sim/nao)? ") then (assert (bomba-reserva falha) (tem-reparo sim))

else (assert (bomba-reserva OK))))

(defrule determine-entupimento-filtro-reserva "'"

(regulador-velocidade problema)

(vazao-sistema problema)

(vazao nao-tem)

(sistema-pressurizacao-oleo falha)

(sistema-principal-pressurizacao-oleo falha)

(vazao-bomba-principal problema) 
(not (entupimento-filtro-reserva ?))

$=>$

(if (yes-or-no-p "O filtro reserva esta entupido (sim/nao)? ")

then (assert (entupimento-filtro-reserva entupido) (tem-reparo $\operatorname{sim}))$

$$
\text { else (assert (entupimento-filtro-reserva OK)))) }
$$

(defrule determine-linha-succao-reserva "'"

(regulador-velocidade problema)

(vazao-sistema problema)

(vazao nao-tem)

(sistema-pressurizacao-oleo falha)

(sistema-principal-pressurizacao-oleo falha)

(vazao-bomba-principal problema)

(not (linha-succao-reserva ?))

$=>$

(if (yes-or-no-p "Ha rupturas na linha de succao reserva (sim/nao)? ")

then (assert (linha-succao-reserva entupido) (tem-reparo sim))

else (assert (linha-succao-reserva OK))))

(defrule determine-valvula-anti-retorno-reserva "'"

(regulador-velocidade problema)

(vazao-sistema problema)

(vazao nao-tem)

(sistema-pressurizacao-oleo falha)

(sistema-principal-pressurizacao-oleo falha)

(not (valvula-anti-retorno-reserva ?))

$=>$

(if (yes-or-no-p "A valvula anti-retorno reserva esta bloqueada (sim/nao)? ") then (assert (valvula-anti-retorno-reserva bloqueada) (tem-reparo $\operatorname{sim}))$ else (assert (valvula-anti-retorno-reserva OK))))

(defrule determine-valvula-alivio-reserva "'"

(regulador-velocidade problema)

(vazao-sistema problema)

(vazao nao-tem)

(sistema-pressurizacao-oleo falha)

(sistema-principal-pressurizacao-oleo falha)

(not (valvula-alivio-reserva ?))

$=>$

(if (yes-or-no-p "A valvula de alivio reserva esta descalibrada (sim/nao)? ")

then (assert (valvula-alivio-reserva descalibrada) (tem-reparo $\operatorname{sim}))$

else (assert (valvula-alivio-reserva OK))))

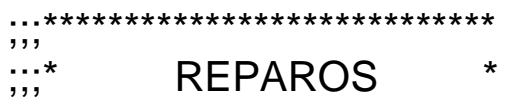


;;;

(defrule print-repair2 "'"

(declare (salience -10))

(tem-reparo sim)

(tanque-estatico falha)

$=>$

(printout $t$ crlf "A falha no tanque estatico pode ser reponsavel pelo problema" crlf))

(defrule print-repair3 "'"

(declare (salience -10))

(atuador-hidraulico-rotor falha)

(fato2.1 ocorre)

$=>$

(printout $t$ crlf "A falha no atuador hidraulico pode ser reponsavel pelo problema" crlf))

(defrule print-repair4 "'

(declare (salience -10))

(tem-reparo sim)

(obstrucao-piloto-hidraulico-rotor obstruido)

$=>$

(printout $\mathrm{t}$ crlf "A obstrucao do piloto hidraulico do rotor pode ser reponsavel pelo problema" crlf))

(defrule print-repair5 "'"

(declare (salience -10))

(tem-reparo sim)

(solenoide-rotor falha)

$=>$

(printout $\mathrm{t}$ crlf "A falha no solenoide do rotor pode ser reponsavel pelo problema" crlf))

(defrule print-repair6 "'"

(declare (salience -10))

(tem-reparo sim)

(valvula-proporcional-rotor-responde-comando nao-responde)

$=>$

(printout t crlf "A falta de resposta da valvula proporcional do rotor pode ser reponsavel pelo problema" crlf))

(defrule print-repair7 "'"

(declare (salience -10))

(tem-reparo sim)

(valvula-distribuidora-rotor-responde-comando nao-responde)

$=>$ 
(printout t crlf "A falta de resposta da valvula distribuidora do rotor pode ser reponsavel pelo problema" crlf))

(defrule print-repair8 "'"

(declare (salience -10))

(tem-reparo sim)

(atuador-hidraulico-1 falha)

$=>$

(printout t crlf "A falha nos atuadores hidraulicos do distribuidor pode ser reponsavel pelo problema" crlf))

(defrule print-repair12 "'"

(declare (salience -10))

(tem-reparo sim)

(valvula-distribuidora-responde-comando-distribuidor nao-responde)

$=>$

(printout $t$ crlf "A falta de resposta da valvula distribuidora pode ser responsavel pelo problema" crlf))

(defrule print-repair13 "'"

(declare (salience -10))

(tem-reparo sim)

(obstrucao-piloto-hidraulico-distribuidor obstruido)

$=>$

(printout t crlf "A obstrucao do piloto hidraulico do distribuidor pode ser reponsavel pelo problema" crlf))

(defrule print-repair14 "'

(declare (salience -10))

(tem-reparo sim)

(solenoide-distribuidor falha)

$=>$

(printout $t$ crlf "A falha no solenoide do distribuidor pode ser reponsavel pelo problema" crlf))

(defrule print-repair15 "'"

(declare (salience -10))

(valvula-proporcional-distribuidor-responde-comando nao-responde)

(fato2.5 ocorre)

$=>$

(printout t crlf "A falta de resposta da valvula proporcional do distribuidor pode ser reponsavel pelo problema" crlf))

(defrule print-repair16 "'"

(declare (salience -10))

(tem-reparo sim)

(valvula-distribuidora-distribuidor-responde-comando nao-responde)

$=>$

(printout t crlf "A falta de resposta da valvula distribuidora do distribuidor pode ser reponsavel pelo problema" crlf)) 
(defrule print-repair17 "'"

(declare (salience -10))

(tem-reparo sim)

(filtros falha)

$=>$

crlf))

(printout t crlf "A falha nos filtros pode ser reponsavel pelo problema"

(defrule print-repair19 "'"

(declare (salience-10))

(tem-reparo sim)

(acumulador falha)

$=>$

(printout $t$ crlf "A falha no acumulador pode ser reponsavel pelo problema" crlf))

(defrule print-repair20 "'

(declare (salience-10))

(tem-reparo sim)

(sistema-reposicao-ar falha)

$=>$

(printout $\mathrm{t}$ crlf "A falha no sistema de reposicao de ar pode ser reponsavel pelo problema" crlf))

(defrule print-repair21 "'

(declare (salience -10))

(tem-reparo sim)

(valvulaS1 nao-responde)

$=>$

(printout $\mathrm{t}$ crlf "A falta de resposta da valvula $\mathrm{S} 1$ pode ser reponsavel pelo problema" crlf))

(defrule print-repair22 "'"

(declare (salience -10))

(tem-reparo sim)

(nivel-oleo-reservatorio baixo)

$=>$

(printout t crlf "O baixo nivel de oleo no reservatorio reponsavel pelo problema" crlf))

(defrule print-repair23 "'"

(declare (salience -10))

(tem-reparo sim)

(valvula-anti-retorno-principal bloqueada)

$=>$

(printout $\mathrm{t}$ crlf "O bloqueio da valvula anti-retorno principal pode ser responsavel pelo problema" crlf))

(defrule print-repair24 "'" 
(declare (salience -10))

(tem-reparo sim)

(valvula-alivio-principal descalibrada)

$=>$

(printout $\mathrm{t}$ crlf "A valvula de alivio principal descalibrada pode ser reponsavel pelo problema" crlf))

(defrule print-repair25 "'"

(declare (salience -10))

(tem-reparo sim)

(motor-eletrico-principal falha)

$=>$

(printout t crlf "A falha no motor eletrico principal pode ser reponsavel pelo problema" crlf))

(defrule print-repair26 "'"

(declare (salience -10))

(tem-reparo sim)

(bomba-principal falha)

$=>$

(printout $t$ crlf "A falha na bomba principal pode ser reponsavel pelo problema" crlf))

(defrule print-repair27 "'"

(declare (salience -10))

(tem-reparo sim)

(entupimento-filtro-principal entupido)

$=>$

(printout $\mathrm{t}$ crlf "O filtro principal entupido pode ser reponsavel pelo problema" crlf))

(defrule print-repair28 "'"

(declare (salience -10))

(tem-reparo sim)

(linha-succao-principal entupido)

$=>$

(printout $t$ crlf "O entupimento da linha de succao principal pode ser reponsavel pelo problema" crlf))

(defrule print-repair29 "'"

(declare (salience -10))

(tem-reparo sim)

(valvula-anti-retorno-reserva bloqueada)

$=>$

(printout $\mathrm{t}$ crlf "O bloqueio da valvula anti-retorno reserva pode ser responsavel pelo problema" crlf))

(defrule print-repair30 "'

(declare (salience -10))

(tem-reparo sim) 
(valvula-alivio-reserva descalibrada)

$=>$

(printout $\mathrm{t}$ crlf "A valvula de alivio reserva descalibrada pode ser reponsavel pelo problema" crlf))

(defrule print-repair31 "'"

(declare (salience -10))

(tem-reparo sim)

(motor-eletrico-reserva falha)

$=>$

(printout $\mathrm{t}$ crlf "A falha no motor eletrico reserva pode ser responsavel pelo problema" crlf))

(defrule print-repair32 "'

(declare (salience -10))

(tem-reparo sim)

(bomba-reserva falha)

$=>$

(printout $\mathrm{t}$ crlf "A falha na bomba reserva pode ser reponsavel pelo problema" crlf))

(defrule print-repair33 "'"

(declare (salience -10))

(tem-reparo sim)

(entupimento-filtro-reserva entupido)

$=>$

(printout $t$ crlf "O filtro reserva entupido pode ser reponsavel pelo problema" crlf))

(defrule print-repair34 "'

(declare (salience -10))

(tem-reparo sim)

(linha-succao-reserva entupido)

$=>$

(printout $\mathrm{t}$ crlf "O entupimento da linha de succao reserva pode ser reponsavel pelo problema" crlf))

(defrule print-repair34 "'

(declare (salience -10))

(tem-reparo sim)

(linha-succao-reserva entupido)

$=>$

(printout $\mathrm{t}$ crlf "O entupimento da linha de succao reserva pode ser reponsavel pelo problema" crlf))

(defrule print-repair35 "'"

(declare (salience -10))

(tem-reparo sim)

(vazamento-oleo-reservatorio ocorre) 
$=>$

(printout t crlf "O vazamento de oleo no reservatorio pode ser reponsavel pelo problema" crlf))

(defrule print-repair36 "'"

(declare (salience -10))

(tem-reparo sim)

(vazamento-atuadores ocorre)

$=>$

(printout t crlf "O vazamento nos atuadores pode ser reponsavel pelo problema" crlf))

(defrule print-repair37 "'"

(declare (salience -10))

(tem-reparo sim)

(vazamento-valvula-distribuidora ocorre)

$=>$

(printout t crlf "O vazamento na valvula distribuidora pode ser reponsavel pelo problema" crlf))

(defrule print-repair38 "'"

(declare (salience -10))

(tem-reparo sim)

(vazamento-valvula-proporcional ocorre)

$=>$

(printout t crlf "O vazamento na valvula proporcional pode ser reponsavel pelo problema" crlf))

(defrule print-repair39 "'

(declare (salience -10))

(tem-reparo sim)

(vazamento-conexoes ocorre)

$=>$

(printout $\mathrm{t}$ crlf "O vazamento nas conexoes pode ser reponsavel pelo problema" crlf))

(defrule print-repair40 "'"

(declare (salience -10))

(tem-reparo sim)

(vazamento-bomba ocorre)

$=>$

(printout $\mathrm{t}$ crlf "O vazamento na bomba pode ser reponsavel pelo problema" crlf))

(defrule print-repair41 "'

(declare (salience -10))

(tem-reparo sim)

(motor-eletrico-emergencia falha)

$=>$ 
(printout $\mathrm{t}$ crlf "A falha no motor eletrico de emergencia pode ser reponsavel pelo problema" crlf))

(defrule print-repair42 "'"

(declare (salience -10))

(tem-reparo sim)

(bomba-emergencia falha)

$=>$

(printout $t$ crlf "A falha na bomba de emergencia pode ser reponsavel pelo problema" crlf))

(defrule print-repair43 "'

(declare (salience -10))

(tem-reparo sim)

(filtro-emergencia falha)

$=>$

(printout $\mathrm{t}$ crlf "O entupimento do filtro de emergencia pode ser reponsavel pelo problema" crlf))

(defrule print-repair44 "'

(declare (salience -10))

(tem-reparo sim)

(linha-succao-emergencia falha)

$=>$

(printout $t$ crlf "A ruptura na linha de succao de emergencia pode ser reponsavel pelo problema" crlf))

(defrule print-repair45 "'"

(declare (salience -10))

(tem-reparo sim)

(solenoide-distribuidor-emergencia falha)

$=>$

(printout $t$ crlf "A falha no solenoide de emergencia do distribuidor pode ser reponsavel pelo problema" crlf))

(defrule print-repair46 "'"

(declare (salience -10))

(tem-reparo sim)

(valvulaS2 falha)

$=>$ crlf))

(printout t crlf "A falha na valvula S2 pode ser reponsavel pelo problema"

(defrule print-repair47 "'

(declare (salience -10))

(tem-reparo sim)

(solenoide-rotor-emergencia falha)

$=>$

(printout $t$ crlf "A falha no solenoide de emergencia do rotor pode ser reponsavel pelo problema" crlf)) 
(defrule print-repair48 "'"

(declare (salience -10))

(tem-reparo sim)

(valvulaS3 falha)

$=>$

crlf))

(printout t crlf "A falha na valvula S3 pode ser reponsavel pelo problema"

(defrule print-repair49 "'"

(declare (salience -10))

(tem-reparo sim)

(acumulador-APERM falha)

$=>$

(printout t crlf "A falha no acumulador APERM pode ser reponsavel pelo problema" crlf))

(defrule print-repair50 "'"

(declare (salience-10))

(tem-reparo sim)

(sistema-reposicao-ar-APERM falha)

$=>$

(printout t crlf "A falha no sistema de reposicao de ar APERM pode ser reponsavel pelo problema" crlf))

(defrule print-repair51 "'"

(declare (salience -10))

(tem-reparo sim)

(acumulador-APED falha)

$=>$

(printout t crlf "A falha no acumulador APED pode ser reponsavel pelo problema" crlf))

(defrule print-repair52 "'"

(declare (salience -10))

(tem-reparo sim)

(sistema-reposicao-ar-APED falha)

$=>$

(printout $t$ crlf "A falha no sistema de reposicao de ar APED pode ser reponsavel pelo problema" crlf))

(defrule no-repairs "'"

(declare (salience -10))

(not (tem-reparo ?))

$=>$

(assert (tem-reparo desconhecido))

(printout t crlf "Chame um engenheiro especialista" crlf)) 


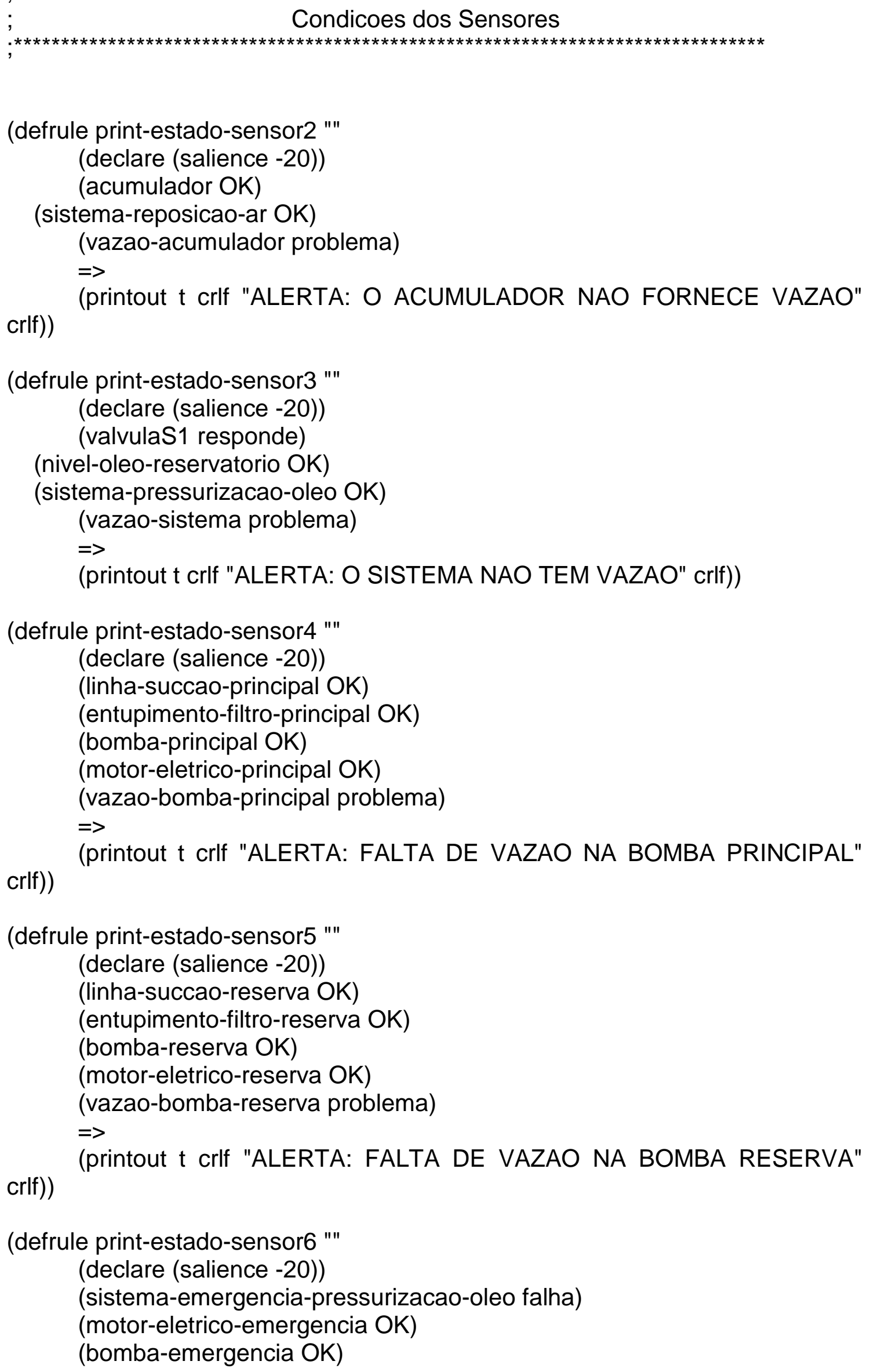


(filtro-emergencia OK)

(linha-succao-emergencia OK)

$=>$

(printout $t$ crlf "ALERTA: FALHA NO SISTEMA DE EMERGENCIA DE PRESSURIZACAO DE OLEO" crlf))

(defrule print-estado-sensor7 "'"

(declare (salience -20))

(vazao-acumulador-APERM falha)

(acumulador-APERM OK)

(sistema-reposicao-ar-APERM OK)

$=>$

(printout $t$ crlf "ALERTA: O ACUMULADOR APERM NAO FORNECE VAZAO APED" crlf))

(defrule print-estado-sensor8 "'"

(declare (salience -20))

(vazao-acumulador-APED falha)

(acumulador-APED OK)

(sistema-reposicao-ar-APED OK)

$=>$

(printout $\mathrm{t}$ crlf "ALERTA: O ACUMULADOR APED NAO FORNECE VAZAO" crlf))

(reset)

(run) 